\title{
POINTWISE LINEAR QUADRATIC OPTIMAL CONTROL OF A TANDEM COLD ROLLING MILL
}

\author{
by \\ John R. Pittner \\ BSEE, Carnegie Mellon University, 1963 \\ MSEE, University of Pittsburgh, 1999 \\ Submitted to the Graduate Faculty of \\ The School of Engineering in partial fulfillment \\ of the requirements for the degree of \\ Doctor of Philosophy
}

University of Pittsburgh 


\section{UNIVERSITY OF PITTSBURGH \\ SCHOOL OF ENGINEERING}

This dissertation was presented

by

John R. Pittner

It was defended on

March 22, 2006

and approved by

Marwan A. Simaan, Bell Atlantic Professor, Department of Electrical and Computer Engineering

Luis F. Chaparro, Associate Professor, Department of Electrical and Computer Engineering

Ching-Chung Li, Professor, Department of Electrical and Computer Engineering

J. Robert Boston, Professor, Department of Electrical and Computer Engineering

Frank H. Beatrous, Jr., Professor, Department of Mathematics

Dissertation Director: Marwan A. Simaan, Bell Atlantic Professor, Department of Electrical and Computer Engineering 


\title{
ABSTRACT \\ POINTWISE LINEAR QUADRATIC OPTIMAL CONTROL OF A TANDEM COLD ROLLING MILL
}

\author{
John R. Pittner, PhD \\ University of Pittsburgh, 2006
}

The tandem cold rolling of metal strip is a complex multivariable process whose control presents a significant engineering challenge. The present technology generally relies on a control structure wherein the interactive coupling between process variables is partially reduced by several single-input-single-output and single-input-multi-output control loops operating on certain variables to decompose the overall problem into several separate problems to attempt to allow independent adjustment of strip tension and thickness anywhere in the mill. However, while the existing systems generally have been successful in producing an acceptable product, their failure to completely counteract the effects of interactions between process variables has limited their capability for improvement in performance and in robustness to disturbances and uncertainties. Various techniques for improvement have been proposed and some have been implemented. Many of these techniques offer some improvements, but also have shortcomings. Therefore there is a need for a better approach. It is considered that the pointwise linear quadratic optimal control might fulfill this need. This dissertation investigates the theoretical and applied aspects of this technique for control of a tandem cold rolling mill using criteria based on practical applications. A mathematical model of the mill is developed from which nonlinear state space equations are derived. Using these equations, a pointwise linear quadratic optimal controller is developed, and its performance for variations in operating speed and product are confirmed by 
simulation. Robustness to disturbances and uncertainties is also confirmed by simulation. The results are compared with those using typical industry practice.

Keywords: Optimal Control, Pointwise Linear Quadratic Optimal Control, StateDependent Algebraic Riccati Equation, Multi-Input-Multi-Output Control, Mathematical Model, Nonlinear State Equations, State-Dependent Matrices, Tandem Cold Mill, Strip Thickness, Strip Tension Stress, Robustness to Disturbances, Robustness to Uncertainties 


\section{TABLE OF CONTENTS}

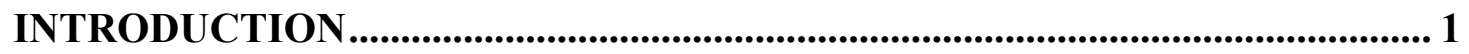

1.1 HISTORICAL BACKGROUND .................................................................. 2

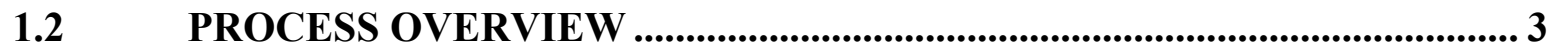

1.3 PROCESS CONTROL METHODS .........................................................6 6

2.0 MATHEMATICAL MODELING................................................................ 11

2.1 THEORETICAL SYSTEM EQUATIONS ……................................................. 12

2.1.1 Specific Roll Force ............................................................................................. 13

2.1.2 Work Roll Torque............................................................................................... 19

2.1.3 Forward Slip........................................................................................................ 19

2.1.4 Interstand Tension Stress........................................................................... 21

2.1.5 Output Thickness ........................................................................................... 21

2.1.6 Interstand Time Delay ............................................................................... 22

2.1.7 Input Thickness ................................................................................................... 22

2.1.8 Work Roll Actuator Position ......................................................................... 22

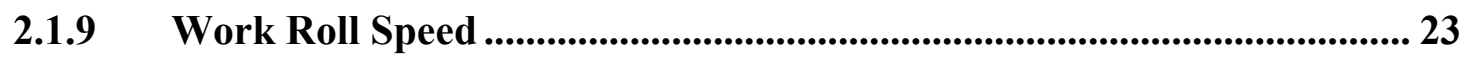

2.2 STATE SPACE AND OUTPUT EQUATIONS............................................... 23

2.3 MODEL VERIFICATION ................................................................................. 25

2.3.1 Operating Points ........................................................................................... 25

2.3.2 Simulation Results ....................................................................................... 27

2.3.3 Comments on Simulation Results.............................................................5 51

3.0 THE POINTWISE LINEAR QUADRATIC OPTIMAL CONTROLLER .........5 54

3.1 THEORETICAL BACKGROUND ................................................................... 55

3.2 APPLICATION TO TANDEM COLD ROLLING .......................................60

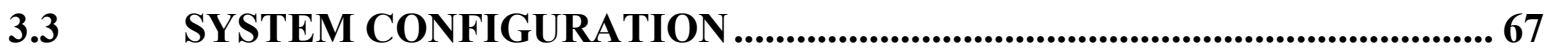




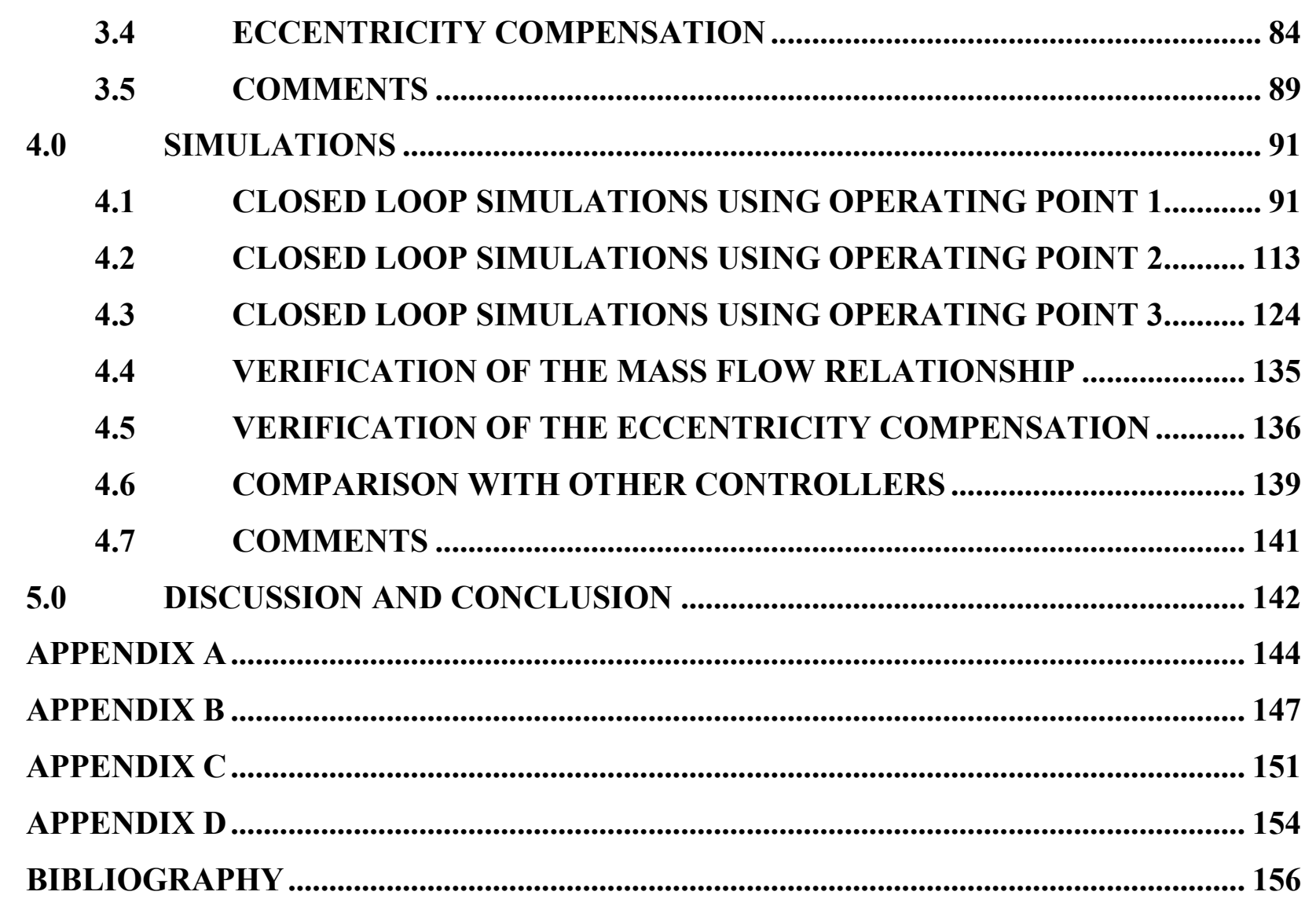




\section{LIST OF TABLES}

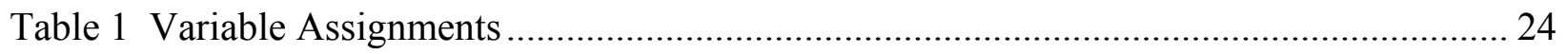

Table 2 Three Typical Production Schedules ............................................................... 26

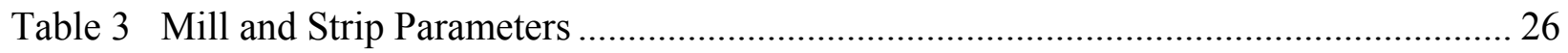

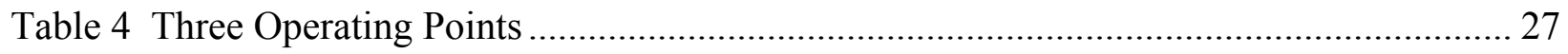

Table 5 Comparison of Changes in Output Thickness for a $+2 \%$ Step Change in Stand 1 Input

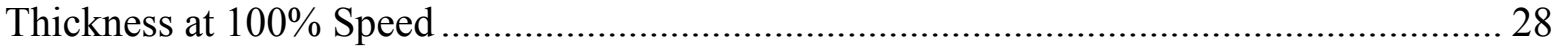

Table 6 Comparison of Changes in Output Thickness for a $+5 \%$ Step Change in Stand 1 Input

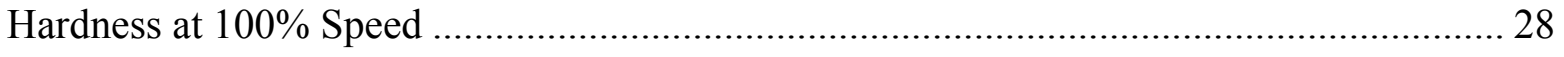

Table 7 Comparison of Changes in Output Thickness for a +.004 Inch Step Change in Stand 1

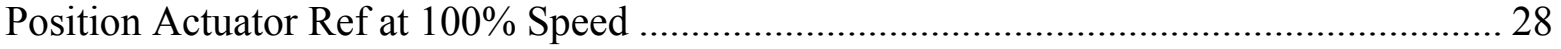

Table 8 Comparison of Changes in Total Roll Force for a +.004 Inch Step Change in Stand 1

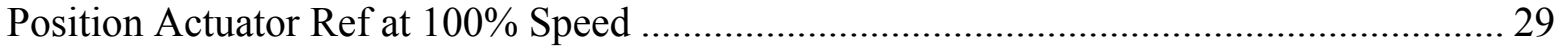

Table 9 Comparison of Changes in Output Thickness for a +.004 Inch Step Change in Stand 3

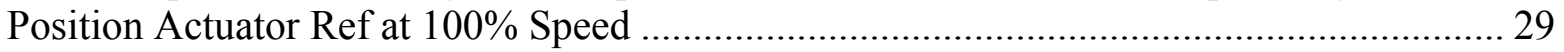

Table 10 Comparison of Changes in Output Thickness for a +.004 Inch Step Change in Stand 5

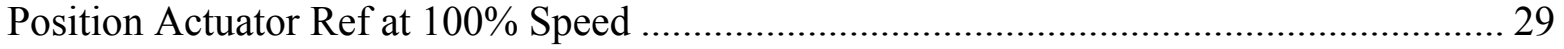

Table 11 Comparison of Changes in Output Thickness for a $+2 \%$ Change in Stand 1 Speed Actuator Ref at 100\% Speed................................................................................... 30

Table 12 Comparison of Changes in Total Roll Force for a $+2 \%$ Change in Stand 1 Speed

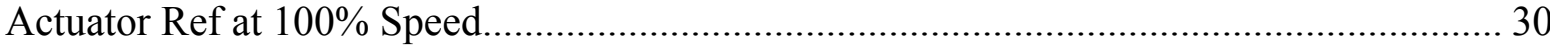

Table 13 Comparison of Changes in Output Thickness for a $+2 \%$ Change in Stand 3 Speed

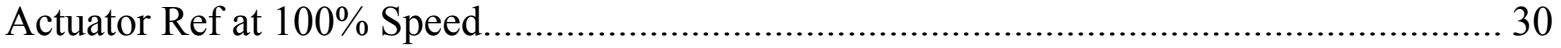

Table 14 Comparison of Changes in Output Thickness for a $+2 \%$ Change in Stand 5 Speed Actuator Ref at 100\% Speed................................................................................ 31

Table 15 Mean and Std Deviation of Percent Deviations of Model from Bryant and Geddes.... 31

Table $16+2 \%$ Step Change in Stand 1 Input Thickness at 100\% Speed................................ 32

Table $17+5 \%$ Step Change in Annealed Thickness at 100\% Speed .................................... 32 
Table $18+5 \%$ Step Change in Stand 1 Input Hardness at 100\% Speed ..................................... 32

Table $19+10 \%$ Step Change in Stand 1 Friction Coefficient at 100\% Speed.............................. 33

Table $20+10 \%$ Step Change in Stand 3 Friction Coefficient at 100\% Speed............................. 33

Table $21+10 \%$ Step Change in Stand 5 Friction Coefficient at 100\% Speed............................. 33

Table $22+.004$ Inch Step Change in Stand 1 Position Actuator Ref at 100\% Speed.................. 34

Table $23+.004$ Inch Step Change in Stand 3 Position Actuator Ref at 100\% Speed................... 34

Table $24+.004$ Inch Step Change in Stand 5 Position Actuator Ref at 100\% Speed................... 34

Table $25+2 \%$ Step Change in Stand 1 Speed Actuator Ref at 100\% Speed ............................... 35

Table $26+2 \%$ Step Change in Stand 3 Speed Actuator Ref at 100\% Speed.............................. 35

Table $27+2 \%$ Step Change in Stand 5 Speed Actuator Ref at 100\% Speed............................... 35

Table $28+2 \%$ Step Change in Stand 1 Input Thickness at 5\% Speed........................................ 36

Table $29+5 \%$ Step Change in Stand 1 Input Hardness at 5\% Speed ........................................ 36

Table $30+.004$ Inch Step Change in Stand 1 Position Actuator Ref at 5\% Speed....................... 36

Table $31+.004$ Inch Step Change in Stand 3 Position Actuator Ref at 5\% Speed...................... 37

Table $32+.004$ Inch Step Change in Stand 5 Position Actuator Ref at 5\% Speed....................... 37

Table $33+2 \%$ Step Change in Stand 1 Speed Actuator Ref at 5\% Speed.................................... 37

Table $34+2 \%$ Step Change in Stand 3 Speed Actuator Ref at 5\% Speed.................................. 38

Table $35+2 \%$ Step Change in Stand 5 Speed Actuator Ref at 5\% Speed................................... 38

Table $36-2 \%$ Step Change in Stand 1 Input Thickness at 100\% Speed...................................... 39

Table $37-5 \%$ Step Change in Stand 1 Input Hardness at 100\% Speed ..................................... 39

Table 38 -.004 Inch Step Change in Stand 1 Position Actuator Ref at 100\% Speed.................. 39

Table $39-2 \%$ Step Change in Stand 1 Speed Actuator Ref at 100\% Speed................................. 40

Table 40 Elements of Vectors $x_{o p}$ and $u_{o p}$ and Associated Variables Which Are Changed During Mill Speed Changes ....................................................................................................... 62

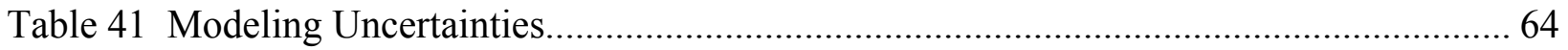

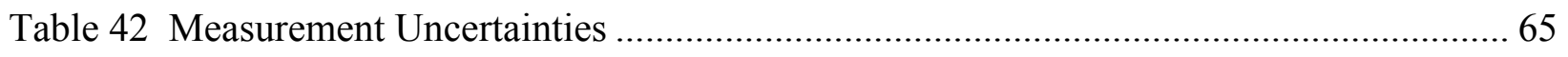

Table 43 Effects of Modeling Uncertainties on Stand 1 Output Thickness ................................ 70

Table 44 State Vector Elements, Variable Assignments Using Modification (1) ....................... 72

Table 45 Values of Time Delay from Stand 1(5) to Thickness Gauge, with Gauge Location of 39

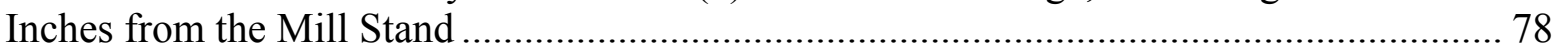

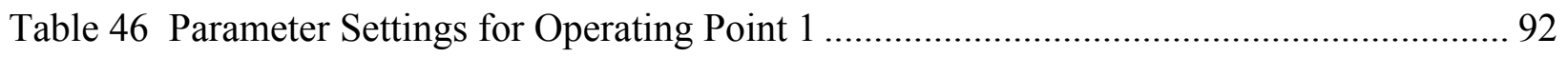


Table 47 Magnitudes of Maximum Percent Deviations of Stand Exit Thicknesses and Interstand Tension Stresses, without Disturbances, Uncertainties, or Eccentricities, with Interstand Tension Operating Point Trims Disabled, Using Operating Point 1 93

Table 48 Magnitudes of Maximum Percent Deviations of Stand Exit Thicknesses and Interstand Tension Stresses, without Disturbances, Uncertainties, or Eccentricities, with Interstand Tension Operating Point Trims Enabled, Using Operating Point 1 94

Table 49 Magnitudes of Maximum Percent Deviations of Stand Exit Thicknesses and Interstand Tensions, with Mill Entry Disturbances, without Uncertainties or Eccentricities, Using Operating Point 1 99

Table 50 Magnitudes of Maximum Percent Deviations of Stand Exit Thicknesses and Interstand Tension Stresses, with Disturbances and Uncertainties, without Eccentricities, Using Operating Point 1 110

Table 51 Magnitudes of Maximum Percent Deviations of Stand Exit Thicknesses and Interstand Tension Stresses, with Disturbances and Uncertainties, without Eccentricities, Using Production Schedule 1 111

Table 52 Magnitudes of Maximum Percent Deviations of Stand Exit Thicknesses and Interstand Tension Stresses, without Disturbances, Uncertainties, or Eccentricities, Using Operating Point 2 ..... 113

Table 53 Magnitudes of Maximum Percent Deviations of Stand Exit Thicknesses and Interstand Tensions, with Mill Entry Disturbances, without Uncertainties or Eccentricities, Using Operating Point 2 114

Table 54 Magnitudes of Maximum Percent Deviations of Stand Exit Thicknesses and Interstand Tension Stresses, with Disturbances and Uncertainties, without Eccentricities, Using Operating Point 2 . 123

Table 55 Magnitudes of Maximum Percent Deviations of Stand Exit Thicknesses and Interstand Tension Stresses, with Disturbances and Uncertainties, without Eccentricities, Using Production Schedule 2 . 124

Table 56 Parameter Settings for Operating Point 3 124

Table 57 Magnitudes of Maximum Percent Deviations of Stand Exit Thicknesses and Interstand Tension Stresses, without Disturbances, Uncertainties, or Eccentricities, Using Operating Point 3 125

Table 58 Magnitudes of Maximum Percent Deviations of Stand Exit Thicknesses and Interstand Tensions, with Mill Entry Disturbances, without Uncertainties or Eccentricities, Using Operating Point 3. 125

Table 59 Magnitudes of Maximum Percent Deviations of Stand Exit Thicknesses and Interstand Tension Stresses, with Disturbances and Uncertainties, without Eccentricities, Using

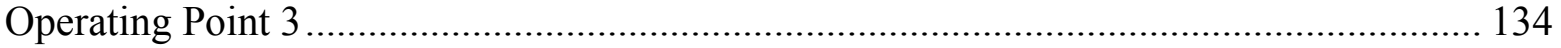

Table 60 Magnitudes of Maximum Percent Deviations of Stand Exit Thicknesses and Interstand Tension Stresses, with Disturbances and Uncertainties, without Eccentricities, Using

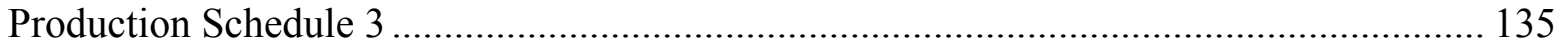


Table 61 Magnitude of Maximum Eccentricity, After Filter Learning, for Case 1 through Case

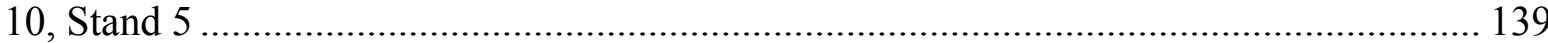

Table 62 Comparison of Magnitudes of Maximum Percent Deviation of Mill Exit Thickness with Industrial Controller A and Industrial Controller B ............................................. 140 


\section{LIST OF FIGURES}

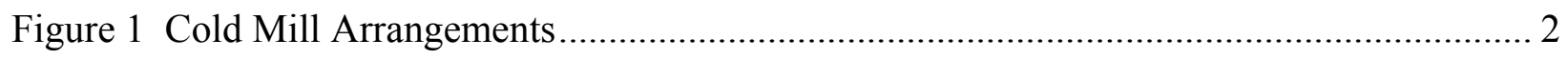

Figure 2 5-Stand Tandem Cold Mill ................................................................................ 4

Figure 3 Typical Mill Stand Arrangement ....................................................................... 5

Figure 4 Mill Stretch Curve and Mill Operation ............................................................. 7

Figure 5 Strip In Roll Bite Area..................................................................................... 13

Figure 6 Element of Strip in Roll Bite (Plastic Zone) ..................................................... 14

Figure 7 Roll Pressure vs Angle in the Roll Bite........................................................... 16

Figure 8 Output Thickness Responses to $+2 \%$ Step Change in Stand 1 Input Thickness at 100\%

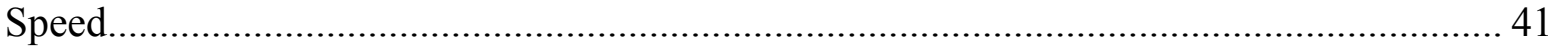

Figure 9 Total Roll Force Responses to +2\% Step Change in Stand 1 Input Thickness at 100\%

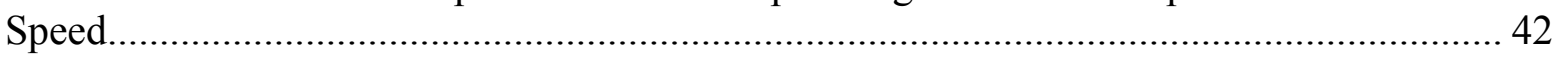

Figure 10 Interstand Tension Responses to $+2 \%$ Step Change in Stand 1 Input Thickness at $100 \%$ Speed

Figure 11 Output Thickness Responses to $+2 \%$ Step Change in Stand 1 Position Actuator Ref at

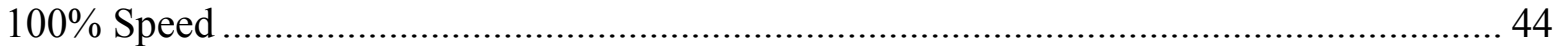

Figure 12 Total Roll Force Responses to $+2 \%$ Step Change in Stand 1 Position Actuator Ref at $100 \%$ Speed

Figure 13 Interstand Tension Responses to $+2 \%$ Step Change in Stand 1 Position Actuator Ref at $100 \%$ Speed 46

Figure 14 Output Thickness Responses to $+2 \%$ Step Change in Stand 1 Speed Actuator Ref at $100 \%$ Speed

Figure 15 Total Roll Force Responses to $+2 \%$ Step Change in Stand 1 Speed Actuator Ref at $100 \%$ Speed

Figure 16 Interstand Tension Responses to $+2 \%$ Step Change in Stand 1 Speed Actuator Ref at $100 \%$ Speed

Figure 17 Output Thickness Responses to $+2 \%$ Step Change in Stand 1 Input Thickness at 5\% Speed. 
Figure 18 Mill Entry Disturbances at 100\% Speed 63

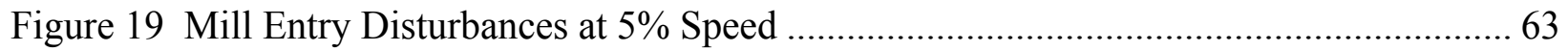

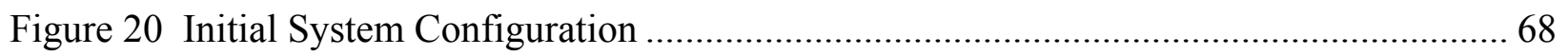

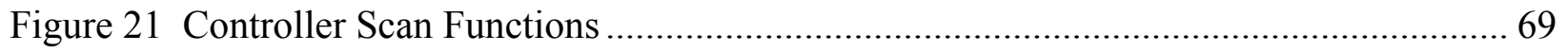

Figure 22 Maximum Percent Excursion in Mill Output Thickness for Mill Input Thickness Disturbance at 100\% Speed, Using Modification (1) ........................................................... 74

Figure 23 System Configuration Using Modification (3)....................................................... 75

Figure 24 5-Stand Tandem Cold Mill Using Modification (3) ..................................................... 77

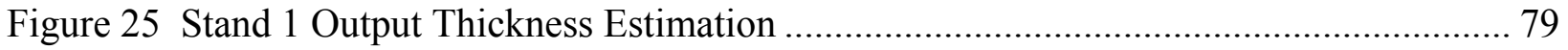

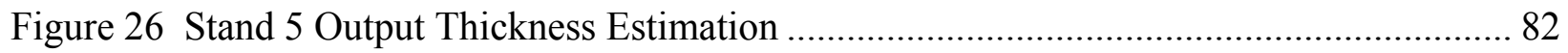

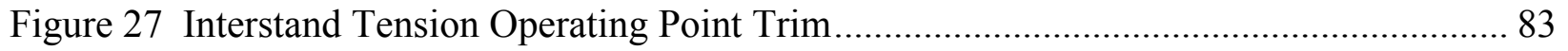

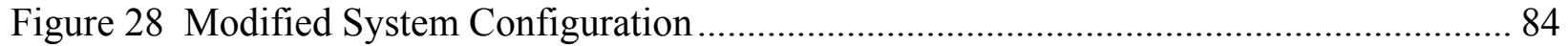

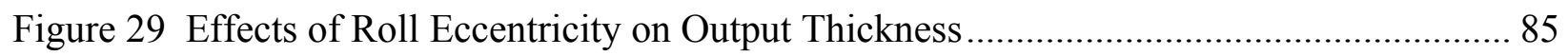

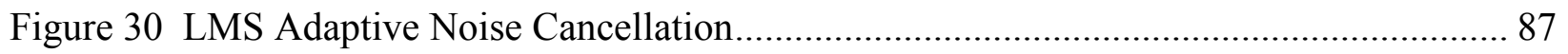

Figure 31 Position Controller Realization with Active Eccentricity Compensation .................... 89

Figure 32 Mill Master Speed Reference During Deceleration .................................................... 93

Figure 33 Mill Master Speed Reference During Acceleration ................................................... 93

Figure 34 Percent Changes in Stand Output Thicknesses from Operating Point Values During Mill Deceleration, without Disturbances, Uncertainties, or Eccentricities, Using Operating

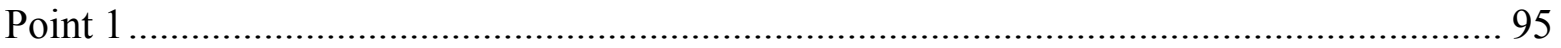

Figure 35 Percent Changes in Interstand Tensions from Operating Point Values During Mill Deceleration, without Disturbances, Uncertainties, or Eccentricities, Using Operating

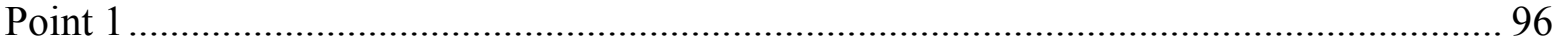

Figure 36 Percent Changes in Stand Output Thicknesses from Operating Point Values During Mill Acceleration, without Disturbances, Uncertainties, or Eccentricities, Using Operating

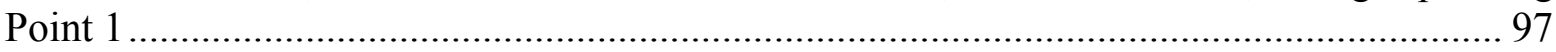

Figure 37 Percent Changes in Interstand Tensions from Operating Point Values During Mill Acceleration, without Disturbances, Uncertainties, or Eccentricities, Using Operating

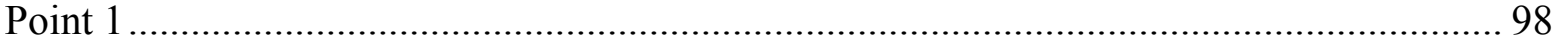

Figure 38 Percent Changes in Stand Output Thicknesses from Operating Point Values at 100\% Speed, with Mill Entry Disturbances, without Uncertainties or Eccentricities, Using

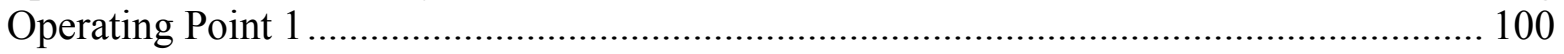

Figure 39 Percent Changes in Interstand Tensions from Operating Point Values at 100\% Speed, with Mill Entry Disturbances, without Uncertainties or Eccentricities, Using Operating Point 1 101 
Figure 40 Percent Changes in Stand Output Thicknesses from Operating Point Values at 5\% Speed, with Mill Entry Disturbances, without Uncertainties or Eccentricities, Using Operating Point 1 102

Figure 41 Percent Changes in Interstand Tensions from Operating Point Values at 5\% Speed, with Mill Entry Disturbances, without Uncertainties or Eccentricities, Using Operating Point 1 103

Figure 42 Percent Changes in Stand Output Thicknesses from Operating Point Values During Mill Deceleration, with Mill Entry Disturbances, without Uncertainties or Eccentricities, Using Operating Point 1 104

Figure 43 Percent Changes in Interstand Tensions from Operating Point Values During Mill Deceleration, with Mill Entry Disturbances, without Uncertainties or Eccentricities, Using Operating Point 1 105

Figure 44 Percent Changes in Stand Output Thicknesses from Operating Point Values During Mill Acceleration, with Mill Entry Disturbances, without Uncertainties or Eccentricities, Using Operating Point 1 106

Figure 45 Percent Changes in Interstand Tensions from Operating Point Values During Mill Acceleration, with Mill Entry Disturbances, without Uncertainties or Eccentricities, Using Operating Point 1 107

Figure 46 Percent Change in the Mill Modulus as a Function of Strip Distance at the Output of Stand 1 108

Figure 47 Percent Changes in Stand Output Thicknesses from Operating Point Values at 100\% Speed, with Mill Entry Disturbances, without Uncertainties or Eccentricities, Using Operating Point 2. 115

Figure 48 Percent Changes in Interstand Tensions from Operating Point Values at 100\% Speed, with Mill Entry Disturbances, without Uncertainties or Eccentricities, Using Operating Point 2 116

Figure 49 Percent Changes in Stand Output Thicknesses from Operating Point Values at 5\% Speed, with Mill Entry Disturbances, without Uncertainties or Eccentricities, Using Operating Point 2 117

Figure 50 Percent Changes in Interstand Tensions from Operating Point Values at 5\% Speed, with Mill Entry Disturbances, without Uncertainties or Eccentricities, Using Operating Point 2 . 118

Figure 51 Percent Changes in Stand Output Thicknesses from Operating Point Values During Mill Deceleration, with Mill Entry Disturbances, without Uncertainties or Eccentricities, Using Operating Point 2 119

Figure 52 Percent Changes in Interstand Tensions from Operating Point Values During Mill Deceleration, with Mill Entry Disturbances, without Uncertainties or Eccentricities, Using Operating Point 2 120

Figure 53 Percent Changes in Stand Output Thicknesses from Operating Point Values During Mill Acceleration, with Mill Entry Disturbances, without Uncertainties or Eccentricities, Using Operating Point 2 121 
Figure 54 Percent Changes in Interstand Tensions from Operating Point Values During Mill Acceleration, with Mill Entry Disturbances, without Uncertainties or Eccentricities, Using Operating Point 2

Figure 55 Percent Changes in Stand Output Thicknesses from Operating Point Values at 100\% Speed, with Mill Entry Disturbances, without Uncertainties or Eccentricities, Using Operating Point 3 126

Figure 56 Percent Changes in Interstand Tensions from Operating Point Values at 100\% Speed, with Mill Entry Disturbances, without Uncertainties or Eccentricities, Using Operating Point 3

Figure 57 Percent Changes in Stand Output Thicknesses from Operating Point Values at 5\% Speed, with Mill Entry Disturbances, without Uncertainties or Eccentricities, Using Operating Point 3 128

Figure 58 Percent Changes in Interstand Tensions from Operating Point Values at 5\% Speed, with Mill Entry Disturbances, without Uncertainties or Eccentricities, Using Operating Point 3 129

Figure 59 Percent Changes in Stand Output Thicknesses from Operating Point Values During Mill Deceleration, with Mill Entry Disturbances, without Uncertainties or Eccentricities, Using Operating Point 3 130

Figure 60 Percent Changes in Interstand Tensions from Operating Point Values During Mill Deceleration, with Mill Entry Disturbances, without Uncertainties or Eccentricities, Using Operating Point 3 131

Figure 61 Percent Changes in Stand Output Thicknesses from Operating Point Values During Mill Acceleration, with Mill Entry Disturbances, without Uncertainties or Eccentricities, Using Operating Point 3 132

Figure 62 Percent Changes in Interstand Tensions from Operating Point Values During Mill Acceleration, with Mill Entry Disturbances, without Uncertainties or Eccentricities, Using Operating Point 3 133

Figure 63 Stand 5 Percent Eccentricity after Compensation, Case 1 138 


\subsection{INTRODUCTION}

The tandem cold rolling of steel strip is a complex nonlinear multivariable process whose control presents a significant engineering challenge. In general, the current technology relies on a structure developed by Bryant [1] wherein the effects of interaction between the process variables are partially mitigated by single-input-single-output (SISO) and single-input-multioutput (SIMO) control loops operating on selected variables, such that the overall control problem is decomposed into several separate problems which has the objective of independent adjustment of strip tension and thickness anywhere in the mill. While this structure and variations $[2,3]$ of it have been effective in producing an acceptable product, it is recognized that applications of other design techniques might result in improvements in performance and in robustness to disturbances and uncertainties, and various methods $[4,5]$ have been proposed and implemented. Many of these methods offer some improvements, but also have some shortcomings. Consequently, there is a need for a better method. It is considered that the pointwise linear quadratic optimal technique has several advantages and thus might fulfill this need.

Therefore, the objective of this dissertation is to investigate the theoretical and applied aspects of the pointwise linear quadratic optimal technique for the control of a tandem cold rolling mill. The success of this method will be evaluated based on the following measures which 
are considered the most significant in the control of the tandem cold mill: (1) Performance based on criteria typical for practical application, and (2) Robustness to disturbances and uncertainties.

\subsection{HISTORICAL BACKGROUND}

Soft metals such as lead and tin were cold rolled into sheets prior to the documented hot rolling of iron into sheets in Great Britain in the late $17^{\text {th }}$ century. Roberts [6] notes that a patent for a tandem hot mill for rolling iron plates into sheets was issued in 1798 and refers to the building of the first tandem mill in Czechoslovakia in 1892. The development of the Lauth mill (3-high with a smaller diameter middle roll (Figure 1) in the 1850s provided the driving force for the cold rolling of steel as a successful production process. In the United States, tandem cold rolling of steel strip was first recorded in the early 1900s by the West Leechburg Steel Company, where the rolling process was performed with slack in the strip between the individual stands. Cold rolling with tension in the strip between the stands was adopted in the mid-1920s in mills near Pittsburgh, Pennsylvania.

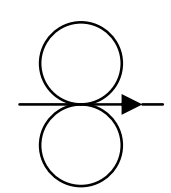

2-high

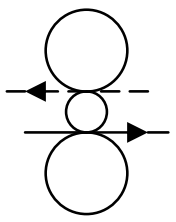

3-high

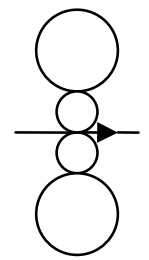

4-high

Figure 1 Cold Mill Arrangements

In the mid-1930s cold reduction became significant in the production process, as the maximum available widths increased and the minimum thickness for a given width decreased. 
Prior to the Second World War, most tandem cold mills were 4-high, four stand; after the War and up to the present most mills were 4-high with five or six stands. Considerable advancements in rolling technology were made in the 1970s [7], and these resulted in improved surface finishes, tighter dimensional tolerances, and higher rolling speeds. Recent advancements also were seen in control applications for control of strip cooling on the runout table $[8,9,10,11]$. Factors that contributed to this progress were larger and faster mill designs, improvements in the mill rolls and housing, advances in variable speed drive technology, enhancements in the instrumentation systems, and the maturing of computer control. More recent developments are fully continuous tandem cold mills, where strip accumulators are utilized for storage during coil changes, and fully continuous mills directly coupled to continuous pickling process lines.

\subsection{PROCESS OVERVIEW}

The tandem cold rolling of steel strip is one process in a sequence of processes performed to convert raw materials into a finished product. The cold rolling process occurs after the hot rolling process wherein steel slabs are heated in a furnace and then rolled into coils of reduced thickness suitable for further processing. After hot rolling and prior to cold rolling, the hot rolled material undergoes a pickling process wherein the coiled strip is unwound and passed through an acid bath to remove the oxides formed during hot rolling. Just prior to recoiling, oil is applied to the strip to prevent rusting, eliminate damage due to scraping of adjacent coil wraps, and to act as a lubricant for the first stand of the tandem cold mill. The cold rolling process then provides an additional reduction to produce thinner material since the reduction in thickness in the hot rolling 
process is limited to about 0.05 inches. In addition, cold rolling is done for one, or both, of the following: (1) To improve the surface finish, and (2) To produce mechanical properties in the strip which make it suitable for the manufacture of various products (e.g. the automated making of cans [12]).

In the five stand tandem cold mill (Figure 2), the strip is passed through five pairs of independently driven work rolls, with each work roll supported by a back-up roll of larger diameter. Figure 3 depicts a typical mill stand arrangement. As the strip passes through the individual pairs of work rolls, the thickness is successively reduced. The reduction in thickness is caused by very high compression stress in a small region (denoted as the roll gap) between the work rolls. In this region the metal is plastically deformed, and there is slipping between the strip and the work roll surface. The necessary compression force is applied by hydraulic rams. The energy required to achieve the reduction in strip thickness causes a temperature rise at the roll gap which is reduced considerably by the cooling effects of air and rolling solution (lubricant) as the strip travels between the stands. Mill instrumentation generally consists of sensors to measure

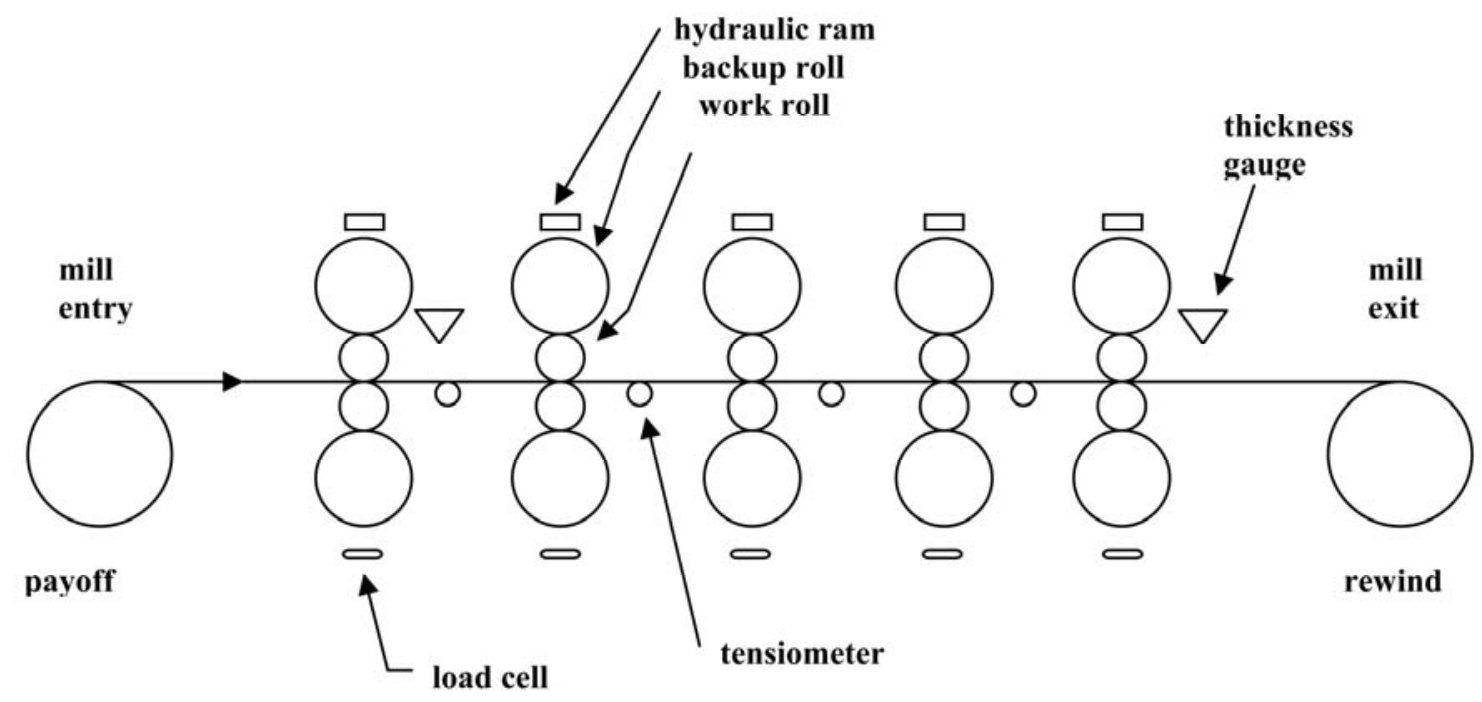

Figure 2 5-Stand Tandem Cold Mill 
roll force at each stand, interstand strip tension force, strip thickness at the exit of the first and last stands, work roll speeds, and roll gap actuator (hydraulic ram) positions.

Prior to rolling, work roll speed and roll gap position actuator references are calculated based on expected steady-state mill behavior. The threading process (discontinuous), where the strip is successively introduced into the mill stands, occurs at low speed. After the last stand is threaded, the mill is accelerated to the desired operating speed (run speed). Near the end of the coil, the mill is decelerated to a reduced speed for de-threading and setup for the next coil. In the case of continuous operation, coils are welded together prior to entering the mill, so that the mill is not stopped for coil change, and strip is always in a mill stand. After cold rolling, the strip is cleaned and annealed to restore its formability, which was reduced by an increase in hardness and a decrease in ductility caused by the cold reduction process.

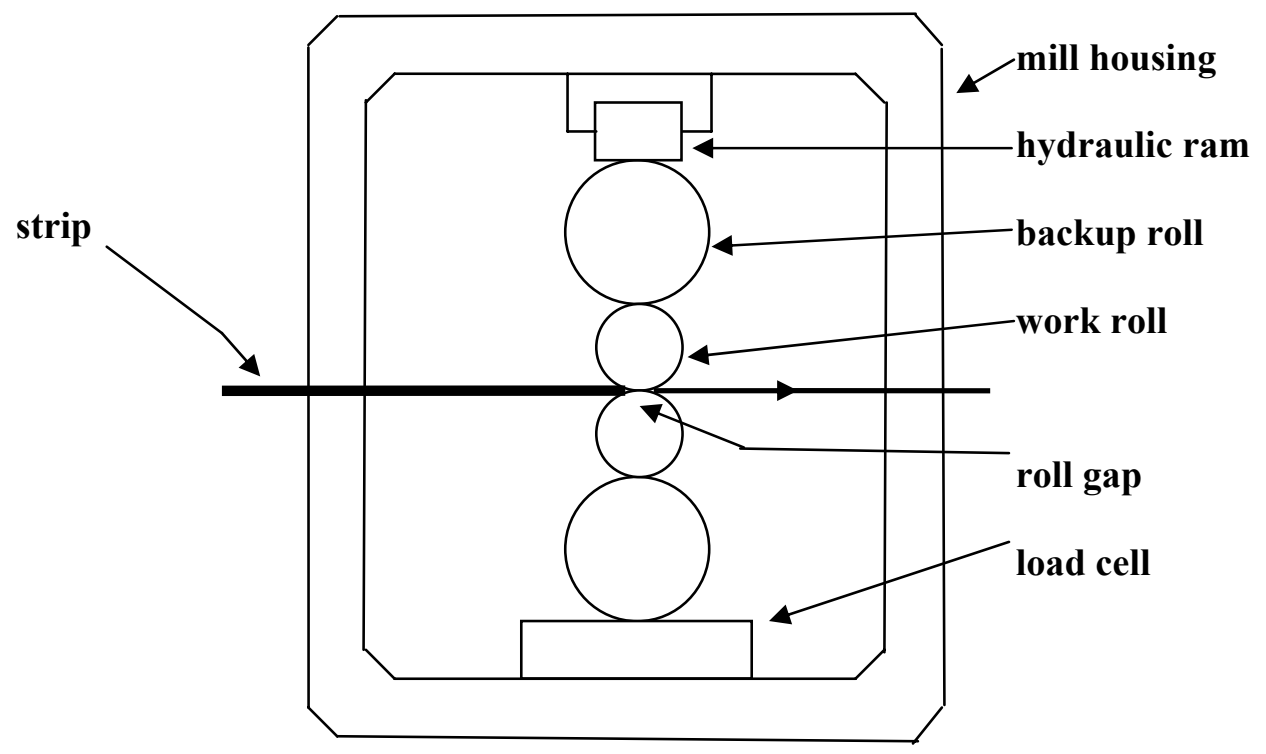

Figure 3 Typical Mill Stand Arrangement 
The above provides a functional introduction to the tandem cold rolling process. Further insight into the detailed process characteristics and system dynamics is provided by the mathematical models and descriptions presented in Section 2.0 .

\subsection{PROCESS CONTROL METHODS}

As noted previously, the tandem cold rolling of steel strip is a complex nonlinear multivariable process with stringent requirements on the finished product. Problems encountered in the development of a suitable control strategy are nonlinearities, inherent coupling between process variables, effects of disturbances, uncertainties in modeling, uncertainties in measurement, errors in controller settings, and significant interstand time delays which change significantly with mill speed. This section provides a brief overview of the strengths and weaknesses of several concepts for control of strip output thickness. This overview is not exhaustive, as a consideration of every concept and its possible variations is beyond the scope of this work. The concepts considered are judged to be the most significant of what is known to exist, and what is presently known to be proposed for possible improvement in performance and robustness.

The concept of BISRA ${ }^{1}$ gaugemeter is an example of an industrial control scheme which is used sometimes for the control of stand output thickness (gauge). Measurement of strip thickness at the exit of the roll gap requires expensive and complex equipment, and therefore is not usually done, except at the exit of the first and last stands. However, for intermediate stands, an estimate of the output thickness can be obtained by measuring the rolling load and using the mill stretch characteristic. The mill stretch characteristic (Figure 4) is a relationship that treats the mill as a

\footnotetext{
${ }^{1}$ BISRA refers to the British Iron and Steel Research Association (England)
} 
spring which stretches according to the rolling load. Since most of the rolling operation occurs where this characteristic is nearly linear, the following linearized model of this relationship is used as a suitable approximation, i.e.

$$
\text { mill stretch }=S_{o}+F / M \text {, }
$$

where $S_{o}$ is the extrapolated intercept of the linearized model on the mill stretch axis, $F$ is the roll force, and $M$ is the mill modulus. If the mill rolls are initially separated by an amount $S$, then under actual operating conditions (i.e. strip in the roll gap), the stand output thickness $h_{\text {out }}$ as depicted in Figure 4 is given by

$$
h_{\text {out }}=S+S_{o}+F / M \text {. }
$$

roll force $(F)$

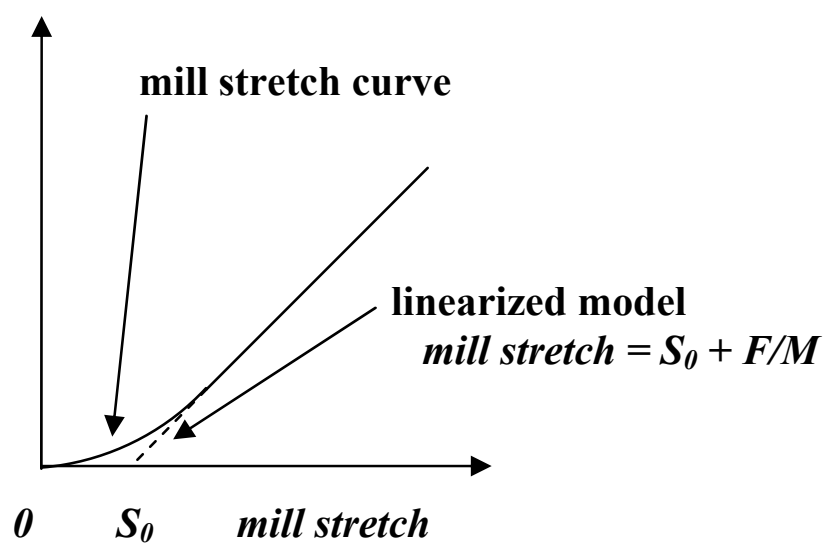

Mill Stretch Curve roll force $(F)$

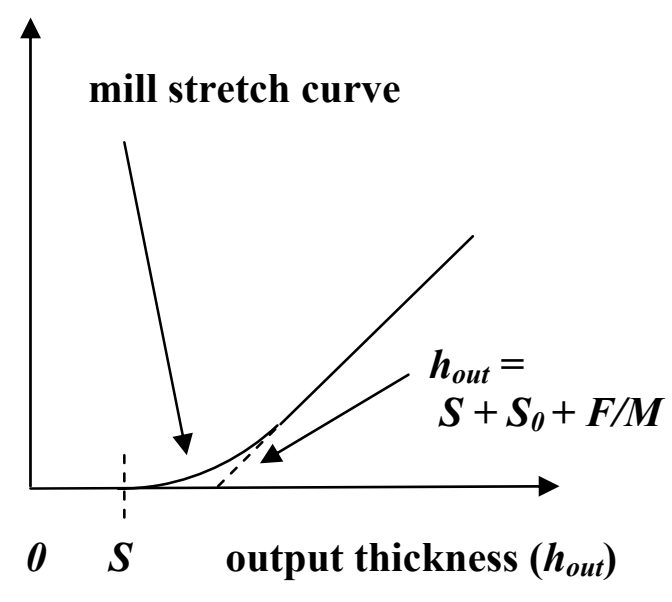

Mill Operation

Figure 4 Mill Stretch Curve and Mill Operation

This phenomenon is utilized to control the output thickness. For example, a change in the measured rolling load is interpreted as a change in output thickness, which is compensated for by a controller which changes the position of the hydraulic actuator controlling the work roll 
position to maintain the desired output thickness. However, eccentricity in the mill rolls can cause an increase in the measured rolling load which is misinterpreted by the BISRA controller as in increase in strip thickness. The controller then causes the position actuator to act in a direction to worsen the effect of the eccentricity disturbance rather than mitigating it, which is a disadvantage of the BISRA scheme. Section 3.4 provides additional information related to roll eccentricity and the compensation for its effects.

The objective of most other industrial control concepts is to reduce the effects of the complex interactions between the process variables. In general this is done using SISO (singleinput-single-output) loops to control interstand tension by the adjustment of the downstream gap, and SIMO (single-input-multi-output) loops to control strip thickness by coordination of the work roll drives. The industrial control strategies [e.g. 2, 3] presented in much of the literature are typical applications of this method, with some variations. For most of these strategies the individual control loops are not complex, commissioning and retuning are straightforward, and gain scheduling to follow variations in speed and product can be readily implemented. The industrial controller has been successful in producing an acceptable product, while only partially mitigating the effects of interactions. However, as noted by Geddes and Postlewaite [4], and Kugi [13], the inability to completely counteract the effects of interactive coupling between the process variables limits the capability of the industrial controller to be improved to produce tighter tolerances in strip thickness. In addition, robustness to disturbances and uncertainties is often not considered in the design descriptions.

The linear $\mathrm{H}^{\infty}$ multi-input-multi-output (MIMO) design technique is a control concept in which performance and robustness are guaranteed in the presence of disturbances and uncertainties. This technique is well known and described in various texts [e.g. 14, 15]. Geddes 
and Postlewaite [4] report work done to apply the technique to the control of a tandem cold mill, and claim, based on simulation, an improvement over a typical industrial controller in robustness and performance (i.e., thickness tolerance), at a nominal operating point. However, there are some features in the technique which make it less attractive: (1) A linearized model based on the nominal operating point is required, (2) The MIMO $\mathrm{H}^{\infty}$ controller has dynamics which make it difficult to commission and retune, (3) Gain scheduling of a series of controllers to accommodate variations in mill speed adds complexity and increases computational requirements, and (4) A change in product (i.e. a change in operating point) requires some redesign and retuning.

Hoshino et. al. [5] use multivariable state space techniques based on a linearized model to control a two-stand aluminum cold mill. The control concept is state feedback based on methods developed by Wonham et. al. [16], with feedforward of disturbances. The interstand time delay is treated as a disturbance. The effects of uncertainties are not specifically addressed, and measurement of thickness at the exit of each stand is required. The simulation and implementation on an operating mill showed improvement over existing control, particularly in reducing thickness excursions during speed change. While the results are successful, the following make this technique somewhat less desirable for extension to a five stand tandem mill: (1) A linearized model is required, (2) Measurement of thickness after each stand is required, (3) Uncertainties are not addressed, and (4) The interstand time delays are not part of the process model.

Thus, considering what was presented this brief review, it is seen that each of the process control concepts has certain strengths, but also has weaknesses which provide reason for consideration of a better approach. One such approach, that is investigated in this dissertation, is the pointwise linear quadratic optimal control technique, which is a pointwise application of the 
state-dependent algebraic Riccati equation method. This method has seen many successful recent applications in the aerospace industry, and is considered desirable by its users because of its simplicity and its capability for the use of physical intuition in the design process. Other approaches are considered in Section 3.0 and are compared in detail to the state-dependent Riccati equation method in the references cited therein. 


\subsection{MATHEMATICAL MODELING}

A mathematical model of the tandem cold rolling process is a group of expressions which relate the rolling parameters to each other. Various mathematical models of the cold rolling process have been developed based on their intended use. For example, Roberts [6] identifies kinetic models which relate rolling force and spindle torque to other factors such as yield stress of the strip and strip tension, thermal models which include the aspects of kinetic models plus temperature distributions in the rolls and the strip, and economic models which are related to cost and profitability. The type of model desired for the work described herein is one which relates the parameters of the tandem cold rolling process that are significant in the development of a process control strategy. In addition, the model must be useful in a practical sense, i.e. it must be capable of being implemented in a straightforward manner without being computationally demanding and yet retain the features needed for process control.

The cold rolling process involves the interaction of three components: (1) The work rolls, (2) The lubricant, and (3) The work piece (i.e. the strip). The roll force model, which predicts the deformation of the strip in the roll bite, is the center of the modeling of this process. Many existing classical roll force models are based on the theoretical work of Orowan [17], who used several simplifying assumptions to solve a differential equation developed by Von Karman which expressed the pressure distribution across the arc of contact in the interface between the work rolls and the strip. As noted by Bryant [1], these classical methods were generally 
computationally demanding and required considerable care to design numerical algorithms which were computationally robust. To attempt to provide a less complex roll force model which was more suitable for work involving control strategies, Bryant developed simplified expressions for a model which reduced the problem to a series of algebraic equations. In addition, similar expressions for prediction of neutral angle, slip, and torque were developed. Simulations were performed by Bryant using the simplified expressions and the results were compared with the results obtained from simulations using the classical methods, which were extensively studied and verified. The comparisons generally showed close agreement between the simplified and classical simulations. Considering this, and since data and simulation results are provided that are typical of practical applications with various products and operating conditions, the theory given in Bryant [1] is used herein as a basis for model development. In addition, certain empirical relationships given in Roberts [6] are used.

\subsection{THEORETICAL SYSTEM EQUATIONS}

In this section theoretical system equations for relevant process variables are developed. The equations are simplified forms of the classical derivations which retain features relevant to the control of the tandem cold mill. The expressions given apply to each mill stand. Where adjacent

mill stands are involved, the subscripts " $i$ " and " $i+l "$ are used, where $i$ represents the mill stand number. Unless indicated otherwise, the subscript "op" indicates the desired value of a variable at an operating point, while the subscript " 0 " indicates the initial value of a variable. 


\subsubsection{Specific Roll Force}

The theory for prediction of specific roll force is central to the development of a model for tandem cold rolling. In this section, theory is presented to provide some insight into phenomena occurring at the roll bite, and a simple but useful model is developed based on the methods of Bryant [1]. Referring to Figure 5, which approximately represents the strip in the roll bite area, the incoming strip is of thickness $h_{\text {in }}$ at its centerline and is moving toward the roll bite with speed $v_{i n}$. The strip exits the roll bite with thickness $h_{\text {out }}$ at its centerline and with speed $v_{\text {out }}$. The incoming strip is under tension stress $\sigma_{\text {in }}$, the exiting strip is under tension stress $\sigma_{\text {out }}$. During rolling, the work roll is elastically flattened from its radius $R$ to a radius $R^{\prime}$. In the strip deformation process there is slipping between the flattened work roll surface and the strip, except

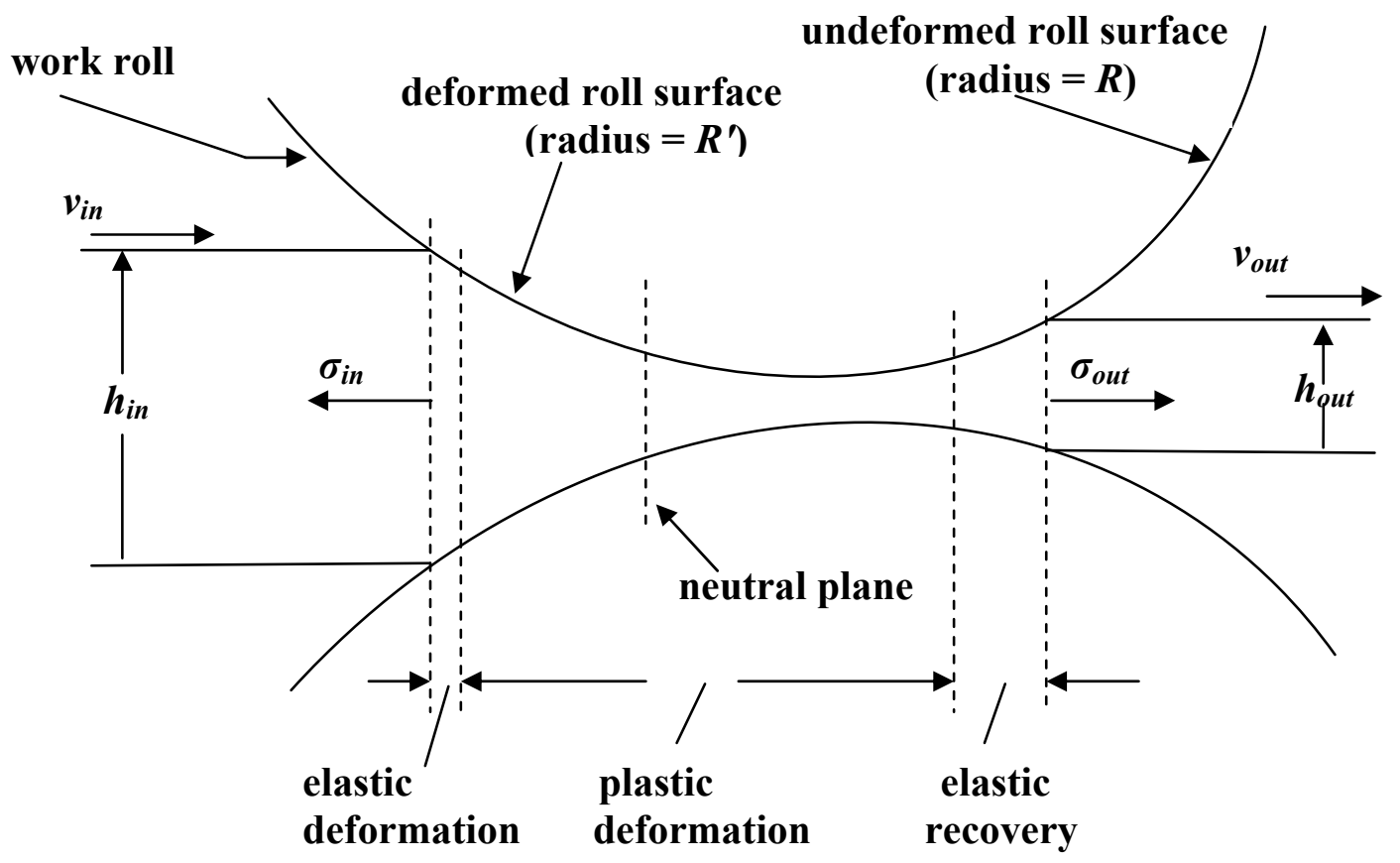

Figure 5 Strip In Roll Bite Area

at the neutral plane. At the neutral plane, the strip speed matches the work roll speed and the friction forces acting on the strip change sign. Three areas related to strip deformation are: (1) 
The zone of elastic deformation, (2) The zone of plastic deformation, and (3) The zone of elastic recovery. Figure 6 shows an element of strip of unit width and length $d x$ in the roll bite, between the entry of the plastic zone and the neutral plane, and at an angle $\phi$ with deformed work roll radius $R^{\prime}$. The change in thickness of the strip element is $d h$, and the compressive stresses exerted on the vertical walls of the strip are $\sigma$ and $(\sigma+d \sigma)$. Figure 6 depicts the horizontal forces exerted on this element of strip in equilibrium. The radial pressure acting on the surface of the element is $p_{r}$, with a corresponding radial force $\frac{p_{r} d x}{\cos \phi}$, and horizontal component $p_{r} \tan \phi d x$. Friction force is $\frac{\mu p_{r} d x}{\cos \phi}$, with horizontal component $\mu p_{r} d x$, where $\mu$ is the coefficient of friction. Resolving horizontal forces on the element of strip in equilibrium gives

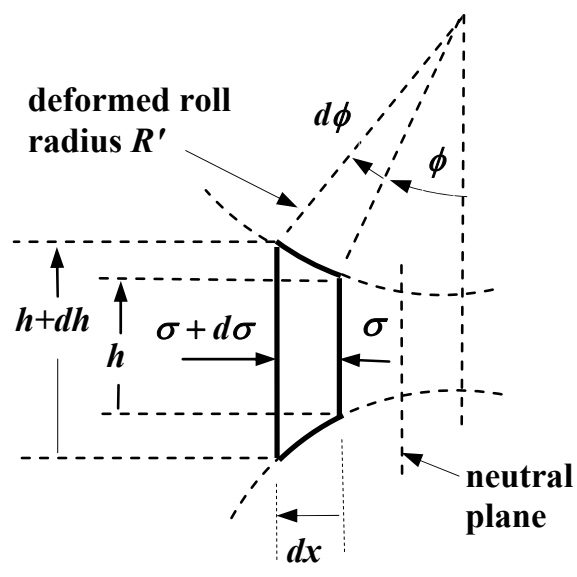

Element of Strip

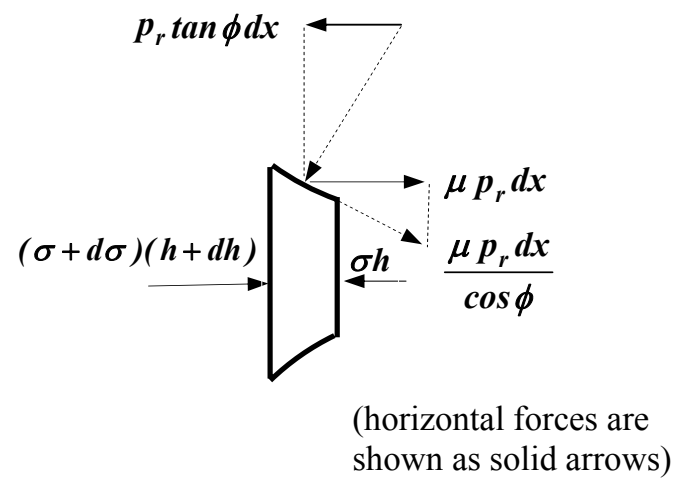

Horizontal Forces on Element of Strip in Equilibrium

Figure 6 Element of Strip in Roll Bite (Plastic Zone)

$$
2 p_{r} \sin \phi \frac{d x}{\cos \phi}-2 \mu p_{r} d x+\sigma h-(h+d h)(\sigma+d \sigma)=0 .
$$


By geometry,

$$
\frac{d x}{\cos \phi}=R^{\prime} d \phi
$$

and substituting (2-2) into (2-1), grouping terms and neglecting $d h d \sigma$ gives $^{2}$

$$
2 p_{r} R^{\prime}(\sin \phi \mp \mu \cos \phi)=d(h \sigma)
$$

where symbols are as defined previously.

The Huber-Mises condition for plasticity [6] relates roll pressure $p_{r}$ to the principal stress $\sigma$ in the horizontal plane and the compressive yield stress $k(h)$ as

$$
p_{r}=\sigma+k(h)
$$

where $k(h)$ denotes the dependency of $k$ on $h$. Assuming this condition applies, and substituting into (2-3) gives

$$
\frac{d\left[h\left(p_{r}-k(h)\right)\right]}{d \phi}=2 p_{r} R^{\prime}(\sin \phi \mp \mu \cos \phi) .
$$

Using some assumptions and approximations, (2-5) can be solved [18] to give a complicated expression for roll pressure $p_{r}$ as a function of the angle $\phi$ in the plastic zone. An example of roll pressure variation in the roll bite area is depicted in Figure 7 which is a typical profile of roll pressure in the plastic and elastic zones as a function of the angle of the arc of contact over the entire roll bite.

\footnotetext{
${ }^{2}$ The plus sign applies for a strip element between the neutral plane and the exit of the plastic zone.
} 


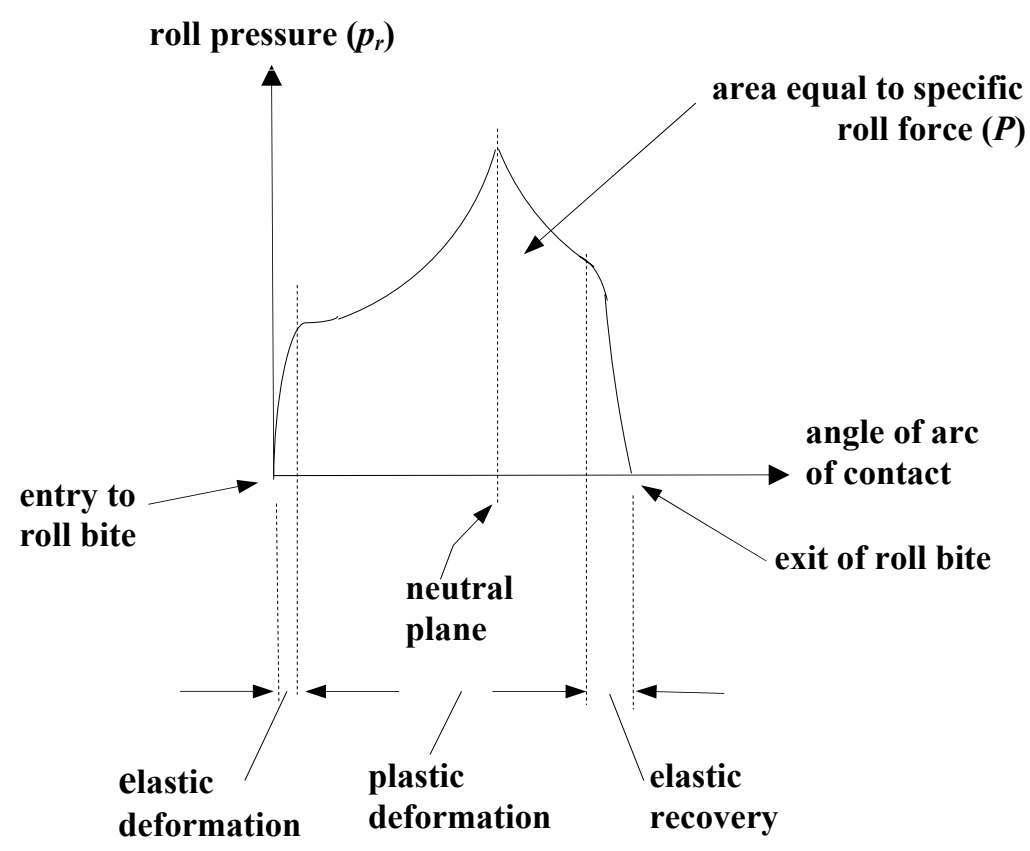

Figure 7 Roll Pressure vs Angle in the Roll Bite

The curve in Figure 7 is frequently denoted as a "friction hill" because of the shape of the upper portion, which results from the effects of the friction components. The peak of the curve is at the neutral plane where the friction forces change sign. The peak depends on the coefficient of friction (i.e. as the coefficient of friction is increased, the peak will increase and move toward the entry of the roll bite, and the specific roll force $\mathrm{P}$ will increase). The area under the friction hill is the specific roll force.

The deformed work roll radius is estimated by assuming an elliptical pressure distribution, with other assumptions, and using calculus and some algebraic manipulations [6]. The resulting expression for the deformed roll radius is

$$
R^{\prime}=R\left(1+\frac{16\left(1-v^{2}\right) P}{\pi E\left(h_{\text {in }}-h_{\text {out }}\right)}\right)
$$


where $v$ is Poisson's ratio, $E$ is Young's modulus, and other symbols are as defined previously. For simplification, $R^{\prime}$ is taken as constant based on the desired initial values of $P, h_{\text {in }}$, and $h_{\text {out }}$ at an operating point prior to rolling, i.e. $P_{0}, h_{\text {in } 0}$, and $h_{\text {out } 0}$.

The compressive yield stress (or hardness) $k$ of the strip affects the pressure distribution and thus the specific roll force $P$. Compressive yield stress is expressed [1] as a base term $k_{0}$ plus an offset term $\Delta k_{\dot{e}}$ to account for dependency on strain rate. The following expression has been determined empirically [1], neglecting thermal effects:

$$
k=k_{0}+\Delta k_{\dot{e}}
$$

where $\quad k_{0}=a(b+r)^{c}$,

$a, b$, and $c$ are constants, $r$ is the reduction corresponding to a thickness $h$ with respect to an annealed thickness $H_{a}$, i.e.

$$
r=\frac{H_{a}-h}{H_{a}}
$$

$\Delta k_{\dot{e}}$ is a speed dependent offset due to strain rate, which is approximated [6] by

$$
\Delta k_{\dot{e}}=\gamma\left(3+\log _{10} \frac{V}{h_{\text {in } 0}} \sqrt{\frac{h_{\text {in } 0}-h_{\text {out } 0}}{R}}\right),
$$

where $V$ is work roll peripheral speed, $h_{\text {in } 0}$ and $h_{\text {out } 0}$ are the desired initial values at an operating point, and $\gamma$ is a constant. The expression for $r$ accounts for work hardening effects caused by rolling in upstream mill stands, and any processing after hot rolling and before entry into the tandem cold mill. The annealed thickness $H_{a}$ is the strip thickness at the exit of the hot rolling process. $H_{a}$ is sometimes significantly different than the thickness at the tandem cold mill entry 
because of processing after hot rolling and prior to cold rolling. The interstand time delay approximation (2-28) is used to estimate the delay in changes in the compressive yield stress from stand $i$ to stand $i+1$.

The coefficient of friction $\mu$, which is speed dependent, also affects the pressure distribution. Empirically, the coefficient of friction is determined [6] as

$$
\mu=\sqrt{\left(\frac{h_{\text {ino } 0}-h_{\text {out }}}{2 R}\right)}\left(.5+\left(K_{1}-.5\right) e^{-K_{2} V}\right),
$$

where $K_{1}$ and $K_{2}$ are constants.

The roll pressure distribution depicted in Figure 7 can be approximated by graphical methods which result in the following simplified expression [1] for specific roll force in the plastic zone, where specific roll force in the elastic zones is assumed negligible for most practical cases:

$$
P=(\bar{k}-\bar{\sigma}) \sqrt{R^{\prime} \delta}(1+.4 \alpha) .
$$

In (2-12) $\bar{k}$ is the mean compressive yield stress given by

$$
\bar{k}=\lambda_{1} k_{\text {in }}+\left(1-\lambda_{1}\right) k_{\text {out }},
$$

where $k_{\text {in }}$ is the compressive yield stress at the entry of the plastic zone, $k_{\text {out }}$ is the compressive yield stress at the exit of the plastic zone, and $\lambda_{1}$ is a constant, $\bar{\sigma}$ is the mean tension stress given by

$$
\bar{\sigma}=\lambda_{2} \sigma_{\text {in }}+\left(1-\lambda_{2}\right) \sigma_{\text {out }},
$$

where $\lambda_{2}$ is a constant, $\alpha$ is given by 


$$
\alpha=\sqrt{\frac{h_{\text {out }}}{h_{\text {in }}}} \exp \left(\mu \sqrt{R^{\prime} \delta} / \bar{h}\right)-1
$$

and $\delta$ is $\left(h_{\text {in }}-h_{\text {out }}\right)$, and $\bar{h}$ is the mean thickness given by

$$
\bar{h}=\beta h_{\text {out }}+(1-\beta) h_{\text {in }}
$$

and where $\beta$ is a constant. Other symbols in (2-12) through (2-15) are as defined previously.

\subsubsection{Work Roll Torque}

A simple approximation of work roll torque is obtained [6] by assuming a constant pressure over the arc of contact, and taking the total force exerted on the strip as the draft multiplied by the average yield stress, with zero tension stress at the entry and exit ends of the roll bite,

$$
G=R\left(h_{\text {in }}-h_{\text {out }}\right) \bar{\sigma}
$$

where $G$ is the specific total work roll torque, and other symbols are as defined before. With tension on each side of the roll bite,

$$
G=R \bar{\sigma}\left[\left(h_{\text {in }}-h_{\text {out }}\right)\left(1+\frac{\sigma_{\text {out }}}{\bar{\sigma}}\right)+\left(\frac{\sigma_{\text {in }}-\sigma_{\text {out }}}{\bar{\sigma}}\right)\right]
$$

Since work roll speed is determined by closed loop speed control, excursions in work roll speed caused by changes in torque are taken as insignificant, with (2-17) and (2-18) provided as background information and not included in the model.

\subsubsection{Forward Slip}

The forward slip $f$ is given approximately [1] by 


$$
f=\frac{V_{\text {out }}-V}{V}
$$

where $V_{\text {out }}$ is the strip speed at the exit of the roll bite, and $V$ is the peripheral speed of the work roll. By conservation of volume through the roll bite and assuming constant strip width,

$$
f=\frac{h_{n}-h_{\text {out }}}{h_{\text {out }}}
$$

where $h_{n}$ is the thickness at the neutral plane. The angle at the neutral plane is approximated [1] by

$$
\phi_{n}=\frac{1}{2} \frac{h_{\text {out }}}{\bar{h}} \sqrt{\frac{\delta}{R^{\prime}}}-\frac{1}{4} \frac{h_{\text {out }} \delta}{\widetilde{h} \mu R^{\prime}}+\frac{1}{4} \frac{h_{\text {out }}}{\mu R^{\prime}}\left[\frac{\sigma_{\text {out }}}{k_{\text {out }}}-\frac{\sigma_{\text {in }}}{k_{\text {in }}}\right] \text {, }
$$

where $\tilde{h}$ is the mean thickness (2-16) except with the value of the constant $\beta$ adjusted slightly. The angle of contact is approximated by

$$
\phi_{1}=\sqrt{\left(\frac{h_{\text {in }}-h_{\text {out }}}{R^{\prime}}\right)} .
$$

Analysis using an element of strip just at the exit side of the neutral plane and using (2-19), (220), and (2-22) gives an expression for the forward slip as

$$
f=\left(\frac{h_{\text {in }}-h_{\text {out }}}{h_{\text {out }}}\right)\left(\frac{\phi_{n}}{\phi_{1}}\right)^{2}
$$

where the symbols are as defined previously. 


\subsubsection{Interstand Tension Stress}

An equation for interstand tension stress is developed by applying Hooke's law to a length of strip between successive mill stands, assuming some average strip thickness and neglecting stretching of the strip. The average tension stress is

$$
\sigma_{i, i+1}=E \frac{\Delta l}{L_{0}}
$$

where $L_{0}$ is the distance between mill stands $i$ and $i+1, \Delta l$ is the change in length due to application of a tension force corresponding to $\sigma_{i, i+1}$, and $E$ is Young's modulus. Over an increment of time $d t$,

$$
\frac{d\left(\sigma_{i, i+1}\right)}{d t} \equiv \dot{\sigma}_{i, i+1}=\frac{E\left(V_{i n, i+1}-V_{o u t, i}\right)}{L_{0}}, \quad \sigma_{i, i+1}(0)=\sigma_{0, i, i+1},
$$

where $V_{i n, i+1}$ is the strip velocity at the input to stand $i+1, V_{\text {out }, i}$ is the strip velocity at the output of stand $i$, and $\sigma_{0, i, i+1}$ is the initial tension stress in the strip between stands $i$ and $i+1$.

\subsubsection{Output Thickness}

An expression for output thickness, assuming operation in the linear region of the mill stretch curve (Figure 4) is derived from (1-2) as

$$
h_{\text {out }}=S+S_{0}+\frac{P W}{M}
$$

where $P$ is the specific roll force, $W$ is the strip width, $S$ is work roll actuator position, $S_{0}$ is the intercept of the linearized portion of the mill stretch curve, and $M$ is the mill modulus. 


\subsubsection{Interstand Time Delay}

The interstand time delay $\tau_{d, i, i+1}$ is the time taken for a small element of strip to travel a distance $L_{0}$ from the exit of stand $i$ to the entry of stand $i+1$, and is defined implicitly as

$$
L_{0}=\int_{0}^{\tau_{d, i, i+1}} V_{\text {out }, i}(t) d t
$$

At any instant of time the time delay is approximated as

$$
\tau_{d, i, i+1}=\frac{L_{0}}{V_{o u t, i}} .
$$

\subsubsection{Input Thickness}

The input thickness to stand 1 is the input thickness to the mill. The input thickness to stands $2,3,4$, and 5 is the output thickness from the previous stand delayed by the interstand time delay $(2-28)$.

\subsubsection{Work Roll Actuator Position}

The work roll hydraulic actuator position controller is modeled (closed loop) as a single first order lag, based on typical data [19]. The model is

$$
\dot{S}=\frac{U_{S}}{\tau_{S}}-\frac{S}{\tau_{S}}, \quad S(0)=S_{0},
$$

where $S$ is the work roll actuator position, $U_{S}$ is the position controller reference, $\tau_{S}$ is the closed loop time constant, and $S_{0}$ is the initial work roll actuator position. 


\subsubsection{Work Roll Speed}

The work roll drive speed controller is modeled (closed loop) as a single first order lag, based on application experience. The model is

$$
\dot{V}=\frac{U_{V}}{\tau_{V}}-\frac{V}{\tau_{V}}, \quad V(0)=V_{0},
$$

where $V$ is the work roll peripheral speed, $U_{V}$ is the drive speed reference, $\tau_{V}$ is the closed loop time constant, and $V_{0}$ is the initial work roll peripheral speed.

\subsection{STATE SPACE AND OUTPUT EQUATIONS}

In this section, the relationships developed in Section 2.1 are put into the forms of a state equation (2-31) and an output equation (2-32),

$$
\begin{array}{cl}
\frac{d x}{d t} \equiv \dot{x}=a\left(x(t), x\left(t-\tau_{d, 12}\right), \ldots x\left(t-\tau_{d, 45}\right)\right)+B u, & \\
y=g\left(x(t), x\left(t-\tau_{d, 12}\right), \ldots x\left(t-\tau_{d, 45}\right)\right), & \\
x(t)=x_{0}, & t=0, \\
x\left(t-\tau_{d, i, i+1}\right)=x_{0}, & t \leq \tau_{d, i, i+1}, i=1,2,3,4,
\end{array}
$$

where $x(t) \in R^{n}$ is a vector whose elements represent the individual state variables at time $t$, $x\left(t-\tau_{d, i, i+1}\right) \in R^{n}$ is a vector whose elements represent the individual state variables at time $\left(t-\tau_{d, i, i+1}\right), a\left(x(t), x\left(t-\tau_{d, 12}\right), \ldots x\left(t-\tau_{d, 45}\right)\right) \in R^{n}$ is a vector whose elements depend on both 
the states and the delayed states, $u \in R^{m}$ is a vector whose elements represent the individual control variables, $y \in R^{p}$ is a vector whose elements represent the individual output variables, $B \in R^{n x m}$ is a constant matrix, $g\left(x(t), x\left(t-\tau_{d, 12}\right), \ldots x\left(t-\tau_{d, 45}\right)\right) \in R^{p}$ is a vector whose elements depend on both the states and the delayed states, and $\tau_{d, i, i+1}$ is a scalar representing the interstand time delays (2-28). The individual state variables, control variables, and output variables represented by the elements of the vectors $x, u$, and $y$ respectively in (2-31) and (2-32) are as shown in Table 1, where the variables and subscripts are as defined previously.

Table 1 Variable Assignments

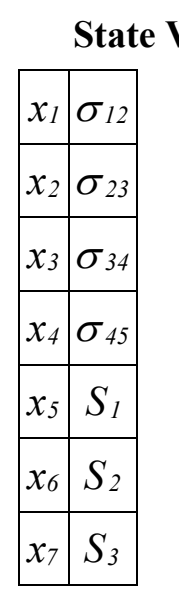

ector
\begin{tabular}{|l|l|}
\hline$x_{8}$ & $S_{4}$ \\
\hline$x_{9}$ & $S_{5}$ \\
\hline$x_{10}$ & $V_{1}$ \\
\hline$x_{11}$ & $V_{2}$ \\
\hline$x_{12}$ & $V_{3}$ \\
\hline$x_{13}$ & $V_{4}$ \\
\hline$x_{14}$ & $V_{5}$ \\
\hline
\end{tabular}

\section{Control Vector}

\begin{tabular}{|c|c|c|c|}
\hline & $U_{S 1}$ & $u_{6}$ & $U_{V 1}$ \\
\hline$u_{2}$ & $U_{S 2}$ & $u_{7}$ & $U_{V 2}$ \\
\hline$u_{3}$ & $U_{S 3}$ & $u_{8}$ & $U_{V 3}$ \\
\hline$u_{4}$ & $U_{S 4}$ & $u_{9}$ & $U_{V 4}$ \\
\hline$u_{5}$ & $U_{S 5}$ & $u_{10}$ & $U_{V 5}$ \\
\hline
\end{tabular}

\section{Output Vector}

\begin{tabular}{|c|c|c|c|}
\hline$y_{1}$ & $h_{\text {out } 1}$ & $y_{8} \sigma$ & $\sigma_{34}$ \\
\hline$y$ & $h_{\text {out } 2}$ & $y_{9} \sigma$ & $\sigma_{45}$ \\
\hline$y_{3}$ & $h_{\text {out } 3}$ & $y_{10} I$ & $P_{1}$ \\
\hline$y_{4}$ & $h_{\text {out } 4}$ & $y_{11} I$ & $P_{2}$ \\
\hline$y_{5}$ & $h_{\text {out } 5}$ & $y_{12}$ & $P_{3}$ \\
\hline$y_{6}$ & $\sigma_{12}$ & $y_{13}$ & $P_{4}$ \\
\hline 37 & $\sigma_{23}$ & $y_{14}$ & $P_{5}$ \\
\hline
\end{tabular}

The state equation (2-31) and the output equation (2-32) show a dependency on timedelayed states which result from the interstand time delays (2-28). These delays cause timedelayed state variables to appear in the model as shown in Appendix C, which derives various relationships as functions of state variables and of time-delayed state variables. 


\subsection{MODEL VERIFICATION}

The model was verified by simulation using three operating points with reduction patterns similar to the typical production schedules given by Bryant [1]. Since it is impractical to use a physical mill to perform open loop tests to verify the model, the results are compared to the results of Byrant's simulations, which are considered a "benchmark" for mill model verification, and to Geddes' results [20] and to Gou's results [21] both of which are based on reduction patterns similar to Bryant's. The simulations were open loop (i.e. the mill is uncontrolled), with mill entry and mill exit tensions held constant by the coiler controllers. Small step changes, both positive and negative, in each of the following variables were applied separately, with the other listed variables remaining at their operating point values:

- Strip thickness at the entry to stand 1 , accompanied by an equal change in strip annealed thickness,

- Strip annealed thickness,

- Strip hardness (compressive yield stress) at the entry to stand 1 ,

- Coefficient of friction at stands 1, 3, and 5 (individually),

- Work roll actuator position references of stands 1,3 , and 5 (individually), and

- Work roll peripheral speed references of stands 1,3 , and 5 (individually).

The mill speed was lowered to thread speed and the above repeated. Dynamic responses to selected perturbations were recorded and compared to results presented in Bryant [1] and to the results presented in Geddes [20].

\subsubsection{Operating Points}

Table 2 presents the three typical Production Schedules used for model verification. Table 3 presents the mill and strip parameters used. Prior to the application of perturbations to the mill 
model, three Operating Points were established using the three typical Production Schedules of Table 2. The strip speed at the mill exit was set to 4000 feet per minute and the individual work roll peripheral speeds were set based on typical values of forward slips [1]. Specific roll forces then were set to attempt to closely approximate the reduction patterns of Table 2. Using this

Table 2 Three Typical Production Schedules

\begin{tabular}{llll} 
Schedule Number & \multicolumn{1}{c}{} & $\mathbf{2}$ & $\mathbf{3}$ \\
Mill Entry Thickness & 0.140 in & 0.093 in & 0.070 in \\
Exit Thickness, Stand 1 & 0.116 & 0.075 & 0.048 \\
Exit Thickness, Stand 2 & 0.096 & 0.060 & 0.031 \\
Exit Thickness, Stand 3 & 0.079 & 0.048 & 0.022 \\
Exit Thickness, Stand 4 & 0.066 & 0.038 & 0.015 \\
Exit Thickness, Stand 5 & 0.062 & 0.036 & 0.014 \\
Tension Stress, Mill Entry & $0.0{\text { tons } / \text { in }^{2}}^{2}$ & 0.0 tons/in & 0.0 tons/in \\
Tension Stress, Stands 1,2 & 5.6 & 5.9 & 6.3 \\
Tension Stress, Stands 2,3 & 5.7 & 6.1 & 6.9 \\
Tension Stress, Stands 3,4 & 5.8 & 6.3 & 7.7 \\
Tension Stress, Stands 4,5 & 6.0 & 6.6 & 8.9 \\
Tension Stress, Mill Exit & 1.8 & 1.8 & 1.8
\end{tabular}

Table 3 Mill and Strip Parameters

$\begin{array}{ll}\text { Work Roll Radii } & 11.5 \mathrm{in} \\ \text { Mill Moduli } & 10^{4} \text { tons/in } \\ \text { Distance Between Stands } & 170 \mathrm{in} \\ \text { Strip Width } & 36 \mathrm{in} \\ \text { Annealed Thickness/Mill Entry Thickness } & 1.095 \\ \text { Young's Modulus } & 30 \times 10^{6} \mathrm{lbs} / \mathrm{in}^{2} \\ \text { Poisson's Ratio } & 0.3 \\ \text { Long Tons } & 2240 \mathrm{lbs} / \mathrm{ton}\end{array}$

method, the resulting three Operating Points corresponding to the three Production Schedules (Table 2) are presented in Table 4. Except for discrepancies in the tension stresses, the resulting operating point values are those given in the schedules of Table 2. These discrepancies do not result in significant increases or decreases in interstand tensions which would cause the strip to 
break or become slack. Control of interstand tensions to be very nearly the values given in Table 2 is addressed in Section 3.3.

Table 4 Three Operating Points

\begin{tabular}{llll} 
Operating Point Number & \multicolumn{1}{c}{} & \multicolumn{1}{c}{$\mathbf{2}$} & \multicolumn{1}{c}{$\mathbf{3}$} \\
Mill Entry Thickness & 0.140 in & 0.093 in & $0.070 \mathrm{in}$ \\
Exit Thickness, Stand 1 & 0.116 & 0.075 & 0.048 \\
Exit Thickness, Stand 2 & 0.096 & 0.060 & 0.031 \\
Exit Thickness, Stand 3 & 0.079 & 0.048 & 0.021 \\
Exit Thickness, Stand 4 & 0.066 & 0.038 & 0.015 \\
Exit Thickness, Stand 5 & 0.062 & 0.036 & 0.014 \\
Tension Stress, Mill Entry & 0.0 tons/in & 0.0 tons/in & 0.0 tons/in \\
Tension Stress, Stands 1,2 & 5.2 & 6.7 & 7.2 \\
Tension Stress, Stands 2,3 & 5.1 & 8.2 & 8.6 \\
Tension Stress, Stands 3,4 & 3.7 & 6.2 & 8.6 \\
Tension Stress, Stands 4,5 & 3.6 & 3.9 & 5.5 \\
Tension Stress, Mill Exit & 1.8 & 1.8 & 1.8
\end{tabular}

\subsubsection{Simulation Results}

Step changes in the variables noted in Section 2.3 were applied to the model for each of the three Operating Points (Table 4). For purposes of comparison to the results of Bryant [1] and to the results of Geddes [20], the sizes of the step changes were approximately those given in Bryant, which also were used by Geddes. Table 16 through Table 27 give the steady-state responses for each of the cases given in Bryant, while Table 5 through Table 14 compare selected cases to Bryant and to Geddes on a percent basis to provide some quantitative indication of how well the model conforms to these sources. In addition, a summary is provided in Table 15 wherein the mean and the standard deviation of the percent deviations from the values given in Bryant and in Geddes are presented. In the tables which follow, the percent change in a variable represents an average of the results for the three Operating Points, and similarly for a percent change in a variable taken from Bryant or Geddes. A table entry of n/a indicates "not applicable." Where a 
percent change in a variable for Geddes is unavailable, the corresponding table entry is either omitted or entered as "u/a." The simulations were done assuming a strip speed (at the mill exit) of 4000 feet per minute which is taken as $100 \%$ speed.

Table 5 Comparison of Changes in Output Thickness for a $+2 \%$ Step Change in Stand 1 Input Thickness at 100\% Speed

\begin{tabular}{|c|c|c|c|c|c|}
\cline { 2 - 6 } \multicolumn{1}{c|}{} & \multicolumn{3}{c|}{ Percent Change in } & \multicolumn{2}{c|}{$\begin{array}{c}\text { Percent Deviation of Model } \\
\text { Output Thickness (steady-state) }\end{array}$} \\
\cline { 2 - 6 } \multicolumn{1}{c|}{} & Model & Bryant & Geddes & Bryant & Geddes \\
\hline Stand 1 & 2.40 & 1.8 & 2.32 & 33.0 & 3.4 \\
\hline Stand 2 & 2.38 & 1.8 & 2.13 & 32.0 & 11.7 \\
\hline Stand 3 & 2.39 & 1.8 & 1.90 & 33.0 & 25.8 \\
\hline Stand 4 & 2.31 & 1.8 & 2.14 & 28.0 & 7.9 \\
\hline Stand 5 & 2.42 & 1.7 & 2.21 & 42.4 & 9.5 \\
\hline
\end{tabular}

Table 6 Comparison of Changes in Output Thickness for a $+5 \%$ Step Change in Stand 1 Input Hardness at $100 \%$ Speed

\begin{tabular}{|l|c|c|c|c|c|}
\cline { 2 - 6 } \multicolumn{1}{c|}{} & \multicolumn{3}{c|}{ Percent Change in } & \multicolumn{2}{c|}{$\begin{array}{c}\text { Percent Deviation of Model } \\
\text { Output Thickness (steady-state) }\end{array}$} \\
\cline { 2 - 6 } \multicolumn{1}{c|}{} & Model & Bryant & Geddes & Bryant & Geddes \\
\hline Stand 1 & 1.27 & 2.1 & 1.23 & -39.5 & 3.2 \\
\hline Stand 2 & 1.51 & 3.0 & 1.47 & -49.7 & 2.7 \\
\hline Stand 3 & 1.56 & 3.3 & 1.66 & $-52,7$ & -6.0 \\
\hline Stand 4 & 1.56 & 3.4 & 1.49 & -54.1 & 4.7 \\
\hline Stand 5 & 1.86 & 3.7 & 1.52 & -49.7 & 22.4 \\
\hline
\end{tabular}

Table 7 Comparison of Changes in Output Thickness for a +.004 Inch Step Change in Stand 1 Position Actuator Ref at 100\% Speed

\begin{tabular}{|l|c|c|c|c|c|}
\cline { 2 - 6 } \multicolumn{1}{c|}{} & \multicolumn{3}{c|}{$\begin{array}{c}\text { Percent Change in } \\
\text { Output Thickness (steady-state) }\end{array}$} & \multicolumn{2}{c|}{$\begin{array}{c}\text { Percent Deviation of Model } \\
\text { from Byrant and Geddes }\end{array}$} \\
\cline { 2 - 6 } \multicolumn{1}{c|}{} & Model & Bryant & Geddes & Bryant & Geddes \\
\hline Stand 1 & 1.55 & 1.5 & 2.42 & 3.3 & -36.0 \\
\hline Stand 2 & 1.42 & 1.3 & 2.04 & 9.2 & -30.0 \\
\hline Stand 3 & 1.41 & 1.3 & 1.77 & 8.5 & -20.0 \\
\hline Stand 4 & 1.37 & 1.3 & 2.10 & 5.4 & -35.0 \\
\hline Stand 5 & 1.42 & 1.2 & 2.04 & 18.3 & -30.4 \\
\hline
\end{tabular}


Table 8 Comparison of Changes in Total Roll Force for a +.004 Inch Step

Change in Stand 1 Position Actuator Ref at 100\% Speed

\begin{tabular}{|l|r|r|r|r|c|}
\cline { 2 - 6 } \multicolumn{1}{c|}{} & \multicolumn{3}{c|}{$\begin{array}{c}\text { Percent Change in } \\
\text { Total Roll Force (steady-state) }\end{array}$} & \multicolumn{2}{c|}{$\begin{array}{c}\text { Percent Deviation of Model } \\
\text { from Byrant and Geddes }\end{array}$} \\
\cline { 2 - 6 } \multicolumn{1}{c|}{} & Model & Bryant & Geddes & Bryant & Geddes \\
\hline Stand 1 & -3.23 & -3.5 & -4.42 & 7.7 & 27.0 \\
\hline Stand 2 & 0.95 & 0.8 & 2.17 & 18.8 & -56.0 \\
\hline Stand 3 & 0.76 & 0.3 & 1.17 & 153.0 & -35.0 \\
\hline Stand 4 & 0.62 & 0.3 & 1.22 & 107.0 & -50.0 \\
\hline Stand 5 & 0.88 & 0.8 & 1.64 & 10.0 & -46.3 \\
\hline
\end{tabular}

Table 9 Comparison of Changes in Output Thickness for a +.004 Inch Step Change in Stand 3 Position Actuator Ref at 100\% Speed

\begin{tabular}{|l|c|c|c|c|c|}
\cline { 2 - 6 } \multicolumn{1}{c|}{} & \multicolumn{3}{c|}{$\begin{array}{c}\text { Percent Change in } \\
\text { Output Thickness (steady-state) }\end{array}$} & \multicolumn{2}{c|}{$\begin{array}{c}\text { Percent Deviation of Model } \\
\text { from Byrant and Geddes }\end{array}$} \\
\cline { 2 - 6 } \multicolumn{1}{c|}{} & Model & Bryant & Geddes & Bryant & Geddes \\
\hline Stand 1 & + trace & +trace & 0.16 & n/a & n/a \\
\hline Stand 2 & -0.27 & -0.4 & -0.43 & 32.5 & 37.2 \\
\hline Stand 3 & 0.34 & 0.4 & 0.55 & -15.0 & -38.2 \\
\hline Stand 4 & 0 & +trace & 0 & $\mathrm{n} / \mathrm{a}$ & $\mathrm{n} / \mathrm{a}$ \\
\hline Stand 5 & 0 & +trace & 0 & $\mathrm{n} / \mathrm{a}$ & $\mathrm{n} / \mathrm{a}$ \\
\hline
\end{tabular}

Table 10 Comparison of Changes in Output Thickness for a +.004 Inch Step Change in Stand 5 Position Actuator Ref at 100\% Speed

\begin{tabular}{|l|c|c|c|c|c|}
\cline { 2 - 6 } \multicolumn{1}{c|}{} & \multicolumn{3}{c|}{$\begin{array}{c}\text { Percent Change in } \\
\text { Output Thickness (steady-state) }\end{array}$} & \multicolumn{2}{c|}{$\begin{array}{c}\text { Percent Deviation of Model } \\
\text { from Byrant and Geddes }\end{array}$} \\
\cline { 2 - 6 } & Model & Bryant & Geddes & Bryant & Geddes \\
\hline Stand 1 & 0 & 0 & $\mathrm{u} / \mathrm{a}$ & $\mathrm{n} / \mathrm{a}$ & $\mathrm{n} / \mathrm{a}$ \\
\hline Stand 2 & 0 & 0 & $\mathrm{u} / \mathrm{a}$ & $\mathrm{n} / \mathrm{a}$ & $\mathrm{n} / \mathrm{a}$ \\
\hline Stand 3 & 0 & + trace & $\mathrm{u} / \mathrm{a}$ & $\mathrm{n} / \mathrm{a}$ & $\mathrm{n} / \mathrm{a}$ \\
\hline Stand 4 & -0.38 & -0.5 & $\mathrm{u} / \mathrm{a}$ & 24.0 & $\mathrm{n} / \mathrm{a}$ \\
\hline Stand 5 & 0.23 & 0.2 & $\mathrm{u} / \mathrm{a}$ & 15.0 & $\mathrm{n} / \mathrm{a}$ \\
\hline
\end{tabular}


Table 11 Comparison of Changes in Output Thickness for a $+2 \%$ Change in Stand 1 Speed Actuator Ref at 100\% Speed

\begin{tabular}{|c|c|c|c|c|c|}
\cline { 2 - 6 } \multicolumn{1}{c|}{} & \multicolumn{3}{c|}{$\begin{array}{c}\text { Percent Change in } \\
\text { Output Thickness (steady-state) }\end{array}$} & \multicolumn{2}{c|}{$\begin{array}{c}\text { Percent Deviation of Model } \\
\text { from Byrant and Geddes }\end{array}$} \\
\cline { 2 - 6 } \multicolumn{1}{c|}{} & Model & Bryant & Geddes & Bryant & Geddes \\
\hline Stand 1 & 0.46 & 0.5 & 0.44 & -8.0 & 4.5 \\
\hline Stand 2 & 1.57 & 1.6 & 1.47 & -1.9 & 6.8 \\
\hline Stand 3 & 1.81 & 1.8 & 1.47 & 0.5 & 23.1 \\
\hline Stand 4 & 1.82 & 1.9 & 1.86 & -4.2 & -2.2 \\
\hline Stand 5 & 1.85 & 1.8 & 1.78 & 2.8 & 3.9 \\
\hline
\end{tabular}

Table 12 Comparison of Changes in Total Roll Force for a $+2 \%$ Change in Stand 1 Speed Actuator Ref at 100\% Speed

\begin{tabular}{|c|c|c|c|c|c|}
\cline { 2 - 6 } \multicolumn{1}{c|}{} & \multicolumn{3}{c|}{$\begin{array}{c}\text { Percent Change in } \\
\text { Total Roll Force (steady-state) }\end{array}$} & \multicolumn{2}{c|}{$\begin{array}{c}\text { Percent Deviation of Model } \\
\text { from Byrant and Geddes }\end{array}$} \\
\cline { 2 - 6 } \multicolumn{1}{c|}{} & Model & Bryant & Geddes & Bryant & Geddes \\
\hline Stand 1 & 0.35 & trace & 0.66 & n/a & -47.0 \\
\hline Stand 2 & 1.27 & 1.6 & 1.67 & -20.6 & -24.0 \\
\hline Stand 3 & 1.16 & 1.4 & 1.09 & -17.1 & 6.4 \\
\hline Stand 4 & 1.01 & 0.8 & 1.24 & 26.3 & -18.5 \\
\hline Stand 5 & 1.30 & 1.3 & 1.64 & 0 & -20.7 \\
\hline
\end{tabular}

Table 13 Comparison of Changes in Output Thickness for a $+2 \%$ Change in Stand 3 Speed Actuator Ref at 100\% Speed

\begin{tabular}{|c|c|c|c|c|c|}
\cline { 2 - 6 } \multicolumn{1}{c|}{} & \multicolumn{3}{c|}{ Percent Change in } & \multicolumn{2}{c|}{$\begin{array}{c}\text { Percent Deviation of Model } \\
\text { Output Thickness (steady-state) }\end{array}$} \\
\cline { 2 - 6 } \multicolumn{1}{c|}{} & Model & Bryant & Geddes & Bryant & Geddes \\
\hline Stand 1 & + trace & 0 & + trace & $\mathrm{n} / \mathrm{a}$ & $\mathrm{n} / \mathrm{a}$ \\
\hline Stand 2 & -0.53 & -0.5 & -0.52 & -6.0 & -1.9 \\
\hline Stand 3 & -1.30 & -1.4 & -1.07 & 7.2 & -21.5 \\
\hline Stand 4 & -0.13 & -0.2 & + trace & 35.0 & $\mathrm{n} / \mathrm{a}$ \\
\hline Stand 5 & - trace & 0 & 0 & $\mathrm{n} / \mathrm{a}$ & $\mathrm{n} / \mathrm{a}$ \\
\hline
\end{tabular}


Table 14 Comparison of Changes in Output Thickness for a $+2 \%$ Change in Stand 5 Speed Actuator Ref at 100\% Speed

\begin{tabular}{|c|c|c|c|c|c|}
\cline { 2 - 6 } \multicolumn{1}{c|}{} & \multicolumn{3}{c|}{ Percent Change in } & \multicolumn{2}{c|}{$\begin{array}{c}\text { Percent Deviation of Model } \\
\text { Output Thickness (steady-state) }\end{array}$} \\
\cline { 2 - 6 } \multicolumn{1}{c|}{} & Model & Bryant & Geddes & Bryant & Geddes \\
\hline Stand 1 & 0 & 0 & $\mathrm{u} / \mathrm{a}$ & $\mathrm{n} / \mathrm{a}$ & $\mathrm{n} / \mathrm{a}$ \\
\hline Stand 2 & 0 & 0 & $\mathrm{u} / \mathrm{a}$ & $\mathrm{n} / \mathrm{a}$ & $\mathrm{n} / \mathrm{a}$ \\
\hline Stand 3 & + trace & + trace & $\mathrm{u} / \mathrm{a}$ & $\mathrm{n} / \mathrm{a}$ & $\mathrm{n} / \mathrm{a}$ \\
\hline Stand 4 & -1.01 & -0.8 & $\mathrm{u} / \mathrm{a}$ & -26.3 & $\mathrm{n} / \mathrm{a}$ \\
\hline Stand 5 & -1.61 & -1.9 & $\mathrm{u} / \mathrm{a}$ & 15.3 & $\mathrm{n} / \mathrm{a}$ \\
\hline
\end{tabular}

Table 15 gives the mean and standard deviation ${ }^{3}$ of the percent deviations from the values of Bryant [1] and Geddes [20] using the data of Table 16 through Table 27, which present the complete results for each of the cases given in Bryant [1].

Table 15 Mean and Standard Deviation of Percent Deviations of Model from Bryant and Geddes

\begin{tabular}{|c|c|c|c|c|}
\cline { 2 - 5 } \multicolumn{1}{c|}{} & \multicolumn{2}{c|}{\begin{tabular}{c} 
Mean of Percent Deviations of \\
\multicolumn{1}{c|}{ Model from Bryant and Geddes }
\end{tabular}} & \multicolumn{2}{c|}{$\begin{array}{c}\text { Standard Deviation of Percent } \\
\text { Deviations of Model from Bryant and } \\
\text { Geddes }\end{array}$} \\
\hline Variable & Bryant & Geddes & Bryant & Geddes \\
\hline $\begin{array}{c}\text { Output } \\
\text { Thickness }\end{array}$ & -4.5 & -2.7 & 25.7 & 13.1 \\
\hline $\begin{array}{c}\text { Total Roll } \\
\text { Force }\end{array}$ & 2.0 & -23.6 & 40.6 & 23.5 \\
\hline $\begin{array}{c}\text { Interstand } \\
\text { Tension }\end{array}$ & 3.8 & 68.7 & 73.7 & 203.3 \\
\hline
\end{tabular}

${ }^{3}$ (a) The mean of a vector $x$ is computed as the mean value of the elements of $x$.

(b) The standard deviation of the vector $x$ is computed as $\|\widetilde{x}\| /(m-1)^{1 / 2}$, where $m$ is the number of elements in the vector $x$, and $\tilde{x}$ is a vector of m elements, with each element $\tilde{x}_{i}$ equal to $x_{i}-$ mean $(x) / m$.

(c) The vector $x$ is the percent deviation of a variable from Bryant or Geddes using the data of Table 16 through Table 27. Certain cases for Bryant are excluded when there is significant uncertainty resulting from difficulty in reading Bryant's data. 
Table $16+2 \%$ Step Change in Stand 1 Input Thickness at 100\% Speed

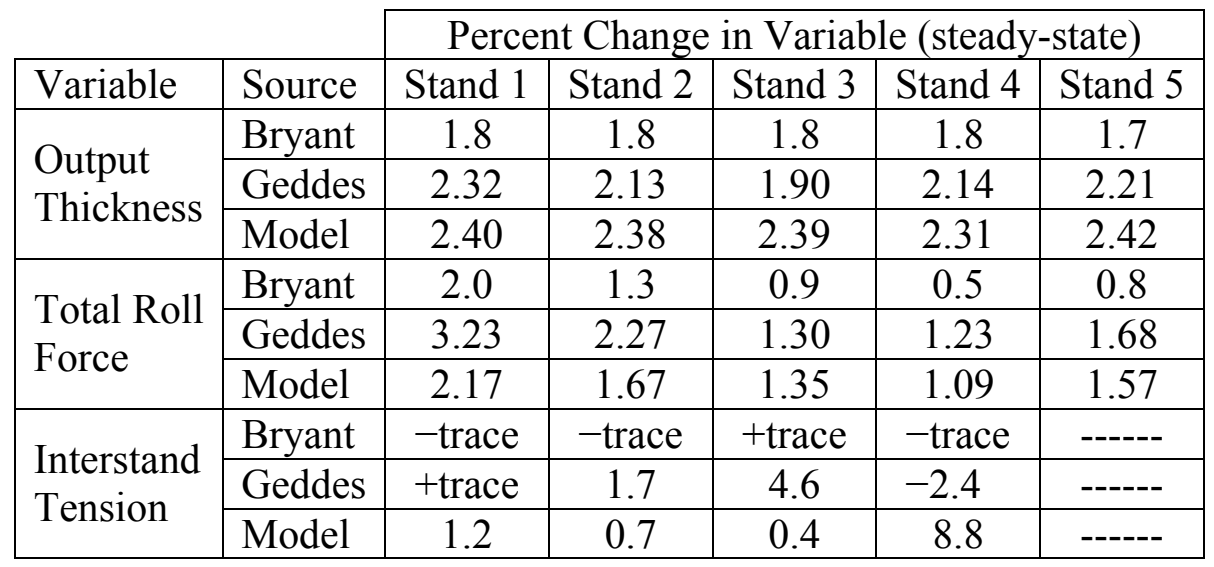

Table $17+5 \%$ Step Change in Annealed Thickness at 100\% Speed

\begin{tabular}{|l|c|c|c|c|c|c|}
\cline { 3 - 7 } \multicolumn{2}{c|}{} & \multicolumn{5}{c|}{ Percent Change in Variable (steady-state) } \\
\hline Variable & Source & Stand 1 & Stand 2 & Stand 3 & Stand 4 & Stand 5 \\
\hline Output & Bryant & 2.5 & 2.6 & 2.6 & 2.7 & 2.6 \\
\cline { 2 - 8 } Thickness & Model & 1.42 & 1.52 & 1.51 & 1.46 & 1.53 \\
\hline Total Roll & Bryant & 2.8 & 2.4 & 1.9 & 0.8 & 1.7 \\
\cline { 2 - 7 } Force & Model & 1.27 & 1.13 & 1.00 & 0.91 & 1.11 \\
\hline Interstand & Bryant & 6.0 & 5.0 & 4.7 & 2.3 & ----- \\
\cline { 2 - 7 } Tension & Model & 9.9 & 6.9 & 6.2 & 10.1 & ------ \\
\hline
\end{tabular}

Table $18+5 \%$ Step Change in Stand 1 Input Hardness at 100\% Speed

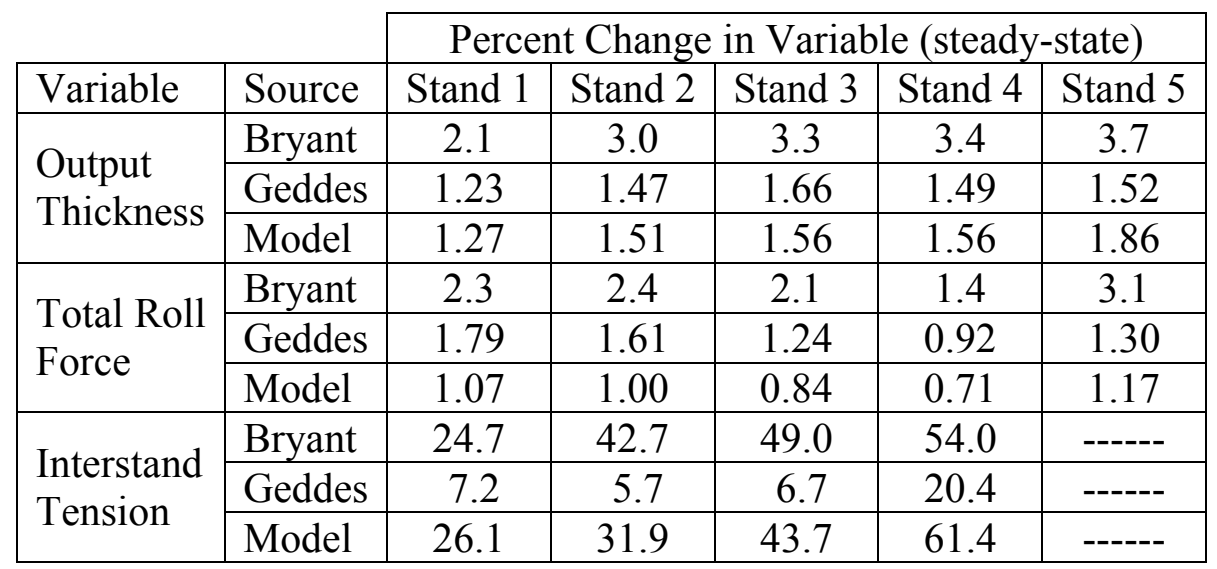


Table $19+10 \%$ Step Change in Stand 1 Friction Coefficient at 100\% Speed

\begin{tabular}{|l|l|c|c|c|c|c|}
\cline { 3 - 7 } \multicolumn{2}{c|}{} & \multicolumn{5}{|c|}{ Percent Change in Variable (steady-state) } \\
\hline Variable & Source & Stand 1 & Stand 2 & Stand 3 & Stand 4 & Stand 5 \\
\hline \multirow{2}{*}{$\begin{array}{l}\text { Output } \\
\text { Thickness }\end{array}$} & Bryant & 0.4 & 0.4 & 0.4 & 0.4 & 0.30 \\
\cline { 2 - 7 } & Geddes & 0.61 & 0.54 & 0.48 & 0.55 & 0.50 \\
\cline { 2 - 7 } & Model & 0.98 & 0.95 & 0.95 & 0.93 & 0.96 \\
\hline \multirow{3}{*}{$\begin{array}{l}\text { Total Roll } \\
\text { Force }\end{array}$} & Bryant & + trace & + trace & +trace & +trace & +trace \\
\cline { 2 - 7 } & Geddes & 0.70 & 0.40 & 0.21 & 0.19 & 0.24 \\
\cline { 2 - 7 } $\begin{array}{l}\text { Interstand } \\
\text { Tension }\end{array}$ & Model & 0.63 & 0.43 & 0.37 & 0.30 & 0.43 \\
\cline { 2 - 7 } & Bryant & -2.0 & - trace & - trace & - trace & ------ \\
\cline { 2 - 7 } & Geddes & -2.9 & -2.7 & 2.2 & 7.1 & \\
\hline
\end{tabular}

Table $20+10 \%$ Step Change in Stand 3 Friction Coefficient at 100\% Speed

\begin{tabular}{|l|l|c|c|c|c|c|}
\cline { 3 - 7 } \multicolumn{2}{c|}{} & \multicolumn{5}{c|}{ Percent Change in Variable (steady-state) } \\
\hline Variable & Source & Stand 1 & Stand 2 & Stand 3 & Stand 4 & Stand 5 \\
\hline \multirow{2}{*}{$\begin{array}{l}\text { Output } \\
\text { Thickness }\end{array}$} & Bryant & + trace & -0.2 & +trace & 0 & 0 \\
\cline { 2 - 7 } & Geddes & + trace & -0.26 & +trace & +trace & +trace \\
\cline { 2 - 7 } & Model & 0.05 & -0.24 & 0 & 0 & 0 \\
\hline \multirow{3}{*}{$\begin{array}{l}\text { Total Roll } \\
\text { Force }\end{array}$} & Bryant & + trace & - trace & 0 & 0 & 0 \\
\cline { 2 - 8 } & Geddes & + trace & 0.26 & 0 & 0 & -trace \\
\cline { 2 - 8 } & Model & 0 & -0.16 & 0 & 0 & 0 \\
\hline \multirow{2}{*}{$\begin{array}{l}\text { Interstand } \\
\text { Tension }\end{array}$} & Bryant & 0 & 10.0 & 0 & 0 & ------ \\
\cline { 2 - 8 } & Geddes & -2.8 & 3.0 & -1.1 & 9.4 & \\
\cline { 2 - 8 } & Model & -1.4 & 13.8 & -0.8 & -0.4 & ------ \\
\hline
\end{tabular}

Table $21+10 \%$ Step Change in Stand 5 Friction Coefficient at 100\% Speed

\begin{tabular}{|l|c|c|c|c|c|c|}
\cline { 3 - 7 } \multicolumn{2}{c|}{} & \multicolumn{5}{c|}{ Percent Change in Variable (steady-state) } \\
\hline Variable & Source & Stand 1 & Stand 2 & Stand 3 & Stand 4 & Stand 5 \\
\hline Output & Bryant & 0 & 0 & +trace & -trace & +trace \\
\cline { 2 - 7 } Thickness & Model & 0 & 0 & 0 & -trace & 0 \\
\hline Total Roll & Bryant & 0 & 0 & 0 & -trace & 0 \\
\cline { 2 - 7 } Force & Model & 0 & 0 & 0 & 0 & 0 \\
\hline Interstand & Bryant & 0 & 0 & -trace & 7.3 & ------ \\
\cline { 2 - 7 } Tension & Model & 0 & +trace & -trace & 5.9 & ------ \\
\hline
\end{tabular}


Table $22+.004$ Inch Step Change in Stand 1 Position Actuator Ref at 100\% Speed

\begin{tabular}{|l|l|c|c|c|c|c|}
\cline { 3 - 7 } \multicolumn{2}{c|}{} & \multicolumn{5}{|c|}{ Percent Change in Variable (steady-state) } \\
\hline Variable & Source & Stand 1 & Stand 2 & Stand 3 & Stand 4 & Stand 5 \\
\hline \multirow{2}{*}{$\begin{array}{l}\text { Output } \\
\text { Thickness }\end{array}$} & Bryant & 1.5 & 1.3 & 1.3 & 1.3 & 1.2 \\
\cline { 2 - 7 } & Geddes & 2.42 & 2.04 & 1.77 & 2.10 & 2.04 \\
\cline { 2 - 7 } & Model & 1.55 & 1.42 & 1.41 & 1.37 & 1.42 \\
\hline \multirow{3}{*}{\begin{tabular}{l} 
Total Roll $\begin{array}{l}\text { Force } \\
\text { Foll }\end{array}$ \\
\cline { 2 - 7 } $\begin{array}{l}\text { Interstand } \\
\text { Tension }\end{array}$
\end{tabular}} & Bryant & -3.5 & 0.8 & 0.3 & 0.3 & 0.8 \\
\cline { 2 - 7 } & Geddes & -4.42 & 2.17 & 1.17 & 1.22 & 1.64 \\
\cline { 2 - 7 } & Bodel & -3.23 & 0.95 & 0.76 & 0.62 & 0.88 \\
\cline { 2 - 7 } & Geddes & -6.3 & -5.3 & -1.8 & -1.8 & ------ \\
\hline
\end{tabular}

Table $23+.004$ Inch Step Change in Stand 3 Position Actuator Ref at 100\% Speed

\begin{tabular}{|l|l|c|c|c|c|c|}
\cline { 3 - 7 } \multicolumn{2}{c|}{} & \multicolumn{5}{|c|}{ Percent Change in Variable (steady-state) } \\
\hline Variable & Source & Stand 1 & Stand 2 & Stand 3 & Stand 4 & Stand 5 \\
\hline \multirow{2}{*}{$\begin{array}{l}\text { Output } \\
\text { Thickness }\end{array}$} & Bryant & + trace & -0.4 & 0.4 & +trace & +trace \\
\cline { 2 - 7 } & Geddes & 0.16 & -0.43 & 0.55 & 0 & 0 \\
\cline { 2 - 7 } & Model & + trace & -0.27 & 0.34 & 0 & 0 \\
\hline \multirow{2}{*}{$\begin{array}{l}\text { Total Roll } \\
\text { Force }\end{array}$} & Bryant & 0 & - trace & -4.3 & 0 & 0 \\
\cline { 2 - 8 } & Geddes & 0.14 & -0.92 & -6.17 & +trace & +trace \\
\cline { 2 - 7 } & Model & 0 & -0.30 & -4.60 & 0 & 0 \\
\hline \multirow{3}{*}{$\begin{array}{l}\text { Interstand } \\
\text { Tension }\end{array}$} & Bryant & - trace & 18.7 & 1.7 & 0 & ------ \\
\cline { 2 - 7 } & Geddes & -1.9 & 9.7 & 2.1 & - trace & ------ \\
\cline { 2 - 7 } & Model & -1.5 & 23.1 & 6.8 & 2.1 & ------ \\
\hline
\end{tabular}

Table $24+.004$ Inch Step Change in Stand 5 Position Actuator Ref at 100\% Speed

\begin{tabular}{|l|c|c|c|c|c|c|}
\cline { 3 - 7 } \multicolumn{2}{c|}{} & \multicolumn{5}{c|}{ Percent Change in Variable (steady-state) } \\
\hline Variable & Source & Stand 1 & Stand 2 & Stand 3 & Stand 4 & Stand 5 \\
\hline Output & Bryant & 0 & 0 & trace & -0.5 & 0.2 \\
\cline { 2 - 7 } Thickness & Model & 0 & 0 & 0 & -0.38 & 0.23 \\
\hline Total Roll & Bryant & 0 & 0 & 0 & 0 & -7.8 \\
\cline { 2 - 7 } Force & Model & 0 & 0 & 0 & - trace & -7.39 \\
\hline Interstand & Bryant & 0 & 0 & -1.8 & 24.0 & ------ \\
\cline { 2 - 7 } Tension & Model & -trace & 0.2 & -1.1 & 37.4 & ------ \\
\hline
\end{tabular}


Table $25+2 \%$ Step Change in Stand 1 Speed Actuator Ref at 100\% Speed

\begin{tabular}{|l|l|c|c|c|c|c|}
\cline { 3 - 7 } \multicolumn{2}{c|}{} & \multicolumn{5}{c|}{ Percent Change in Variable (steady-state) } \\
\hline Variable & Source & Stand 1 & Stand 2 & Stand 3 & Stand 4 & Stand 5 \\
\hline \multirow{2}{*}{$\begin{array}{l}\text { Output } \\
\text { Thickness }\end{array}$} & Bryant & 0.5 & 1.6 & 1.8 & 1.9 & 1.8 \\
\cline { 2 - 7 } & Geddes & 0.44 & 1.47 & 1.47 & 1.86 & 1.78 \\
\cline { 2 - 7 } & Model & 0.46 & 1.57 & 1.81 & 1.82 & 1.85 \\
\hline \multirow{3}{*}{$\begin{array}{l}\text { Total Roll } \\
\text { Force }\end{array}$} & Bryant & + trace & 1.6 & 1.4 & 0.8 & 1.3 \\
\cline { 2 - 7 } & Geddes & 0.66 & 1.67 & 1.09 & 1.24 & 1.64 \\
\cline { 2 - 7 } & Model & 0.35 & 1.27 & 1.16 & 1.01 & 1.30 \\
\hline \multirow{3}{*}{$\begin{array}{l}\text { Interstand } \\
\text { Tension }\end{array}$} & Bryant & -18.3 & -8.0 & -4.7 & -5.3 & ------ \\
\cline { 2 - 7 } & Geddes & -10.0 & -5.1 & -0.2 & -10.4 & ------ \\
\cline { 2 - 7 } & Model & -27.0 & -6.9 & -3.6 & 3.3 & ----- \\
\hline
\end{tabular}

Table $26+2 \%$ Step Change in Stand 3 Speed Actuator Ref at 100\% Speed

\begin{tabular}{|l|l|c|c|c|c|c|}
\cline { 3 - 7 } \multicolumn{2}{c|}{} & \multicolumn{5}{|c|}{ Percent Change in Variable (steady-state) } \\
\hline Variable & Source & Stand 1 & Stand 2 & Stand 3 & Stand 4 & Stand 5 \\
\hline \multirow{2}{*}{$\begin{array}{l}\text { Output } \\
\text { Thickness }\end{array}$} & Bryant & 0 & -0.5 & -1.4 & -0.2 & 0 \\
\cline { 2 - 7 } & Geddes & +trace & -0.52 & -1.07 & +trace & 0 \\
\cline { 2 - 7 } & Model & +trace & -0.53 & -1.30 & -0.13 & -trace \\
\hline \multirow{3}{*}{$\begin{array}{l}\text { Total Roll } \\
\text { Force }\end{array}$} & Bryant & 0 & - trace & - trace & 0 & 0 \\
\cline { 2 - 7 } & Geddes & + trace & -0.66 & -0.83 & 0 & - trace \\
\cline { 2 - 7 } $\begin{array}{l}\text { Interstand } \\
\text { Tension }\end{array}$ & Model & 0 & -0.42 & -0.72 & - trace & -trace \\
\cline { 2 - 7 } & Bryant & 0 & 20.0 & -13.0 & -6.0 & ------ \\
\cline { 2 - 7 } & Geddes & -1.1 & 10.0 & -5.2 & 0.3 & ------ \\
\hline
\end{tabular}

Table $27+2 \%$ Step Change in Stand 5 Speed Actuator Ref at 100\% Speed

\begin{tabular}{|l|c|c|c|c|c|c|}
\cline { 3 - 7 } \multicolumn{2}{c|}{} & \multicolumn{5}{c|}{ Percent Change in Variable (steady-state) } \\
\hline Variable & Source & Stand 1 & Stand 2 & Stand 3 & Stand 4 & Stand 5 \\
\hline Output & Bryant & 0 & 0 & +trace & -0.8 & -1.9 \\
\cline { 2 - 7 } Thickness & Model & 0 & 0 & +trace & -1.01 & -1.61 \\
\hline Total Roll & Bryant & 0 & 0 & 0 & - trace & -trace \\
\cline { 2 - 7 } Force & Model & 0 & 0 & 0 & -0.5 & -1.10 \\
\hline Interstand & Bryant & 0 & 0 & -7.0 & 46.7 & ----- \\
\cline { 2 - 7 } Tension & Model & -0.1 & 0.5 & -1.4 & 97.6 & ----- \\
\hline
\end{tabular}


The strip speed at the mill exit was lowered to thread speed (200 feet per minute, i.e. $5 \%$ of top speed) and the simulations repeated. Steady-state responses considered more pertinent to the development of the control strategy are presented in Table 28 through Table 35. Steady-state responses at 100 percent speed are also shown to facilitate comparison.

Table $28+2 \%$ Step Change in Stand 1 Input Thickness at 5\% Speed

\begin{tabular}{|l|c|c|c|c|c|c|}
\cline { 3 - 7 } \multicolumn{2}{c|}{} & \multicolumn{5}{c|}{ Percent Change in Variable (steady-state) } \\
\hline Variable & Speed & Stand 1 & Stand 2 & Stand 3 & Stand 4 & Stand 5 \\
\hline Output & $100 \%$ & 2.40 & 2.38 & 2.39 & 2.31 & 2.42 \\
\cline { 2 - 7 } Thickness & $5 \%$ & 2.39 & 2.35 & 2.33 & 2.27 & 2.40 \\
\hline Total Roll & $100 \%$ & 2.17 & 1.67 & 1.35 & 1.09 & 1.57 \\
\cline { 2 - 7 } Force & $5 \%$ & 2.16 & 1.65 & 1.34 & 1.09 & 1.56 \\
\hline Interstand & $100 \%$ & 1.2 & 0.7 & 0.4 & 8.8 & ----- \\
\cline { 2 - 7 } Tension & $5 \%$ & 0.6 & +trace & -0.9 & 9.2 & ------ \\
\hline
\end{tabular}

Table $29+5 \%$ Step Change in Stand 1 Input Hardness at 5\% Speed

\begin{tabular}{|l|c|c|c|c|c|c|}
\cline { 3 - 7 } \multicolumn{2}{c|}{} & \multicolumn{5}{c|}{ Percent Change in Variable (steady-state) } \\
\hline Variable & Speed & Stand 1 & Stand 2 & Stand 3 & Stand 4 & Stand 5 \\
\hline Output & $100 \%$ & 1.27 & 1.51 & 1.56 & 1.56 & 1.86 \\
\cline { 2 - 7 } Thickness & $5 \%$ & 1.23 & 1.31 & 1.41 & 1.44 & 1.64 \\
\hline Total Roll & $100 \%$ & 1.07 & 1.00 & 0.84 & 0.71 & 1.17 \\
\cline { 2 - 7 } Force & $5 \%$ & 1.00 & 0.91 & 0.75 & 0.62 & 1.05 \\
\hline Interstand & $100 \%$ & 26.1 & 31.9 & 43.7 & 61.4 & ----- \\
\cline { 2 - 7 } Tension & $5 \%$ & 20.3 & 23.0 & 24.9 & 55.5 & ----- \\
\hline
\end{tabular}

Table $30+.004$ Inch Step Change in Stand 1 Position Actuator Ref at 5\% Speed

\begin{tabular}{|l|c|c|c|c|c|c|}
\cline { 3 - 7 } \multicolumn{2}{c|}{} & \multicolumn{5}{c|}{ Percent Change in Variable (steady-state) } \\
\hline Variable & Speed & Stand 1 & Stand 2 & Stand 3 & Stand 4 & Stand 5 \\
\hline Output & $100 \%$ & 1.55 & 1.42 & 1.41 & 1.37 & 1.42 \\
\cline { 2 - 7 } Thickness & $5 \%$ & 1.41 & 1.21 & 1.21 & 1.18 & 1.25 \\
\hline Total Roll & $100 \%$ & -3.23 & 0.95 & 0.76 & 0.62 & 0.88 \\
\cline { 2 - 7 } Force & $5 \%$ & -3.29 & 0.87 & 0.70 & 0.57 & 0.81 \\
\hline Interstand & $100 \%$ & -0.5 & -1.4 & -1.5 & 2.5 & ------ \\
\cline { 2 - 7 } Tension & $5 \%$ & -0.1 & -1.1 & -1.5 & 3.0 & ------ \\
\hline
\end{tabular}


Table $31+.004$ Inch Step Change in Stand 3 Position Actuator Ref at 5\% Speed

\begin{tabular}{|l|c|c|c|c|c|c|}
\cline { 3 - 7 } \multicolumn{2}{c|}{} & \multicolumn{5}{c|}{ Percent Change in Variable (steady-state) } \\
\hline Variable & Speed & Stand 1 & Stand 2 & Stand 3 & Stand 4 & Stand 5 \\
\hline Output & $100 \%$ & trace & -0.27 & 0.34 & 0 & 0 \\
\cline { 2 - 7 } Thickness & $5 \%$ & 0 & -0.16 & 0.38 & 0 & 0 \\
\hline Total Roll & $100 \%$ & 0 & -0.30 & -4.60 & 0 & 0 \\
\cline { 2 - 7 } Force & $5 \%$ & 0 & -0.23 & -4.61 & 0 & 0 \\
\hline Interstand & $100 \%$ & -1.5 & 23.1 & 6.8 & 2.1 & ----- \\
\cline { 2 - 7 } Tension & $5 \%$ & -1.4 & 15.8 & 4.2 & 2.1 & ------ \\
\hline
\end{tabular}

Table $32+.004$ Inch Step Change in Stand 5 Position Actuator Ref at 5\% Speed

\begin{tabular}{|l|c|c|c|c|c|c|}
\cline { 3 - 7 } \multicolumn{2}{c|}{} & \multicolumn{5}{c|}{ Percent Change in Variable (steady-state) } \\
\hline Variable & Speed & Stand 1 & Stand 2 & Stand 3 & Stand 4 & Stand 5 \\
\hline Output & $100 \%$ & 0 & 0 & 0 & -0.38 & 0.23 \\
\cline { 2 - 7 } Thickness & $5 \%$ & 0 & 0 & 0 & -0.19 & 0.43 \\
\hline Total Roll & $100 \%$ & 0 & 0 & 0 & - trace & -7.39 \\
\cline { 2 - 7 } Force & $5 \%$ & 0 & 0 & 0 & -0.13 & -7.35 \\
\hline Interstand & $100 \%$ & -trace & 0.2 & -1.1 & 37.4 & ------ \\
\cline { 2 - 7 } Tension & $5 \%$ & -trace & 0.3 & -1.7 & 38.0 & ------ \\
\hline
\end{tabular}

Table $33+2 \%$ Step Change in Stand 1 Speed Actuator Ref at 5\% Speed

\begin{tabular}{|l|c|c|c|c|c|c|}
\cline { 3 - 7 } \multicolumn{2}{c|}{} & \multicolumn{5}{c|}{ Percent Change in Variable (steady-state) } \\
\hline Variable & Speed & Stand 1 & Stand 2 & Stand 3 & Stand 4 & Stand 5 \\
\hline Output & $100 \%$ & 0.46 & 1.57 & 1.81 & 1.82 & 1.85 \\
\cline { 2 - 7 } Thickness & $5 \%$ & 0.56 & 1.72 & 1.98 & 1.82 & 2.17 \\
\hline Total Roll & $100 \%$ & 0.35 & 1.27 & 1.16 & 1.01 & 1.30 \\
\cline { 2 - 7 } Force & $5 \%$ & 0.50 & 1.23 & 1.12 & 1.59 & 1.32 \\
\hline Interstand & $100 \%$ & -27.0 & -6.9 & -3.6 & 3.3 & ------ \\
\cline { 2 - 7 } Tension & $5 \%$ & -23.0 & -5.0 & -3.0 & 4.8 & ------ \\
\hline
\end{tabular}


Table $34+2 \%$ Step Change in Stand 3 Speed Actuator Ref at 5\% Speed

\begin{tabular}{|l|c|c|c|c|c|c|}
\cline { 3 - 7 } \multicolumn{2}{c|}{} & \multicolumn{5}{c|}{ Percent Change in Variable (steady-state) } \\
\hline Variable & Speed & Stand 1 & Stand 2 & Stand 3 & Stand 4 & Stand 5 \\
\hline Output & $100 \%$ & +trace & -0.53 & -1.30 & -0.13 & - trace \\
\cline { 2 - 7 } Thickness & $5 \%$ & trace & -0.64 & -1.30 & -0.10 & 0 \\
\hline Total Roll & $100 \%$ & 0 & -0.42 & -0.72 & - trace & - trace \\
\cline { 2 - 7 } Force & $5 \%$ & 0 & -0.43 & -0.76 & - trace & 0 \\
\hline Interstand & $100 \%$ & -1.2 & 29.9 & -30.5 & -14.5 & ------ \\
\cline { 2 - 7 } Tension & $5 \%$ & -1.8 & 24.8 & -21.6 & -10.5 & ------ \\
\hline
\end{tabular}

Table $35+2 \%$ Step Change in Stand 5 Speed Actuator Ref at 5\% Speed

\begin{tabular}{|l|c|c|c|c|c|c|}
\cline { 3 - 7 } \multicolumn{2}{c|}{} & \multicolumn{5}{c|}{ Percent Change in Variable (steady-state) } \\
\hline Variable & Speed & Stand 1 & Stand 2 & Stand 3 & Stand 4 & Stand 5 \\
\hline Output & $100 \%$ & 0 & 0 & +trace & -1.01 & -1.61 \\
\cline { 2 - 7 } Thickness & $5 \%$ & 0 & 0 & 0.15 & -0.78 & -1.50 \\
\hline Total Roll & $100 \%$ & 0 & 0 & 0 & -0.50 & -1.10 \\
\cline { 2 - 7 } Force & $5 \%$ & 0 & 0 & 0 & -0.39 & -1.07 \\
\hline Interstand & $100 \%$ & -0.1 & 0.5 & -1.4 & 97.6 & ------ \\
\cline { 2 - 7 } Tension & $5 \%$ & -0.1 & 0.7 & -3.9 & 102.6 & ------ \\
\hline
\end{tabular}

Negative step changes of the same magnitude as the positive step changes were applied at 100 percent speed and at 5 percent speed. In general, the resulting magnitudes of the output thickness and roll force did not change significantly from the magnitudes resulting from application of the positive steps. Some changes in the magnitudes of interstand tension occurred in those instances where the change in interstand tension was not large. Where the change in interstand tension was larger (e.g. a step change in hardness), the change in magnitude was of the same order as the change in magnitude with the positive step. Some typical results are depicted in Table 36 through Table 39 for 100 percent speed. The results for 5 percent speed are similar. The percent changes for positive step changes also are shown to facilitate comparison. 
Table $36-2 \%$ Step Change in Stand 1 Input Thickness at 100\% Speed

\begin{tabular}{|l|c|c|c|c|c|c|}
\cline { 3 - 7 } \multicolumn{2}{c|}{} & \multicolumn{5}{c|}{ Percent Change in Variable (steady-state) } \\
\hline Variable & Step & Stand 1 & Stand 2 & Stand 3 & Stand 4 & Stand 5 \\
\hline Output & Pos & 2.40 & 2.38 & 2.39 & 2.31 & 2.42 \\
\cline { 2 - 7 } Thickness & Neg & -2.48 & -2.45 & -2.43 & -2.55 & -2.35 \\
\hline Total Roll & Pos & 2.17 & 1.67 & 1.35 & 1.09 & 1.57 \\
\cline { 2 - 7 } Force & Neg & -2.22 & -1.69 & -1.36 & -1.19 & -1.51 \\
\hline Interstand & Pos & 1.2 & 0.7 & 0.4 & 8.8 & ------ \\
\cline { 2 - 7 } Tension & Neg & -1.0 & 0.1 & 0.1 & 10.2 & ------ \\
\hline
\end{tabular}

Table $37-5 \%$ Step Change in Stand 1 Input Hardness at 100\% Speed

\begin{tabular}{|l|c|c|c|c|c|c|}
\cline { 3 - 7 } \multicolumn{2}{c|}{} & \multicolumn{5}{|c|}{ Percent Change in Variable (steady-state) } \\
\hline Variable & Step & Stand 1 & Stand 2 & Stand 3 & Stand 4 & Stand 5 \\
\hline Output & Pos & 1.27 & 1.51 & 1.56 & 1.56 & 1.86 \\
\cline { 2 - 7 } Thickness & Neg & -1.34 & -1.60 & -1.62 & -1.81 & -1.96 \\
\hline Total Roll & Pos & 1.07 & 1.00 & 0.84 & 0.71 & 1.17 \\
\cline { 2 - 7 } Force & Neg & -1.13 & -1.05 & -0.88 & -0.82 & -1.25 \\
\hline Interstand & Pos & 26.1 & 31.9 & 43.7 & 61.4 & ----- \\
\cline { 2 - 7 } Tension & Neg & -25.7 & -31.4 & -43.5 & -44.5 & ------ \\
\hline
\end{tabular}

Table 38 -.004 Inch Step Change in Stand 1 Position Actuator Ref at 100\% Speed

\begin{tabular}{|l|c|c|c|c|c|c|}
\cline { 3 - 7 } \multicolumn{2}{c|}{} & \multicolumn{5}{c|}{ Percent Change in Variable (steady-state) } \\
\hline Variable & Step & Stand 1 & Stand 2 & Stand 3 & Stand 4 & Stand 5 \\
\hline Output & Pos & 1.55 & 1.42 & 1.41 & 1.37 & 1.42 \\
\cline { 2 - 7 } Thickness & Neg & -1.55 & -1.43 & -1.41 & -1.47 & -1.39 \\
\hline Total Roll & Pos & -3.23 & 0.95 & 0.76 & 0.62 & 0.88 \\
\cline { 2 - 7 } Force & Neg & -3.21 & -0.96 & -0.77 & -0.65 & -0.86 \\
\hline $\begin{array}{l}\text { Interstand } \\
\text { Tension }\end{array}$ & Pos & -0.5 & -1.4 & -1.5 & 2.5 & ------ \\
\cline { 2 - 7 } & Neg & 1.6 & 1.7 & 3.1 & 0.0 & ------ \\
\hline
\end{tabular}


Table $39-2 \%$ Step Change in Stand 1 Speed Actuator Ref at 100\% Speed

\begin{tabular}{|l|c|c|c|c|c|c|}
\cline { 3 - 7 } \multicolumn{2}{c|}{} & \multicolumn{5}{c|}{ Percent Change in Variable (steady-state) } \\
\hline Variable & Step & Stand 1 & Stand 2 & Stand 3 & Stand 4 & Stand 5 \\
\hline Output & Pos & 0.46 & 1.57 & 1.81 & 1.82 & 1.85 \\
\cline { 2 - 7 } Thickness & Neg & -0.49 & -1.68 & -1.85 & -1.95 & -1.85 \\
\hline Total Roll & Pos & 0.35 & 1.27 & 1.16 & 1.01 & 1.30 \\
\cline { 2 - 7 } Force & Neg & -0.44 & -1.33 & -1.02 & -0.91 & -1.18 \\
\hline Interstand & Pos & -27.0 & -6.9 & -3.6 & 3.3 & ------ \\
\cline { 2 - 7 } Tension & Neg & 26.6 & 7.1 & 3.8 & 7.3 & ------ \\
\hline
\end{tabular}

Dynamic responses of stand exit thicknesses, interstand tensions, and stand specific roll forces to step changes in the variables noted in Section 2.3 were taken with operation at $100 \%$ speed and at 5\% speed using Operating Point 1 (Table 4). In all cases the model was stable and there were no undesirable excursions in the responses. Figure 8 through Figure 17 depict dynamic responses for four selected cases:

- $\mathrm{A}+2 \%$ step change in the input thickness to stand 1 at $100 \%$ speed (Figure 8 through Figure 10).

- $\mathrm{A}+2 \%$ step change in the stand 1 position actuator reference at $100 \%$ speed (Figure 11 through Figure 13).

- A $+2 \%$ step change in the stand 1 speed actuator reference at $100 \%$ speed (Figure 14 through Figure 16).

- $\mathrm{A}+2 \%$ step change in the stand 1 position actuator reference at $5 \%$ speed (Figure 17 ). 
Percent Change in Output Thickness
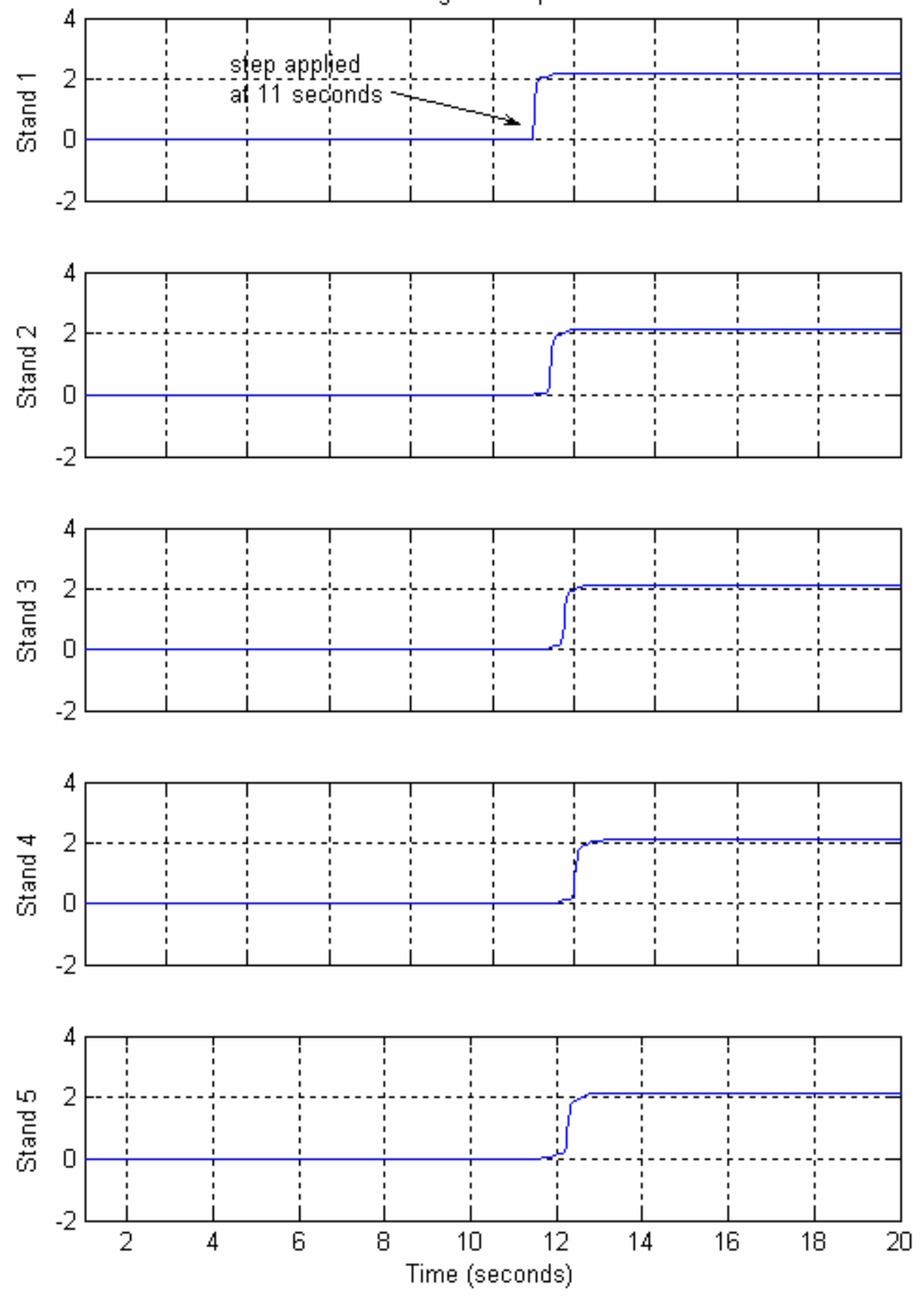

Figure 8 Output Thickness Responses to $+2 \%$ Step Change in Stand 1 Input Thickness at 100\% Speed 

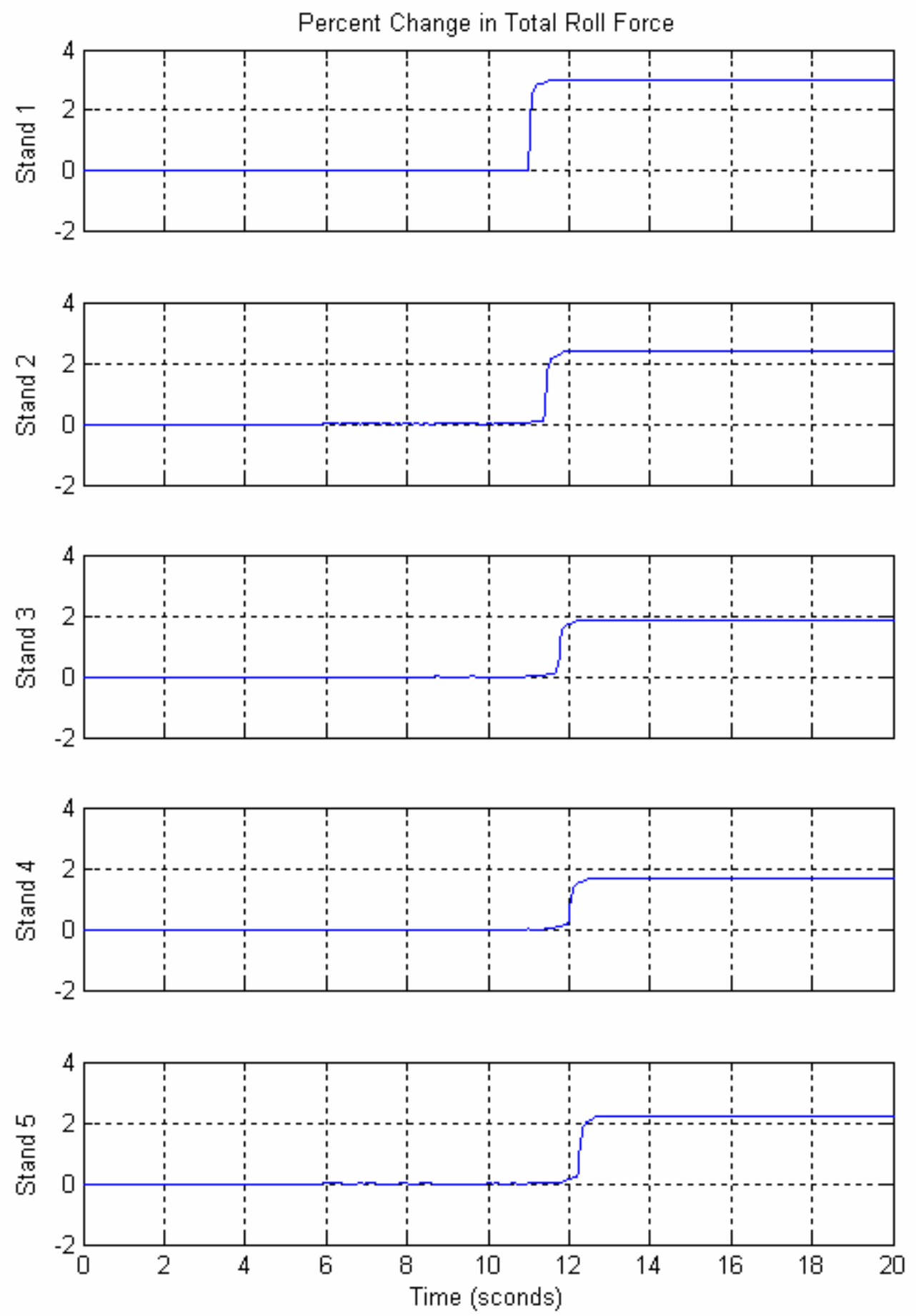

Figure 9 Total Roll Force Responses to $+2 \%$ Step Change in Stand 1 Input Thickness at 100\% Speed 

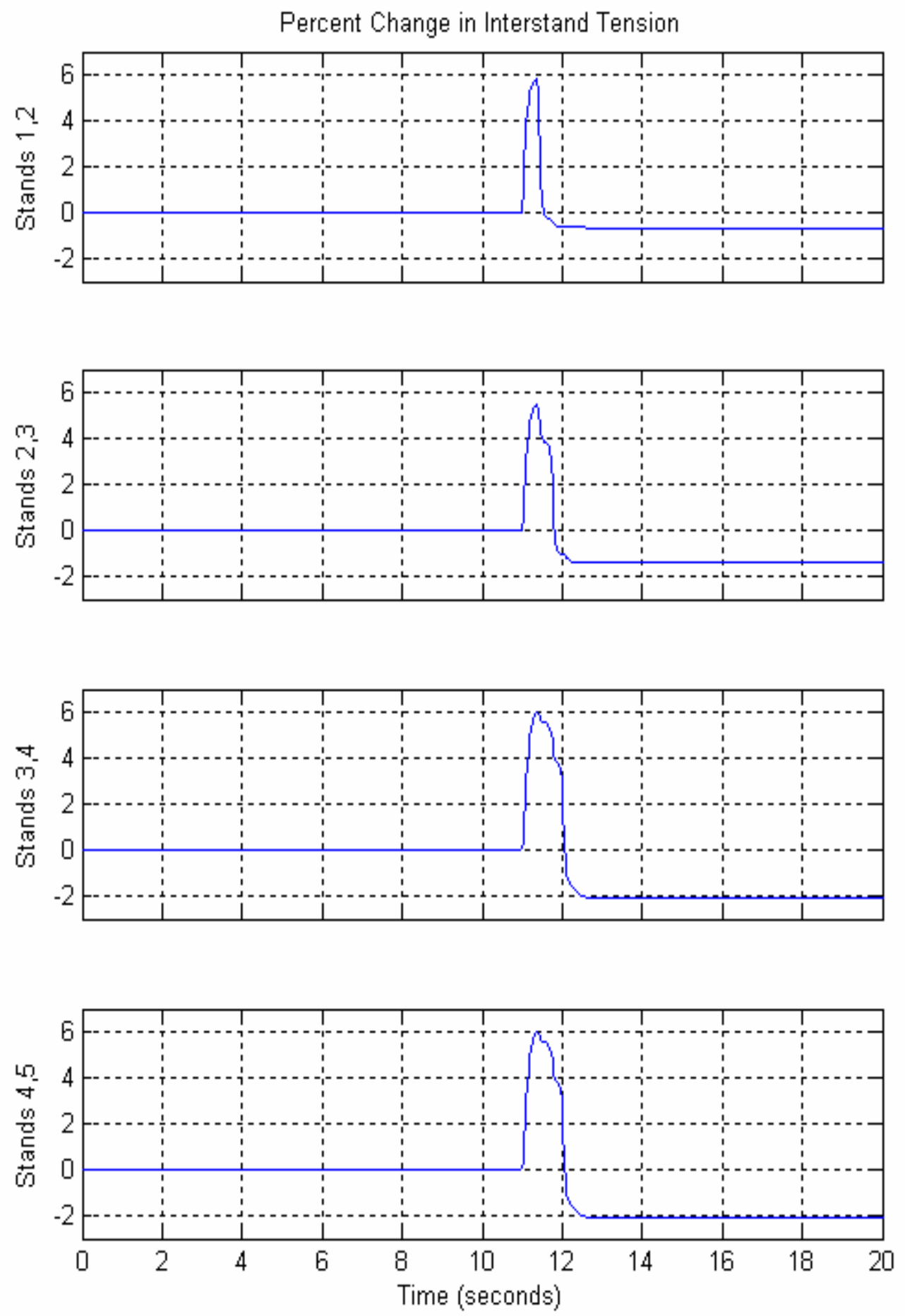

Figure 10 Interstand Tension Responses to $+2 \%$ Step Change in Stand 1 Input Thickness at 100\% Speed 

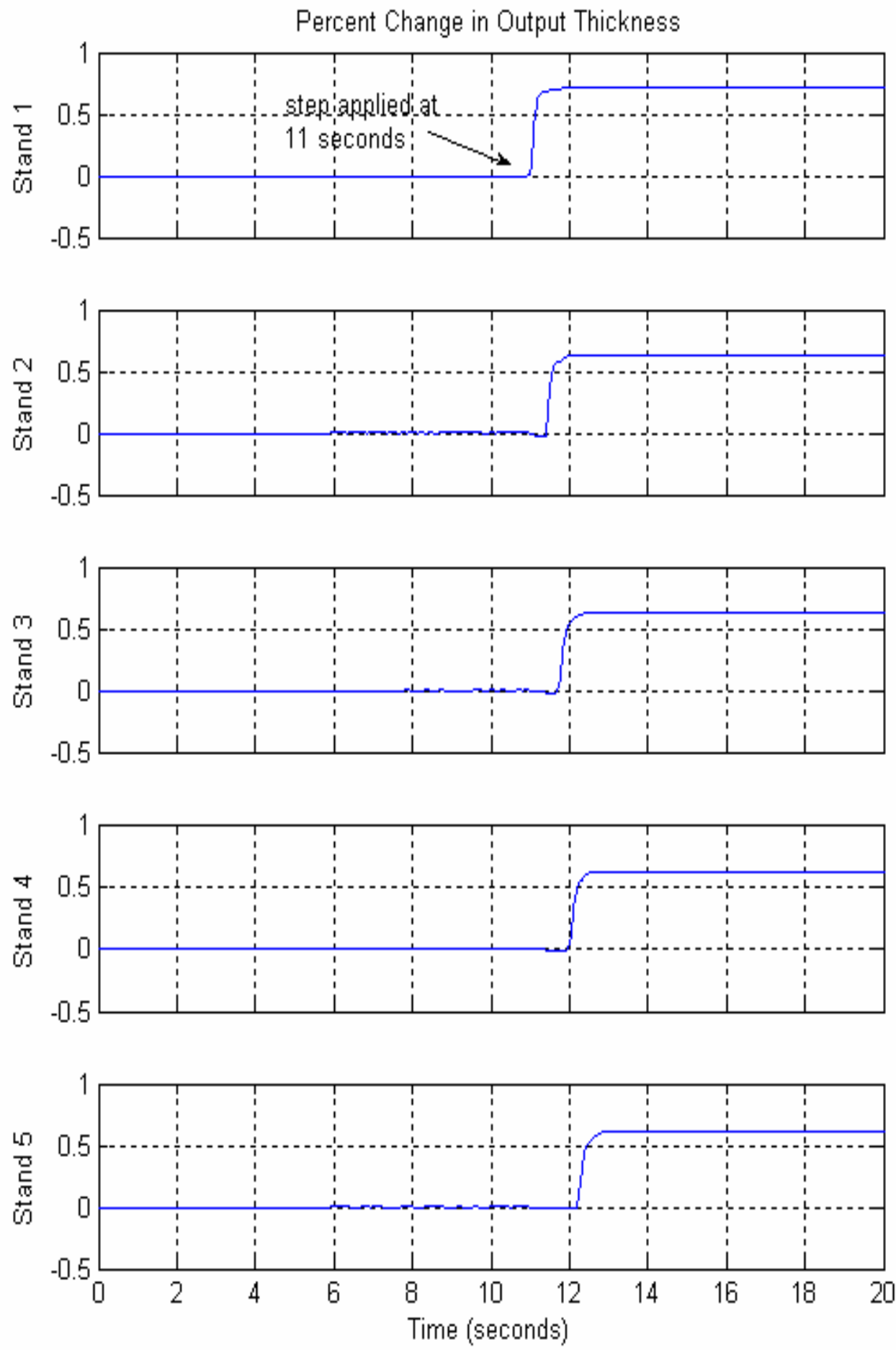

Figure 11 Output Thickness Responses to $+2 \%$ Step Change in Stand 1 Position Actuator Ref at 100\% Speed 

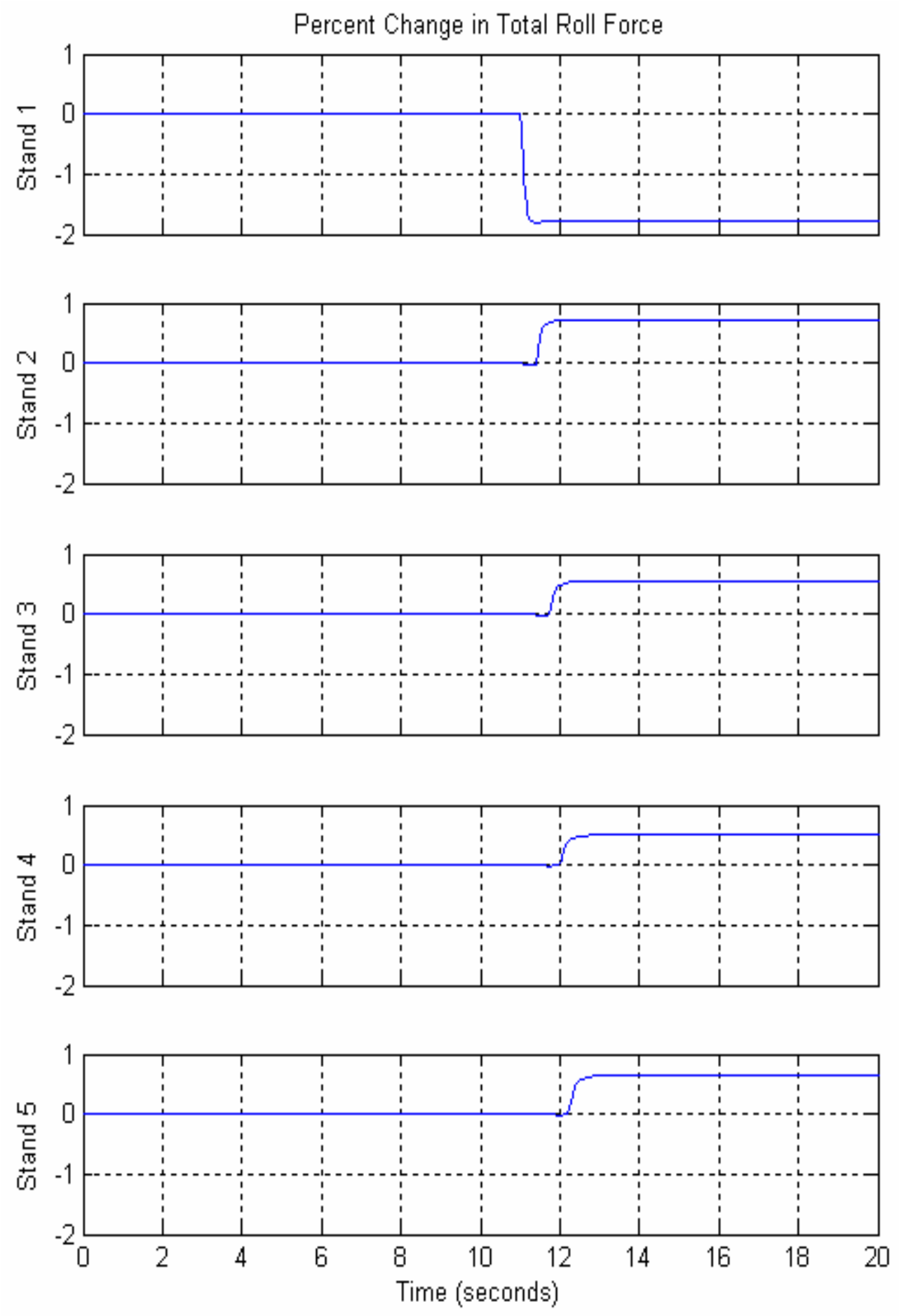

Figure 12 Total Roll Force Responses to $+2 \%$ Step Change in Stand 1 Position Actuator Ref at $100 \%$ Speed 

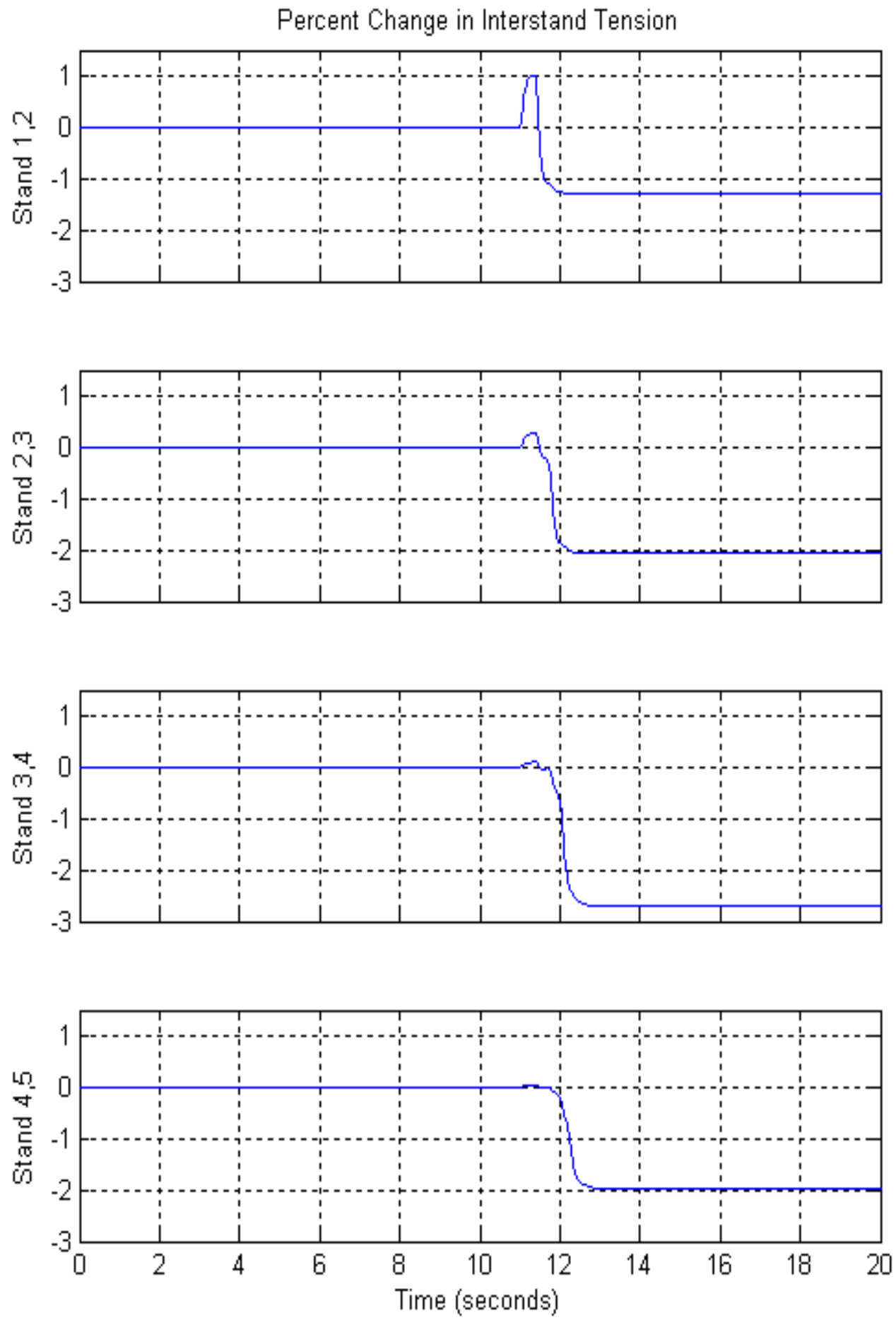

Figure 13 Interstand Tension Responses to $+2 \%$ Step Change in Stand 1 Position Actuator Ref at 100\% Speed 

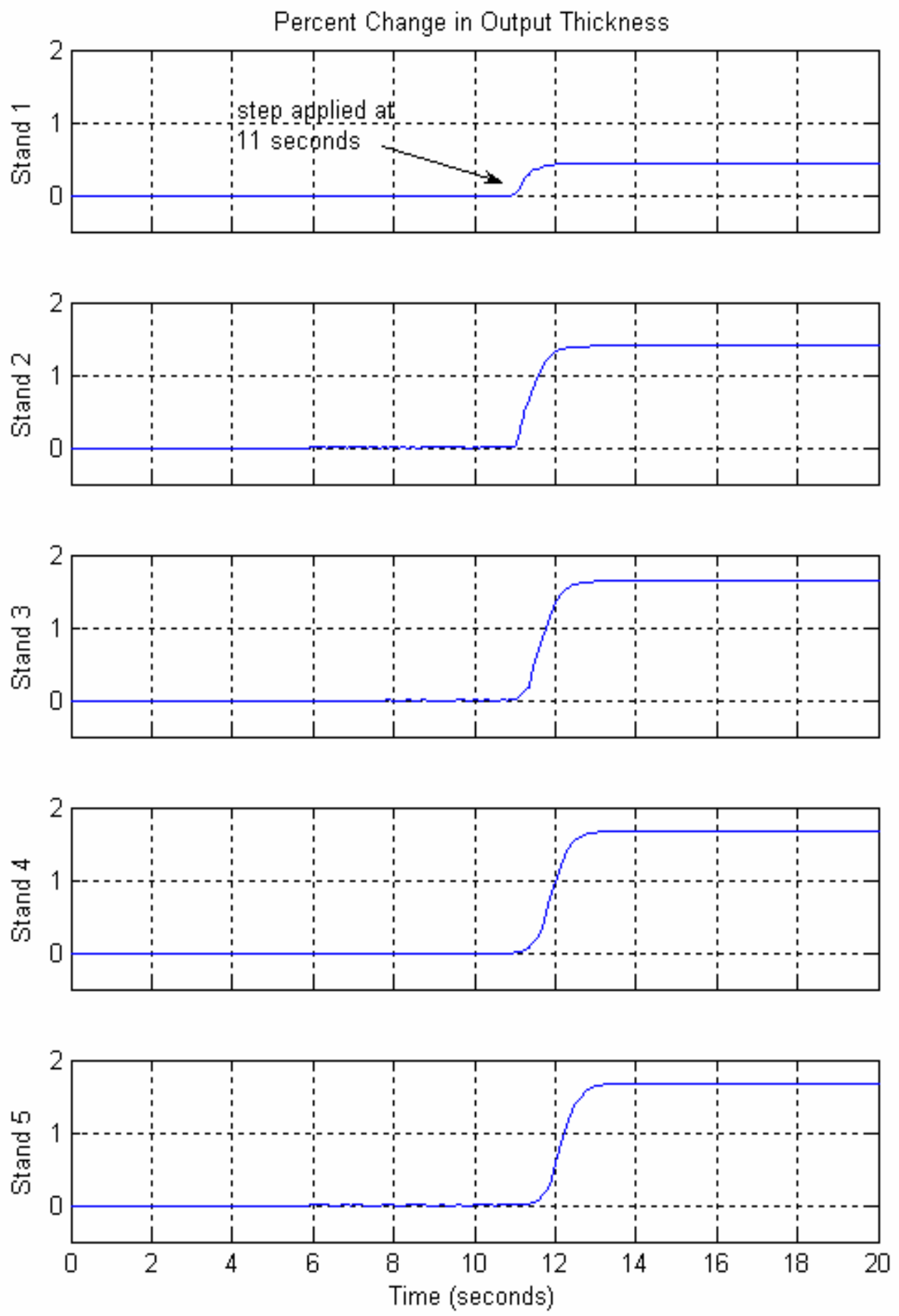

Figure 14 Output Thickness Responses to $+2 \%$ Step Change in Stand 1 Speed Actuator Ref at 100\% Speed 

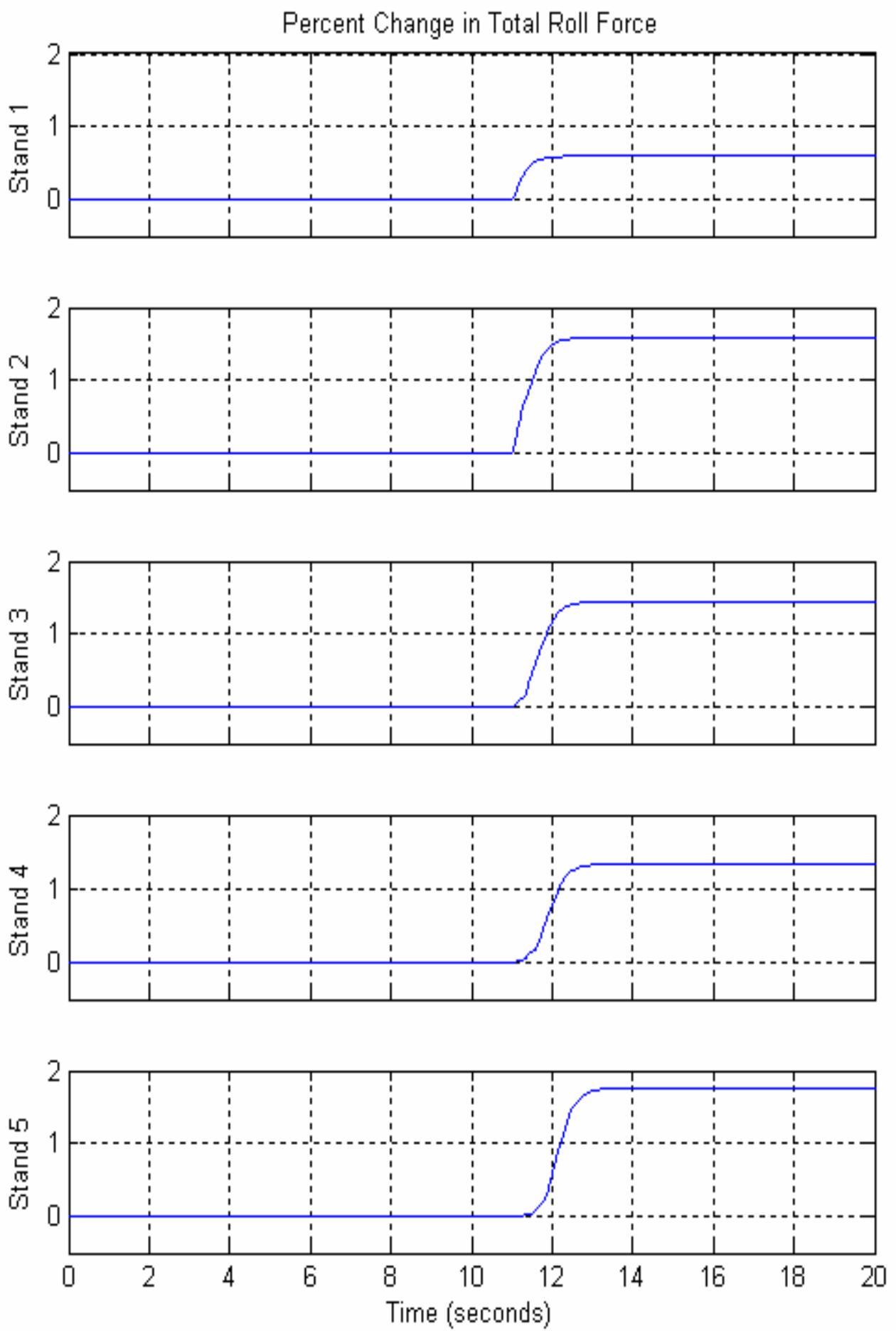

Figure 15 Total Roll Force Responses to $+2 \%$ Step Change in Stand 1 Speed Actuator Ref at $100 \%$ Speed 

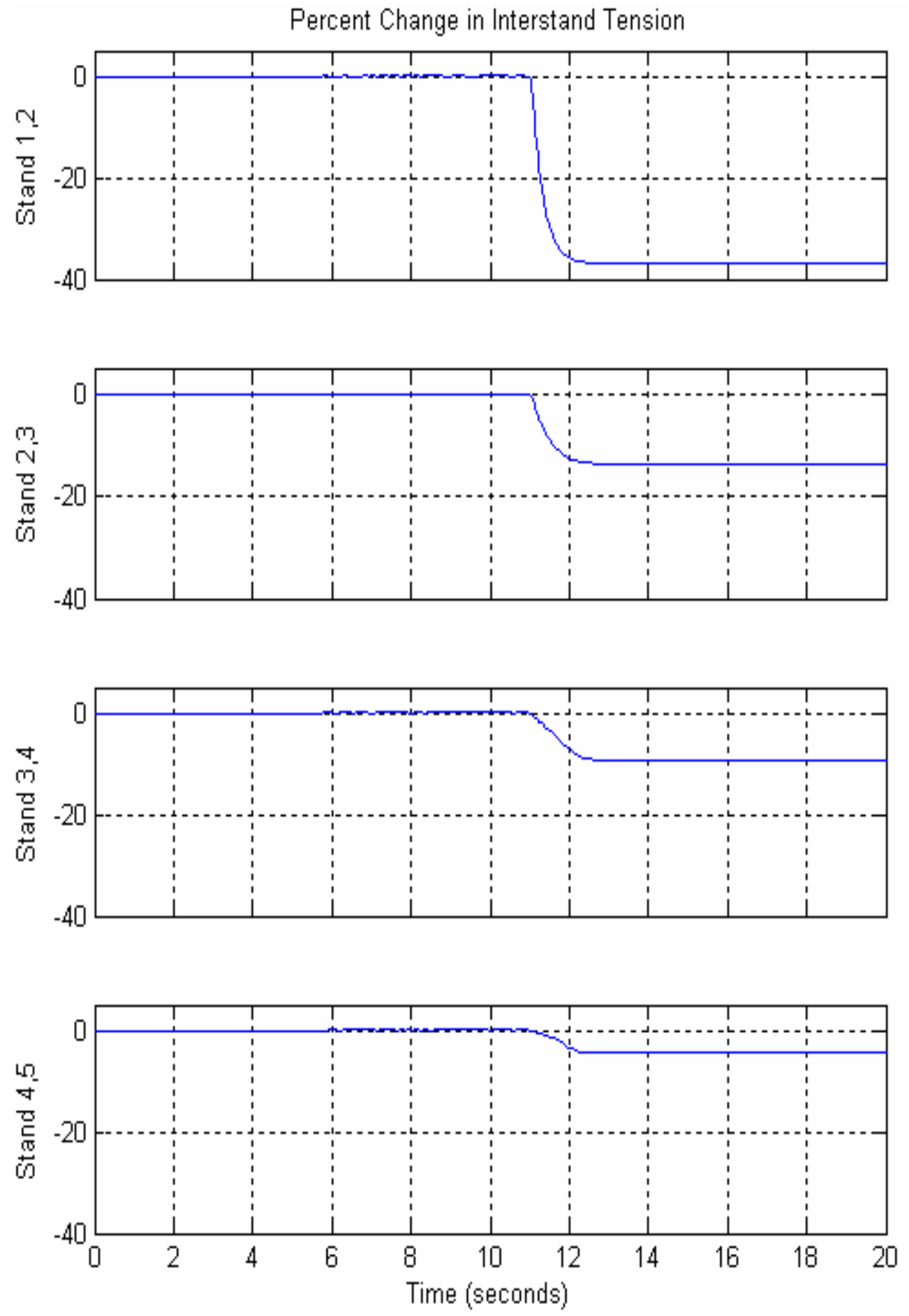

Figure 16 Interstand Tension Responses to $+2 \%$ Step Change in Stand 1 Speed Actuator Ref at 100\% Speed 

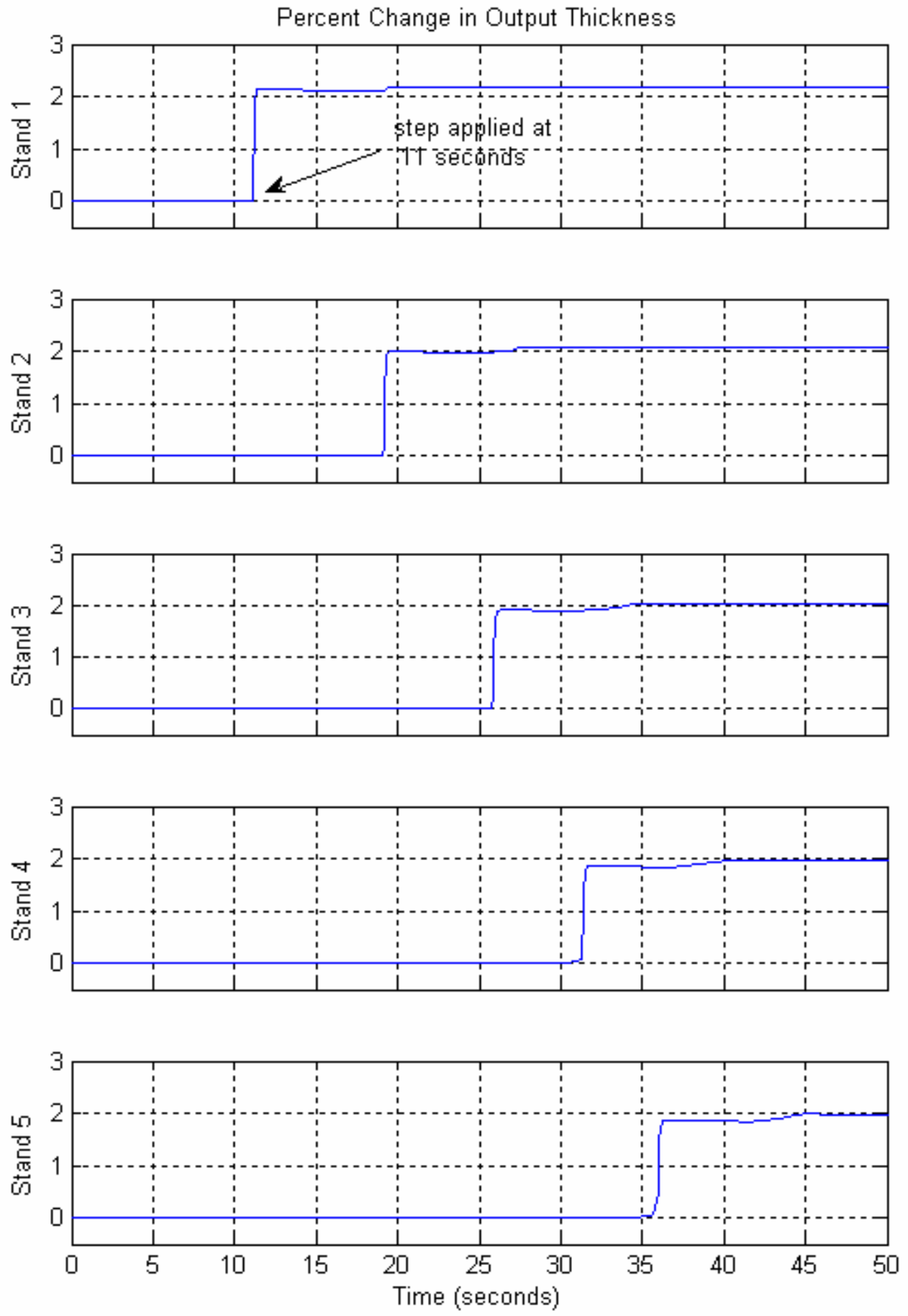

Figure 17 Output Thickness Responses to $+2 \%$ Step Change in Stand 1 Input Thickness at 5\% Speed 


\subsubsection{Comments on Simulation Results}

The reduction patterns of the three Operating Points (Table 4) closely match those of Bryant [1], however there are some discrepancies in the interstand tensions. As previously noted, the discrepancies do not result in significant increases or decreases in interstand tensions which would cause the strip to break or become slack. These discrepancies may be attributed to differences in annealed thicknesses, friction coefficients, hardness functions, or a combination of these, all of which are unavailable in Bryant specifically for the three schedules being considered. Geddes' [20] results also display discrepancies from Bryant in interstand tensions and Geddes attributes them mostly to differences in the estimates of the friction coefficients. Guo [21] lists the schedules of Table 2 which are assumed to be the operating points used for simulation.

The interstand tensions given in Operating Point 2 (Table 4) were determined using the typical values of forward slips given in Bryant [1] for Production Schedule 2 (Table 2), with values of forward slips taken for Production Schedule 1 and for Production Schedule 3 to establish Operating Point 1 and Operating Point 3. It is assumed that under closed loop control, the individual forward slips and other process variables will be set by control action to have the interstand tensions correspond more closely to the interstand tensions given for the three Production Schedules of Table 2. This is investigated more fully in Section 3.3.

The application of step changes in input thickness, annealed thickness, and input hardness caused changes in the steady-state magnitudes of output thicknesses which differ somewhat from those noted in Bryant [1] and Geddes [20]. These differences are not severe and may be attributed to differences in modeling, differences in the selection of operating point values, or both, and are considered acceptable for the intended purposes of the model. More significantly, 
the directions of the changes in the steady-state output thicknesses are in good agreement with Bryant [1], Geddes [20], and Guo [21], as are the directions in the changes in roll forces and the directions of the larger changes in interstand tensions.

The application of step changes in actuator references produced steady-state changes in output thicknesses and total roll forces that closely matched Byrant [1] both in magnitude and direction. Steady-state changes in interstand tensions generally conformed to Bryant [1], except where the changes in interstand tension were not large. These differences in smaller changes in interstand tensions are not considered significant.

Step changes in the friction coefficients produced less significant changes in output thicknesses, total roll forces, and interstand tensions, and mostly are consistent with the results of the other three simulations.

The magnitudes of interstand tension showed greater discrepancies with Geddes [20] than with Bryant [1] in most cases (Table 15). This might be attributed to the differences between Bryant and Geddes in the estimates of the friction coefficients, as noted earlier.

In Figure 8 the percent change in the output thickness of stand 1 propagates through the downstream stands essentially without attenuation. Taking mass flow as constant, this is what would be expected intuitively assuming nearly constant forward slips, and conforms to the dynamic responses of both Bryant [1] and Geddes [20], and to the relative magnitudes of the steady-state responses of Guo [21]. The dynamic responses of the specific roll forces (Figure 9) follow the changes in the stand output thicknesses. In Figure 10 the dynamic responses of interstand tension for stands 1,2, stands 2,3, and stands 3,4 generally agree with those of Bryant and Geddes. 
In Figure 11 the change in the stand 1 output thickness propagates through the downstream stands in a manner consistent with the relative changes in the steady-state responses of output thickness given in Bryant [1], Geddes [20], and Guo [21]. The relative changes in the steadystate responses of the specific roll forces (Figure 12) and in the steady-state responses of the interstand tensions (Figure 13) generally are consistent with the relative changes in the corresponding responses of Bryant and Geddes.

Similarly in Figure 14, Figure 15, and Figure 16 the steady-state responses in output thicknesses and interstand tensions generally agree with the relative changes in the applicable responses of Bryant [1], Geddes [20], and Guo [21].

Figure 17 depicts the output thickness responses for a $2 \%$ change in stand 1 input thickness at $5 \%$ speed, showing the longer interstand time delays at the lower speed.

Based on the foregoing it is concluded that the Operating Points, the steady-state responses, and the dynamic responses resulting from simulations using the model are consistent on an overall basis with the "benchmark" results of Bryant [1], with the results of Geddes [20] and with the results of Guo [21], and therefore are considered to provide adequate verification of the suitability of the model for development of a control strategy. 


\subsection{THE POINTWISE LINEAR QUADRATIC OPTIMAL CONTROLLER}

This section presents the theoretical background for the pointwise linear quadratic optimal control technique and investigates this method as a novel means of control for the tandem cold rolling process. The pointwise linear quadratic technique implements a method denoted as the state-dependent Riccati equation (SDRE) technique [22] on a pointwise basis. The SDRE technique, which is based on the method of "extended linearization" of the process dynamics as described by Friedland [23], has the same structure as the well-established linear quadratic regulator (LQR) described in various texts [e.g., 24, 25], except that the coefficient matrices are state-dependent. The SDRE technique has seen several recent successful applications [26], among which are a nonlinear autopilot, an advanced guidance law development, satellite and spacecraft control, process reactor control, control of an artificial human pancreas, plus others. In addition, comparisons $[27,28]$ of the SDRE technique to other methods for control of nonlinear systems such as feedback linearization, gain scheduling [29], nonlinear $\mathrm{H}^{\infty}$, and nonlinear model predictive control [30, 31, 32], have been favorable toward this technique in the areas of: (1) Capability to use physical intuition in the design process, (2) Simplicity of implementation and

retuning, (3) Flexibility provided via the state-dependent weighting matrices, (4) Retention of beneficial nonlinearities, (5) Optimality, and (6) Provision of a systematic design approach.

Initially it is assumed for simplification that the interstand time delays (2-28) are negligible. The theoretical background then is developed on this basis, so that the state equation (2-31) and 
the output equation (2-32) are modified as in (3-1) and (3-2) to delete the dependencies on the delayed states, which is consistent with the models assumed for the SDRE method in the related references [e.g., 22, 27, 33]. Under this assumption and in the presence of disturbances and uncertainties it is determined that the estimation of stability, performance, and robustness using analytical methods is quite difficult, and therefore the application of the pointwise linear quadratic technique to the control of the tandem cold rolling mill must rely mostly on physical intuition and simulation. Since the addition of delayed states is expected to increase the difficulty, it is considered that the design of the controller, with the time delays restored to the plant model, must be developed heuristically, with stability, performance, and robustness confirmed by simulation. What is presented herein is based on this consideration.

Some definitions and theorems related to the pointwise linear quadratic technique as applied to the plant dynamics described by (3-1) and (3-2) are given in Appendix A.

\subsection{THEORETICAL BACKGROUND}

Consider a system with nonlinear plant dynamics described by a state equation (3-1) and an output equation (3-2):

$$
\begin{aligned}
& \frac{d x}{d t} \equiv \dot{x}=a(x)+b(x) u, \quad x(0)=x_{0}, \\
& y=g(x)
\end{aligned}
$$


where $x \in R^{n}$ is a vector whose elements represent the individual state variables, $a(x) \in R^{n}$ is a state-dependent vector, $u \in R^{m}$ is a vector whose elements represent the individual control variables, $y \in R^{p}$ is a vector whose elements represent the individual output variables, $b(x) \in R^{n x m}$ is a state-dependent matrix, and $g(x) \in R^{p}$ is a state-dependent vector. By factorizing ${ }^{4}$ the state-dependent vectors $a(x)$ into $A(x) x, g(x)$ into $C(x) x$, and with $b(x)=B$, the above becomes a form resembling linear state space equations

$$
\begin{aligned}
& \dot{x}=A(x) x+B u, \quad x(0)=x_{0}, \\
& y=C(x) x,
\end{aligned}
$$

where $A(x) \in R^{n x n}$ is a state-dependent matrix, $C(x) \in R^{p x n}$ is a state-dependent matrix, $x, u, y$, and $B$ are as noted previously, and assuming $g(x) \in C^{l}$ and $g(0)=0$. The optimal control problem is to minimize the performance index

$$
J=\frac{1}{2} \int_{0}^{\infty}\left(x^{\prime} Q(x) x+u^{\prime} R(x) u\right) d t
$$

with respect to the control vector $\mathrm{u}$, subject to the constraint (3-3), where $Q(x)$ and $R(x)$ are statedependent weighting matrices, with $Q(x)^{5} \geq 0, R(x)>0$, and $a(x)^{6} \in C^{k}, Q(x) \in C^{k}, R(x) \in C^{k}$, $k \geq 1$, for all $x^{7}$, and assuming $a(0)=0$ and $B \neq 0$. The objective (3-5) is to find a control law which regulates the system to the origin.

\footnotetext{
${ }^{4}$ It is known [26] that if $a(0)=0$, and $a(x) \in C^{l}$, an infinite number of such factorizations exist, and similarly with $g(x)$.

${ }^{5}$ When used with a matrix, the notation " $>0$ " indicates the matrix is positive definite; the notation " $\geq 0$ " indicates the matrix is positive semi-definite.

${ }^{6}$ The notation that a matrix or a vector $\in C^{k}$ is intended to mean that the elements of the matrix or vector have continuous partial derivatives of order $k$.

${ }^{7}$ Herein, the expression "for all $x$ " is intended to mean "for all $x$ in the control space" unless indicated otherwise.
} 
The method of solution is first to find a factorization of $a(x)$ such that (3-1) can be expressed in the form of (3-3). Then the state-dependent algebraic Riccati equation

$$
A^{\prime}(x) K(x)+K(x) A(x)-K(x) B R^{-1}(x) B^{\prime} K(x)+Q(x)=0,
$$

is solved pointwise for $K(x)$, resulting in the control law

$$
u=-R^{-1}(x) B^{\prime} K(x) x,
$$

where $K^{\prime}(x)=K(x) \geq 0$, for all $x$. In order to insure a solution to (3-6) at each point, the method requires that the pair $(A(x), B)$ be pointwise stabilizable for all $x$, assuming the availability of full state measurement.

Local asymptotic stability is assured [22] if $(A(x), B)$ is pointwise stabilizable, if there exists a matrix $C_{l}(x)$ such that $Q(x)=C^{\prime}{ }_{1}(x) C_{l}(x)$, and if $\left(A(x), C_{l}(x)\right)$ is pointwise detectable, assuming that $A(x) \in C^{k}$. In addition, a method to estimate conservatively the region of attraction around the origin has been developed [33]. However, a prudent design approach requires that simulation be performed to confirm local asymptotic stability, particularly for systems that have significant uncertainties in the plant model or in the measurements of variables. This is especially so if the plant model is large and complex, as in the case of the tandem cold mill. Further, in [33] the method for estimating a useful (i.e. not overly conservative) region of attraction requires establishing an appropriate upper bound on $\left\|\exp \left(A_{c l}(x) t\right)\right\|$, where $A_{c l}(x)$ is the state coefficient matrix for the closed loop system, for all $t$, and considering all possible uncertainties in $A_{c l}(x)$, which could be quite difficult (if not impossible) for such systems. Global asymptotic stability must be confirmed by simulation since (except for certain special cases [27]) at present there is no useful theory which assures it. It also should be noted that, even though the pointwise linear quadratic technique produces a closed loop system matrix which has its eigenvalues in the open 
left half plane for all $x$, this does not assure global asymptotic stability. This is shown by the following, which is one of at least two counterexamples $[28,34,35]$ to a previous proposition presented in [36] for global asymptotic stability based on the eigenvalues all having negative real parts:

Consider (3-8) which represents the closed loop dynamics of a plant coupled to a pointwise linear quadratic controller with control law (3-7):

$$
\dot{x}=a_{c l}(x), \quad x_{1}(0)=2, x_{2}(0)=2,
$$

where $x \in R^{2}$ is the state vector, $a_{c l}(x) \in R^{2}$ is a state-dependent vector, $x_{1}$ and $x_{2}$ are the elements of $x$, with

$$
\begin{aligned}
& a_{c l, 1}(x)=-x_{1}+x_{1}^{2} x_{2}, \\
& a_{c l, 2}(x)=-x_{2} .
\end{aligned}
$$

Factorizing (3-8) in the form $a_{c l}(x)=A_{c l}(x) x$ gives

$$
A_{c l}(x)=\left[\begin{array}{cc}
-1 & x_{1}^{2} \\
0 & -1
\end{array}\right]
$$

The eigenvalues of $A_{c l}(x)$ are $(-1,-1)$ for all $x$. The solution to (3-8) is

$$
\begin{aligned}
& x_{1}(t)=\frac{2 x_{2}(t)}{x_{2}^{2}(t)-2}, \\
& x_{2}(t)=2 e^{-t} .
\end{aligned}
$$

As $t \rightarrow \log \sqrt{2}, x_{1}(t) \rightarrow \infty$ (unstable).

A necessary condition for optimality of the SDRE controller has been derived [22] using the Lagrange multiplier method for the case (3-1) where $b(x) \in R^{n x m}$ is a state-dependent matrix. For the pointwise linear quadratic case (3-3) with $b(x)$ as a constant matrix $B \in R^{n x m}$ the derivation is similar. In the Lagrange multiplier method, which is based on Lagrange theory using the calculus 
of variations, a Hamiltonian function is formed from the cost function (3-5) and the nonlinear constraint (3-4) as

$$
H(x, u, \lambda)=\frac{1}{2}\left(x^{\prime} Q(x) x+u^{\prime} R(x) u\right)+\lambda^{\prime}(A(x) x+B u),
$$

where $\lambda \in R^{n}$ is a Lagrange multiplier. Using the Hamiltonian, the necessary conditions for optimality of a nonlinear controller then are derived in the form of a state equation (3-15), a costate equation (3-16), and a stationarity condition (3-17) as:

$$
\begin{aligned}
& \nabla_{\lambda} H=\dot{x}, \\
& \nabla_{x} H=-\dot{\lambda}, \\
& \nabla_{u} H=0 .
\end{aligned}
$$

Solving (3-15), (3-16), and (3-17) as in Appendix D, results in a necessary condition (3-18) for the optimality of the pointwise linear quadratic controller, i.e. if this condition is satisfied, the necessary conditions for optimality of a nonlinear controller also are satisfied,

$\dot{K}(x) x+\frac{1}{2}\left(x^{\prime} \nabla_{x} Q(x) x+x^{\prime} K(x) B R^{-1}(x) \nabla_{x} R(x) R^{-1}(x) B^{\prime} K(x) x\right)+x^{\prime} \nabla_{x} A^{\prime}(x) K(x) x=0$,

where computation of $x^{\prime} \nabla_{x} Q(x) x$ and other gradient functions are as noted in Appendix B. In general this condition is satisfied [37] only for a unique $A(x)$, which is difficult to determine unless the optimal cost function is known a priori. However, if the matrix functions $A(x), K(x)$, $Q(x)$, and $R(x)$, and their gradients $\nabla_{x} A(x), \nabla_{x} K(x), \nabla_{x} Q(x)$, and $\nabla_{x} R(x)$ are bounded for all $x$ in the control space, and under global asymptotic stability, then as shown in [22] the state trajectories converge to the optimal state trajectories as the states are driven to zero. This is taken to be a near-optimal (i.e. suboptimal) condition in a neighborhood of the origin. 
There is no known theory which assures robustness of the pointwise linear quadratic technique to modeling uncertainties, measurement uncertainties, or disturbances. Therefore robustness must be considered on a case basis and confirmed by simulation.

As inferred by the foregoing and as previously noted, the application of the pointwise linear quadratic control technique to the tandem cold rolling process must rely heavily on physical intuition and simulation to develop and confirm a controller design. This is mostly because no useful theory presently exists which assures global asymptotic stability or robustness. In addition, the process is large, is highly nonlinear with complex interactions between variables, and has significant interstand time delays, which make estimations of performance and robustness to disturbances and uncertainties difficult using analytical methods.

\subsection{APPLICATION TO TANDEM COLD ROLLING}

The application of the pointwise linear quadratic technique to the tandem cold rolling process requires the establishment of an operating point. A control objective is that excursions in the individual stand output thicknesses and interstand tensions from this operating point be as low as reasonably achievable in the presence of internal and external disturbances and considering uncertainties in modeling and in measurements. Initially, Operating Point 1 (Table 4) is chosen as the operating point because control of the stand output thicknesses and interstand tensions generally is easier when thicker strip is being processed. Operating Point 2 and Operating Point 3 then are used to confirm operation with thinner strip. The three Operating Points have been verified by simulation (Section 2.3) to be open loop equilibrium points. After an operating point 
is chosen, a coordinate change is performed to shift the operating point to the origin and simulation is done to confirm local asymptotic stability of the closed loop system. For the coordinate change a new variable $\mathrm{z}$ is introduced as

$$
z=x-x_{o p}
$$

where $z \in R^{n}$ is a vector, $x \in R^{n}$ is a vector whose elements represent the individual state variables (Table 1), and $x_{o p} \in R^{n}$ is a vector whose elements are the desired values of the individual state variables at the operating point. The performance index (3-5) then is modified to be

$$
J=\frac{1}{2} \int_{0}^{\infty}\left(z^{\prime} Q z+\left(u-u_{o p}\right)^{\prime} R\left(u-u_{o p}\right)\right) d t,
$$

so that minimization is with respect to $\left(u-u_{o p}\right)$, where $u \in R^{m}$ is a vector whose elements represent the individual control variables (Table 1), and $u_{o p} \in R^{m}$ is a vector whose elements are the values of the individual control variables at the operating point. For simplification, the weighting matrices $Q \in R^{n x n}$ and $R \in R^{m x m}$ are taken as diagonal matrices with tunable constant elements. If during simulation it is determined that there is sufficient need, one or both of these matrices can be changed to have some or all of its elements modified to become functions of the state variables, or to have off-diagonal elements, or both.

The Operating Points (Table 4) are at 100\% speed (i.e. run speed, or about 4000 feet per minute), which is the speed of the strip exiting the last mill stand. During operation, which is considered typical for the purposes of this work, the speed after threading is raised from $5 \%$ speed (i.e. thread speed, or about 200 feet per minute) to run speed. Prior to dethreading the speed is lowered from run speed to thread speed. The changes in speed result from a shifting in 
the operating point which is a change in certain elements of $x_{o p}$ and of $u_{o p}$ as depicted in Table 40. Other elements of $x_{o p}$ and $u_{o p}$ remain unchanged during mill operation.

Table 40 Elements of Vectors $x_{o p}$ and $u_{o p}$
and Associated Variables Which Are
Changed During Mill Speed Changes
\begin{tabular}{|l|l|l|}
\hline$x_{o p, 10}$ & $V_{1 o p}$ \\
\hline$x_{o p, 11}$ & $V_{2 o p}$ \\
\hline$x_{o p, 12}$ & $V_{3 o p}$ \\
\hline$x_{o p, 13}$ & $V_{4 o p}$ \\
\hline$x_{o p, 14}$ & $V_{5 o p}$ & $U_{V 1 o p}$ \\
\hline$u_{o p, 7}$ & $U_{V 2 o p}$ \\
\hline$u_{o p, 8}$ & $U_{V 3 o p}$ \\
\hline$u_{o p, 9}$ & $U_{V 4 o p}$ \\
\hline$u_{o p, 10}$ & $U_{V 5 o p}$ \\
\hline
\end{tabular}

External disturbances are changes in mill entry thickness and in mill entry hardness which arise mostly from previous processing in the hot rolling area. These changes generally are caused by colder areas in the slabs prior to hot rolling, and also in the case of changes in mill entry thickness, by the eccentricity effects of the hot mill rolls. The colder areas in the slabs result from contact of the hot metal with support skids in the reheat furnace, and occur even though this effect (referred to as skid chill) is reduced considerably by rocking the slabs on the skids. Thus when processed in the hot mill, the slabs have gradients in temperature which cause variations in thickness and hardness to be rolled into the strip. These variations are approximately periodic, with thickness and hardness changing essentially in phase with each other. The so-called roll eccentricity is actually a combination of irregularities in the mill rolls, in the mill bearings, or in both, which causes an axial deviation between the roll barrel and the roll neck that results in a cyclic variation in the strip thickness during rolling. The frequency of this variation is much higher than that of the variation in thickness caused by the skid chill effect as can be seen in Figure 18 and Figure 19 which depict typical disturbances [20] in entry thickness and in entry hardness at $100 \%$ speed and at 5\% speed. Internal disturbances are eccentricity effects of the cold mill rolls which are addressed separately in Section 3.4. 

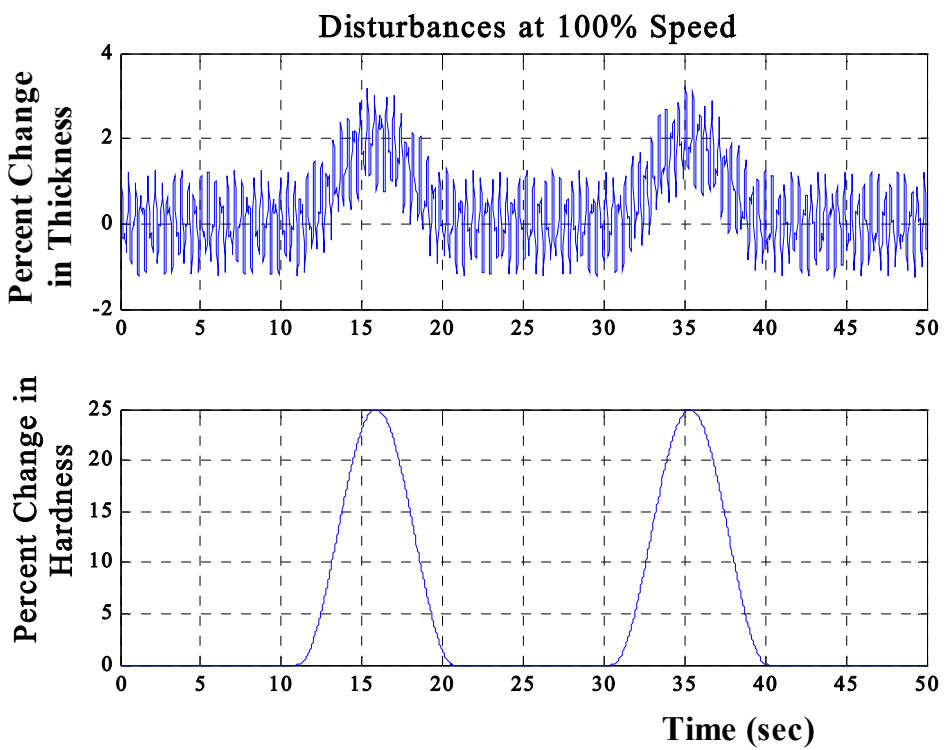

Figure 18 Mill Entry Disturbances at 100\% Speed
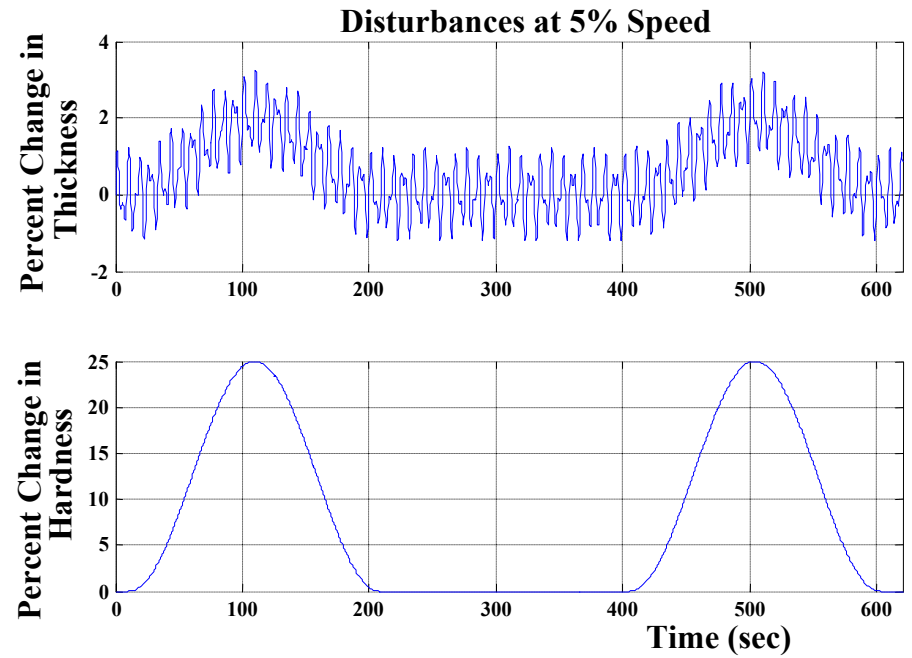

Figure 19 Mill Entry Disturbances at 5\% Speed

Uncertainties in the model and in the measurements of process variables can result in undesirable deviations in the stand output thicknesses and in the interstand tensions from their values at an operating point, and thus a strong robustness to these uncertainties is essential. In the model, there can be significant uncertainties in: (1) The coefficient of friction of an individual stand, (2) The compressive yield stress (hardness) of the strip, and (3) The modulus of elasticity 
of an individual stand. Aside from these uncertainties, there also are deviations in the model from the physical plant which are unavoidable since there is no model which can duplicate the plant exactly. These deviations however are less significant since the model has been verified against simulations [1] which are generally accepted as "benchmarks" for model verification and against data from operating mills [1]. Table 41 lists the individual uncertainties and the source for each listing. The percentage listed for an individual entry in the table represents the uncertainty in the initial estimate plus any uncertainty occurring during operation which could result from effects (such as temperature change, roll wear, variations in lubrication parameters, or others) which are not explicitly described by the model. In each case data relating to the

Table 41 Modeling Uncertainties

$\begin{array}{ccc}\text { Parameter } & \begin{array}{c}\text { Estimated } \\ \text { Uncertainty }\end{array} & \begin{array}{c}\text { Source of } \\ \text { Estimate } \\ \mu\end{array} \\ 20 \% & {[6,40]} \\ \bar{k} & 25 \% & {[1]} \\ M & 10 \% & {[38,39]}\end{array}$

uncertainty in a particular parameter was either difficult to find or to estimate from the source material, and therefore the source listing represents the best of what could be found or estimated consistent with experience and physical intuition. The relationship (2-11) for the coefficient of friction $\mu$ is derived empirically [6] by evaluating the rolling lubricant in terms of two parameters designated as the first and second frictional characteristics, based on the effectiveness of the lubricant. This effectiveness depends on conditions [40] such as the physical and chemical nature of the lubricant, the physical and chemical nature of the roll and of the strip surfaces, the design of the mill stand, the mill speed, and the reduction. The uncertainty given in Table 41 for $\mu$ is based on best judgment using the data given $[6,40]$, however a full evaluation of the coefficient of friction is well beyond the scope of this work. More detail can be found in the works of 
Roberts $[6,40]$ and the references cited therein. The relationship (2-13) for average strip compressive yield stress $\bar{k}$ is empirical for mild steel based on data from an operating mill [1]. The uncertainty given in Table 41 for $\bar{k}$ is the deviation (7\%) in the measurements [1] of compressive yield stress of actual coils entering the mill plus an additional $18 \%$ for conservatism in the estimate based on experience. While the mill modulus $M$ is inferred to be constant in many references [e.g., 41, 42], in fact it depends heavily on the back-up roll diameter [43] and varies as the back-up roll diameter changes with temperature and roll wear. This is significant in that very slight changes in the back-up roll diameter can cause large changes in the output thickness according to the BISRA relation (1-2). The uncertainty given in Table 41 for $M$ is considered conservative compared to what would be expected from experience. Robustness to uncertainty in measurement of the individual state variables and in measurement of other variables also is essential to reducing the error in the stand output thicknesses and in the interstand tensions. The uncertainty in each of the measured variables is listed in Table 42 , which is derived $[6,40,44$, 45] from recent manufacturer's data and includes all sources of error in the measurement available at the controller. It is assumed that the individual uncertainties occur concurrently with each other and with the disturbances. The method of combining the individual uncertainties and the disturbances is addressed in Section 4.1. The uncertainty for the thickness measurement

Table 42 Measurement Uncertainties

$\begin{array}{ccc}\text { Parameter } & \begin{array}{c}\text { Estimated } \\ \text { Uncertainty }\end{array} & \begin{array}{c}\text { Source of } \\ \text { Estimate }\end{array} \\ h_{\text {out } 1 m(5 m)} & 0 \% & \mathrm{n} / \mathrm{a} \\ F & 0.2 \% & {[6]} \\ T & 0.2 \% & {[44]} \\ S & 0.05 \% & {[44]} \\ V & 0.1 \% & {[44,40]} \\ V_{\text {in }, i} & 0.025 \% & {[45] \quad(i=2,3,4,5)} \\ V_{\text {out } 5} & 0.025 \% & {[45]}\end{array}$


is listed as zero based on the assumption of a suitable calibration so that any offset caused by error is eliminated and only deviations around the operating point are given. This is consistent with data presented from operating mills and therefore simplifies comparison with other control methods. The listings for uncertainties in other measurements in Table 42 are percentages of measured values except for total roll force $F$, interstand tension force $T$, and position actuator position $S$ which are percentages of full scale values. The listing for $\mathrm{V}$ includes the uncertainty [40] in work roll diameter. It is noted that the listings for stand input strip speeds $V_{i n, i}(i=2,3,4,5)$ and stand 5 output strip speed $V_{\text {out }}$ are additions to what is typical (Figure 2) for mill instrumentation. The need for these additional measurements is justified in Section 3.3.

Both disturbances and uncertainties are modeled as "what they are, where they are" [15]. Their combined effect is denoted as a "disturbance effect" which is represented as a change in the $A(x)$ matrix and a change in the $C(x)$ matrix, so that (3-3) and (3-4) become

$$
\begin{aligned}
& \dot{x}=A(x) x+\delta A(x) x+B u, \quad x(0)=x_{0}, \\
& y=C(x) x+\delta C(x) x,
\end{aligned}
$$

where $\delta A(x) \in R^{n x n}$ is a matrix whose elements are changes in the elements of $A(x)$ caused by the disturbances, by the uncertainties, or by both, and similarly for $\delta C(x) \in R^{p x n}$, with the "disturbance effect" represented (Figure 20) as $\delta A(x) x$ and $\delta C(x) x$. 


\subsection{SYSTEM CONFIGURATION}

The final system configuration is the result of an iterative heuristic effort, the various steps of which are presented in this section. The initial system configuration as described by the modified state equation (3-21), the modified output equation (3-22), and the control law (3-26), is depicted in Figure 20, where it is understood that the time-delayed states resulting from the interstand time delays are included in the state-dependent matrices $A(x)$ and $C(x)$, although not shown explicitly. It is assumed that any differences between the model and the plant (i.e. the mill with the actuators) are negligible, that the system initially is at an operating point, and that there are no disturbances or uncertainties, so that

$$
\begin{aligned}
& x=x_{o p}, \\
& y=y_{o p},
\end{aligned}
$$

and

$$
u=u_{o p} .
$$

Subsequent disturbances or uncertainties cause a "disturbance effect" which changes the measured values of the variables represented by the elements of the state vector $x$, which then change the values of the elements of the vector $z$. Using the vector $z$, a signal $u_{f}$ is computed by the control law, a modification to (3-7), as

$$
u_{f}=-R^{-1} B^{\prime} K(x) z \text {, }
$$

where $u_{f} \in R^{m}$ is a correction to the control vector $u$ resulting from the disturbance or uncertainty. The corrections applied to the control vector $u$ reduce the deviations in the variables represented by the elements of the state vector $x$; however, because the "disturbance effect" also 
affects the $C(x)$ matrix, the correction may be less effective in reducing the deviations in the variables represented by the elements of the vector $y$.

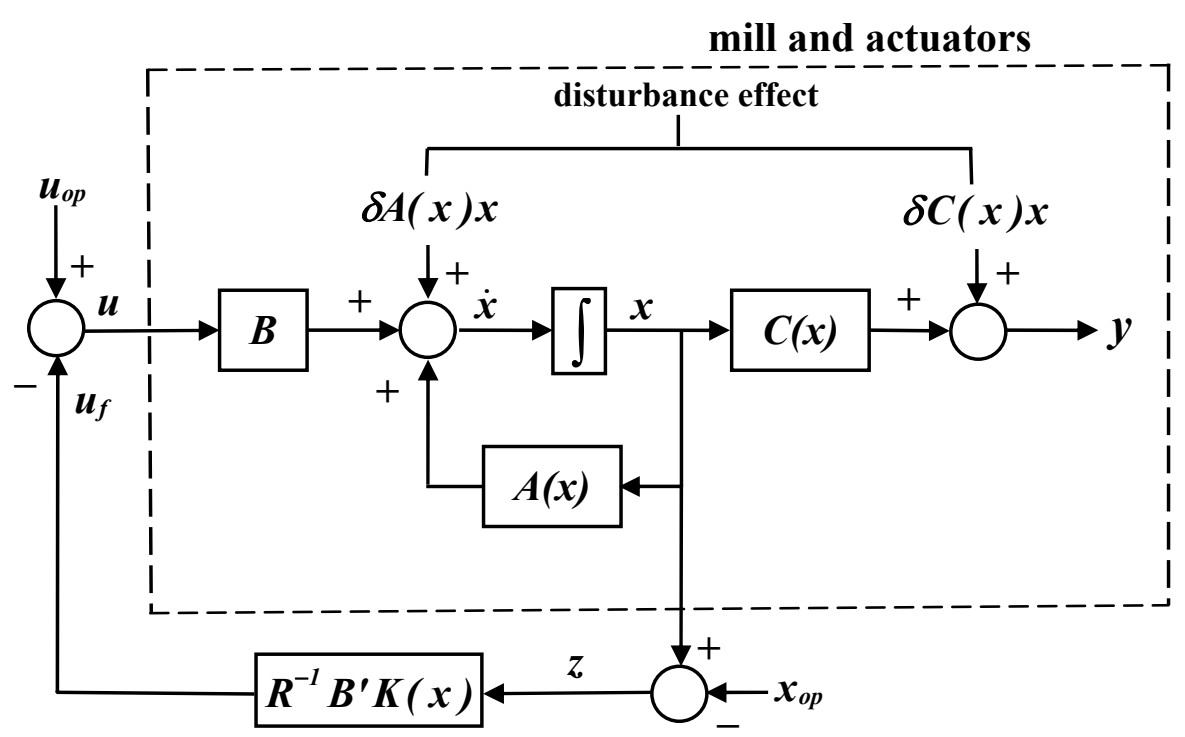

Figure 20 Initial System Configuration

For actual usage, the controller is discretized and implemented using a digital scan that is repeated at a rate such that the controller has dynamics which are nearly the same as the dynamics of its continuous counterpart. The functions performed by the controller to update the elements of the vector $u_{f}$ during each scan are depicted in Figure 21. The algebraic Riccati equation that is solved in Step 3 during the scan is a modification of (3-6) to use diagonal weighting matrices with tunable constant elements as noted previously, i.e.

$$
A^{\prime}(x) K(x)+K(x) A(x)-K(x) B R^{-1} B^{\prime} K(x)+Q=0 .
$$




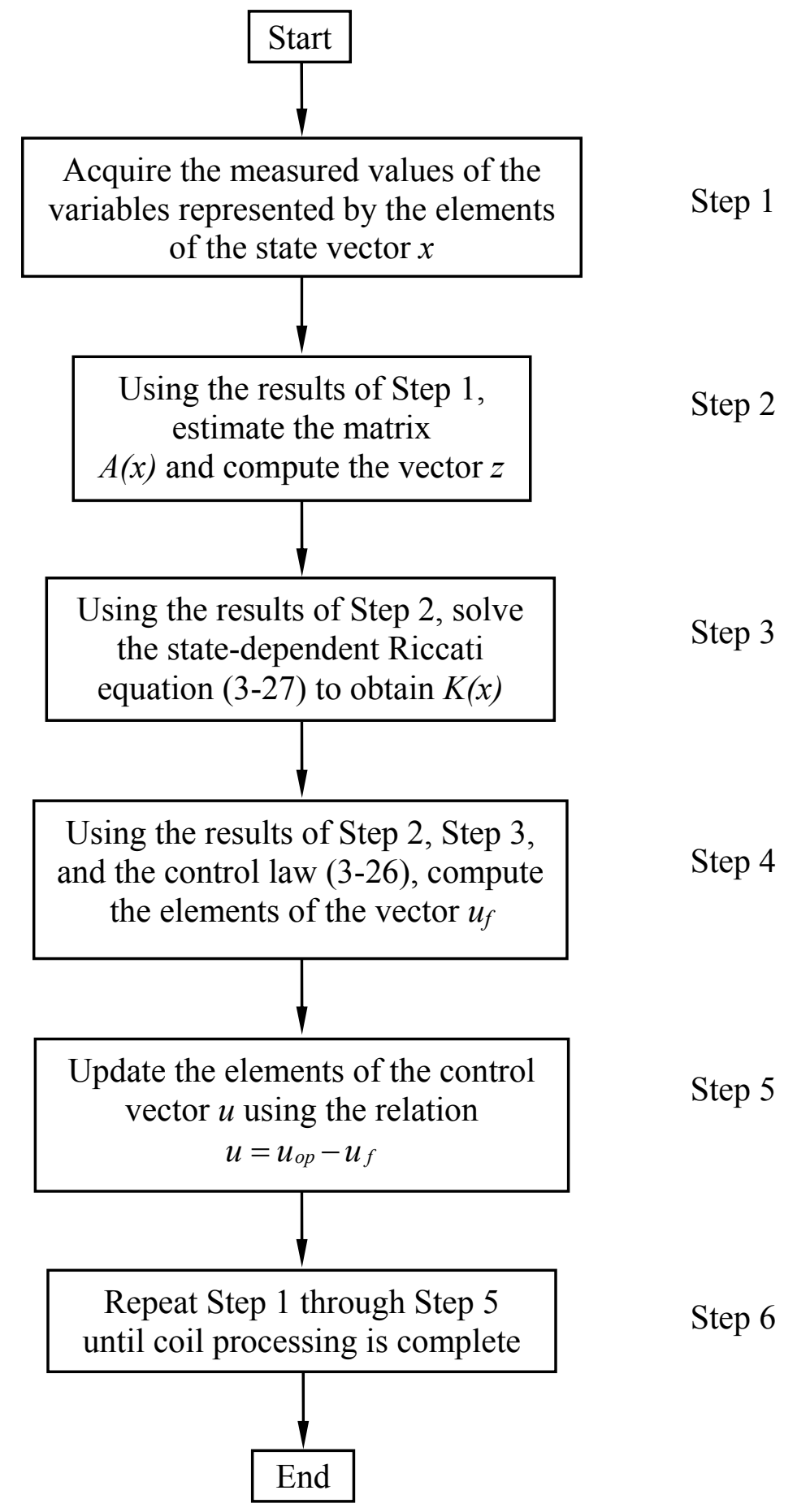

Figure 21 Controller Scan Functions

If during a scan a disturbance occurs which causes the measured values of the variables represented by the elements of the state vector $x$ to change, on the next scan the values of these 
variables are updated and the functions depicted in Figure 21 are executed to provide a correction to the control vector $u$ in response to the disturbance.

An important objective of the control strategy is the reduction of deviations in the strip thicknesses at the output of the mill and at the output of each intermediate stand due to disturbances, and due to modeling and measurement uncertainties. During initial simulation, with the disturbance in mill entry thickness at 100\% speed (Figure 18) applied to the system of Figure 20, and with no uncertainties, the peak excursion in mill exit thickness was about 2.2 percent, which could not be reduced appreciably by varying the settings of the elements of the weighting matrices $Q$ and $R$. When the modeling uncertainties (Table 41) are considered but with no disturbances applied, the magnitudes of the maximum deviations in mill output thickness and in the output thicknesses of the intermediate stands increase significantly. For example, using the configuration of Figure 20, simulations were done at 100\% speed with the uncertainties of Table 41 included in the model for stand 1 , assuming no modeling uncertainties for stands $2,3,4$, and 5, no measurement uncertainties, no disturbances, and with various settings of the weighting matrices $Q$ and $R$. The results are presented in Table 43, where the maximum percent change in stand 1 output thickness represents the effect of each modeling uncertainty applied separately,

Table 43 Effects of Modeling Uncertainties on Stand 1 Output Thickness

\begin{tabular}{|c|c|c|}
\hline Variable & Uncertainty & $\begin{array}{c}\text { Maximum Percent Change in } \\
\text { Stand 1 Output Thickness }\end{array}$ \\
\hline$\mu$ & $20 \%$ & $.7 \%$ \\
\hline $\bar{k}$ & $25 \%$ & 4.5 \\
\hline$M$ & $-10 \%$ & 2.6 \\
\hline$\mu, \bar{k}, M$ concurrently & 6.0 \\
\hline
\end{tabular}

and the effect of the individual modeling uncertainties applied concurrently in a manner to produce the maximum percent change in the stand 1 output thickness. Similar results were seen 
for simulations using the modeling uncertainties in the other mill stands. Therefore, even with no disturbances, these deviations are unacceptable for control of the mill stand output thicknesses; however, they can be reduced by modifying the system such that the modeling uncertainties and most measurement uncertainties are included inside closed loops, so that, assuming stability, the significant errors in the output thicknesses mostly are due to uncertainties in those measurements outside the control loops. Three modifications are considered for evaluation of disturbance rejection and of robustness to uncertainties:

(1) The addition of elements to the state vector $x$ with adjustments to the elements of the $Q$ and $R$ weighting matrices to penalize those added states which have a significant influence on the mill output thickness and on the output thicknesses of the intermediate stands $[46,47]$,

(2) The addition of a strip thickness measurement at the output of each stand for feedback for closed loop control of the estimated output thicknesses, and

(3) The addition of a trim function for each stand, with the measurement of strip thickness at the output of stand 1 and at the output of stand 5 for feedback to the trim functions of these stands, plus the addition of measurements of strip speed at the inputs of stands 2, 3,4 , and 5 , and at the output of stand 5 , to infer by using mass flow techniques, the strip thicknesses as feedback to the trim functions for stands 2, 3, 4, 5 [48].

Modification (1) was implemented by approximating (in the controller) each interstand time delay with four first order lags so that, for an individual mill stand, the input thickness is the output thickness of the previous stand delayed by the series of first order lags. This results in the addition of sixteen additional states so that the total number of states in the controller is increased from fourteen to thirty, as depicted in Table 44, where elements $x_{15}$ to $x_{30}$ of the state vector $x$ 
Table 44 State Vector Elements, Variable Assignments Using Modification (1)

\begin{tabular}{|l|l|}
\hline$x_{1}$ & $\sigma_{12}$ \\
\hline$x_{2}$ & $\sigma_{23}$ \\
\hline$x_{3}$ & $\sigma_{34}$ \\
\hline$x_{4}$ & $\sigma_{45}$ \\
\hline$x_{5}$ & $S_{1}$ \\
\hline$x_{6}$ & $S_{2}$ \\
\hline$x_{7}$ & $S_{3}$ \\
\hline$x_{8}$ & $S_{4}$ \\
\hline$x_{9}$ & $S_{5}$ \\
\hline$x_{10}$ & $V_{1}$ \\
\hline
\end{tabular}

\begin{tabular}{|l|l|}
\hline$x_{11}$ & $V_{2}$ \\
\hline$x_{12}$ & $V_{3}$ \\
\hline$x_{13}$ & $V_{4}$ \\
\hline$x_{14}$ & $V_{5}$ \\
\hline$x_{15}$ & $h_{\text {in } 2}$ \\
\hline$x_{16}$ & $h_{\text {in } 3}$ \\
\hline$x_{17}$ & $h_{\text {in } 4}$ \\
\hline$x_{18}$ & $h_{\text {in } 5}$ \\
\hline$x_{19}$ & $q 12_{1}$ \\
\hline$x_{20}$ & $q 12_{2}$ \\
\hline
\end{tabular}

\begin{tabular}{|l|l|}
\hline$x_{21}$ & $q 12_{3}$ \\
\hline$x_{22}$ & $q 23_{1}$ \\
\hline$x_{23}$ & $q 23_{2}$ \\
\hline$x_{24}$ & $q 23_{3}$ \\
\hline$x_{25}$ & $q 34_{1}$ \\
\hline$x_{26}$ & $q 34_{2}$ \\
\hline$x_{27}$ & $q 34_{3}$ \\
\hline$x_{28}$ & $q 45_{1}$ \\
\hline$x_{29}$ & $q 45_{2}$ \\
\hline$x_{30}$ & $q 45_{3}$ \\
\hline
\end{tabular}

represent the variables associated with the added first order lags, which are described by sixteen differential equations of the form

$$
\begin{array}{lr}
\dot{q} i, i+1_{1}=\left(\frac{4}{\tau_{d, i, i+1}}\right)\left(h_{\text {out }, i}-q i, i+1_{1}\right), & q i, i+1_{1}(0)=q 1, i+1,0_{1}, \\
\dot{q} i, i+1_{2}=\left(\frac{4}{\tau_{d, i, i+1}}\right)\left(q i, i+1_{1}-q i, i+1_{2}\right), & q i, i+1_{2}(0)=q 1, i+1,0_{2}, \\
\dot{q} i, i+1_{3}=\left(\frac{4}{\tau_{d, i, i+1}}\right)\left(q i, i+1_{2}-q i, i+1_{3}\right), & q i, i+1_{3}(0)=q 1, i+1,0_{3}, \\
\dot{h}_{i n, i+1}=\left(\frac{4}{\tau_{d, i, i+1}}\right)\left(q i, i+1_{3}-h_{i n, i+1}\right), & h_{i n, i+1}(0)=h_{\text {in }, i+1,0}, \\
(i=1,2,3,4)
\end{array}
$$

where $i$ is an index representing the individual stand number, $q i, i+1 \in R^{3}$ is a vector whose elements are the values of individual states associated with the approximations of the interstand time delays, $q i, i+1,0 \in R^{3}$ is a vector whose elements are the initial values of the elements of the vector $q i, i+1$, and other variables are as defined previously. For an initial simulation using this 
modification, the weighting matrix $R$ was set to $I_{10}$, weighting matrix $Q$ was set to $I_{30}$, an input thickness disturbance (Figure 18, except without hot mill eccentricity) was applied at $100 \%$ speed assuming no uncertainties, and the resulting maximum excursion in output thickness was recorded. This was repeated with element $Q(15,15)$ set to various values between 1 and $10^{6}$. Element $Q(15,15)$ was chosen because penalizing the variable represented by the corresponding element of the state vector (i.e. element $x_{15}$, Table 44) strongly influences the output thickness of stand 1 , and also that stand 1 has a more significant influence on the output thickness of the mill than do the other four stands. The entire simulation was repeated with element $R(1,1)$ set to a value of 0.1 , and again with element $R(1,1)$ set to 0.01 , and then again with element $R(1,1)$ set to 0.001 . The element $R(1,1)$ was chosen because it also could influence the output thickness of stand 1 by penalizing the corresponding element of the control vector (i.e. element $u_{l}$ of Table 1). The results (plotted in Figure 22) show that for this configuration of the elements of the weighting matrices $Q$ and $R$, and for variations in the settings of elements $Q(15,15)$ and $R(1,1)$, the least maximum excursion in mill output thickness that could be achieved was about $0.2 \%$, which is assumed to increase if uncertainties are present, and therefore is considered unacceptable for tight control of strip thickness. 


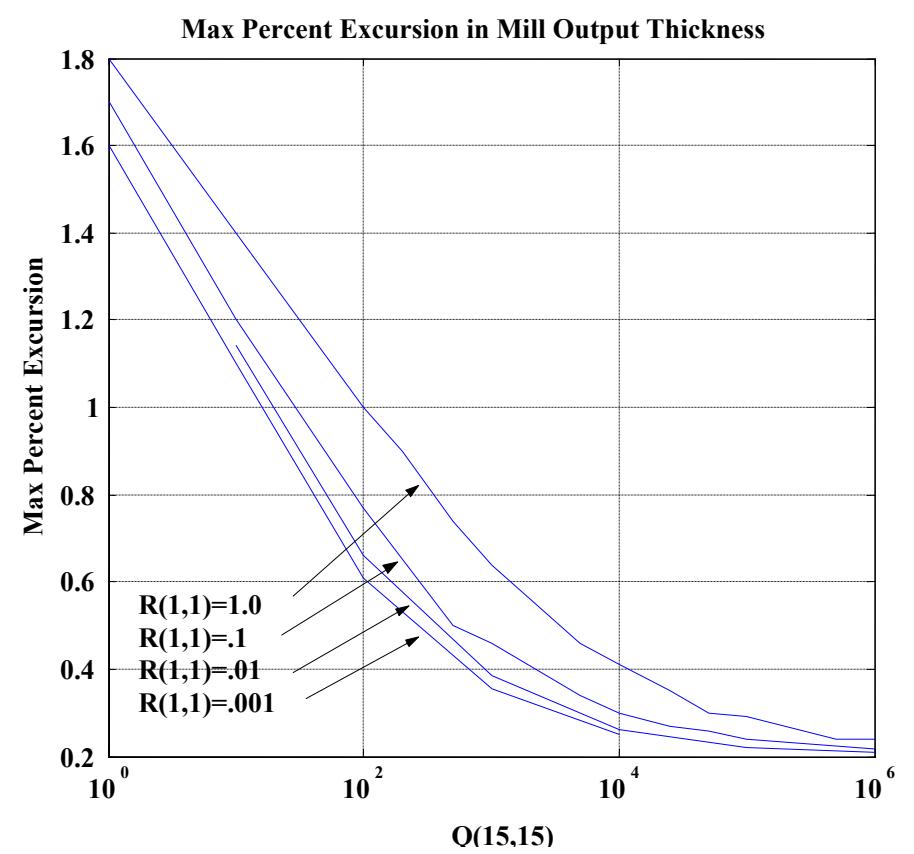

Figure 22 Maximum Percent Excursion in Mill Output Thickness for Mill Input Thickness Disturbance at 100\% Speed, Using Modification (1)

Modification (2) requires a thickness measurement at each stand, which is implemented typically using radiation gauging methods, which are very expensive and require additional physical space between the mill stands for the thickness sensors. Thus while this modification provides a measured thickness feedback signal for each stand, it is impractical to implement using the present technology, especially for cases where the modification is being applied for a revamp of an existing installation, and therefore is not evaluated further.

Modification (3) uses thickness measurements at the output of stand 1 and at the output of stand 5 as feedback signals, which is typical (Figure 2) for many cold mills. Locating a thickness measurement at the output of stand 1 enables the effects of disturbances in both thickness and hardness at the mill input to be detected close to the mill entry, which provides the capability of using both stand 1 and the downstream mill stands for correction of errors in the measured thickness. Locating a thickness measurement at the output of stand 5 provides feedback to reduce 
errors in mill exit thickness. The use of strip speed sensors at the input of stands 2, 3, 4, and 5, and at the output of stand 5, represents an addition to the instrumentation complement depicted in Figure 2. The strip speed sensors are commercially available laser velocimeters [45] with low error $(.025 \%)$ in the measured speed signal. Modification (3) is implemented by adding feedback (trims) as shown in Figure 23, where $y_{m}$ represents the measurable elements of the output vector

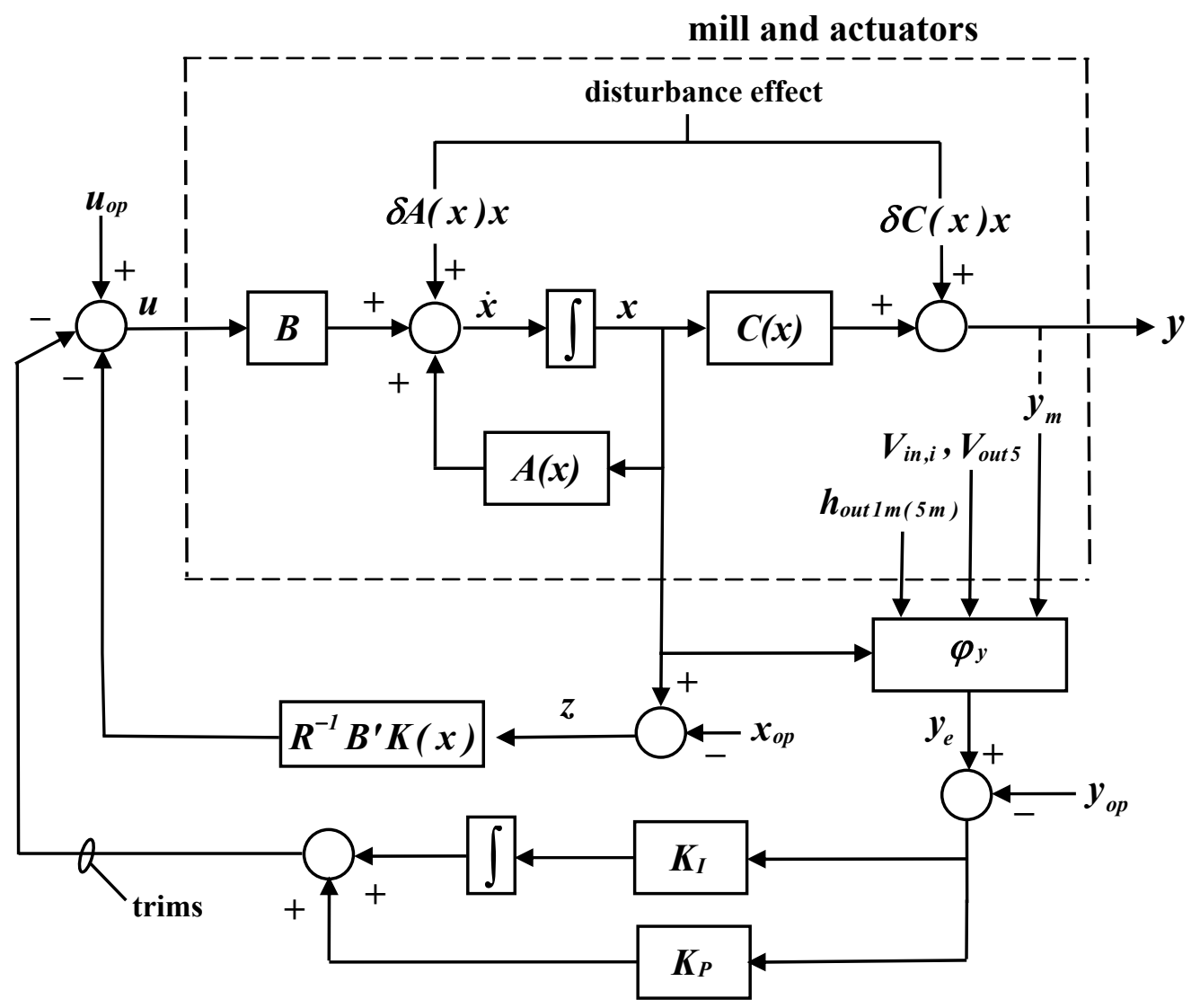

Figure 23 System Configuration Using Modification (3)

$y, V_{i n, i}(i=2,3,4,5)$ are the measured strip speeds at the inputs of stands $2,3,4$, and $5, V_{\text {out }}$ is the measured strip speed at the output of stand $5, h_{\text {out } 1 m}$ and $h_{\text {out } 5 m}$ are the measured strip thicknesses at stand 1 and stand 5, $y_{e} \in R^{p}(p=14)$ is a vector whose elements are estimates of the elements of $y, \varphi_{y}$ is an algorithm which uses $h_{\text {out } 1 m}, h_{\text {out } 5 m}, V_{\text {in,i }}, V_{\text {out } 5}, y_{m}$, and the 
measured values of certain variables represented by the elements of the state vector $x$ to generate $y_{e}, K_{I} \in R^{m \times p}(m=10, p=14)$ and $K_{p} \in R^{m \times p}$ are matrices whose elements are zero except for elements $(j, j),(j=1,2,3,4,5)$, which are the gains for the integral and proportional thickness trim functions for each stand. The input thickness disturbance applied in the case of modification (1) also was applied using modification (3) at $100 \%$ speed and assuming no uncertainties. Initially the settings of the elements of the $Q$ and $R$ matrices were $I_{14}$ and $I_{10}$, and with these settings using modification (3) the greatest maximum excursion in mill exit thickness was less than $0.01 \%$. When uncertainties are present the results were not significantly different. Based on this, and noting that modification (3) is less complicated than modification (1), mostly because it requires no additional states, modification (3) was chosen as the preferred method. While this choice might have been intuitively obvious before making the simulations, it was considered that performing the simulations for modification (1) would lead to a somewhat better insight into the effects of varying the values of the elements of the $Q$ and $R$ matrices. Additional simulations using modification (1) could be performed with different configurations of the elements of these matrices, or with state-dependent elements, or with both; however it is judged that the results would not differ significantly and that the resulting system would be more complex than the system using modification (3). Figure 24 depicts the 5 -stand tandem cold mill with the strip speed sensors (laser velocimeters) added as part of modification (3).

Under steady-state conditions and with almost constant strip width, the strip thickness at the output of a mill stand can be estimated using conservation of mass flow across the roll gap as

$$
h_{\text {out }, i}=\frac{h_{\text {in }, i} V_{\text {in }, i}}{V_{\text {out }, i}} k_{i, e}, \quad(i=1,2,3,4,5),
$$


where $i$ is an index representing the individual stand number, $h_{\text {in }, i}\left(h_{\text {out }, i}\right)$ and $V_{\text {in }, i}\left(V_{\text {out }, i}\right)$ are the stand $i$ input (output) strip thickness and input (output) strip speed respectively, and $k_{i, e}$ is a

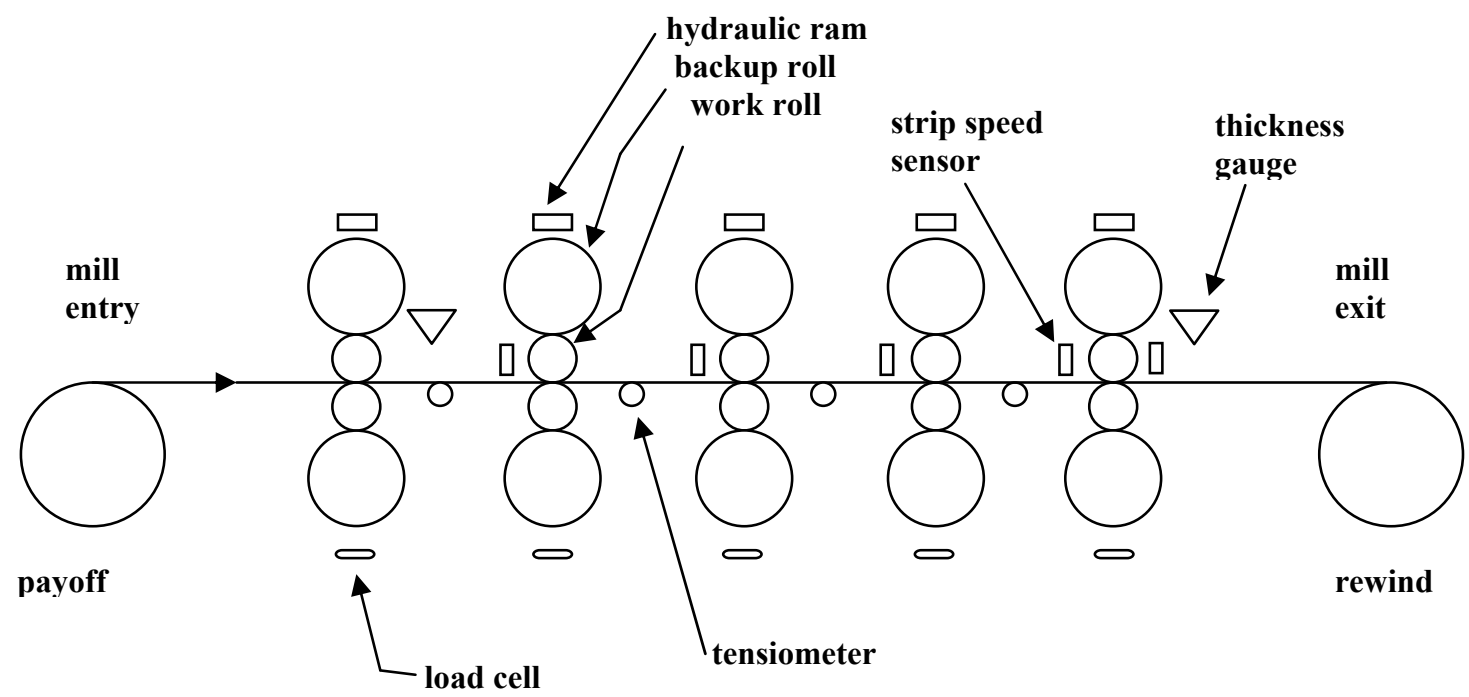

Figure 24 5-Stand Tandem Cold Mill Using Modification (3)

correction factor to adjust for very small errors in the estimated output thickness caused by spreading of the strip and reduction in width [40], and other effects. Substituting the strip speed at the input of the next stand for the output strip speed gives, for stands 2, 3, and 4,

$$
h_{\text {out }, i}=\frac{h_{\text {in }, i} V_{\text {in,i }}}{V_{\text {in }, i+1}} k_{i, e}, \quad(i=2,3,4),
$$

with (3-32) and $i=5$ being used for stand 5. This substitution, which eliminates the need for a speed sensor at the output of the stands 2,3 , and 4, results in very little error in the estimation of the output thickness as shown by simulation in Section 4.4. In addition, the simulation also has confirmed that using the relationship (3-33) during transient conditions does not cause significant error in the estimation of the output thickness. During operation, a separate mill adaptation system determines the correction factors $k_{i, e}$ heuristically. For example, a possible method similar 
to that described [49] for setting $k_{5 e}$ would be to compare the uncompensated mass flow computed thickness

$$
h_{\text {out } 5 m f}=\frac{V_{\text {in } 5}}{V_{\text {out } 5}} h_{\text {in } 5 e},
$$

as tracked from the mill stand to the thickness gauge, against the measured thickness $h_{\text {out } 5 m}$, and then use smoothing functions based on the previous estimates of $k_{5 e}$. The adjustment for stand $i$ $(i=2,3,4)$, is estimated by using the adjustment determined for stand 5 as modified by the scheduled input/output thickness ratios for stand $i$. The effects of $k_{i, e}$ on the error in the mill exit thickness are considered in Section 4.6.

The physical location of the thickness gauge at the exit of stand 1 causes a time delay in the measured thickness of the strip exiting the stand, and similarly for stand 5. Values of this time delay at $100 \%$ speed and at $5 \%$ speed are given in Table 45 for a typical gauge location of 39

Table 45 Values of Time Delay from Stand 1(5) to Thickness Gauge, with Gauge Location of 39 Inches from the Mill Stand

\begin{tabular}{|c|c|c|}
\cline { 2 - 3 } \multicolumn{1}{c|}{} & \multicolumn{2}{c|}{ Time Delay } \\
\hline Speed & Stand 1 & Stand 5 \\
\hline $100 \%$ & $.095 \mathrm{sec}$ & $.047 \mathrm{sec}$ \\
\hline $5 \%$ & $1.90 \mathrm{sec}$ & $.940 \mathrm{sec}$ \\
\hline
\end{tabular}

inches from the stand. Because of the time delay in the thickness measurement, faster transient errors in thickness at the exit of the stand will result in greater deviations in thickness from the operating point value than if there were no time delay. To partially compensate for this at stand 1, a BISRA estimate (2-26) of the thickness at the exit of the stand is made, which is then trimmed by the difference between the measured thickness and a previous BISRA estimate delayed by the time delay, as depicted in Figure 25 . The integral gain $K_{g_{-} \text {int } 1}$ is set intuitively and is confirmed by simulation in Sections 4.1, 4.2 and 4.3. Thus there is some immediate 


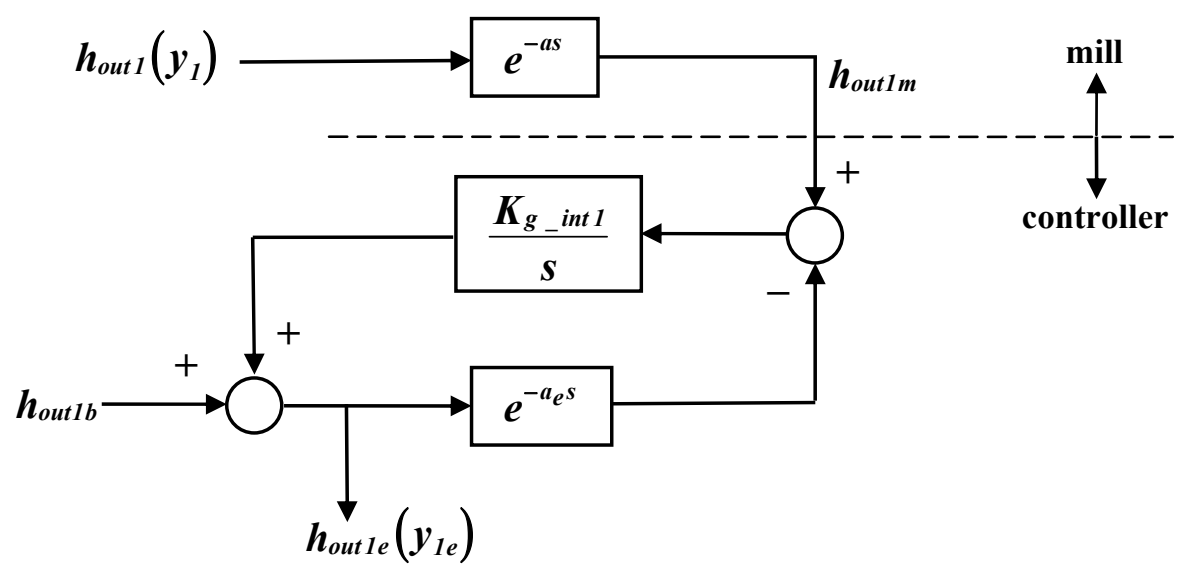

Figure 25 Stand 1 Output Thickness Estimation

correction for faster transient errors while the steady-state thickness is held to the desired operating point value. The BISRA estimate is made as part of the algorithm $\varphi_{y}$ as

$$
h_{\text {out } I b}=x_{5}+S_{0}+\frac{F_{l m}}{M_{l e}},
$$

where $h_{\text {out }}$ is is the BISRA estimate, $x_{5}$ is the stand 1 position actuator position (Table 1 ), $S_{0}$ is the intercept of the linearized portion of the mill stretch curve for stand $1, F_{1 m}$ is the measured total roll force for stand 1 , and $M_{l e}$ is the estimated mill modulus for stand 1 . The effects of back-up roll eccentricity are addressed in Section 3.4. In Figure 25, the notation $h_{\text {outle }}\left(y_{\text {le }}\right)$ indicates that the variable $h_{\text {outle }}$ is represented by element 1 of vector $y_{e}$, and similarly for other variables represented by the elements of $y$ and $y_{e}$. In Figure 25, the time delay from stand 1 to the thickness gauge is represented as $a$. The tracking of thickness in the controller from stand 1 to the thickness gauge is represented as a time delay

$$
a_{e}=\frac{L_{m 1}}{V_{i n 2}},
$$


where $L_{m 1}$ is the distance from stand 1 to the thickness gauge, and $V_{\text {in } 2}$ is the measured strip speed at the input of stand 2, which very closely approximates the strip speed at the output of stand 1 and is used for the tracking of the thickness. As noted previously, the BISRA estimate is very sensitive to uncertainties in the estimated mill modulus $M_{l e}$. To reduce the effects of this uncertainty, $M_{l e}$ is estimated by applying a BISRA relationship for an element of strip at the thickness gauge as

$$
h_{\text {out } \operatorname{lm}}(t)=x_{5}\left(t-a_{e}\right)+S_{0}+\frac{F_{1 m}\left(t-a_{e}\right)}{M_{1}\left(t-a_{e}\right)},
$$

or by rearranging,

$$
M_{1}\left(t-a_{e}\right)=\frac{F_{1 m}\left(t-a_{e}\right)}{h_{\text {out Im }}(t)-x_{5}\left(t-a_{e}\right)-S_{0}}
$$

and approximating $M_{l e}(t)$ as

$$
M_{1 e}(t)=M_{1}\left(t-a_{e}\right)
$$

where $F_{1 m}\left(t-a_{e}\right), x_{5}\left(t-a_{e}\right)$, and $M_{1}\left(t-a_{e}\right)$ are the variables $F_{1 m}(t), x_{5}(t)$, and $M_{1}(t)$ delayed by $a_{e}$. As noted earlier, changes in $M_{1}$ are mostly the result of changes in the back-up roll diameter due to mechanical wear and heating effects, which occur slowly compared to the time delay $a_{e}$. Thus it is reasonable to approximate $M_{l e}(t)$ by $M_{l}\left(t-a_{e}\right)$.

The measured thickness $h_{\text {out } 1 m}$ is tracked in the controller from the thickness gauge at the exit of stand 1 to stand 2 using the measured strip speed $V_{i n 2}$, so that the input thickness at stand 2 is determined as

$$
h_{\text {in } 2 e}(t)=h_{\text {out Im }}\left(t-\left(\tau_{d 12}-a_{e}\right)\right) \text {, }
$$


where $\tau_{d 12}$ is the interstand time delay (2-28) between stand 1 and stand 2. Then using (3-33) the output thickness at stand 2 is estimated in the controller as

$$
h_{\text {out } 2 e}=\frac{h_{\text {in } 2 e} V_{\text {in } 2}}{V_{\text {in } 3}} k_{2 e} \text {. }
$$

Similarly the thickness at the input to stand 3 can be estimated in the controller by using the measured strip speed at the input of stand 3 to track the thickness from stand 2 to stand 3 , so that the input thickness at stand 3 is approximated by

$$
h_{\text {in } 3 e}(t)=h_{\text {out } 2 e}\left(t-\tau_{d 23}\right) \text {, }
$$

where $\tau_{d 23}$ is the interstand time delay (2-28) between stand 2 and stand 3. Using (3-33) to estimate the stand 3 output thickness gives,

$$
h_{\text {out } 3 e}=\frac{h_{\text {in } 3 e} V_{\text {in } 3}}{V_{\text {in } 4}} k_{3 e} .
$$

The output thickness at stand 4 is estimated in a similar manner. The output thickness at stand 5 is estimated as in (3-32) with $i=5$, where $V_{\text {ins } 5}$ and $V_{\text {out } 5}$ are measured variables. In the case of stand 5, both the estimate of the output thickness $h_{\text {out } 5 b}$ and the thickness measurement just downstream of the stand are used in a configuration similar to that of stand 1, as depicted in Figure 26 , to obtain the thickness estimate $h_{\text {out } 5 e}\left(y_{5 e}\right)$, where $h_{\text {out } 5 b}$ is computed as

$$
h_{\text {out } 5 b}=\frac{h_{\text {in } 5 e} V_{\text {in } 5}}{V_{\text {out } 5}} k_{5 e}
$$




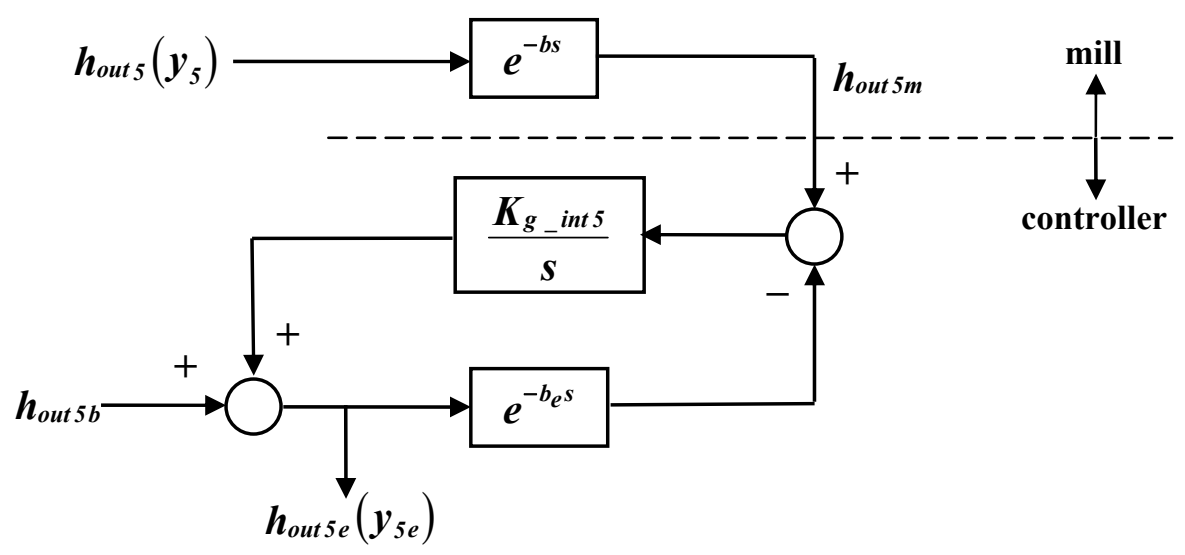

Figure 26 Stand 5 Output Thickness Estimation

with $h_{\text {inse }}$ approximated by

$$
h_{\text {inse }}(t)=h_{\text {out } 4 e}\left(t-\tau_{d 45}\right) \text {, }
$$

and where $\tau_{d 45}$ is the interstand time delay between stand 4 and stand 5. In Figure 26 the time delay from stand 5 to the thickness gauge is represented as $b$. The tracking of thickness in the controller from stand 5 to the thickness gauge is represented as a time delay

$$
b_{e}=\frac{L_{m} 5}{V_{\text {out } 5}},
$$

where $L_{m 5}$ is the distance from stand 5 to the thickness gauge, and $V_{o u t}$ is the measured strip speed at the output of stand 5 and is used for the tracking of the thickness. As in the case of stand 1, the integral gain $K_{g_{-} \text {int } 5}$ is set intuitively and is confirmed by simulation in Sections 4.1, 4.2, and 4.3.

Modification (3) is effective in reducing the effects of uncertainties in the measurements of $F, S$, and $V$ (Table 42) on the individual stand output thicknesses since these uncertainties are inside closed loops. In the case of the measurements of the input strip speeds $V_{i n, i}$ of stands 2, 3, 4 , and 5 , the uncertainties are small and therefore have less effect on the output thicknesses 
determined for stands 2,3 , and 4 . Thus, based on the foregoing, modification (3) appears to work well in reducing the effects of both modeling uncertainties and measurement uncertainties on the mill output thickness and on the output thicknesses at the individual mill stands, and provides strong rejection of external disturbances. This is confirmed by the simulations which follow in Section 4.0 .

The settings of the elements of the $Q$ and $R$ matrices to reduce excursions in the interstand tensions from their operating point values also are confirmed by the initial simulations presented in Section 4.1. However these excursions can be reduced further by the addition of operating point trim functions as depicted in Figure 27. In Figure 27, $x_{o p, i}(i=1,2,3,4)$ is an element of the vector $x_{o p}$ which represents the operating point for the interstand tension for stands $i, i+1, \sigma_{i, i+1, \text { ref }}$

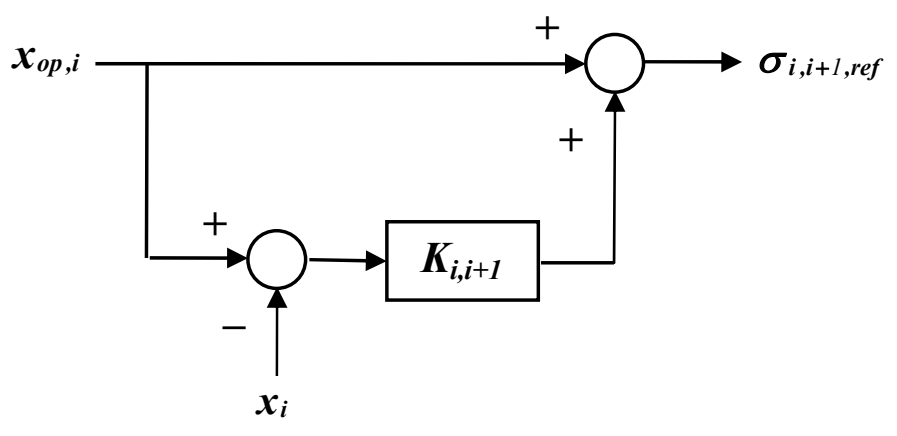

Figure 27 Interstand Tension Operating Point Trim

is the interstand tension reference for stands $i, i+1, x_{i}$ is the element of the state vector which represents the measured interstand tension for stands $i, i+1$, and $K_{i . i+1}$ is a gain term for stands $i, i+1$ which is set intuitively and confirmed by simulation. The system configuration (Figure 23) is modified as shown in Figure 28 to add the algorithm $\phi_{r}$ which implements the interstand tension operating point trims for elements $x_{o p, i}(i=1,2,3,4)$ of the $x_{o p}$ vector, and provides a direct feed-through for elements $x_{o p, i}(i=5, \ldots 14)$ of the $x_{o p}$ vector. The capability of the operating point 
trims to provide significant reductions in the excursions in the interstand tensions is shown in the simulations of Sections 4.1, 4.2, and 4.3.

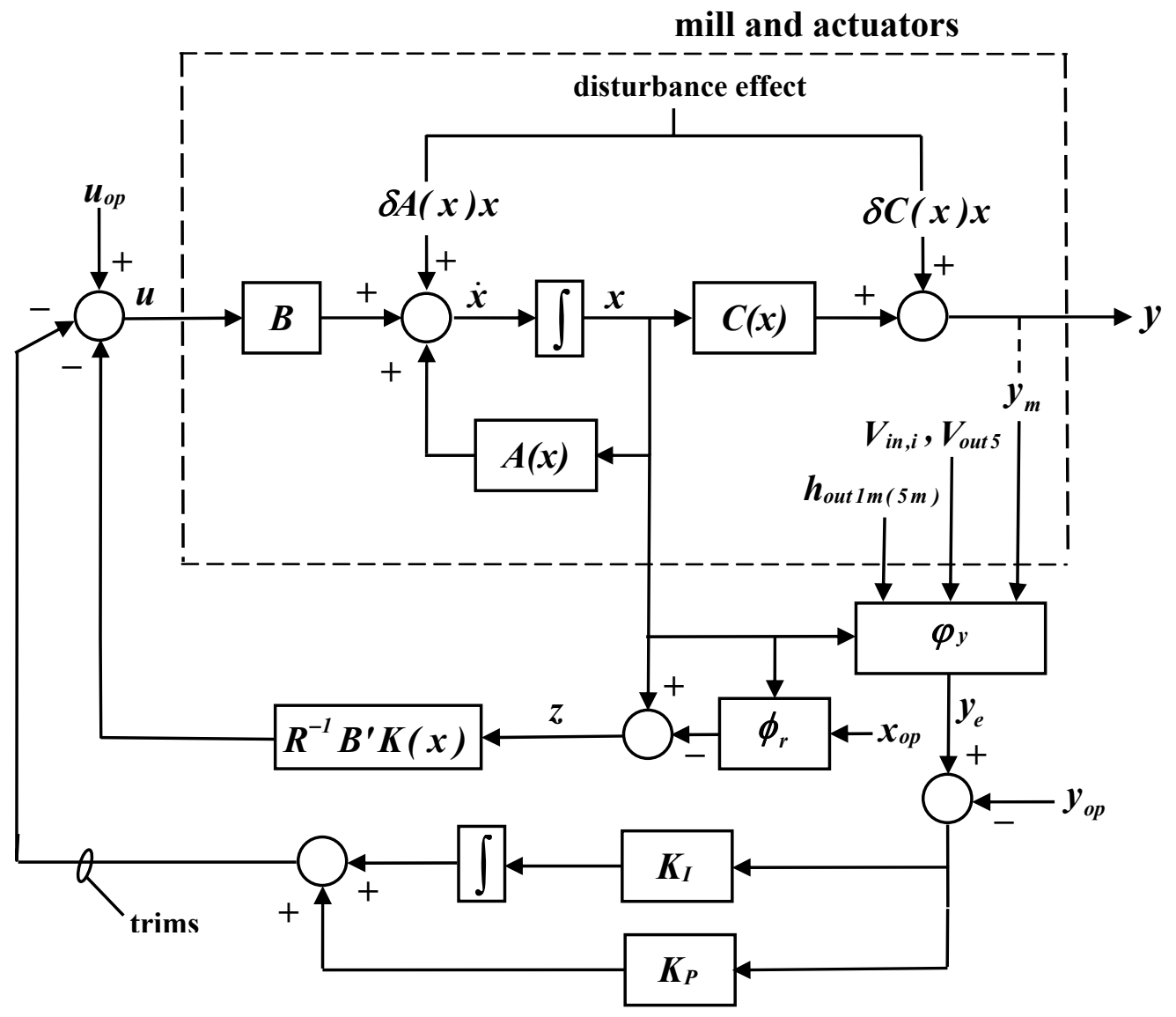

Figure 28 Modified System Configuration

\subsection{ECCENTRICITY COMPENSATION}

Roll eccentricity is a general term which refers to any condition caused by axial deviations between the roll barrel and the roll necks that results in irregularities in the mill rolls or the roll bearings [50]. Some examples of these conditions are (1) Eccentricity of the backup roll journals with respect to the roll body, (2) Out-of-roundness of the roll, (3) Non-uniformity of rollers in 
the roller bearings, plus others. These irregularities cause cyclic deviations in the strip thickness at the output of a mill stand which are taken as an internal disturbance in the tandem cold mill model. Figure 29 presents an example [51] that demonstrates the effects of roll eccentricity on

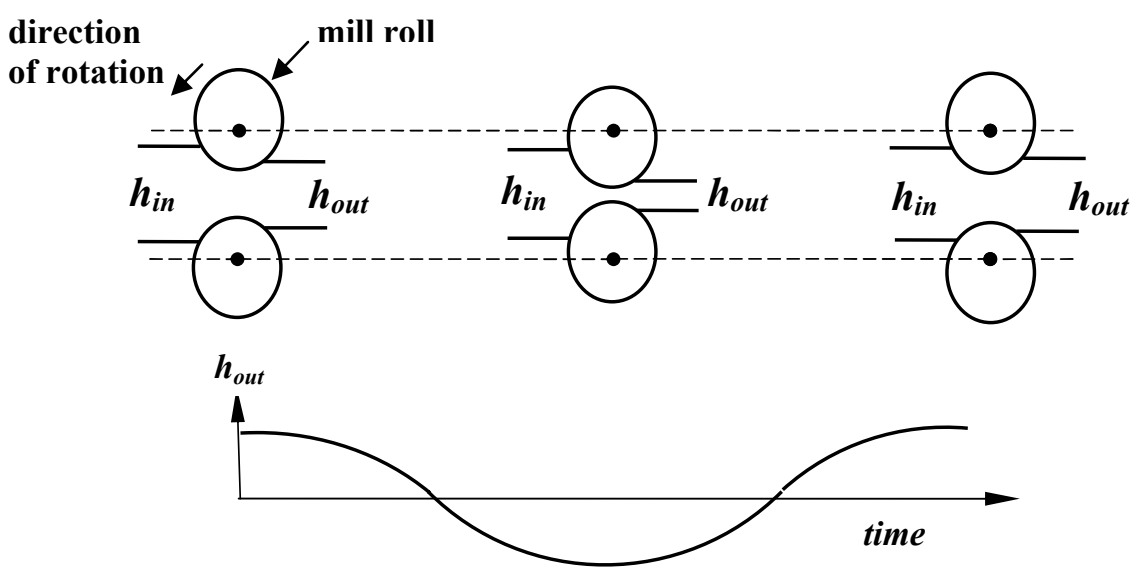

Figure 29 Effects of Roll Eccentricity on Output Thickness

strip thickness at the stand output. In addition, in the case of a BISRA control scheme as noted in Section 1.3, the eccentricity disturbance can cause the thickness controller to exacerbate the effect of the eccentricity disturbance instead of mitigating it. Thus it is desirable to provide a means for eccentricity compensation.

While each of the rolls of the four-high arrangement depicted in Figure 3 has some eccentricity which contributes to the cyclic deviation in the strip thickness, the greatest effect is from the backup rolls, mostly because they have a larger diameter than the work rolls. The deviation in strip thickness contributed by the eccentricity in the upper backup roll is not identical to the deviation contributed by the eccentricity in the lower backup roll, because the roll diameters are slightly different. The development of a method to adequately compensate for the eccentricity in each of the rolls in a tandem cold mill under all conditions of operation requires extensive effort that is outside the scope of the work described herein. However, since numerous papers [e.g., 51, 52, 53], patents [e.g., 54], and theses [e.g., 55] describing various methods of 
eccentricity compensation have been published with successful implementations reported, it is assumed that a method of compensation exists, or could be developed, to fit within the framework of the pointwise linear quadratic controller and be effective in rejecting the internal disturbances caused by roll eccentricities. To justify this assumption, a technique described in a recent paper [52] and reported to be implemented successfully in an actual operating multi-stand mill is used as a basis for a conceptual method that compensates for the eccentricity of a backup roll, and can be expanded to compensate for the eccentricity of the other backup roll and the eccentricity of the work rolls. The concept is verified by the simulation described in Section 4.5.

In the model the roll eccentricity is an internal disturbance that modifies (2-26) as

$$
h_{\text {out }}=S+S_{0}+\frac{P W}{M}+e,
$$

where $e$ is the roll eccentricity. The conceptual method for compensation of $e$ is a form of adaptive noise cancellation that relies on the fact that the backup roll eccentricity is always periodic with a frequency that is proportional to the measured angular velocity of the roll, so that there is correlation between the eccentricity and a sinusoid generated from the measurement of the roll angular velocity. In general, adaptive noise cancellation is a technique that relies on the correlation between the noise in a noisy signal and the measured noise generated by a separate source. The concept, as described in various texts [e.g., 56, 57], is depicted in Figure 30 and is used in the discretized eccentricity compensation (Figure 31) which interfaces with the pointwise linear quadratic controller that is discretized for actual usage. In Figure 30, $n$ represents the discrete time step, $v_{1}(n)$ and $v_{2}(n)$ are correlated noise sources, the signal $y(n)$ is uncorrelated with $v_{I}(n), v_{2}(n)$, and $\hat{v}_{1}(n)$, where $\hat{v}_{I}(n)$ is the output of the LMS (least mean square ) adaptive filter, and it is assumed that $v_{2}(n)$ contains no components of $y(n)$. The LMS 


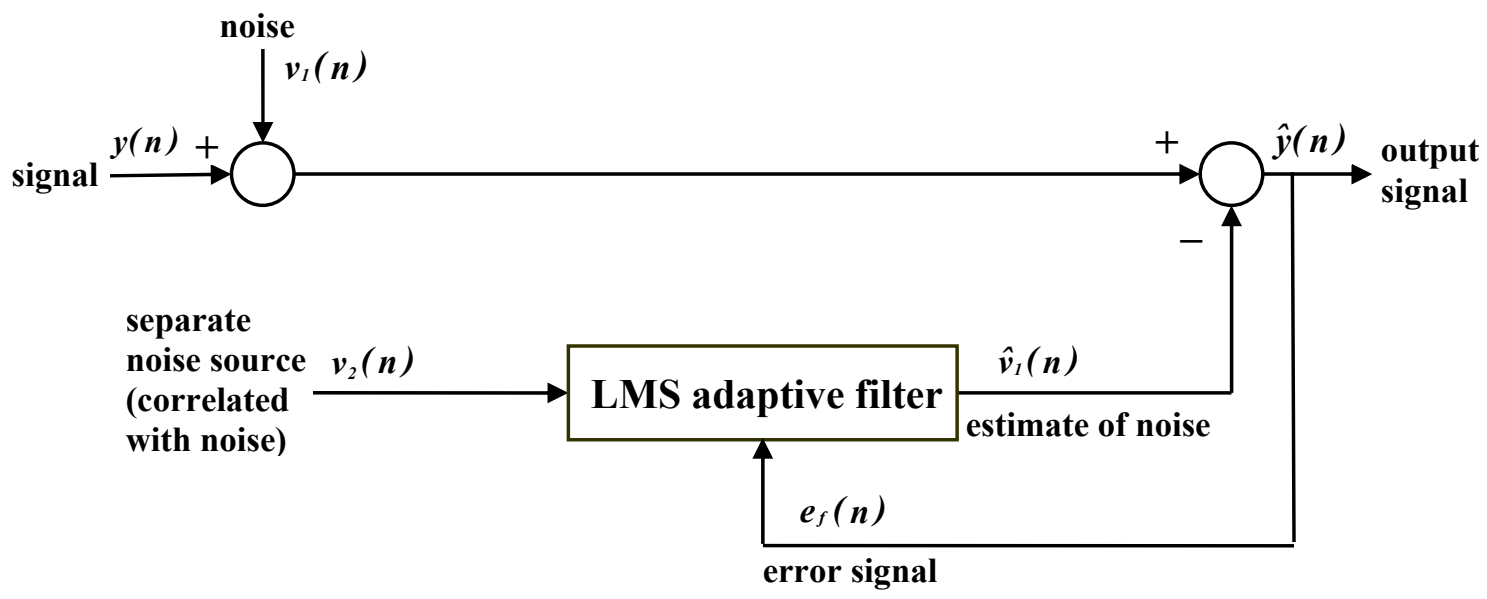

Figure 30 LMS Adaptive Noise Cancellation

adaptive filter uses $v_{2}(n)$ to predict $\hat{v}_{I}(n)$. The following relationship as depicted in Figure 30 is applicable:

$$
e_{f}(n)=\hat{y}(n)=y(n)+\left(v_{l}(n)-\hat{v}_{l}(n)\right),
$$

where $e_{f}(n)$ is the error signal applied to the adaptive filter. Squaring and taking expected values gives

$$
E\left[e_{f}^{2}(n)\right]=E\left[\hat{y}^{2}(n)\right]=E\left[y^{2}(n)\right]+E\left[\left(v_{l}(n)-\hat{v}_{l}(n)\right)^{2}\right],
$$

where it is noted that the term $2 E\left[y(n)\left(v_{l}(n)-\hat{v}_{1}(n)\right)\right]$ is zero because $y(n)$ is uncorrelated with $v_{l}(n)$ and $\hat{v}_{l}(n)$, and therefore is not shown in (3-49). The LMS adaptive filter will adjust itself to minimize $E\left[e_{f}^{2}(n)\right]$ and thus minimize $E\left[\left(v_{l}(n)-\hat{v}_{l}(n)\right)^{2}\right]$ while not affecting $y(n)$, which reduces the noise in the output signal $\hat{y}(n)$.

The position actuator controller for a mill stand is taken as an inner control loop for the displacement of the hydraulic spool with a nonlinear inner controller coupled to a linear outer control loop. A factorization approach [52] results in a realization, to which is added the LMS 
adaptive noise cancellation algorithm, as depicted in Figure 31. In Figure 31, $s$ is the position actuator reference, $y$ is the position feedback, $\omega$ is a signal whose frequency is proportional to the measured angular velocity of the roll, $d$ is the eccentricity disturbance, $Y_{L M S}$ is the input to LMS algorithm, $U_{L M S}$ is the output of the LMS algorithm, $P_{u}$ is a BIBO-stable transfer function which describes the input-output linearization obtained by an input transformation in the nonlinear controller, $P_{d}, Q_{L}, K_{L}$, and $C_{d}$ are BIBO-stable transfer functions where $C_{d}$ is determined such that $\left|C_{d}(j \omega) P_{u}(j \omega)-l\right|$ is nearly zero in the range of frequencies pertinent to the roll eccentricity. The intent is that the disturbance signal $P_{d} d$ is cancelled by the signal $P_{u} C_{d} U_{L M S}$ so that the output $y$ is essentially eccentricity free, and the changes in the strip thickness due to the eccentricity are reduced. Further insight into the use of the LMS algorithm in the eccentricity compensation can be gained by comparing the signals in Figure 31 with those in Figure 30. In Figure 31 the signals $Y_{L M S}, P_{u} C_{d} U_{L M S}$, and $P_{d} d$ correspond to the signals $e_{f}(n), \hat{v}_{l}(n)$, and $v_{l}(n)$, respectively, in Figure 30, with $y(n)$ being zero, and a sinusoid generated using the frequency $\omega$ corresponding to $v_{2}(n)$. Thus the estimated eccentricity signal $P_{u} C_{d} U_{L M S}$, corresponding to the estimated noise signal $\hat{v}_{l}(n)$, is subtracted from the eccentricity signal $P_{d} d$, corresponding to the noise signal $v_{l}(n)$, to reduce the eccentricity component in the output $y$. In addition, it is assumed that the eccentricity noise in the signal representing roll force, and any remaining eccentricity noise in the signal representing actuator position, are reduced by adaptive filtering techniques [e.g., 58], so that the signals representing roll force and actuator position both have negligible eccentricity components. The effects on eccentricity compensation caused by changes in roll diameter due to heating and mechanical wear, and by harmonics in the eccentricity waveform, are addressed in Section 4.5 as part of 


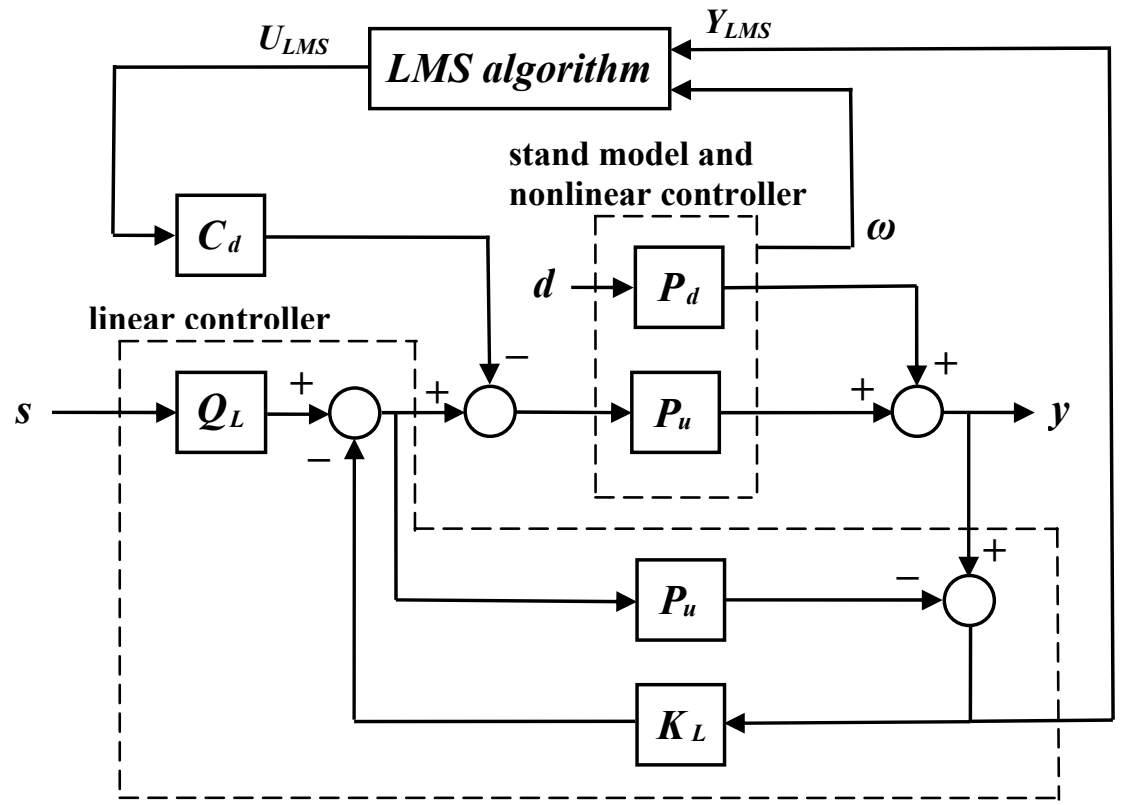

Figure 31 Position Controller Realization with Active Eccentricity Compensation

the simulation. This method can be extended to estimate the eccentricity of the other backup roll and the eccentricities of the work rolls by using the signal $\omega$ to generate sinusoids of appropriate frequencies.

\subsection{COMMENTS}

1. The eccentricity compensation technique depicted in Figure 31 reduces the eccentricity component in the actuator position. Under this condition the eccentricity actually imprinted on the strip depends on the compressive yield stress (hardness) of the material being rolled and the mill modulus, i.e. if the material is very hard, there will be less imprinting than if the material is softer. For the strip and the mill stands considered herein, the compressive yield stress and the mill modulus are such that there is reduced imprinting of eccentricity. However, it is considered that a modification to the technique shown in Figure 31 could reduce the imprinting further by 
having the correction signal, provided by the LMS algorithm to the position controller, adjust the actuator position to reduce the eccentricity component in the total roll force instead of reducing the eccentricity component in the actuator position. This would require additional investigation which could be done as part of future work related to eccentricity compensation.

2. The pointwise linear quadratic technique described herein appears to offer improvements in performance, in rejection of disturbances, and in robustness to uncertainties, and therefore is well suited for control of a tandem cold mill. The simulation results presented in the following section confirm this for several conditions of operation. 


\subsection{SIMULATIONS}

Open loop simulations (Section 2.3) were performed to confirm the validity of the model. The closed loop simulations described in this section were performed with the controller coupled to the model (i.e. the mill and actuators) as depicted in Figure 28 to confirm performance, robustness to external disturbances, robustness to modeling uncertainties, robustness to measurement uncertainties, and to evaluate the effects of roll eccentricities, with several different operating points. To show the effect of the interstand tension operating point trims, initial simulations are done with these trims disabled, and then repeated with the trims enabled.

\subsection{CLOSED LOOP SIMULATIONS USING OPERATING POINT 1}

For these simulations, the operating point first was taken as Operating Point 1 (Table 4). The simulations were then repeated except with the interstand tensions given in Production Schedule

1 (Table 2), which represented a slight shift in the operating point. For the simulations using Operating Point 1, the weighting matrix $Q$ was set to $I_{14}$, except for elements $Q(1,1), Q(2,2)$, $Q(3,3)$ and $Q(4,4)$ which were set to $10^{8}$ to reduce excursions in interstand tensions, and with the weighting matrix $R$ set to $I_{10}$. Using physical intuition, and with a few trials, the settings of controller parameters $K_{I}$ and $K_{P}$ (Figure 28) and the settings of parameters $K_{g_{-} \text {int } 1}$ (Figure 25) and $K_{g_{-} \text {int5 }}$ (Figure 26) were determined as shown in Table 46. 
Table 46 Parameter Settings for Operating Point 1

$\begin{array}{ccl}\text { Parameter } & \text { Setting } & \text { Stand Number } \\ K_{I, i} & 1000 & \text { Stand } i(i=1,2,3,4,5) \\ K_{P, i} & 500 & \text { Stand } i(i=1,2,3,4,5) \\ K_{g_{-} \text {int } 1} & .25 & \text { Stand 1 } \\ K_{g_{-} \text {int } 5} & .50 & \text { Stand 5 }\end{array}$

To obtain some insight into the effects of the external disturbances, the uncertainties, and the roll eccentricities, the controlled mill was simulated initially assuming ideal conditions, with simulations performed subsequently to evaluate each of these effects. The initial simulations were performed at $100 \%$ speed, at $5 \%$ speed, during deceleration from $100 \%$ speed to $5 \%$ speed, and during acceleration from 5\% speed to $100 \%$ speed. The peripheral speeds of the work rolls of the individual stands were determined by setting the values of the variables associated with certain elements of the vectors $x_{o p}$ and $u_{o p}$, as shown in Table 40, using the output thicknesses of Operating Point 1 (Table 4) and typical forward slips [1]. Each of these values is proportional to a mill master speed reference which was set to $100 \%$ at $100 \%$ speed and to $5 \%$ at $5 \%$ speed. During deceleration and acceleration, the mill master speed reference was shaped as depicted in Figure 32 and in Figure 33 to avoid severe excursions in the interstand tensions. The times for deceleration and acceleration are typical, consistent with the capabilities of the drive systems and the mill mechanics. These initial simulations were first performed with the interstand tension operating point trims disabled, and then repeated with the trims enabled with $K_{i, i+1}=100$, where $K_{i, i+1}$ is as shown in Figure 27. The results of the simulations with the trims disabled are presented in Table 47 which summarizes the magnitudes of the maximum deviations in the stand output thicknesses and in the interstand tensions from their operating point values. As these results show, the magnitudes of the deviations in the output thicknesses of each stand from their 


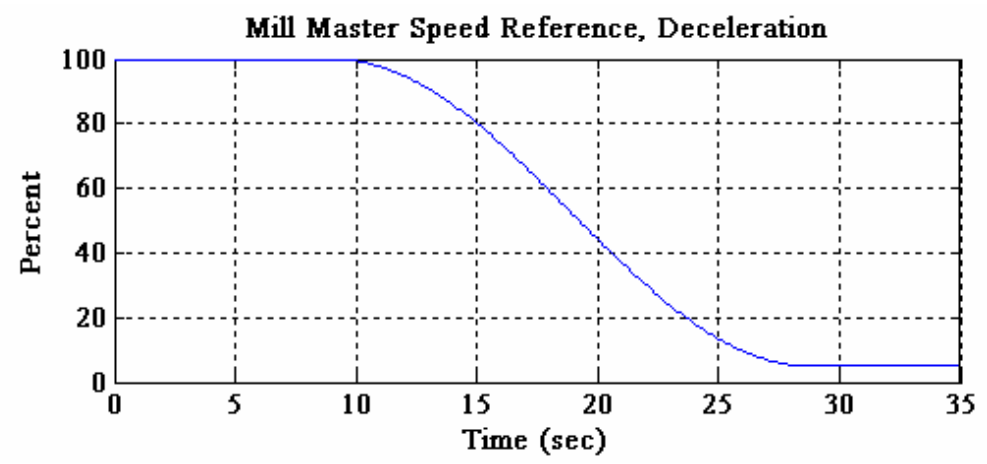

Figure 32 Mill Master Speed Reference During Deceleration

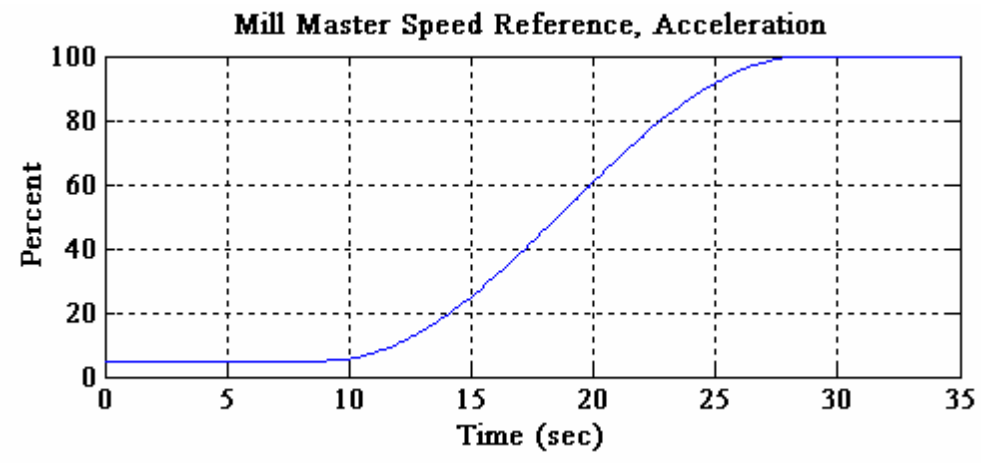

Figure 33 Mill Master Speed Reference During Acceleration

Table 47 Magnitudes of Maximum Percent Deviations of Stand Exit

Thicknesses and Interstand Tension Stresses, without Disturbances, Uncertainties, or Eccentricities, with Interstand Tension Operating Point Trims Disabled, Using Operating Point 1

\begin{tabular}{|c|c|c|c|c|}
\cline { 2 - 5 } \multicolumn{1}{c|}{} & \multicolumn{4}{c|}{$\begin{array}{c}\text { Magnitude of Maximum Percent Deviation } \\
\text { of Variable from Operating Point Value }\end{array}$} \\
\hline \multirow{2}{*}{ Variable } & $\begin{array}{c}\mathbf{1 0 0 \%} \\
\text { Speed }\end{array}$ & $\begin{array}{c}\mathbf{5 \%} \\
\text { Speed }\end{array}$ & $\begin{array}{c}\text { Decel from } \\
\mathbf{1 0 0 \%} \text { to 5\% } \\
\text { Speed }\end{array}$ & $\begin{array}{c}\text { Accel from } \\
\mathbf{5 \%} \text { to 100\% } \\
\text { Speed }\end{array}$ \\
\hline$h_{\text {out } 1}$ & $0 \%$ & $0 \%$ & $<.001 \%$ & $<.001 \%$ \\
\hline$h_{\text {out } 2}$ & 0 & 0 & $<.001$ & $<.001$ \\
\hline$h_{\text {out } 3}$ & 0 & 0 & $<.001$ & $<.001$ \\
\hline$h_{\text {out } 4}$ & 0 & 0 & $<.001$ & $<.001$ \\
\hline$h_{\text {out } 5}$ & 0 & 0 & $<.001$ & $<.001$ \\
\hline$\sigma_{12}$ & $2.0 \%$ & $2.0 \%$ & $2.0 \%$ & $2.0 \%$ \\
\hline$\sigma_{23}$ & 3.0 & 0.5 & 1.0 & 1.0 \\
\hline$\sigma_{34}$ & 0.5 & 1.0 & 1.4 & 1.5 \\
\hline$\sigma_{45}$ & 5.0 & 5.0 & 2.5 & 2.0 \\
\hline
\end{tabular}


desired operating point values are negligible at steady state and are less than $.001 \%$ during acceleration or deceleration. The magnitudes of the deviations in interstand tensions from their desired operating point values are no more than 5\% at steady-state, during deceleration, and during acceleration. The simulations were repeated, except with the interstand tension operating point trims enabled. The results are presented in Figure 34, Figure 35, Figure 36, and Figure 37, and summarized in Table 48. As can be seen from Table 48, the magnitudes of the deviations in output thicknesses of the stands from their operating point values are about the same as with the trims disabled, while the magnitudes of the deviations in the interstand tensions from their desired operating point values (Table 4) are no more than $0.1 \%$ at steady-state, during deceleration, and during acceleration. Based on these results, the interstand tension operating point trims were enabled for the remainder of the simulations described herein, and as noted previously, become part of the control system configuration shown in Figure 28.

Table 48 Magnitudes of Maximum Percent Deviations of Stand Exit Thicknesses and Interstand Tension Stresses, without Disturbances, Uncertainties, or Eccentricities, with Interstand Tension Operating Point Trims Enabled, Using Operating Point 1

\begin{tabular}{|c|c|c|c|c|}
\cline { 2 - 5 } \multicolumn{1}{c|}{} & \multicolumn{4}{c|}{$\begin{array}{c}\text { Magnitude of Maximum Percent Deviation } \\
\text { of Variable from Operating Point Value }\end{array}$} \\
\hline \multirow{2}{*}{ Variable } & $\begin{array}{c}\mathbf{1 0 0 \%} \\
\text { Speed }\end{array}$ & $\begin{array}{c}\mathbf{5 \%} \\
\text { Speed }\end{array}$ & $\begin{array}{c}\text { Decel from } \\
\mathbf{1 0 0 \%} \text { to 5\% } \\
\text { Speed }\end{array}$ & $\begin{array}{c}\text { Accel from } \\
\mathbf{5 \%} \text { to 100\% } \\
\text { Speed }\end{array}$ \\
\hline$h_{\text {out } 1}$ & $0 \%$ & $0 \%$ & $<.001 \%$ & $<.001 \%$ \\
\hline$h_{\text {out } 2}$ & 0 & 0 & $<.001$ & $<.001$ \\
\hline$h_{\text {out } 3}$ & 0 & 0 & $<.001$ & $<.001$ \\
\hline$h_{\text {out } 4}$ & 0 & 0 & $<.001$ & $<.001$ \\
\hline$h_{\text {out } 5}$ & 0 & 0 & $<.001$ & $<.001$ \\
\hline$\sigma_{12}$ & $.03 \%$ & $.02 \%$ & $.03 \%$ & $.03 \%$ \\
\hline$\sigma_{23}$ & .04 & .00 & .05 & .05 \\
\hline$\sigma_{34}$ & .01 & .01 & .02 & .02 \\
\hline$\sigma_{45}$ & .10 & .05 & .10 & .10 \\
\hline
\end{tabular}


Percent Changes in Stand Output Thicknesses from x $10^{-4}$ Operating Point Values During Mill Deceleration
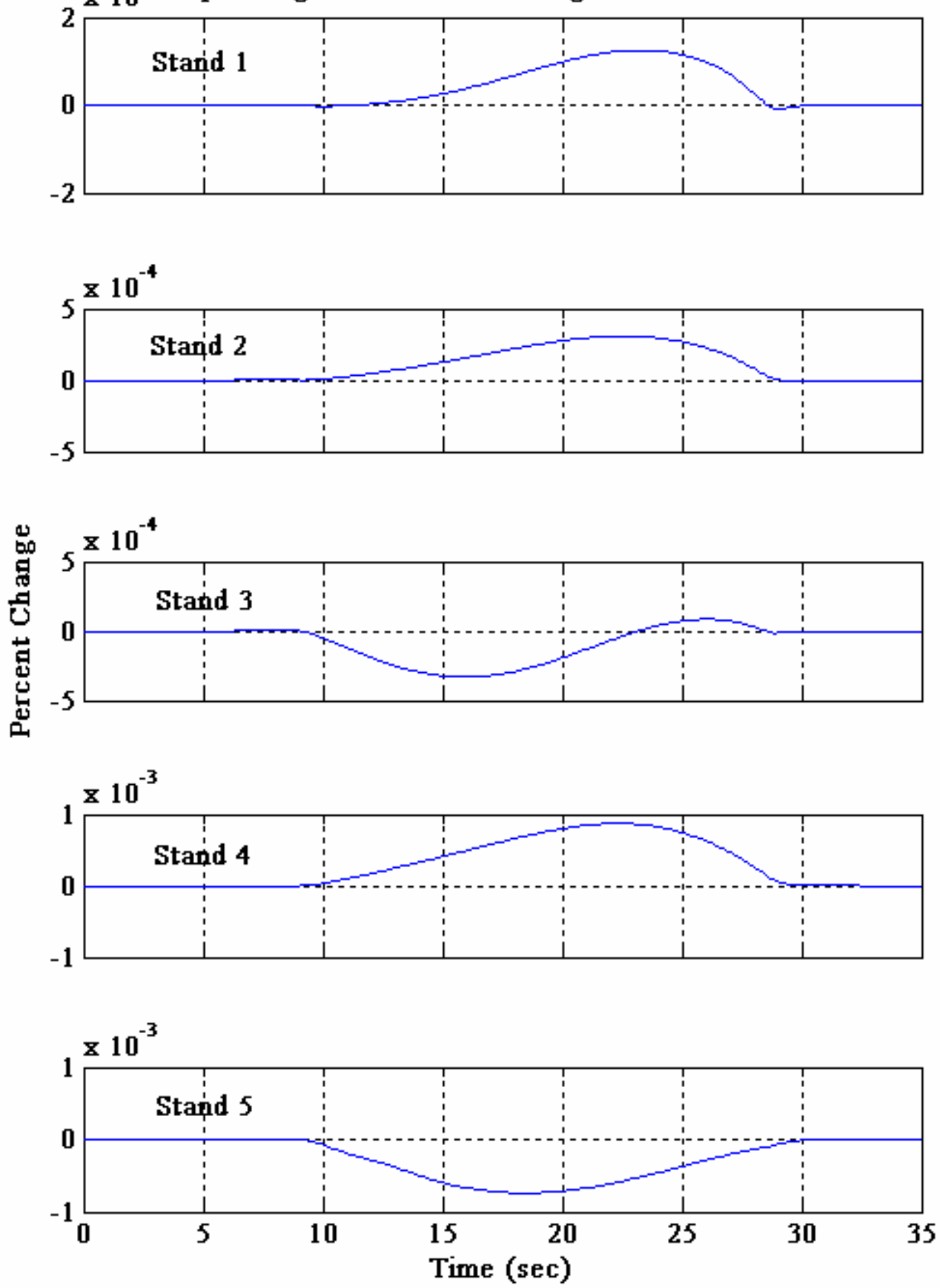

Figure 34 Percent Changes in Stand Output Thicknesses from Operating Point Values During Mill Deceleration, without Disturbances, Uncertainties, or Eccentricities, Using Operating Point 1 

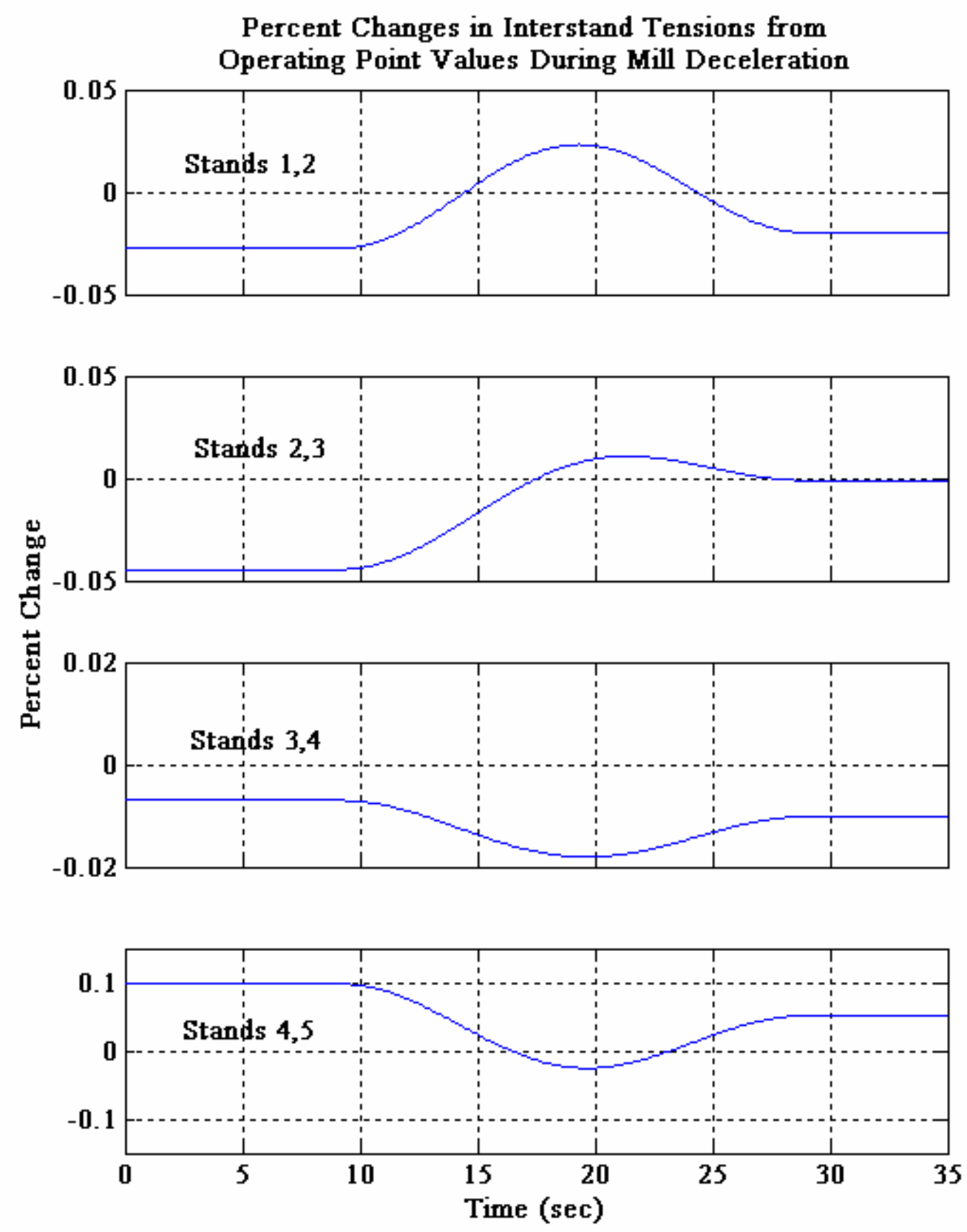

Figure 35 Percent Changes in Interstand Tensions from Operating Point Values During Mill Deceleration, without Disturbances, Uncertainties, or Eccentricities, Using Operating Point 1 

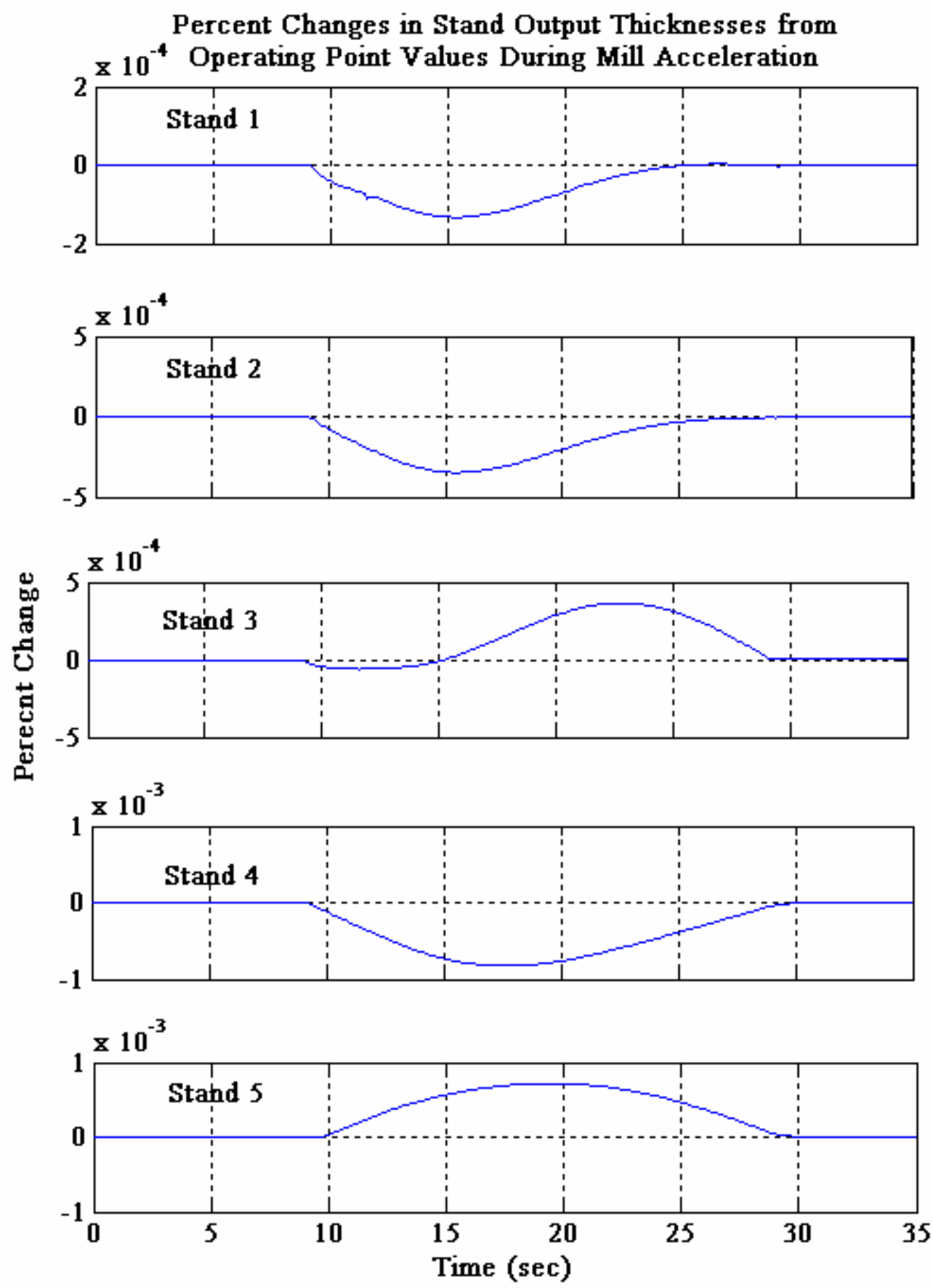

Figure 36 Percent Changes in Stand Output Thicknesses from Operating Point Values During Mill Acceleration, without Disturbances, Uncertainties, or Eccentricities, Using Operating Point 1 


\section{Percent Changes in Interstand Tensions from Operating Point Values During Mill Acceleration}
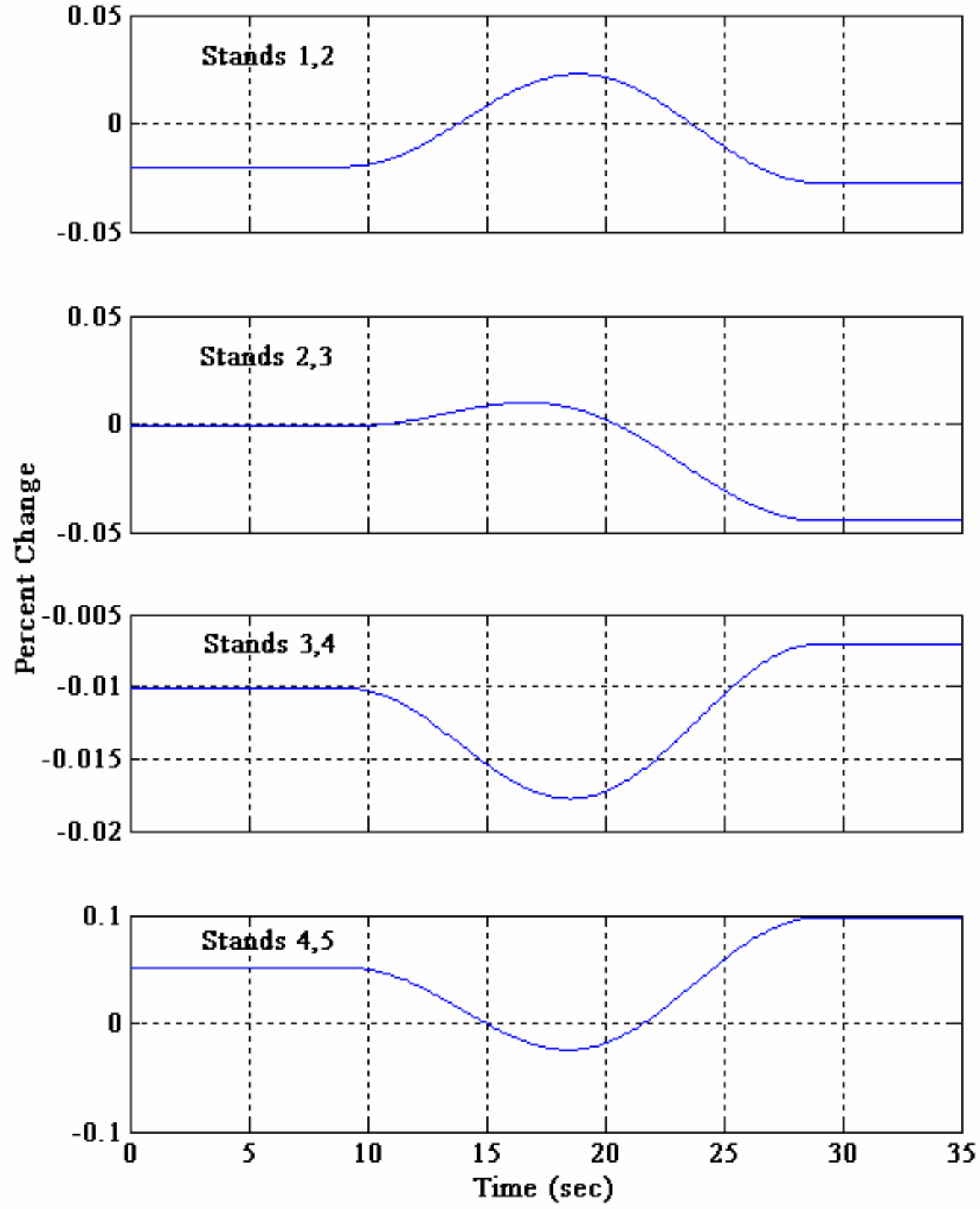

Figure 37 Percent Changes in Interstand Tensions from Operating Point Values During Mill Acceleration, without Disturbances, Uncertainties, or Eccentricities, Using Operating Point 1 
The previous simulations were repeated except with the mill entry disturbances applied, with no uncertainties and no eccentricities. The disturbances, shown in Figure 18 and in Figure 19 as functions of time, were applied as functions of strip distance. The results are given in Figure 38 through Figure 45. As can be seen from Figure 38, Figure 40, Figure 42, and Figure 44 the magnitude of the maximum deviation in mill output thickness from the operating point value was about $.01 \%$. The magnitudes of the maximum deviations in the stand output thicknesses and in the interstand tensions from their operating point values are summarized in Table 49.

Table 49 Magnitudes of Maximum Percent Deviations of Stand Exit Thicknesses and Interstand Tensions, with Mill Entry Disturbances, without Uncertainties or Eccentricities, Using Operating Point 1

\begin{tabular}{|c|c|c|c|c|}
\hline \multirow[b]{2}{*}{ Variable } & \multicolumn{4}{|c|}{$\begin{array}{l}\text { Magnitude of Maximum Percent Deviation } \\
\text { of Variable from Operating Point Value }\end{array}$} \\
\hline & $\begin{array}{l}100 \% \\
\text { Speed }\end{array}$ & $\begin{array}{c}5 \% \\
\text { Speed }\end{array}$ & $\begin{array}{l}\text { Decel from } \\
100 \% \text { to } 5 \% \\
\text { Speed } \\
\end{array}$ & $\begin{array}{c}\text { Accel from } \\
5 \% \text { to } 100 \% \\
\text { Speed } \\
\end{array}$ \\
\hline$h_{\text {out } 1}$ & $.022 \%$ & $.005 \%$ & $.021 \%$ & $.025 \%$ \\
\hline$h_{\text {out } 2}$ & .012 & $<.001$ & .011 & .011 \\
\hline$h_{\text {out } 3}$ & .014 & $<.001$ & .012 & .013 \\
\hline$h_{\text {out } 4}$ & .015 & $<.001$ & .014 & .013 \\
\hline$h_{\text {out } 5}$ & .011 & $<.001$ & .010 & .010 \\
\hline$\sigma_{12}$ & $.11 \%$ & $.02 \%$ & $.10 \%$ & $.10 \%$ \\
\hline$\sigma_{23}$ & .05 & .00 & .05 & .05 \\
\hline$\sigma_{34}$ & .04 & .01 & .04 & .04 \\
\hline$\sigma_{45}$ & .14 & .05 & .10 & .10 \\
\hline
\end{tabular}




\section{Percent Changes in Stand Output Thicknesses from Operating Point Values at $\mathbf{1 0 0 \%}$ Speed}

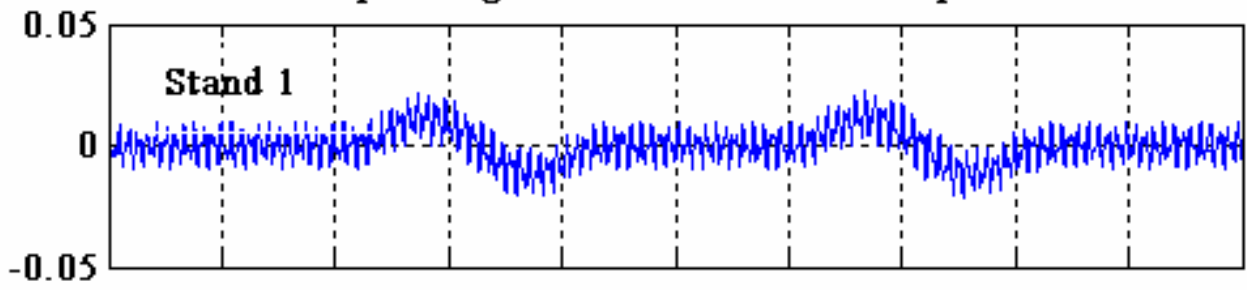

$-0.02$
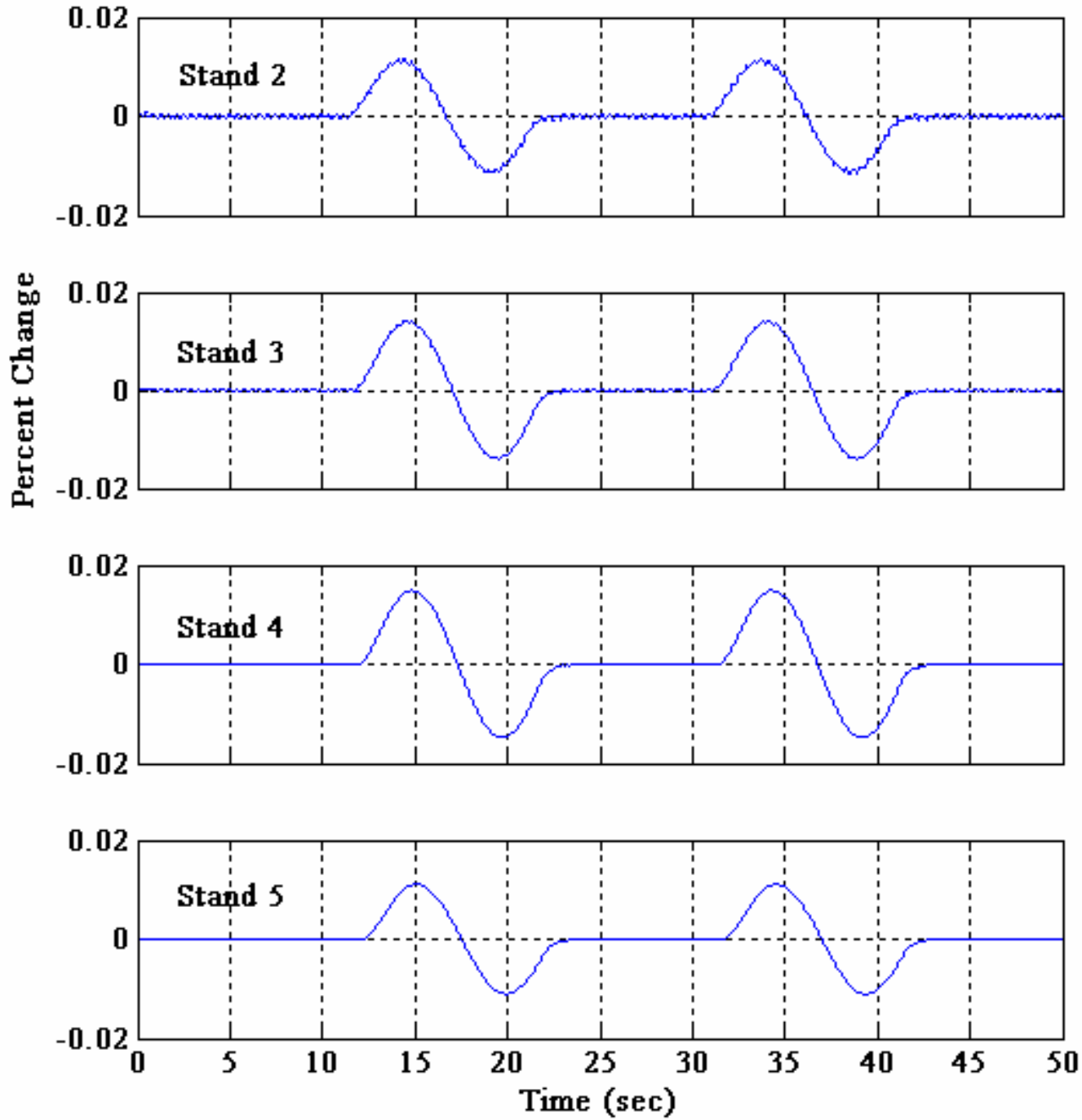

Figure 38 Percent Changes in Stand Output Thicknesses from Operating Point Values at 100\% Speed, with Mill Entry Disturbances, without Uncertainties or Eccentricities, Using Operating Point 1 
Percent Changes in Interstand Tensions from

Operating Point Values at $100 \%$ Speed
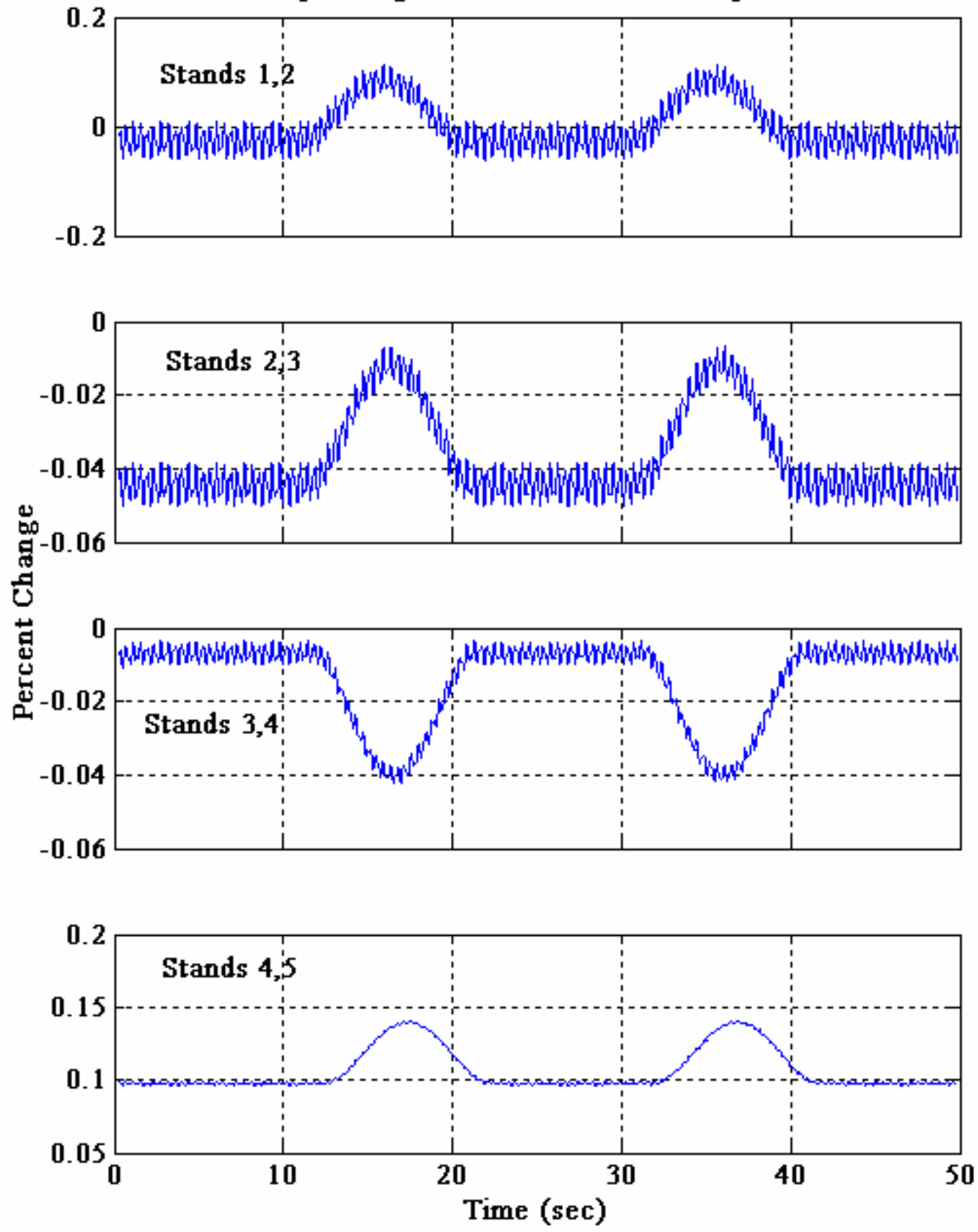

Figure 39 Percent Changes in Interstand Tensions from Operating Point Values at $100 \%$ Speed, with Mill Entry Disturbances, without Uncertainties or Eccentricities, Using Operating Point 1 

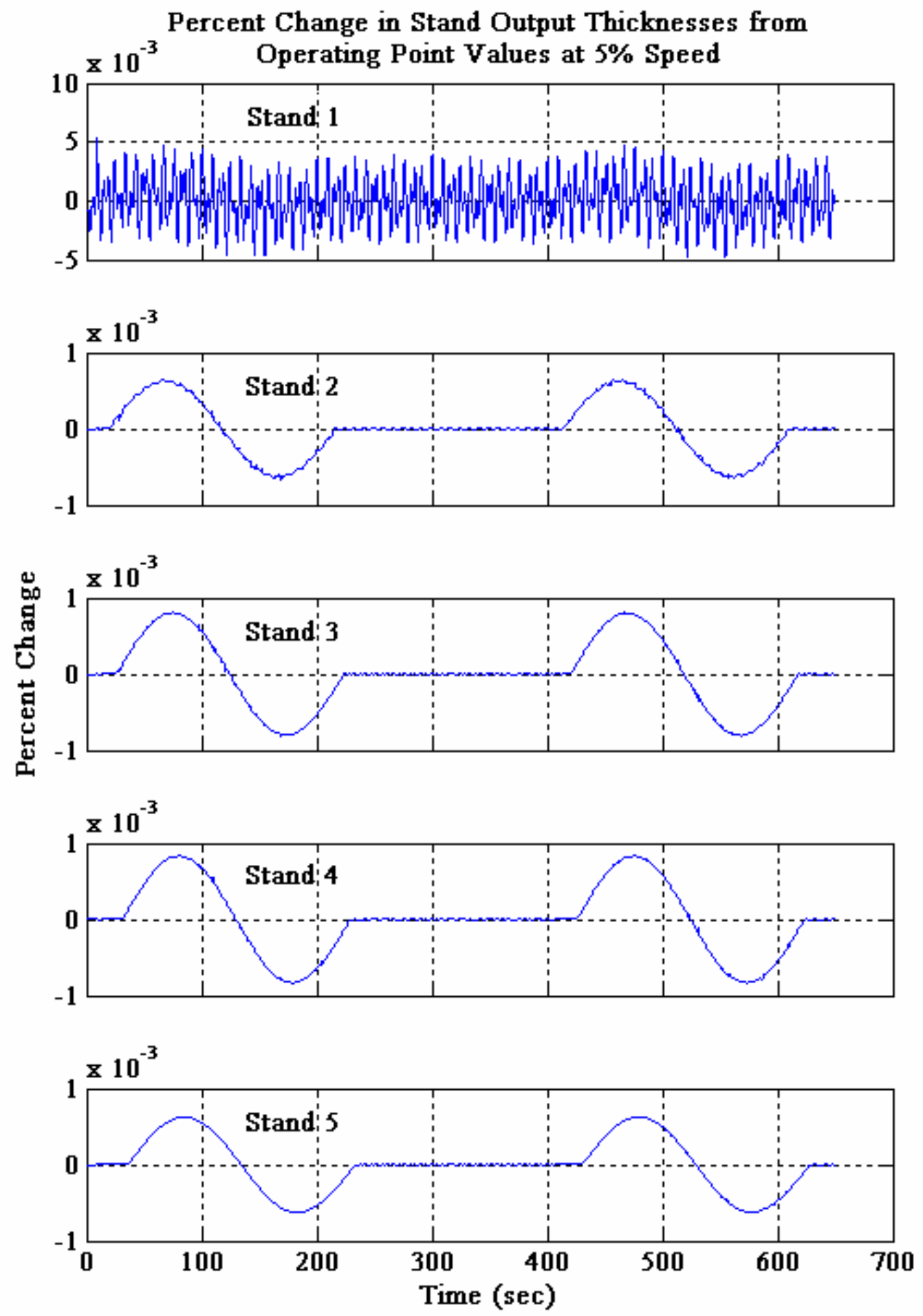

Figure 40 Percent Changes in Stand Output Thicknesses from Operating Point Values at 5\% Speed, with Mill Entry Disturbances, without Uncertainties or Eccentricities, Using Operating Point 1 

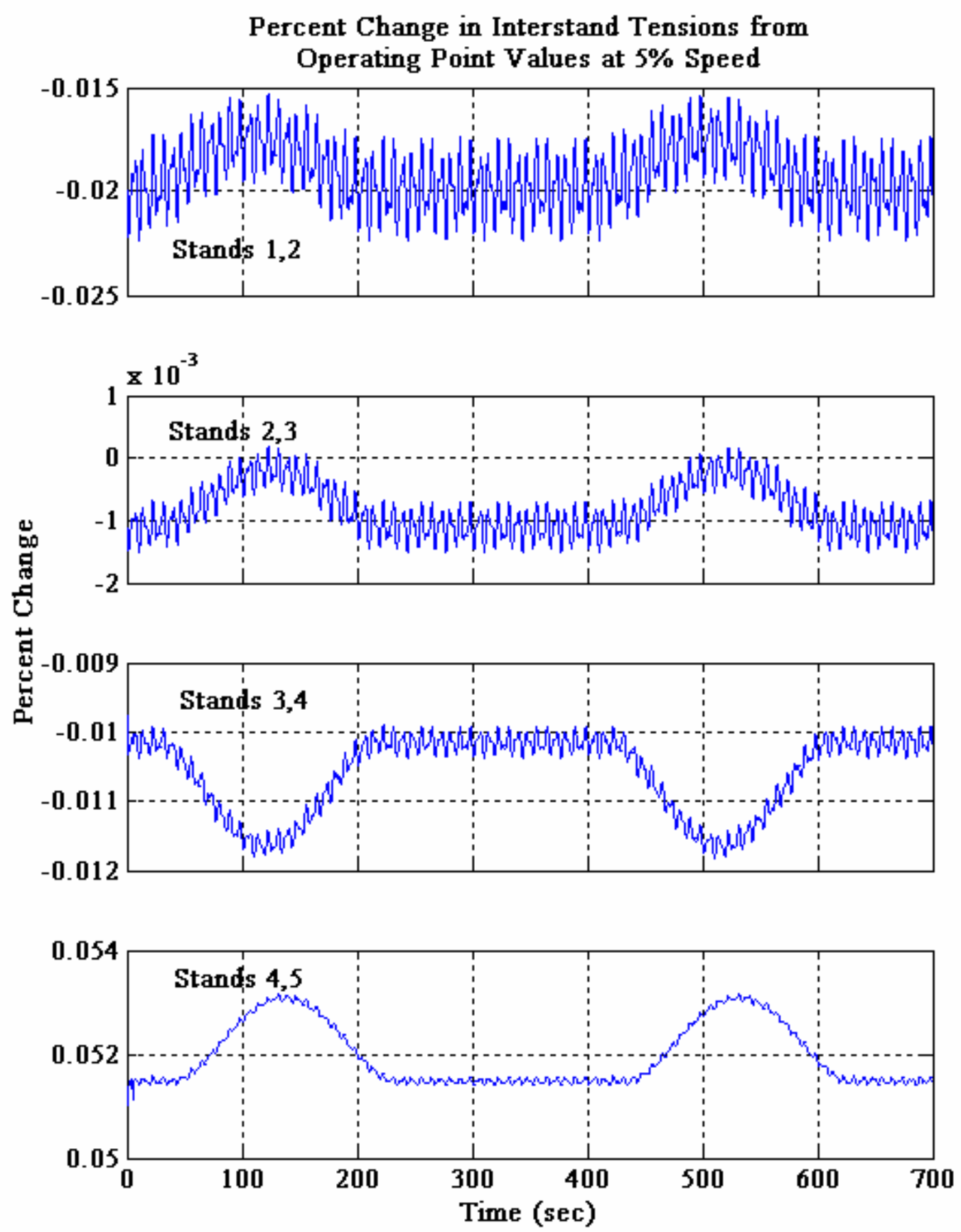

Figure 41 Percent Changes in Interstand Tensions from Operating Point Values at 5\% Speed, with Mill Entry Disturbances, without Uncertainties or Eccentricities, Using Operating Point 1 

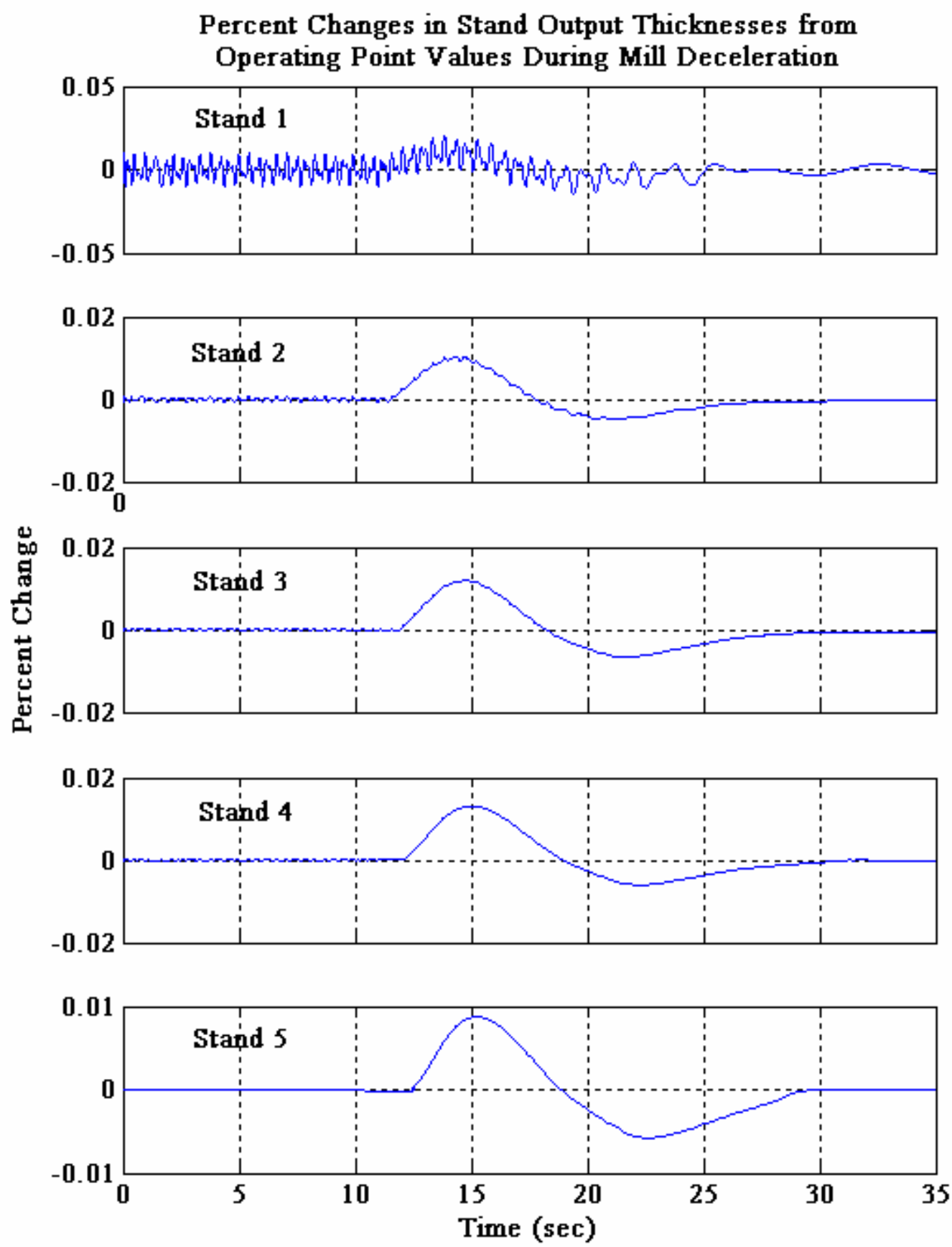

Figure 42 Percent Changes in Stand Output Thicknesses from Operating Point Values During Mill Deceleration, with Mill Entry Disturbances, without Uncertainties or Eccentricities, Using Operating Point 1 

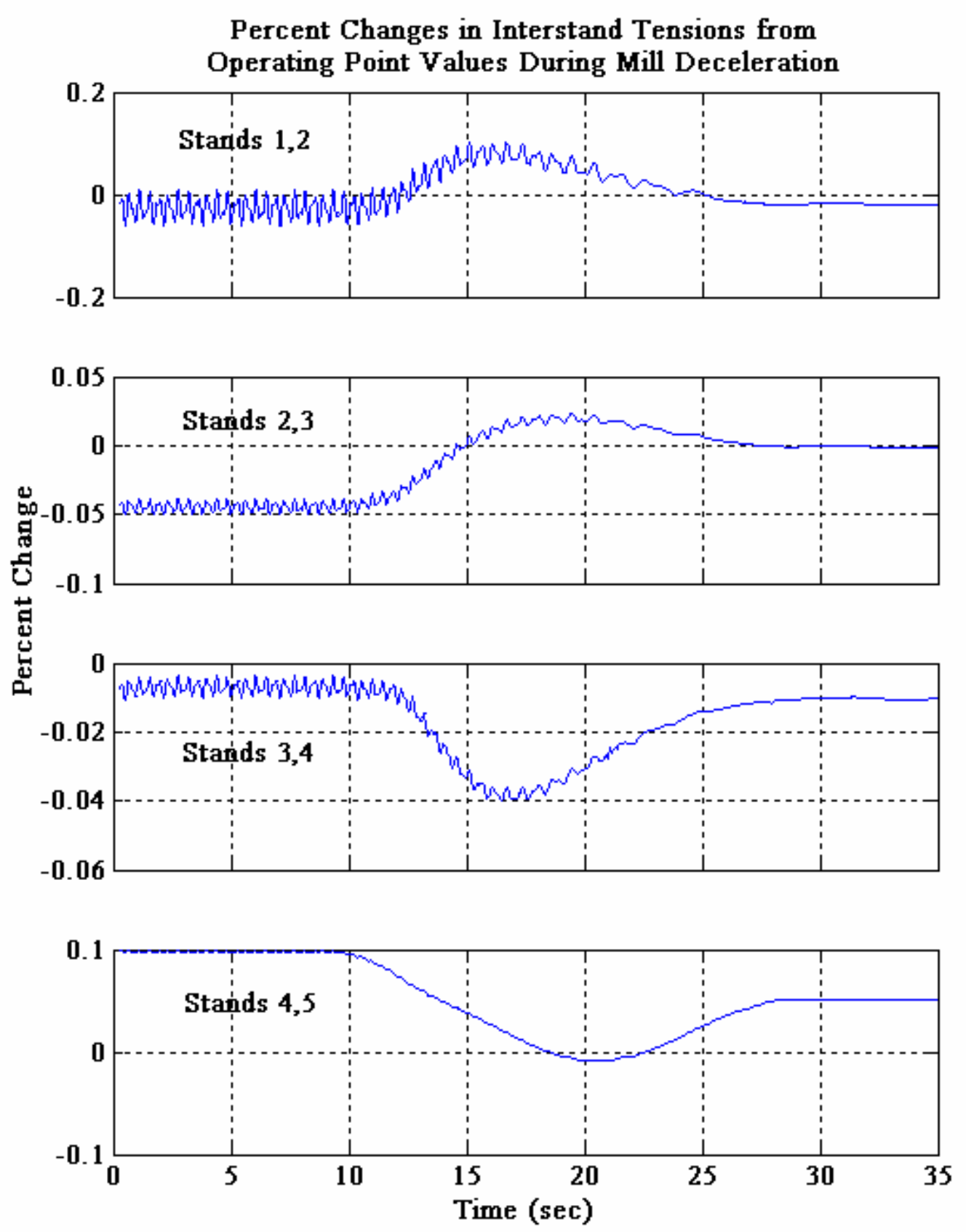

Figure 43 Percent Changes in Interstand Tensions from Operating Point Values During Mill Deceleration, with Mill Entry Disturbances, without Uncertainties or Eccentricities, Using Operating Point 1 


\section{Percent Changes in Stand Output Thicknesses from Operating Point Values During Mill Acceleration}
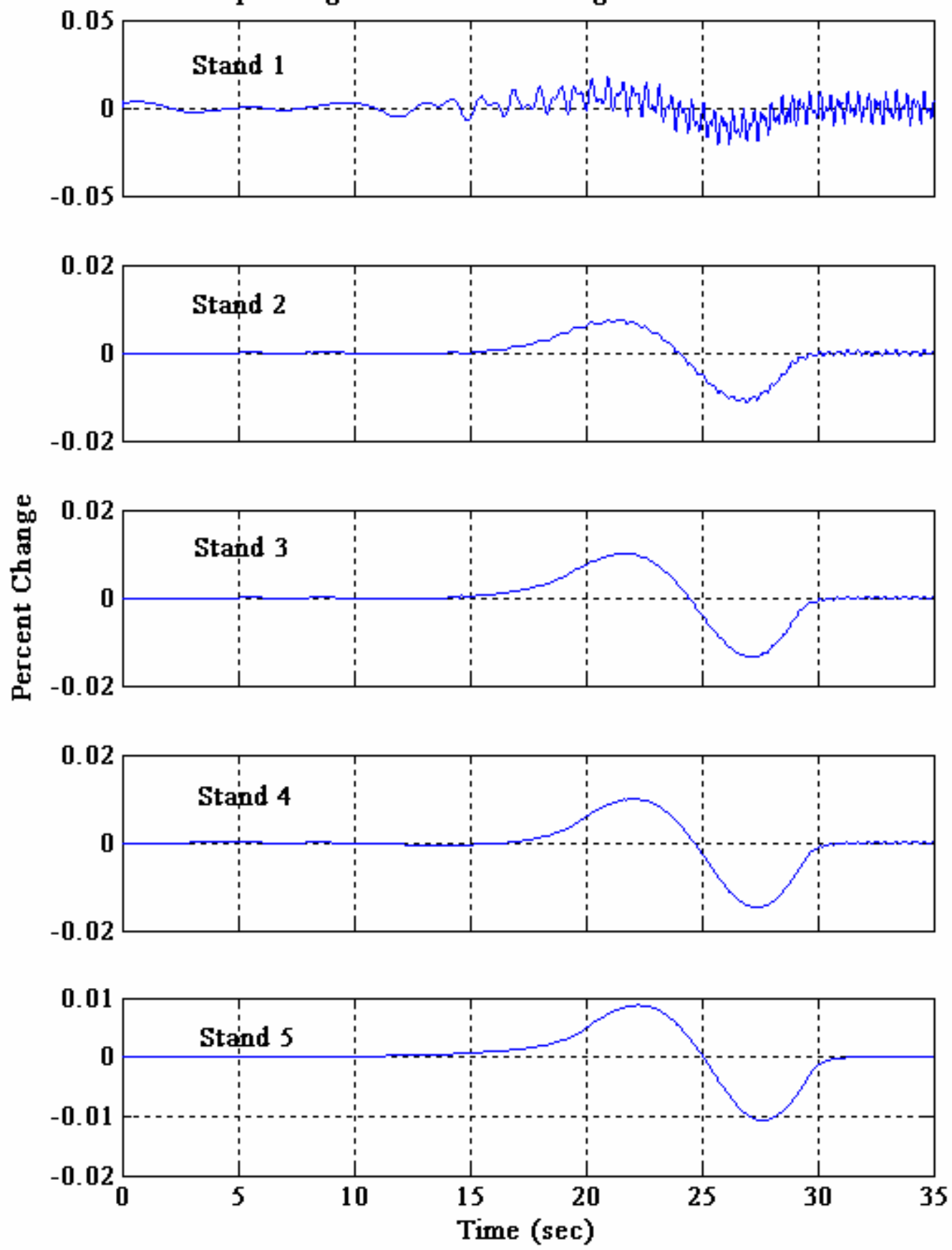

Figure 44 Percent Changes in Stand Output Thicknesses from Operating Point Values During Mill Acceleration, with Mill Entry Disturbances, without Uncertainties or Eccentricities, Using Operating Point 1 

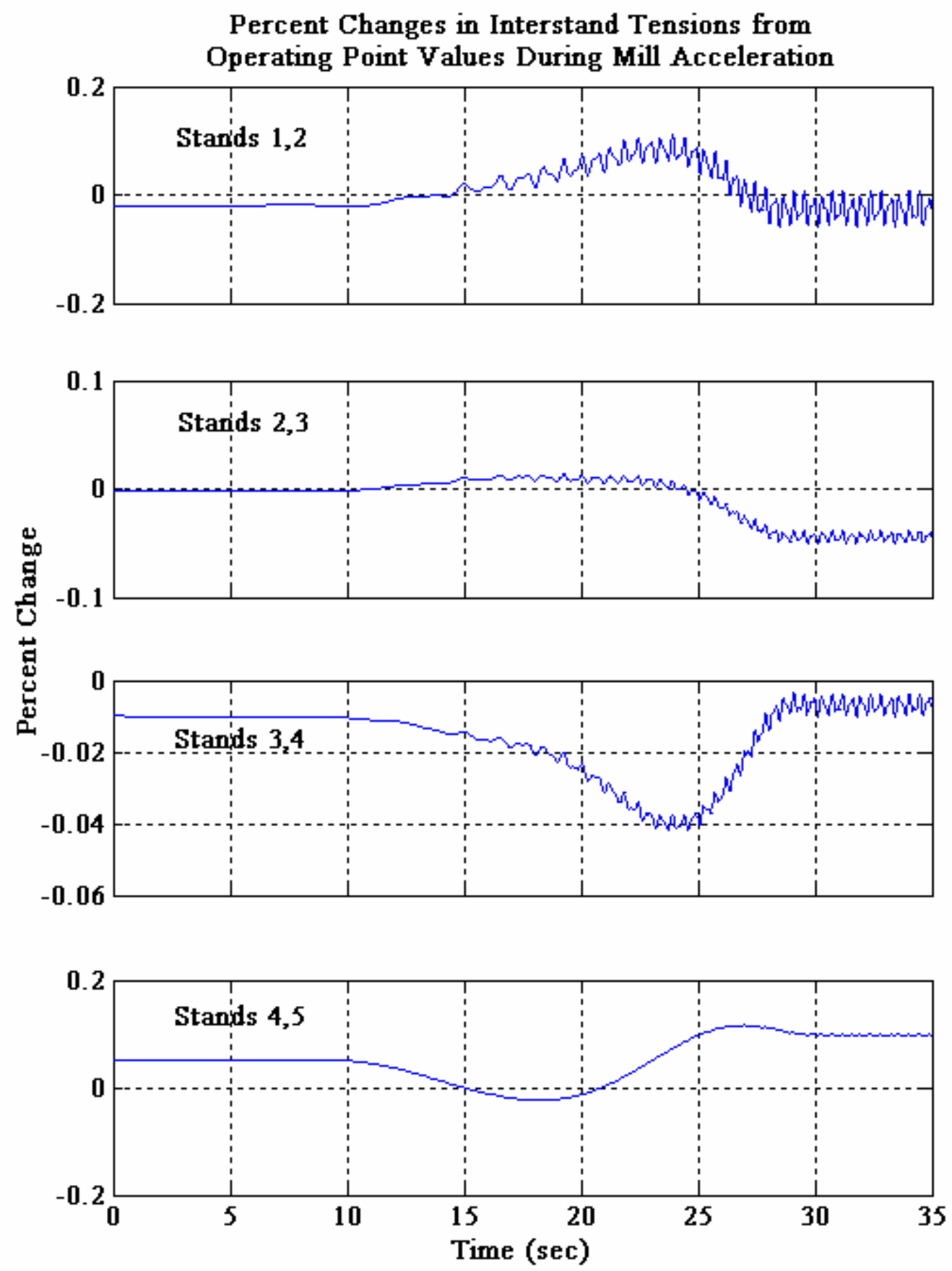

Figure 45 Percent Changes in Interstand Tensions from Operating Point Values During Mill Acceleration, with Mill Entry Disturbances, without Uncertainties or Eccentricities, Using Operating Point 1 
The previous simulations were repeated with the uncertainties in the model (Table 41) and the uncertainties in the measurements (Table 42) applied concurrently with each other and concurrently with the disturbances, with no eccentricities, and in a manner that produced the approximate maximum credible excursion in mill exit thickness. Where the combination of disturbances and uncertainties had an insignificant effect on the mill exit thickness, they were combined to cause the greatest credible excursion in the individual stand exit thickness or the associated interstand tension, whichever was considered worse. The following describes more specifically how the disturbances and uncertainties were applied.

The modeling uncertainty in the mill modulus $M$ at each stand was taken to vary from $0 \%$ to $-10 \%[50,53]$ during the processing of a single typical coil (72 inch diameter) at the mill exit. This uncertainty was assumed to vary as a function of strip distance at the exit of stand 1 as depicted in Figure 46, and similarly for stands 2, 3, 4, and 5. The modeling uncertainty in the coefficient of friction $\mu$ was assumed to vary from $0 \%$ to $20 \%$ [6] during processing of the same

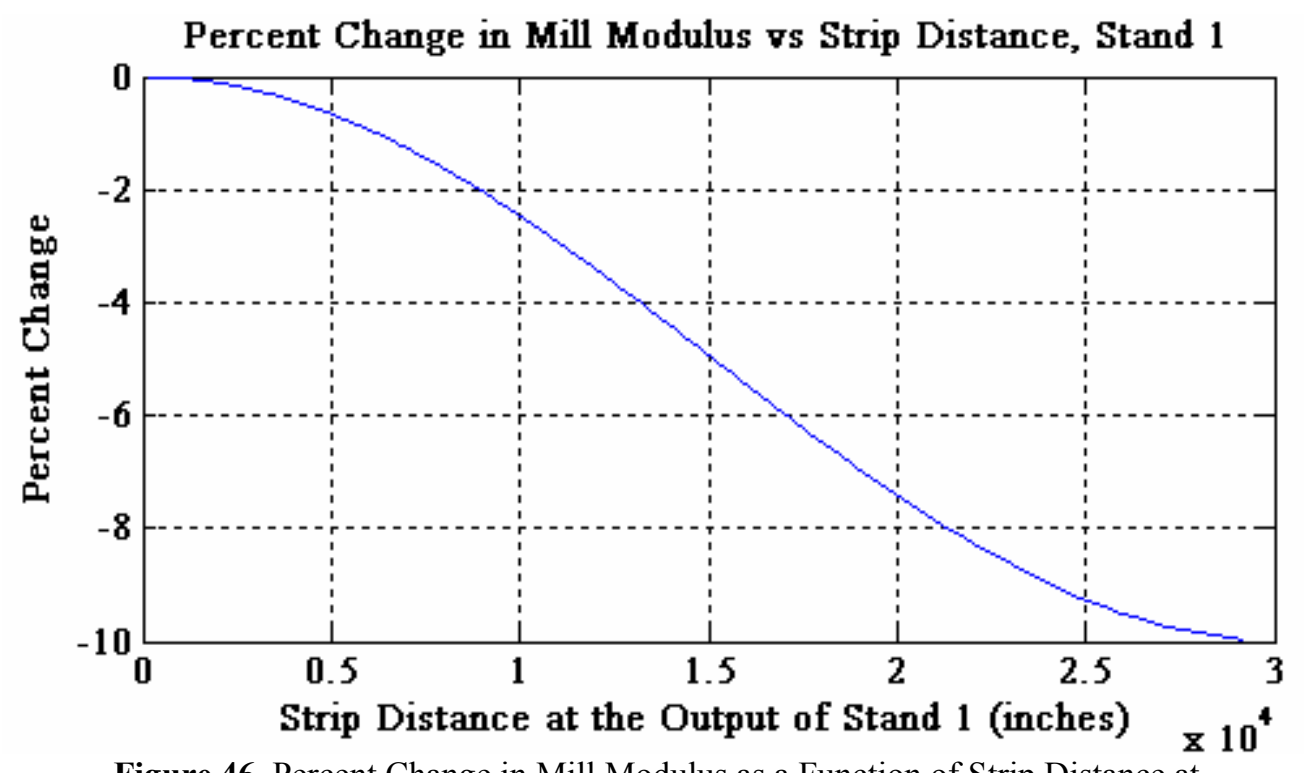

Figure 46 Percent Change in Mill Modulus as a Function of Strip Distance at the Output of Stand 1 
coil. The effects of this uncertainty were insignificant (less than $.001 \%$ ) during simulation of closed loop control and therefore were taken as negligible. The modeling uncertainty in the mean compressive yield stress $\bar{k}$ of the strip was assumed to vary the same as the disturbance in $\bar{k}$ so that the maximum change in $\bar{k}$ of the strip at the mill entry is about $50 \%$ (i.e., $25 \%$ from the disturbance plus $25 \%$ from the modeling uncertainty).

An uncertainty in the measurement of total roll force $F$ was derived from typical manufacturer's data [59] considering linearity, repeatability, and hysteresis over the calibrated span of operation. This uncertainty, with a peak of $0.2 \%$, is assumed to change similarly to the change in total roll force caused by the mill entry disturbances, except that the uncertainty is applied at a time such that, when combined with the mill entry disturbances, the magnitude in the deviation in stand 1 exit thickness is approximately maximized. The uncertainty in the measurement of the strip tension force $T$ is not significant since larger deviations in the interstand tensions from their desired operating points can be tolerated. The uncertainties in position actuator position $S$ and in work roll linear speed $V$ had insignificant effects during the closed loop simulations and therefore were considered negligible. The uncertainties in the laser speed measurements $V_{i n, i}$ and $V_{\text {out } 5}$ were assumed to change instantaneously independent of mill operation. This assumption is made since, in accordance with discussions with manufacturer's engineers, an estimate of how fast the uncertainty in this measurement could change is typically proprietary information [45]. Using (3-33) the output thickness of stand 2, 3, or 4 is expressed as

$$
h_{\text {out }, i}=\frac{h_{\text {in, } i}\left(V_{i n, i}+\delta V_{\text {in }, i}\right)}{\left(V_{\text {in }, i+1}+\delta V_{i n, i+1}\right)} k_{i, e}, \quad(i=2,3,4),
$$


where $\delta V_{i n, i}$ and $\delta V_{i n, i+1}$ are the deviations in $V_{i n, i}$ and $V_{i n, i+1}$ due to errors in the measurements of these strip speeds. Thus for stands 2,3 , and 4, the magnitude of the maximum error in the estimate of a stand output thickness due to $\delta V_{i n, i}$ and $\delta V_{i n, i+1}$ is about $.05 \%$, based on an uncertainty of $.025 \%$ [45] in the measurement of $V_{i n, i}$ and $V_{i n, i+1}$. In the case of stand 5, the output thickness is expressed using (3-32) as

$$
h_{\text {out } 5}=\frac{h_{\text {in } 5}\left(V_{\text {in } 5}+\delta V_{\text {in } 5}\right)}{\left(V_{\text {out } 5}+\delta V_{\text {out } 5}\right)} k_{5 e} \text {, }
$$

where $\delta V_{\text {in } 5}$ and $\delta V_{\text {out } 5}$ are the deviations in $V_{\text {in } 5}$ and $V_{\text {out } 5}$ due to errors in the measurements of these strip speeds. The maximum steady-state error is zero since the errors in the speed estimates are inside a closed loop. The magnitude of the maximum transient deviation in the stand 5 output thickness is determined assuming that the errors in $V_{\text {in } 5}$ and $V_{\text {out } 5}$, due to uncertainties in the

Table 50 Magnitudes of Maximum Percent Deviations of Stand Exit Thicknesses and Interstand Tension Stresses, with Disturbances and Uncertainties, without Eccentricities, Using Operating Point 1

\begin{tabular}{|c|c|c|c|c|}
\hline \multirow[b]{2}{*}{ Variable } & \multicolumn{4}{|c|}{$\begin{array}{l}\text { Magnitude of Maximum Percent Deviation of } \\
\text { Variable from Operating Point Value }\end{array}$} \\
\hline & $\begin{array}{l}100 \% \\
\text { Speed }\end{array}$ & $\begin{array}{c}\mathbf{5 \%} \\
\text { Speed }\end{array}$ & $\begin{array}{l}\text { Decel from } \\
100 \% \text { to } 5 \% \\
\text { Speed }\end{array}$ & $\begin{array}{c}\text { Accel from } \\
5 \% \text { to } 100 \% \\
\text { Speed }\end{array}$ \\
\hline$h_{\text {out } 1}$ & $.161 \%$ & $.020 \%$ & $.141 \%$ & $.101 \%$ \\
\hline$h_{\text {out } 2}$ & .073 & .051 & .062 & .071 \\
\hline$h_{\text {out } 3}$ & .084 & .051 & .082 & .074 \\
\hline$h_{\text {out } 4}$ & .082 & .052 & .063 & .083 \\
\hline$h_{\text {out } 5}$ & .077 & .051 & .074 & .072 \\
\hline$\sigma_{12}$ & $.18 \%$ & $.02 \%$ & $.15 \%$ & $.02 \%$ \\
\hline$\sigma_{23}$ & .05 & .00 & .05 & .05 \\
\hline$\sigma_{34}$ & .10 & .02 & .10 & .10 \\
\hline$\sigma_{45}$ & .22 & .06 & .11 & .17 \\
\hline
\end{tabular}


speed measurements, both change at the same time, and additionally are assumed to occur at a time such that, when combined with the disturbances, cause the magnitude of the mill output thickness to be approximately maximized. Under the above assumptions, simulations were performed with the mill entry disturbances applied simultaneously with the modeling and measurement uncertainties. The results are summarized in Table 50.

The interstand tensions of Operating Point 1 are sufficient to keep the strip from breaking or becoming slack. However, if the control strategy is to be useful for control of strip shape a pattern of interstand tensions as given in Production Schedule 1 (Table 2) is more desireable. As part of the simulation, with mill entry disturbances and uncertainties applied, an attempt was made to realize these tensions by shifting the operating point from Operating Point 1 to Production Schedule 1 by changing the values of the variables represented by elements $x_{o p, i}$ $(i=1,2,3,4)$ of the vector $x_{o p}$. This attempt was successful, so that the desired interstand tensions

Table 51 Magnitudes of Maximum Percent Deviations of Stand Exit Thicknesses and Interstand Tension Stresses, with Disturbances and Uncertainties, without Eccentricities, Using Production Schedule 1

\begin{tabular}{|c|c|c|c|c|}
\hline \multirow[b]{2}{*}{ Variable } & \multicolumn{4}{|c|}{$\begin{array}{l}\text { Magnitude of Maximum Percent Deviation of } \\
\text { Variable from Operating Point Value }\end{array}$} \\
\hline & $\begin{array}{l}100 \% \\
\text { Speed }\end{array}$ & $\begin{array}{c}5 \% \\
\text { Speed }\end{array}$ & $\begin{array}{l}\text { Decel from } \\
100 \% \text { to } 5 \% \\
\text { Speed } \\
\end{array}$ & $\begin{array}{c}\text { Accel from } \\
5 \% \text { to } 100 \% \\
\text { Speed }\end{array}$ \\
\hline$h_{\text {out } 1}$ & $.160 \%$ & $.020 \%$ & $.141 \%$ & $.100 \%$ \\
\hline$h_{\text {out } 2}$ & .073 & .051 & .062 & .072 \\
\hline$h_{\text {out } 3}$ & .079 & .051 & .075 & .068 \\
\hline$h_{\text {out } 4}$ & .081 & .052 & .063 & .079 \\
\hline$h_{\text {out } 5}$ & .072 & .058 & .074 & .071 \\
\hline$\sigma_{12}$ & $.26 \%$ & $.04 \%$ & $.20 \%$ & $.45 \%$ \\
\hline$\sigma_{23}$ & .12 & .02 & .11 & .21 \\
\hline$\sigma_{34}$ & .21 & .02 & .20 & .41 \\
\hline$\sigma_{45}$ & .09 & .02 & .04 & .15 \\
\hline
\end{tabular}


were achieved, but with values of forward slips somewhat different from those given in Bryant [1]. The results of the simulation are summarized in Table 51, which shows the interstand tensions held to within . $5 \%$ and the stand output thicknesses held to within $.08 \%$, consistent with Operating Point 1. The dynamic responses for Production Schedule 1 are similar to those using Operating Point 1 . The shift in the operating point was made with no changes in the settings for Operating Point 1 (Table 46) or in the settings of $K_{i, i+1}$ for the gains of the interstand tension operating point trims. Shifting from Operating Point 1 to various other production schedules are made similarly and several such shifts were simulated successfully.

As can be seen from Table 50 and Table 51, the magnitude of the maximum change in the mill exit thickness due to the combined effects of the mill entry disturbances and the uncertainties is about $.08 \%$. This entry and the other entries presented in these tables are taken as the maximum excursions in the listed variables based on the previously noted assumptions related to the uncertainties. Because several conditions must happen simultaneously for all these assumptions to be valid, it is considered that the excursions occurring most often in actual operation will be less than (possibly about one-half) those presented in Table 50 and Table 51. Thus the entries of these tables, and similarly the entries of Table 54, Table 55, Table 59 and Table 60, can provide a conservative basis for comparison with other techniques for control of the tandem cold mill. 


\subsection{CLOSED LOOP SIMULATIONS USING OPERATING POINT 2}

The closed loop simulations performed using Operating Point 1 with no disturbances applied, no uncertainties, no eccentricities, and with the interstand tension operating point trims enabled, were repeated using Operating Point 2 (Table 4). For these simulations, the settings given for Operating Point 1 in Table 46 for $K_{I, i}, K_{P, i}, K_{g_{-} i n t 1}, K_{g_{-} i n t 5}$, and the settings of $K_{i, i+1}$ for the gain of the interstand tension operating point trims, were retained for Operating Point 2. The magnitudes of the maximum deviations in strip thicknesses and interstand tensions are summarized in Table 52. As shown in Table 52, the results are similar to those obtained with Operating Point 1 (Table 48). The simulations performed using Operating Point 2 were then repeated except with the mill entry disturbances applied. The results are presented in Figure 47 through Figure 54. The

Table 52 Magnitudes of Maximum Percent Deviations of Stand Exit Thicknesses and Interstand Tension Stresses, without Disturbances, Uncertainties, or Eccentricities, Using Operating Point 2

\begin{tabular}{|c|c|c|c|c|}
\cline { 2 - 5 } \multicolumn{1}{c|}{} & \multicolumn{4}{c|}{$\begin{array}{c}\text { Magnitude of Maximum Percent Deviation } \\
\text { of Variable from Operating Point Value }\end{array}$} \\
\hline \multirow{2}{*}{ Variable } & $\begin{array}{c}\mathbf{1 0 0 \%} \\
\text { Speed }\end{array}$ & $\begin{array}{c}\mathbf{5 \%} \\
\text { Speed }\end{array}$ & $\begin{array}{c}\text { Decel from } \\
\mathbf{1 0 0 \%} \text { to 5\% } \\
\text { Speed }\end{array}$ & $\begin{array}{c}\text { Accel from } \\
\mathbf{5 \%} \text { to 100\% } \\
\text { Speed }\end{array}$ \\
\hline$h_{\text {out } 1}$ & $0 \%$ & $0 \%$ & $<.003 \%$ & $<.003 \%$ \\
\hline$h_{\text {out } 2}$ & 0 & 0 & $<.003$ & $<.003$ \\
\hline$h_{\text {out } 3}$ & 0 & 0 & $<.003$ & $<.003$ \\
\hline$h_{\text {out } 4}$ & 0 & 0 & $<.003$ & $<.003$ \\
\hline$h_{\text {out } 5}$ & 0 & 0 & $<.003$ & $<.003$ \\
\hline$\sigma_{12}$ & $.06 \%$ & $.02 \%$ & $.07 \%$ & $.08 \%$ \\
\hline$\sigma_{23}$ & .12 & .00 & .13 & .13 \\
\hline$\sigma_{34}$ & .13 & .00 & .14 & .14 \\
\hline$\sigma_{45}$ & .09 & .04 & .25 & .23 \\
\hline
\end{tabular}


magnitudes of the maximum deviations in strip thicknesses and interstand tensions are summarized in Table 53. As shown in these figures and in Table 53, the results also are similar to those obtained with Operating Point 1 (Figure 38 through Figure 45, and Table 49).

Table 53 Magnitudes of Maximum Percent Deviations of Stand Exit Thicknesses and Interstand Tensions, with Mill Entry Disturbances, without Uncertainties or Eccentricities, Using Operating Point 2

\begin{tabular}{|c|c|c|c|c|}
\hline \multirow[b]{2}{*}{ Variable } & \multicolumn{4}{|c|}{$\begin{array}{l}\text { Magnitude of Maximum Percent Deviation } \\
\text { of Variable from Operating Point Value }\end{array}$} \\
\hline & $\begin{array}{l}100 \% \\
\text { Speed }\end{array}$ & $\begin{array}{c}5 \% \\
\text { Speed }\end{array}$ & $\begin{array}{l}\text { Decel from } \\
100 \% \text { to } 5 \% \\
\text { Speed }\end{array}$ & $\begin{array}{c}\text { Accel from } \\
5 \% \text { to } 100 \% \\
\text { Speed }\end{array}$ \\
\hline$h_{\text {out } 1}$ & $.025 \%$ & $.005 \%$ & $.025 \%$ & $.025 \%$ \\
\hline$h_{\text {out } 2}$ & .015 & $<.001$ & .011 & .010 \\
\hline$h_{\text {out } 3}$ & .019 & $<.001$ & .017 & .018 \\
\hline$h_{\text {out } 4}$ & .023 & $<.002$ & .019 & .023 \\
\hline$h_{\text {out } 5}$ & .015 & $<.001$ & .012 & .015 \\
\hline$\sigma_{12}$ & $.16 \%$ & $<.02 \%$ & $.14 \%$ & $.15 \%$ \\
\hline$\sigma_{23}$ & .13 & $<.01$ & .13 & .13 \\
\hline$\sigma_{34}$ & .14 & $<.01$ & .14 & .14 \\
\hline$\sigma_{45}$ & .13 & .04 & .25 & .24 \\
\hline
\end{tabular}




\section{Percent Changes in Stand Output Thicknesses from Operating Point Values at $100 \%$ Speed}
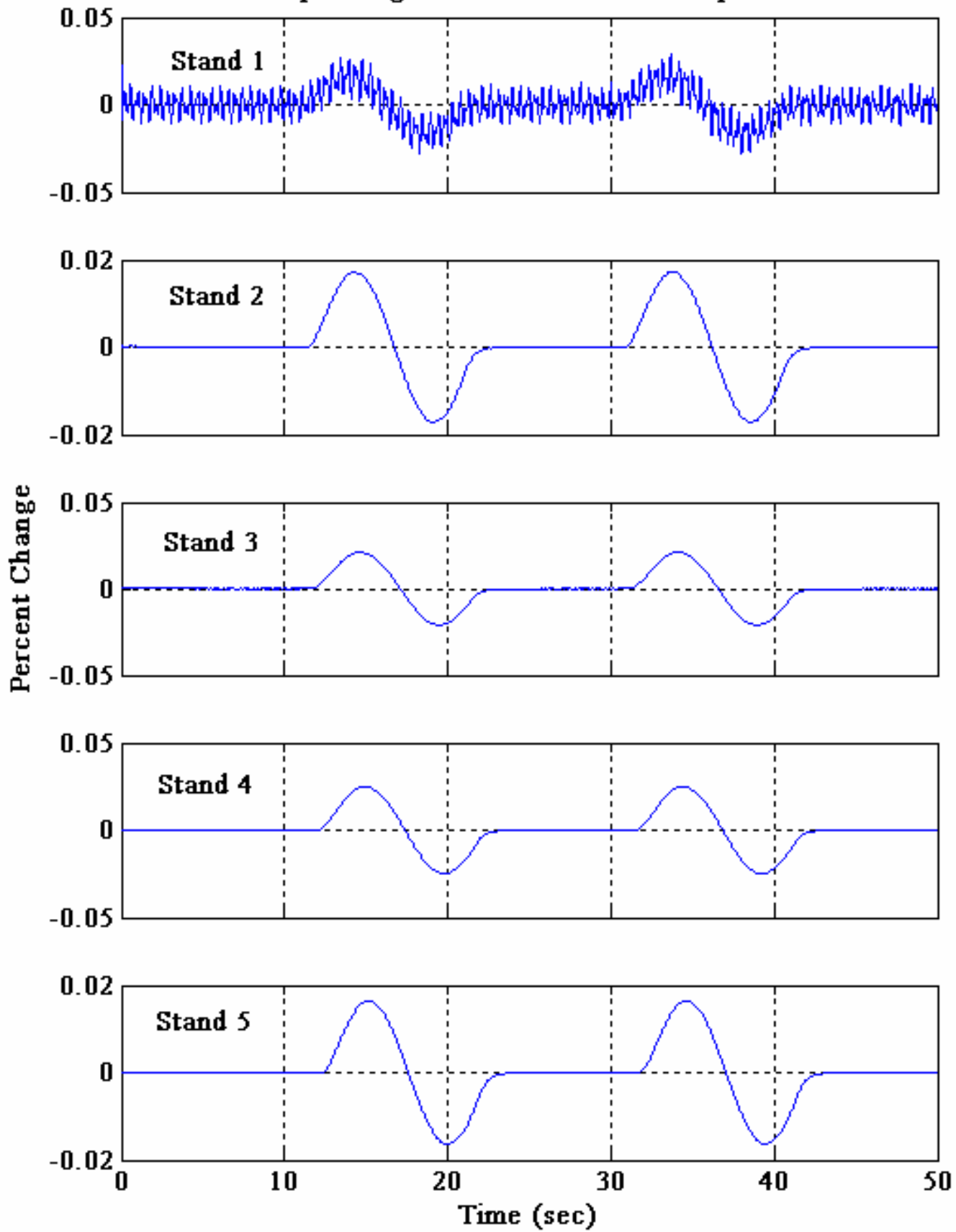

Figure 47 Percent Changes in Stand Output Thicknesses from Operating Point Values at $100 \%$ Speed, with Mill Entry Disturbances, without Uncertainties or Eccentricities, Using Operating Point 2 


\section{Percent Changes in Interstand Tensions from Operating Point Values at $100 \%$ Speed}
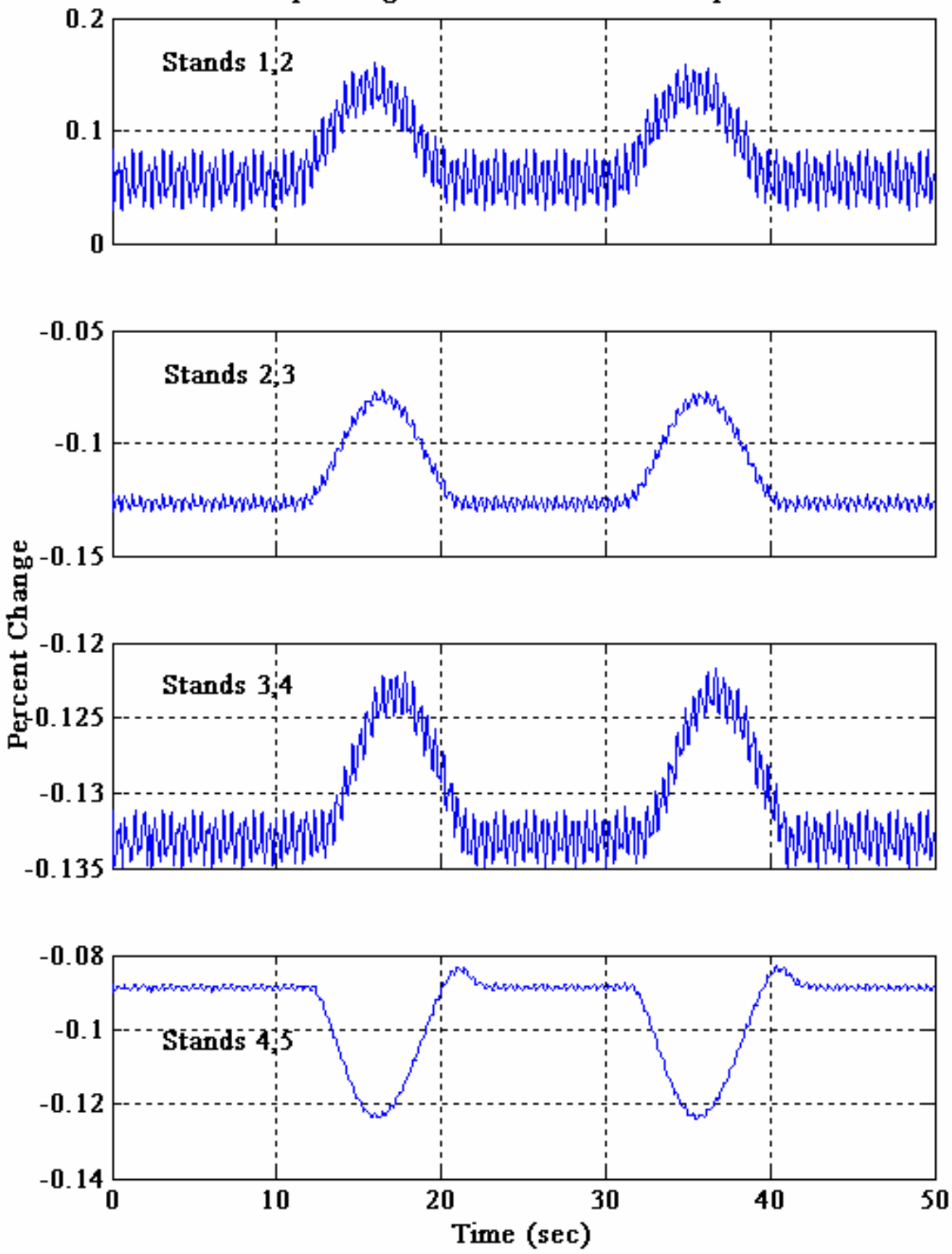

Figure 48 Percent Changes in Interstand Tensions from Operating Point Values at $100 \%$ Speed, with Mill Entry Disturbances, without Uncertainties or Eccentricities, Using Operating Point 2 

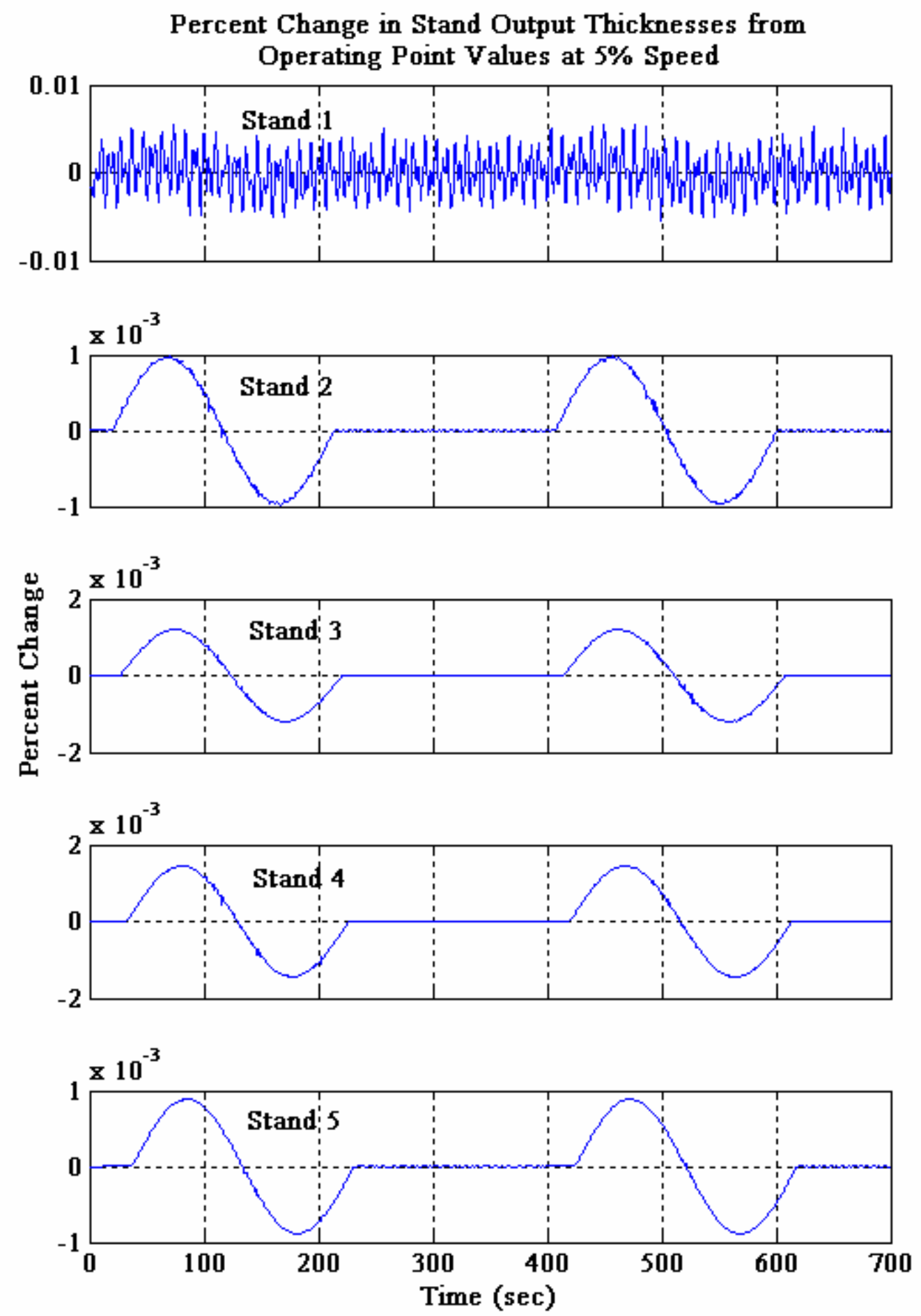

Figure 49 Percent Changes in Stand Output Thicknesses from Operating Point Values at 5\% Speed, with Mill Entry Disturbances, without Uncertainties or Eccentricities, Using Operating Point 2 

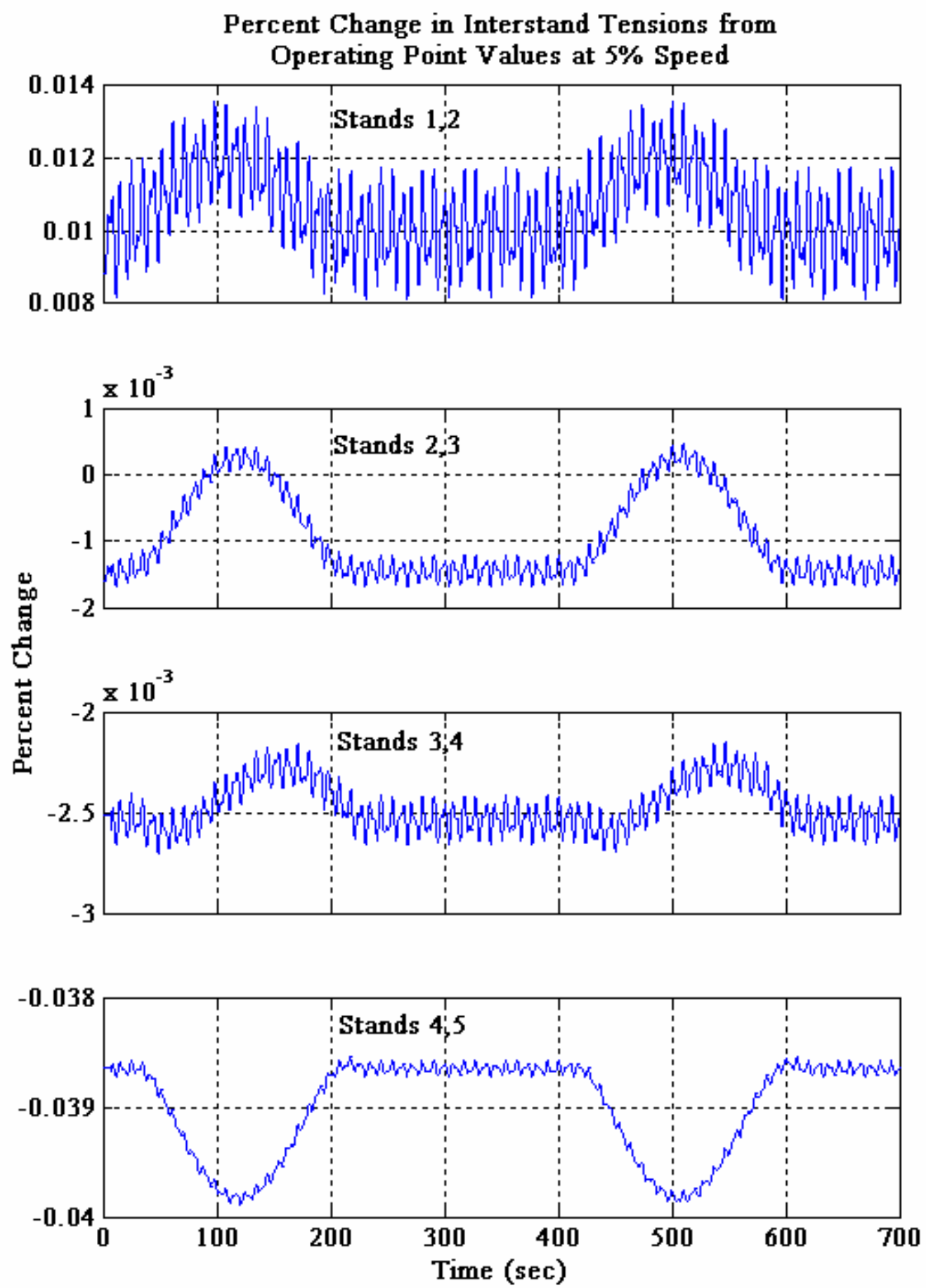

Figure 50 Percent Changes in Interstand Tensions from Operating Point Values at 5\% Speed, with Mill Entry Disturbances, without Uncertainties or Eccentricities, Using Operating Point 2 

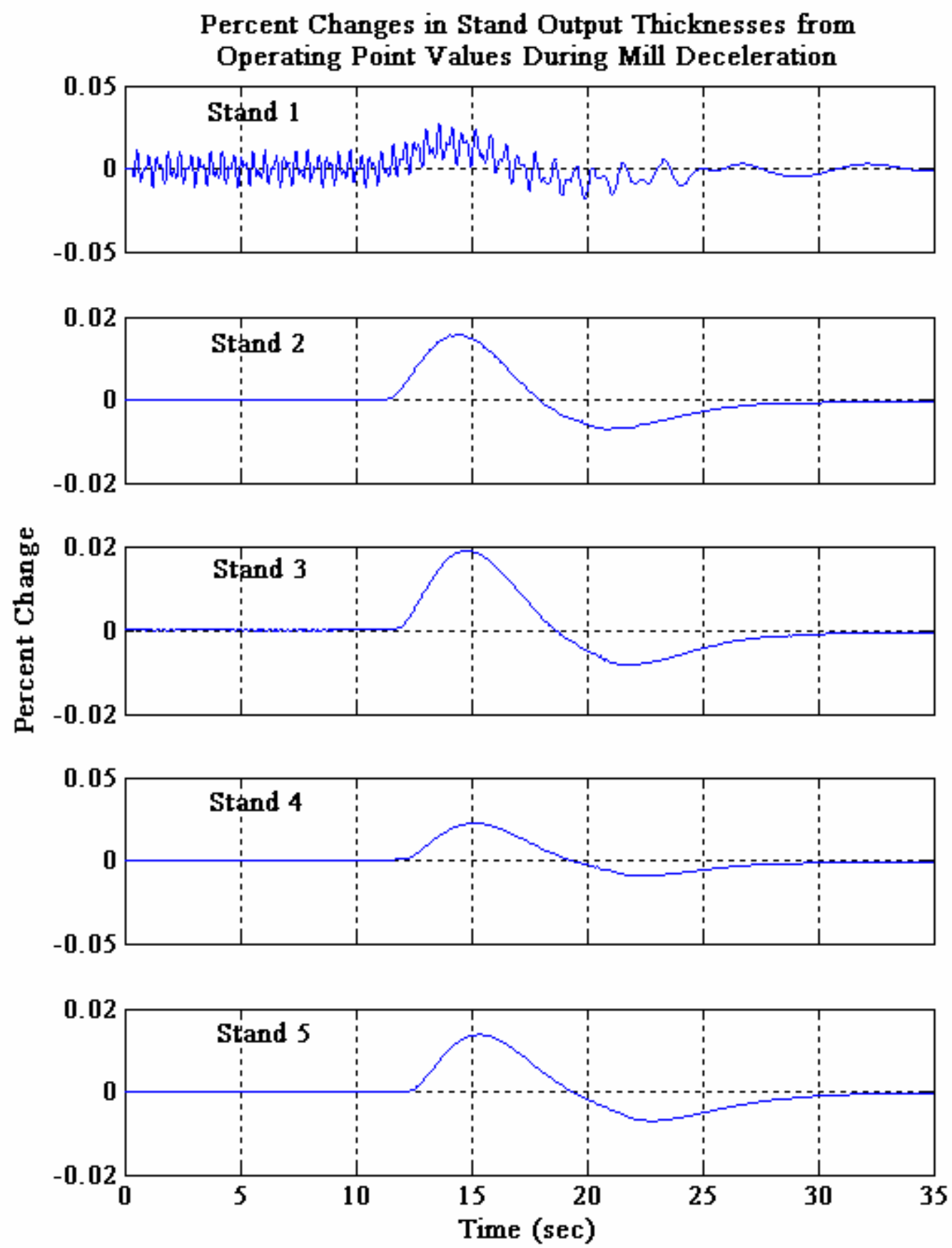

Figure 51 Percent Changes in Stand Output Thicknesses from Operating Point Values During Mill Deceleration, with Mill Entry Disturbances, without Uncertainties or Eccentricities, Using Operating Point 2 

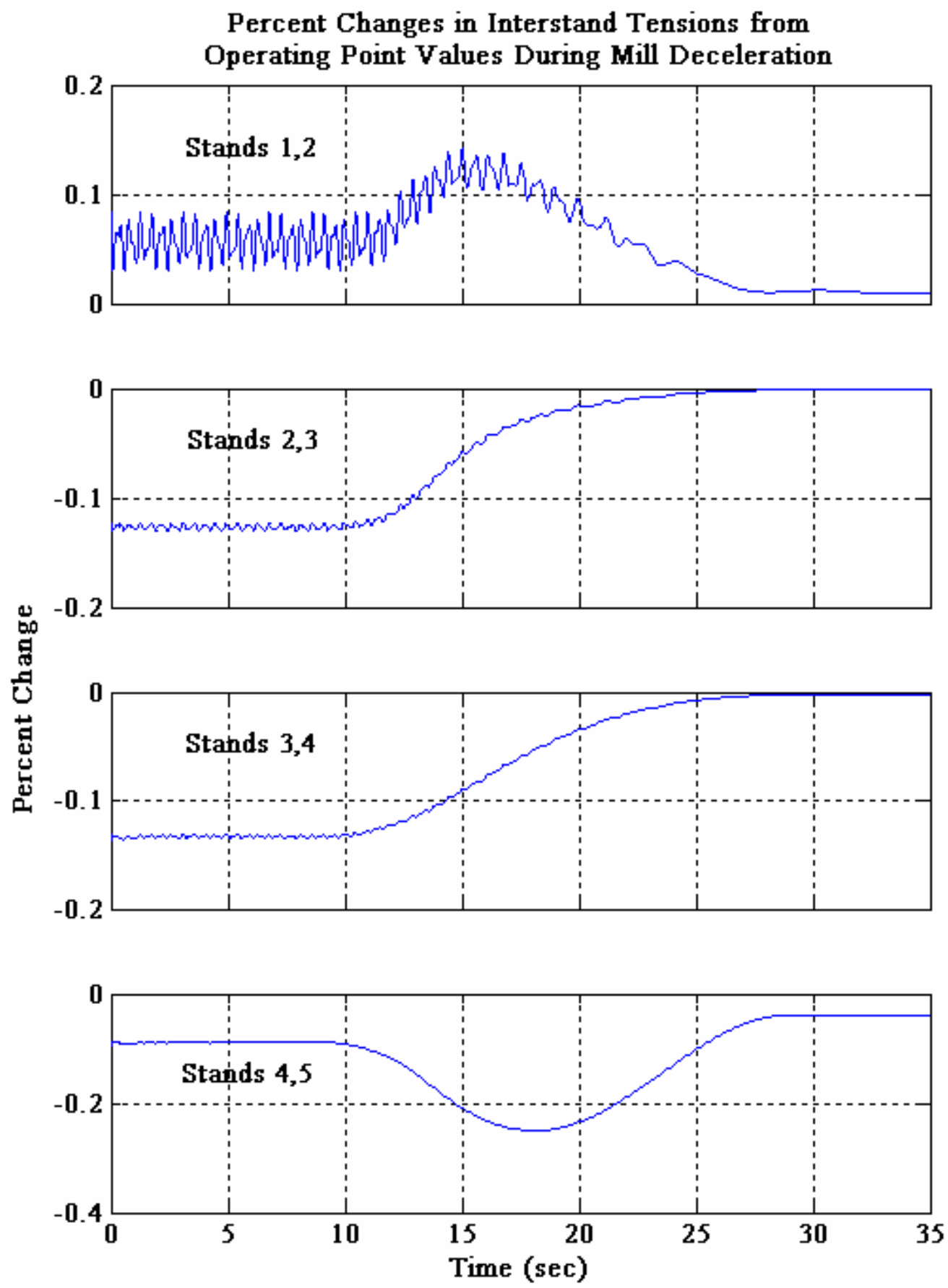

Figure 52 Percent Changes in Interstand Tensions from Operating Point Values During Mill Deceleration, with Mill Entry Disturbances, without Uncertainties or Eccentricities, Using Operating Point 2 

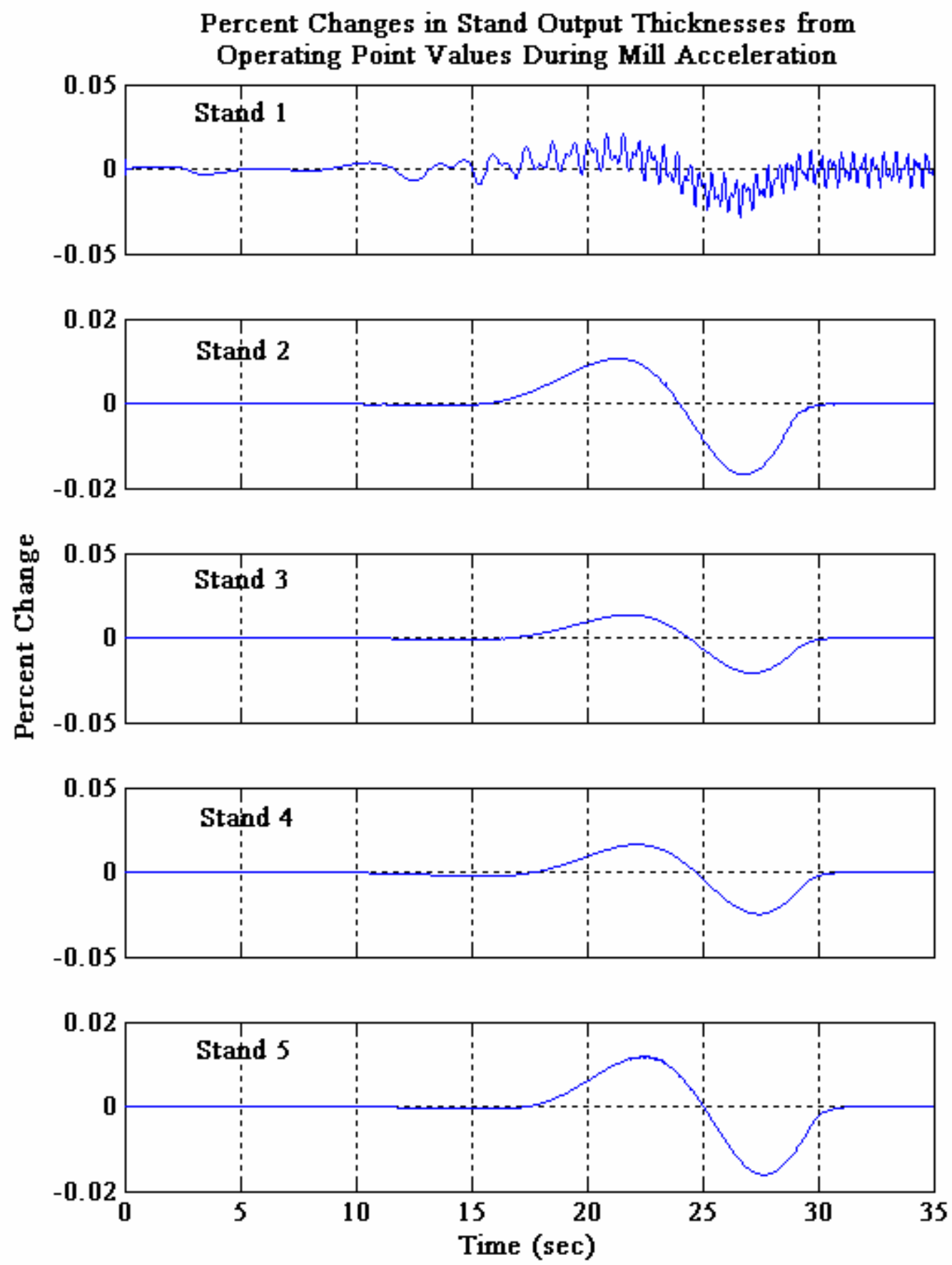

Figure 53 Percent Changes in Stand Output Thicknesses from Operating Point Values During Mill Acceleration, with Mill Entry Disturbances, without Uncertainties or Eccentricities, Using Operating Point 2 
Percent Change in Interstand Tensions from Operating Point Values During Mill Acceleration
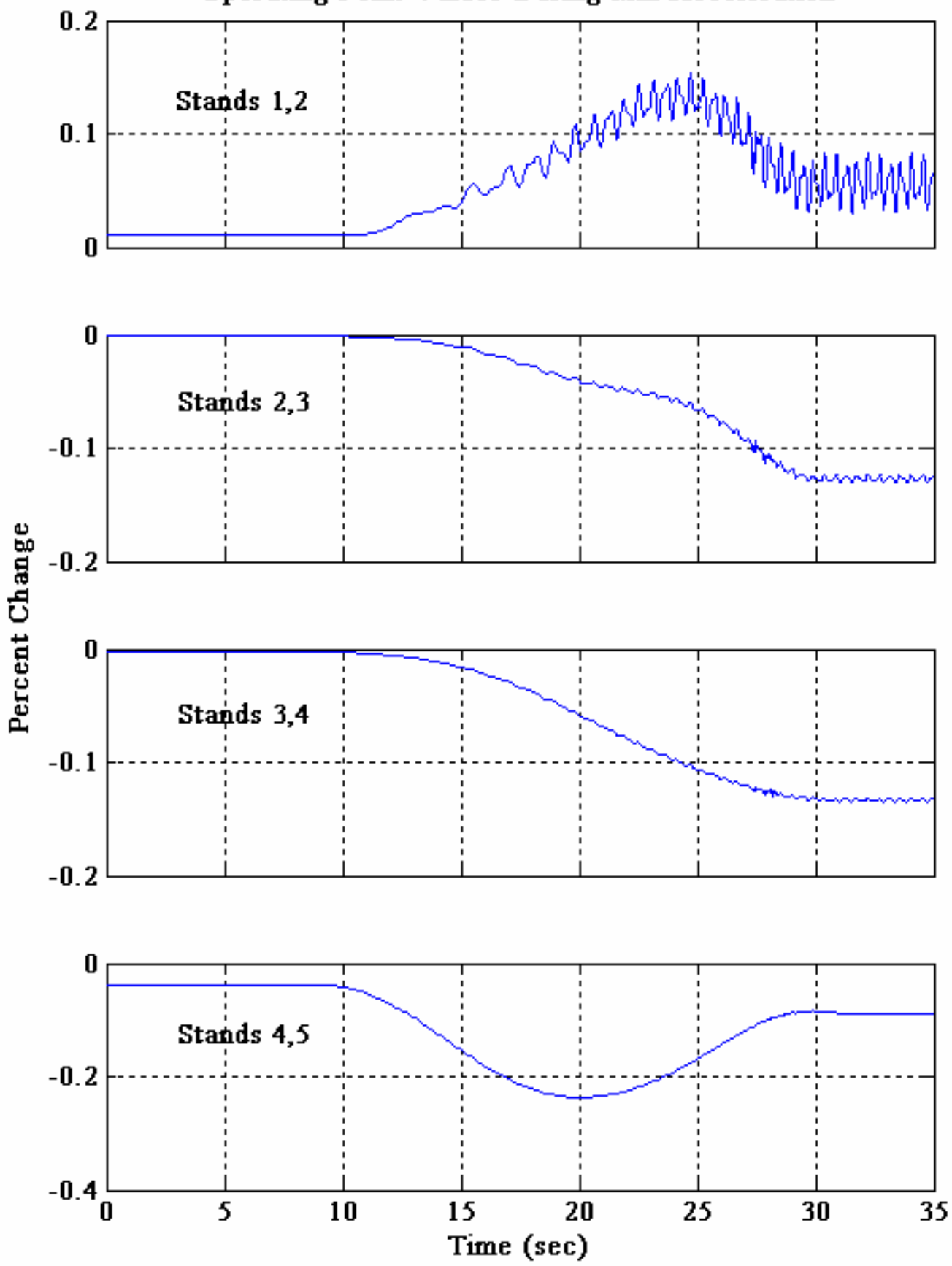

Figure 54 Percent Changes in Interstand Tensions from Operating Point Values During Mill Acceleration, with Mill Entry Disturbances, without Uncertainties or Eccentricities, Using Operating Point 2 
Using Operating Point 2, closed loop simulations were performed with the mill entry disturbances applied simultaneously with the modeling and measurement uncertainties, under the assumptions noted previously for similar simulations using Operating Point 1 . The results, as summarized in Table 54, are about the same as the results for Operating Point 1 as summarized in Table 50, with conclusions similar to the conclusions determined using Operating Point 1. Thus as shown by these simulation results, performance and robustness are nearly the same for Operating Point 1 and Operating Point 2. As in the case of Operating Point 1, the operating point

Table 54 Magnitudes of Maximum Percent Deviations of Stand Exit Thicknesses and Interstand Tension Stresses, with Disturbances and Uncertainties, without Eccentricities, Using Operating Point 2

\begin{tabular}{|c|c|c|c|c|}
\hline \multirow[b]{2}{*}{ Variable } & \multicolumn{4}{|c|}{$\begin{array}{l}\text { Magnitude of Maximum Percent Deviation of } \\
\text { Variable from Operating Point Value }\end{array}$} \\
\hline & $\begin{array}{l}100 \% \\
\text { Speed }\end{array}$ & $\begin{array}{c}5 \% \\
\text { Speed }\end{array}$ & $\begin{array}{l}\text { Decel from } \\
100 \% \text { to } 5 \% \\
\text { Speed }\end{array}$ & $\begin{array}{c}\text { Accel from } \\
5 \% \text { to } 100 \% \\
\text { Speed }\end{array}$ \\
\hline$h_{\text {out } 1}$ & $.210 \%$ & $.025 \%$ & $.200 \%$ & $.13 \%$ \\
\hline$h_{\text {out } 2}$ & .082 & .052 & .060 & .080 \\
\hline$h_{\text {out } 3}$ & .090 & .052 & .070 & .076 \\
\hline$h_{\text {out } 4}$ & .095 & .053 & .065 & .095 \\
\hline$h_{\text {out } 5}$ & .080 & .050 & .075 & .070 \\
\hline$\sigma_{12}$ & $.21 \%$ & $.02 \%$ & $.16 \%$ & $.18 \%$ \\
\hline$\sigma_{23}$ & .11 & .00 & .13 & .11 \\
\hline$\sigma_{34}$ & .17 & .00 & .16 & .17 \\
\hline$\sigma_{45}$ & .13 & .04 & .24 & .24 \\
\hline
\end{tabular}

at Operating Point 2 was then shifted to Production Schedule 2 (Table 2) to realize the interstand tensions desired for control of strip shape. The results of the simulation using Production Schedule 2 are given in Table 55. The shift in the operating point was made with no changes in the settings for Operating Point 2, and the dynamic responses using Production Schedule 2 are about the same as the dynamic responses using Operating Point 2. 
Table 55 Magnitudes of Maximum Percent Deviations of Stand Exit Thicknesses and Interstand Tension Stresses, with Disturbances and Uncertainties, without Eccentricities, Using Production Schedule 2

\begin{tabular}{|c|c|c|c|c|}
\cline { 2 - 5 } \multicolumn{1}{c|}{} & \multicolumn{4}{c|}{$\begin{array}{c}\text { Magnitude of Maximum Percent Deviation of } \\
\text { Variable from Operating Point Value }\end{array}$} \\
\hline \multirow{2}{*}{ Variable } & $\begin{array}{c}\mathbf{1 0 0 \%} \\
\text { Speed }\end{array}$ & $\begin{array}{c}\mathbf{5 \%} \\
\text { Speed }\end{array}$ & $\begin{array}{c}\text { Decel from } \\
\mathbf{1 0 0 \%} \\
\text { Speed }\end{array}$ & $\begin{array}{c}\text { Accel from } \\
\mathbf{5 \%} \text { to 100\% } \\
\text { Speed }\end{array}$ \\
\hline$h_{\text {out } 1}$ & $.221 \%$ & $.025 \%$ & $.210 \%$ & $.121 \%$ \\
\hline$h_{\text {out } 2}$ & .084 & .052 & .065 & .082 \\
\hline$h_{\text {out } 3}$ & .092 & .052 & .087 & .077 \\
\hline$h_{\text {out } 4}$ & .110 & .053 & .071 & .097 \\
\hline$h_{\text {out } 5}$ & .082 & .051 & .079 & .071 \\
\hline$\sigma_{I 2}$ & $.23 \%$ & $.02 \%$ & $.20 \%$ & $.22 \%$ \\
\hline$\sigma_{23}$ & .15 & .01 & .13 & .14 \\
\hline$\sigma_{34}$ & .15 & .00 & .15 & .16 \\
\hline$\sigma_{45}$ & .44 & .04 & .45 & .43 \\
\hline
\end{tabular}

\subsection{CLOSED LOOP SIMULATIONS USING OPERATING POINT 3}

The closed loop simulations using Operating Point 2 were repeated using Operating Point 3 (Table 4), except that the settings for $K_{I, i}$ and $K_{p, i}$ were as shown in Table 56 . For the case where there were no disturbances applied, with no eccentricities and no uncertainties, and with the interstand tension operating point trims enabled, the magnitudes of the maximum deviations in strip thicknesses and interstand tensions, as summarized in Table 57, are similar to the results obtained using Operating Point 1 and using Operating Point 2. The simulations using Operating Point 3 again were repeated except with the mill entry disturbances applied. The results are

Table 56 Parameter Settings for Operating Point 3

Parameter Setting Stand Number

$\begin{array}{lcl}K_{I, i} & 3700 & \text { Stand } i(i=1,2,3,4,5) \\ K_{P, i} & 1750 & \text { Stand } i(i=1,2,3,4,5) \\ K_{g_{\_} \text {int }} & .25 & \text { Stand } 1 \\ K_{g_{\_} \text {int }} & .50 & \text { Stand } 5\end{array}$


Table 57 Magnitudes of Maximum Percent Deviations of Stand Exit Thicknesses and Interstand Tension Stresses, without Disturbances,

Uncertainties, or Eccentricities, Using Operating Point 3

\begin{tabular}{|c|c|c|c|c|}
\cline { 2 - 5 } \multicolumn{1}{c|}{} & \multicolumn{4}{c|}{$\begin{array}{c}\text { Magnitude of Maximum Percent Deviation } \\
\text { of Variable from Operating Point Value }\end{array}$} \\
\hline \multirow{2}{*}{ Variable } & $\begin{array}{c}\mathbf{1 0 0 \%} \\
\text { Speed }\end{array}$ & $\begin{array}{c}\mathbf{5 \%} \\
\text { Speed }\end{array}$ & $\begin{array}{c}\text { Decel from } \\
\mathbf{1 0 0 \%} \text { to 5\% } \\
\text { Speed }\end{array}$ & $\begin{array}{c}\text { Accel from } \\
\mathbf{5 \%} \text { to 100\% } \\
\text { Speed }\end{array}$ \\
\hline$h_{\text {out } 1}$ & $0 \%$ & $0 \%$ & $<.001 \%$ & $<.001 \%$ \\
\hline$h_{\text {out } 2}$ & 0 & 0 & .002 & .002 \\
\hline$h_{\text {out } 3}$ & 0 & 0 & .002 & .002 \\
\hline$h_{\text {out } 4}$ & 0 & 0 & .004 & .004 \\
\hline$h_{\text {out } 5}$ & 0 & 0 & $<.001$ & $<.001$ \\
\hline$\sigma_{12}$ & $.02 \%$ & $<.01 \%$ & $.04 \%$ & $.03 \%$ \\
\hline$\sigma_{23}$ & .06 & $<.01$ & .06 & .06 \\
\hline$\sigma_{34}$ & .17 & $<.01$ & .18 & .17 \\
\hline$\sigma_{45}$ & .06 & .04 & .24 & .20 \\
\hline
\end{tabular}

presented in Figure 55 through Figure 62. The magnitudes of the maximum deviations in strip thickness and in interstand tensions are summarized in Table 58. As shown in these figures and in Table 58, the results are similar to those obtained with Operating Point 1 and to those obtained with Operating Point 2.

Table 58 Magnitudes of Maximum Percent Deviations of Stand Exit Thicknesses and Interstand Tensions, with Mill Entry Disturbances, without Uncertainties or Eccentricities, Using Operating Point 3

\begin{tabular}{|c|c|c|c|c|}
\hline \multirow[b]{2}{*}{ Variable } & \multicolumn{4}{|c|}{$\begin{array}{l}\text { Magnitude of Maximum Percent Deviation } \\
\text { of Variable from Operating Point Value }\end{array}$} \\
\hline & $\begin{array}{l}100 \% \\
\text { Speed }\end{array}$ & $\begin{array}{c}5 \% \\
\text { Speed }\end{array}$ & $\begin{array}{c}\text { Decel from } \\
100 \% \text { to } 5 \% \\
\text { Speed }\end{array}$ & $\begin{array}{c}\text { Accel from } \\
5 \% \text { to } 100 \% \\
\text { Speed }\end{array}$ \\
\hline$h_{\text {out } 1}$ & $.013 \%$ & $.006 \%$ & $.013 \%$ & $.017 \%$ \\
\hline$h_{\text {out } 2}$ & .014 & $<.001$ & .014 & .014 \\
\hline$h_{\text {out } 3}$ & .015 & $<.001$ & .014 & .015 \\
\hline$h_{\text {out } 4}$ & .020 & $<.001$ & .019 & .020 \\
\hline$h_{\text {out } 5}$ & .012 & $<.001$ & .010 & .012 \\
\hline$\sigma_{12}$ & $.06 \%$ & $<.01 \%$ & $.06 \%$ & $.06 \%$ \\
\hline$\sigma_{23}$ & .08 & $<.01$ & .06 & .07 \\
\hline$\sigma_{34}$ & .17 & $<.01$ & .18 & .18 \\
\hline$\sigma_{45}$ & .08 & .04 & .25 & .21 \\
\hline
\end{tabular}




\section{Percent Changes in Output Thicknesses from Operating Point Values at $100 \%$ Speed}

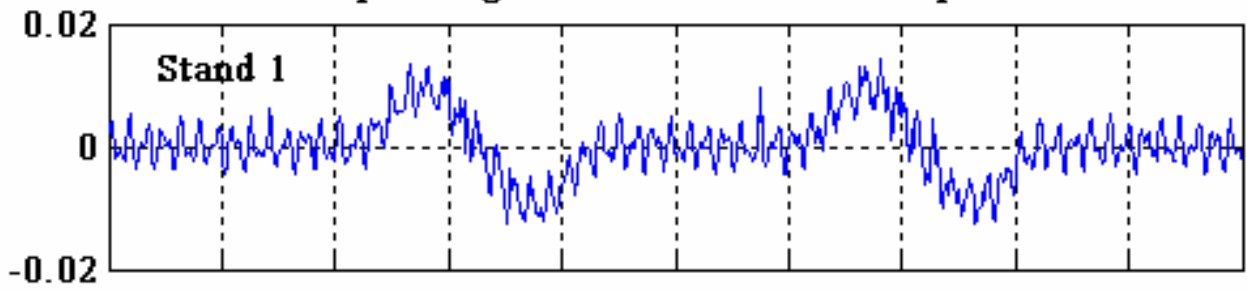

$-0.02$
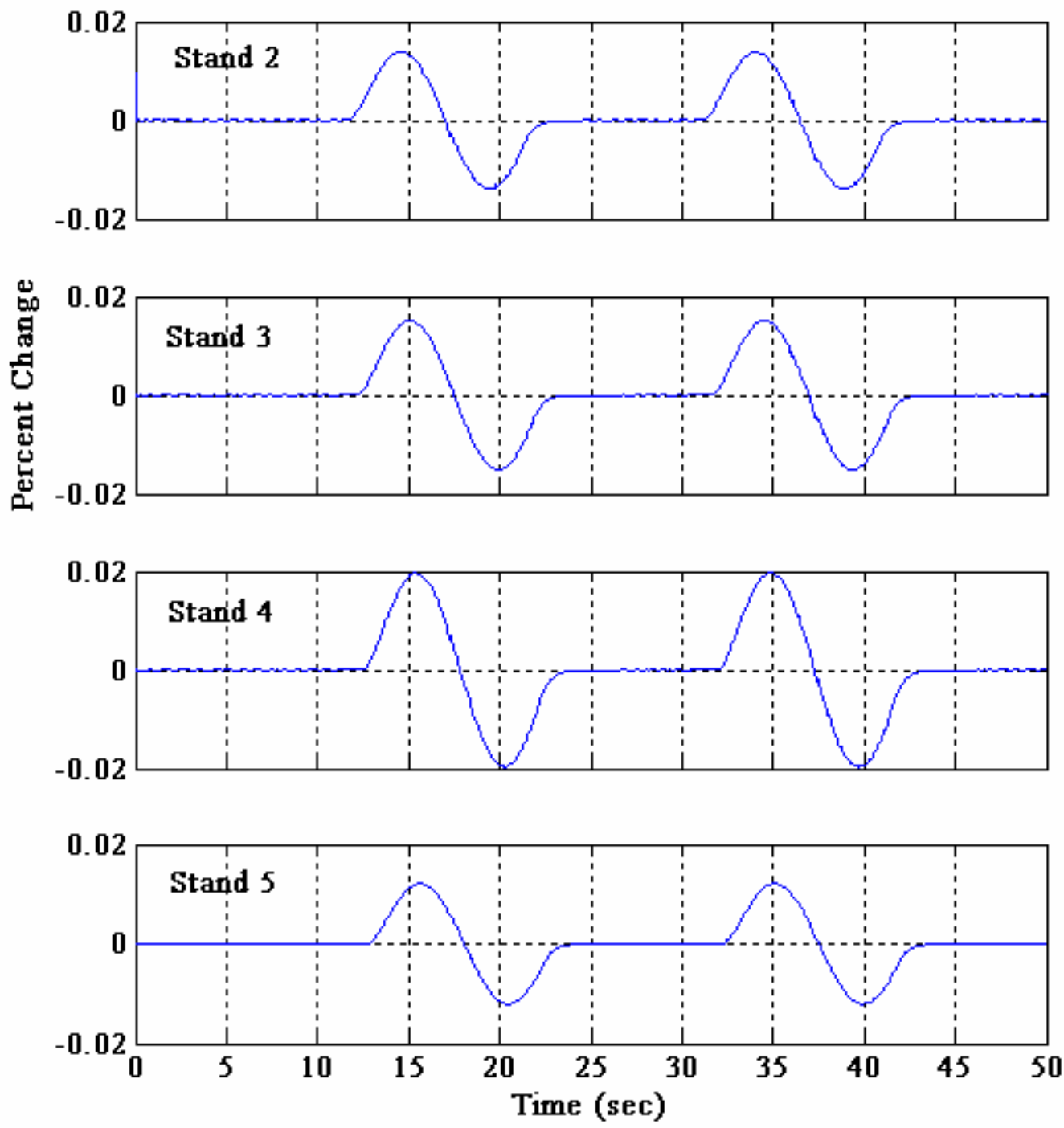

Figure 55 Percent Changes in Stand Output Thicknesses from Operating Point Values at $100 \%$ Speed, with Mill Entry Disturbances, without Uncertainties or Eccentricities, Using Operating Point 3 

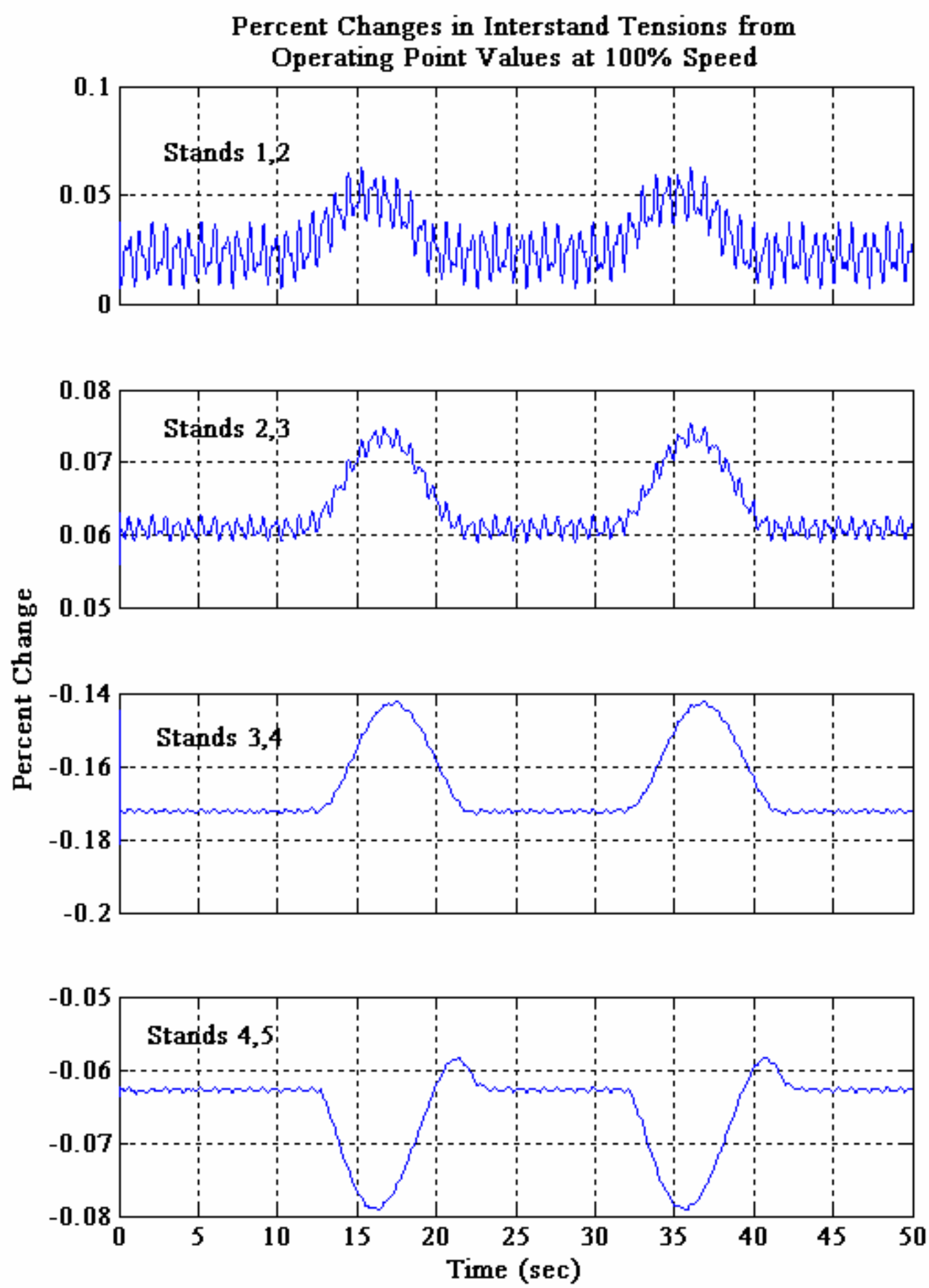

Figure 56 Percent Changes in Interstand Tensions from Operating Point Values at $100 \%$ Speed, with Mill Entry Disturbances, without Uncertainties or Eccentricities, Using Operating Point 3 

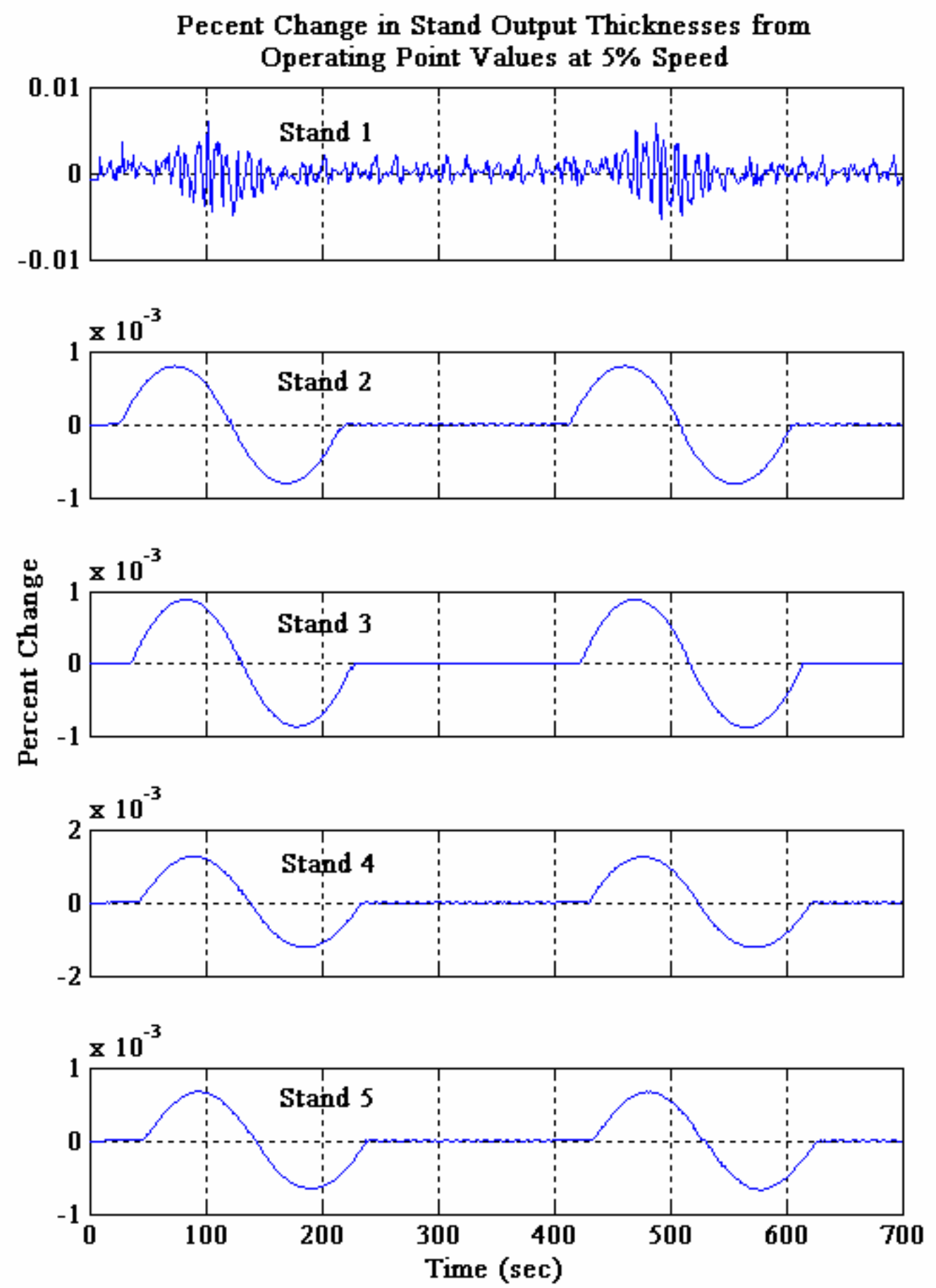

Figure 57 Percent Changes in Stand Output Thicknesses from Operating Point Values at 5\% Speed, with Mill Entry Disturbances, without Uncertainties or Eccentricities, Using Operating Point 3 

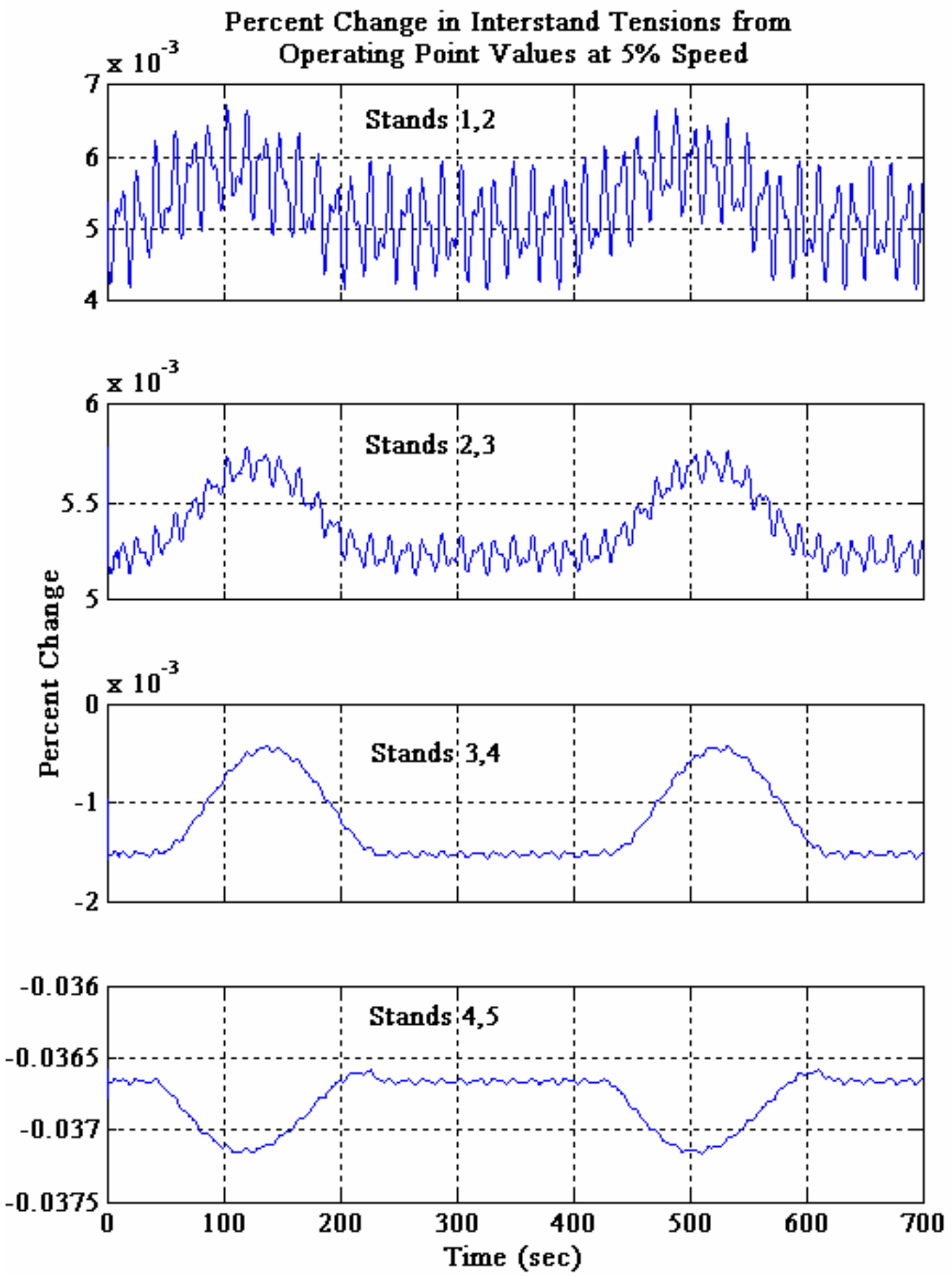

Figure 58 Percent Changes in Interstand Tensions from Operating Point Values at 5\% Speed, with Mill Entry Disturbances, without Uncertainties or Eccentricities, Using Operating Point 3 


\section{Percent Changes in Stand Output Thicknesses from Operating Point Values During Mill Deceleration}
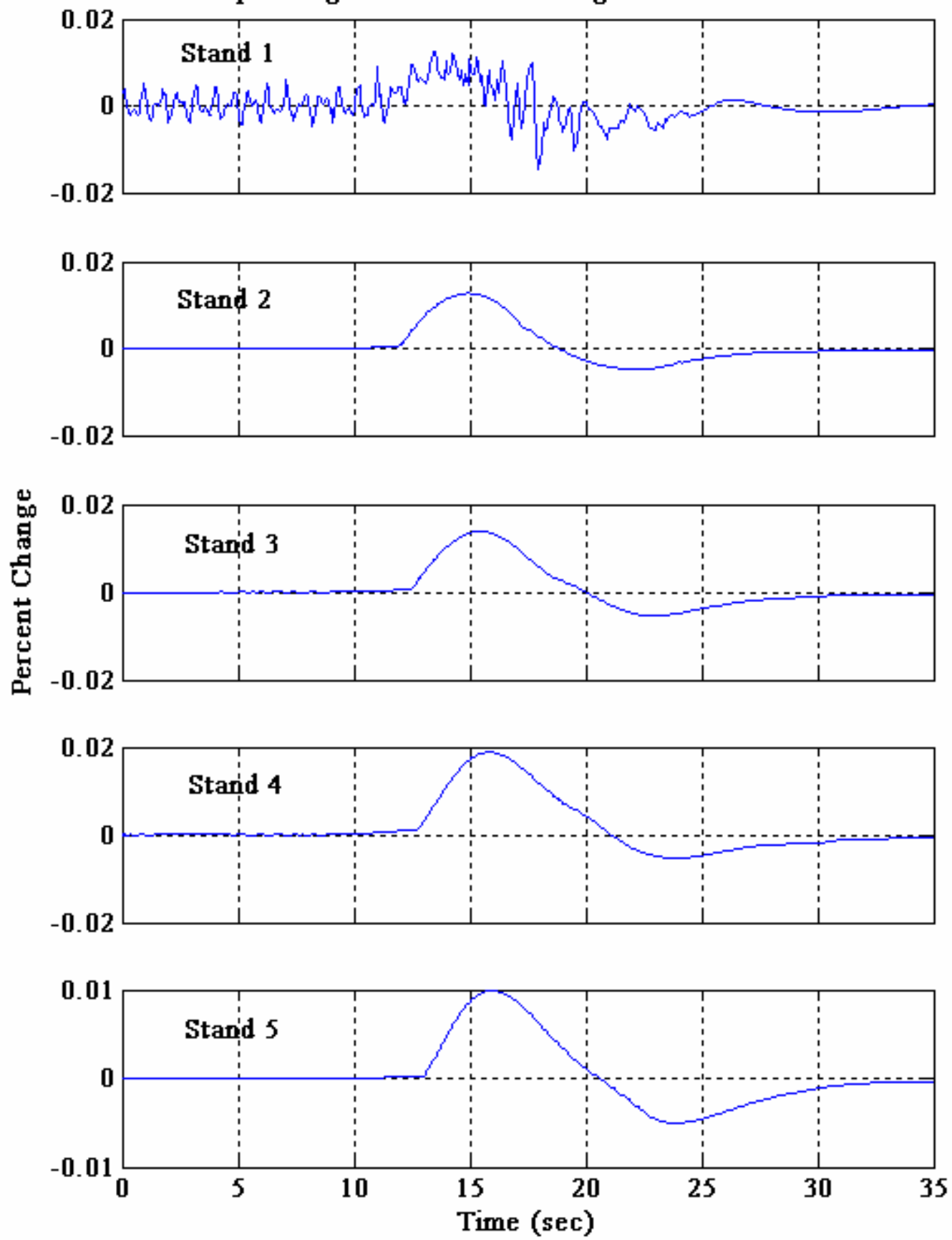

Figure 59 Percent Changes in Stand Output Thicknesses from Operating Point Values During Mill Deceleration, with Mill Entry Disturbances, without Uncertainties or Eccentricities, Using Operating Point 3 

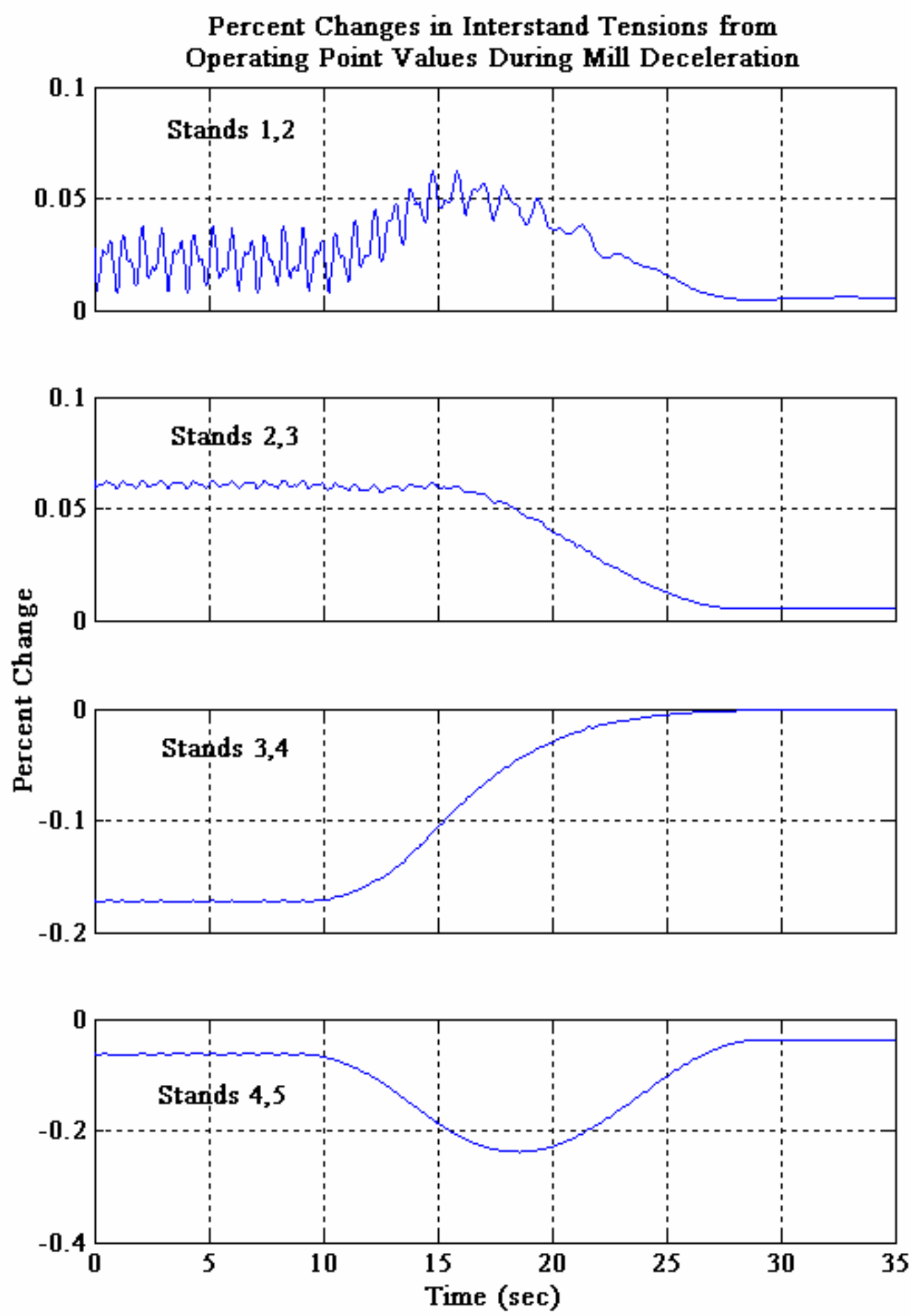

Figure 60 Percent Changes in Interstand Tensions from Operating Point Values During Mill Deceleration, with Mill Entry Disturbances, without Uncertainties or Eccentricities, Using Operating Point 3 

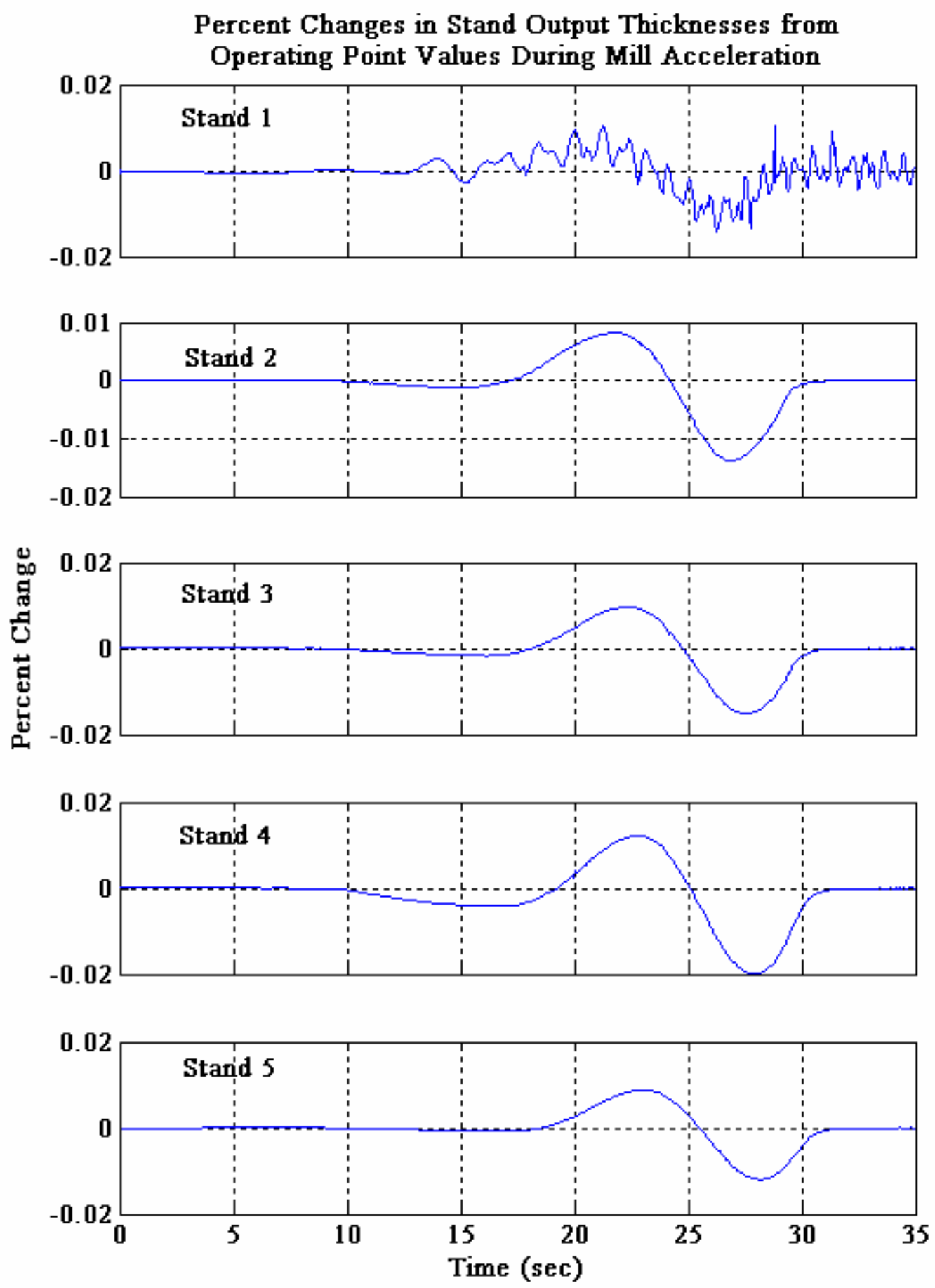

Figure 61 Percent Changes in Stand Output Thicknesses from Operating Point Values During Mill Acceleration, with Mill Entry Disturbances, without Uncertainties or Eccentricities, Using Operating Point 3 

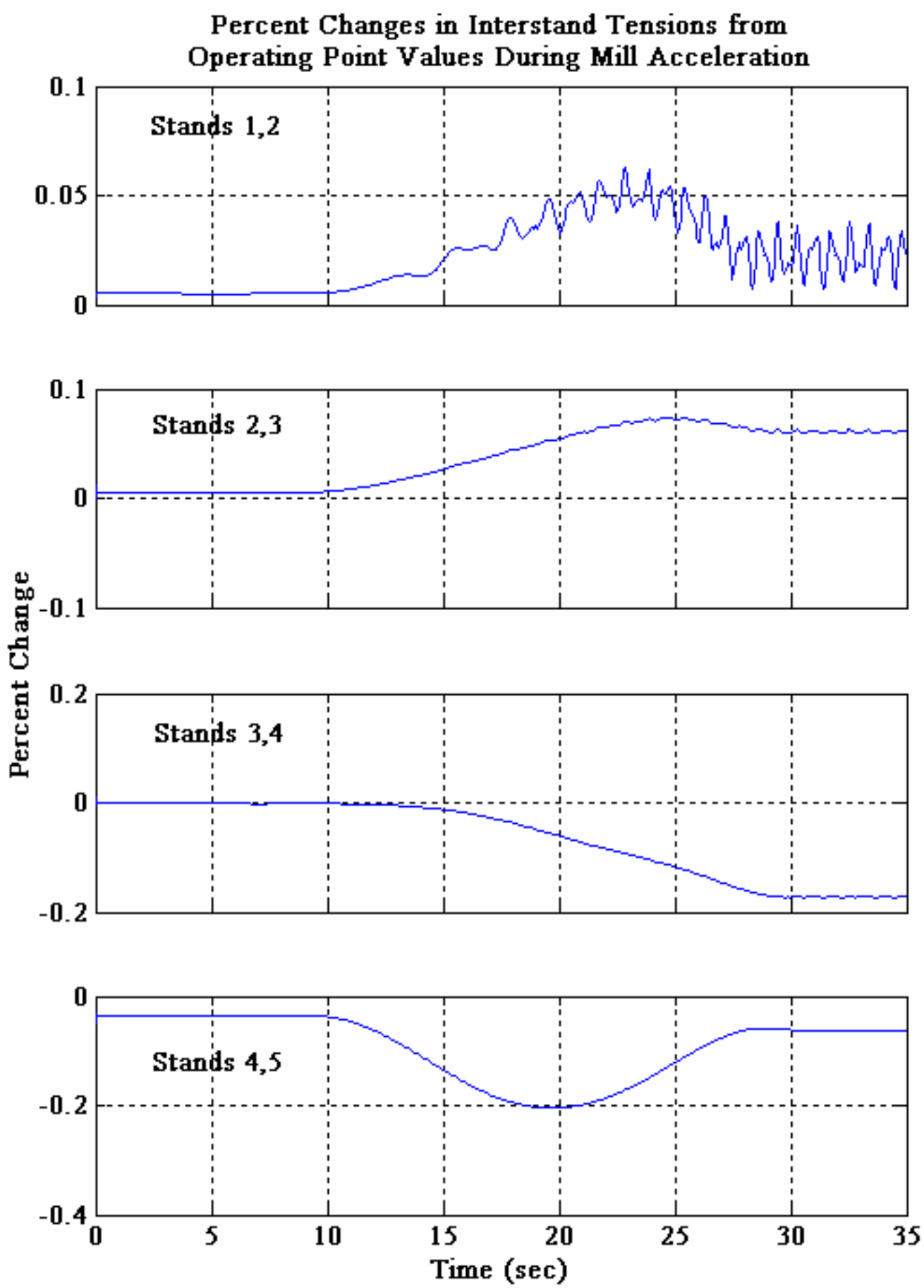

Figure 62 Percent Changes in Interstand Tensions from Operating Point Values During Mill Acceleration, with Mill Entry Disturbances, without Uncertainties or Eccentricities, Using Operating Point 3 
As in the case of Operating Point 2, simulations were performed using Operating Point 3 with the mill entry disturbances applied simultaneously with the modeling and measurement uncertainties, under the assumptions previously noted for Operating Point 1. The results, as summarized in Table 59, are similar to the results for Operating Point 1 (Table 50) and to the results for Operating Point 2 (Table 54). Thus performance and robustness are essentially the same for Operating Point 1, Operating Point 2, and Operating Point 3. The operating point at

Table 59 Magnitudes of Maximum Percent Deviations of Stand Exit Thicknesses and Interstand Tension Stresses, with Disturbances and Uncertainties, without Eccentricities, Using Operating Point 3

\begin{tabular}{|c|c|c|c|c|}
\hline \multirow[b]{2}{*}{ Variable } & \multicolumn{4}{|c|}{$\begin{array}{c}\text { Magnitude of Maximum Percent Deviation of } \\
\text { Variable from Operating Point Value }\end{array}$} \\
\hline & $\begin{array}{l}100 \% \\
\text { Speed }\end{array}$ & $\begin{array}{c}5 \% \\
\text { Speed }\end{array}$ & $\begin{array}{c}\text { Decel from } \\
100 \% \text { to } 5 \% \\
\text { Speed } \\
\end{array}$ & $\begin{array}{c}\text { Accel from } \\
5 \% \text { to } 100 \% \\
\text { Speed } \\
\end{array}$ \\
\hline$h_{\text {out } 1}$ & $.275 \%$ & $.041 \%$ & $.250 \%$ & $.137 \%$ \\
\hline$h_{\text {out } 2}$ & .078 & .052 & .062 & .077 \\
\hline$h_{\text {out } 3}$ & .081 & .052 & .077 & .071 \\
\hline$h_{\text {out } 4}$ & .090 & .053 & .065 & .082 \\
\hline$h_{\text {out } 5}$ & .077 & .001 & .067 & .070 \\
\hline$\sigma_{12}$ & $.07 \%$ & $<.01 \%$ & $.06 \%$ & $.08 \%$ \\
\hline$\sigma_{23}$ & .09 & $<.01$ & .08 & .09 \\
\hline$\sigma_{34}$ & .19 & $<.01$ & .19 & .18 \\
\hline$\sigma_{45}$ & .08 & .04 & .23 & .20 \\
\hline
\end{tabular}

Operating Point 3 was then shifted to Production Schedule 3 (Table 2) to realize the interstand tensions desired for control of strip shape. The results of the simulation using Production Schedule 3 are given in Table 60. The shift in the operating point was made with no changes in the settings for Operating Point 3, except for the setting $K_{i, i+1}$ for the gains of the interstand tension trims which was set to 50. The dynamic responses using Production Schedule 3 are about the same as the dynamic responses using Operating Point 3. 
Table 60 Magnitudes of Maximum Percent Deviations of Stand Exit Thicknesses and Interstand Tension Stresses, with Disturbances and Uncertainties, without Eccentricities, Using Production Schedule 3

\begin{tabular}{|c|c|c|c|c|}
\cline { 2 - 5 } \multicolumn{1}{c|}{} & \multicolumn{4}{c|}{$\begin{array}{c}\text { Magnitude of Maximum Percent Deviation of } \\
\text { Variable from Operating Point Value }\end{array}$} \\
\hline Variable & $\begin{array}{c}\mathbf{1 0 0 \%} \\
\text { Speed }\end{array}$ & $\begin{array}{c}\mathbf{5 \%} \\
\text { Speed }\end{array}$ & $\begin{array}{c}\text { Decel from } \\
\mathbf{1 0 0 \%} \\
\text { Speed }\end{array}$ & $\begin{array}{c}\text { Accel from } \\
\mathbf{5 \%} \text { to 100\% } \\
\text { Speed }\end{array}$ \\
\hline$h_{\text {out } 1}$ & $.275 \%$ & $.045 \%$ & $.250 \%$ & $.142 \%$ \\
\hline$h_{\text {out } 2}$ & .078 & .052 & .062 & .078 \\
\hline$h_{\text {out } 3}$ & .080 & .052 & .077 & .071 \\
\hline$h_{\text {out } 4}$ & .089 & .053 & .065 & .090 \\
\hline$h_{\text {out } 5}$ & .078 & .051 & .071 & .070 \\
\hline$\sigma_{12}$ & $.18 \%$ & $.02 \%$ & $.18 \%$ & $.20 \%$ \\
\hline$\sigma_{23}$ & .35 & .02 & .35 & .35 \\
\hline$\sigma_{34}$ & .14 & .00 & .12 & .14 \\
\hline$\sigma_{45}$ & .80 & .07 & .80 & .78 \\
\hline
\end{tabular}

\subsection{VERIFICATION OF THE MASS FLOW RELATIONSHIP}

The mass flow relationship (3-35) for output thicknesses uses the strip speed $V_{i n, i+l}$ at the input of the next stand in place of the strip speed $V_{\text {out }, i}$ at output of the present stand, i.e.,

$$
h_{\text {out }, i}=\frac{h_{\text {in, },} V_{\text {in }, i}}{V_{\text {in }, i+1}} k_{i, e}, \quad(i=2,3,4),
$$

is taken as equivalent to

$$
h_{\text {out }, i}=\frac{h_{\text {in }, i} V_{\text {in }, i}}{V_{\text {out }, i}} k_{i, e}, \quad(i=2,3,4),
$$

where (4-3) and (4-4) are copies of (3-33) and (3-32) respectively for stands 2, 3, and 4. The relationship (3-33) is verified by repeating the previous simulations with disturbances and uncertainties applied using (4-3), and then, assuming that measurements of $V_{\text {out }, i}$ exist, again 
repeating the previous simulations with disturbances and uncertainties applied using (4-4). The magnitudes of the maximum deviations in the responses with (4-3) from the responses with (4-4) give an indication of the validity of taking (4-3) in place of (4-4). The results of these simulations are that, using (4-3) in place of (4-4), the largest magnitude of the maximum deviation in stand exit thickness is less than $.001 \%$ and the largest magnitude of the maximum deviation in interstand tension also is less than $.001 \%$, which provides the justification for using (3-33) in place of (3-32).

\subsection{VERIFICATION OF THE ECCENTRICITY COMPENSATION}

Simulations based on the following assumptions were performed to verify performance of the eccentricity compensation technique described in Section 3.4.

- The eccentricity is only in the backup rolls, which have identical eccentricity. The work rolls are eccentricity free.

- The diameter of the backup rolls is 53 inches which can change about .1 inch $(.2 \%)$ due to the effects of mechanical wear [6]. For the simulation a change of .5\% in the diameter is assumed for other effects and conservatism.

- The eccentricity is a sinusoid plus a third harmonic. The fundamental is taken to have a period corresponding to one revolution of the backup rolls with a peak of .0012 inches, which is about $2 \%[20,50]$ of the operating point mill exit thickness of .062 inches. The peak of the third harmonic is taken to be $3 \%$ of the peak of the fundamental. The same eccentricity (.0012 inches) is assumed for each mill stand. 
The method of eccentricity compensation uses the LMS (least mean square) adaptive filtering technique which is well known and described in various texts [e.g., 56, 57] on statistical digital signal processing and adaptive filtering. For the simulations, a modified normalized LMS algorithm [56] is used to update the filter coefficients. In this algorithm (4-5), the gradient step size is normalized with respect to the norm of the input vector to reduce the effects of gradient noise amplification, and a small positive constant is added to the denominator of the correction applied to the filter coefficient to prevent similar effects if the norm of the input vector becomes too small. The expression for the algorithm is

$$
w_{n+1}=w_{n}+\frac{\beta X_{2}^{*}(n)}{\varepsilon+\left\|X_{2}(n)\right\|^{2}} e_{f}(n),
$$

where $n$ represents the discrete time step, $w_{n}$ is the filter coefficient, $\beta$ is the normalized gradient step size, $\varepsilon$ is a small positive constant, $X_{2}(n)$ is the filter input vector, and $e_{f}(n)$ is the filter error (scalar). $X_{2}^{*}(n)$ is the complex conjugate of $X_{2}(n)$, which is equal to $X_{2}(n)$ in this case.

The LMS filter used in the simulations was order 12 with a $\beta$ of .5 and a sampling rate of at least 50 samples per period of the sinusoid assumed for the eccentricity. Initially (Case 1) the eccentricity $v_{1}(n)$ was assumed to be equal to the sinusoid $v_{2}(n)$ generated using the speed of the backup roll, as inferred from the measured speed of the work roll, with no harmonic. For this case, the resulting eccentricity after compensation was negligible (less than $.003 \%$ ), following filter learning which occurred in less than 2 revolutions of the backup roll. The learning curve of the filter for this case is plotted in Figure 63. The following variations from Case 1 were then individually simulated:

- Case 2: The magnitude of $v_{1}(n)$ is twice the magnitude of the magnitude of $v_{2}(n)$. 
- Case 3: The magnitude of $v_{1}(n)$ is one half the magnitude of the magnitude of $v_{2}(n)$.

- Case 4: The frequency of $v_{1}(n)$ is . $5 \%$ greater than the frequency of $v_{2}(n)$.

- Case 5: The frequency of $v_{1}(n)$ is .5\% less than the frequency of $v_{2}(n)$.

- Cases 6 through 8: $v_{1}(n)$ is shifted by $N_{i}(i=1,2,3)$ time steps, where $N_{i}$ is $\frac{N}{4}$ rounded to the nearest integer, with $N$ equal to the number of time steps for one period of the sinusoid.

- Case 9: The third harmonic is added to the fundamental.

- Case 10: The results of the above were combined such that approximately the greatest deviation in eccentricity after compensation was realized.

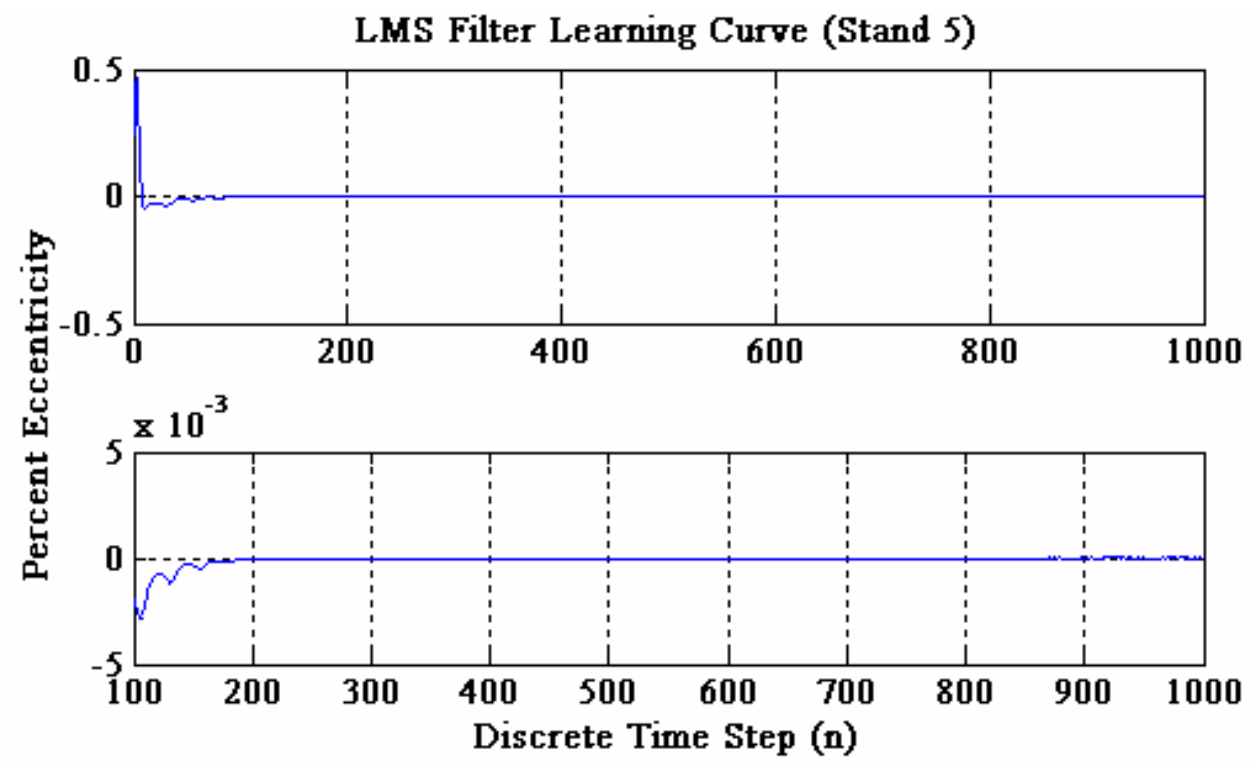

Figure 63 Stand 5 Percent Eccentricity after Compensation, Case 1

The results are presented in Table 61. As can be seen from these results, the maximum eccentricity remaining after compensation is about $.05 \%$ which supports the assumption that a 
workable eccentricity compensation technique compatible with the pointwise linear quadratic controller can be developed.

Table 61 Magnitude of Maximum Eccentricity, After Filter Learning, for Case 1 through Case

\begin{tabular}{|c|c|}
\hline Case & $\begin{array}{c}\text { Magnitude of } \\
\text { Max Eccentricity }\end{array}$ \\
\hline 1 & $.003 \%$ \\
\hline 2 & .006 \\
\hline 3 & .002 \\
\hline 4 & .01 \\
\hline 5 & .01 \\
\hline 6 & .02 \\
\hline 7 & .003 \\
\hline 8 & .02 \\
\hline 9 & .05 \\
\hline 10 & .05 \\
\hline
\end{tabular}

\subsection{COMPARISON WITH OTHER CONTROLLERS}

The results presented in Table 50, Table 51, Table 54, Table 55, Table 59, and Table 60, with additional deviations in the mill output thickness to account for cold mill eccentricity, were compared with actual operating data from two industrial controllers [49, 60]. For the pointwise linear quadratic controller, the cold mill eccentricity was assumed to be about $.12 \%$, which is the $.05 \%$ given in Table 61 for the magnitude of the maximum eccentricity at stand 5 after compensation, plus an additional $.07 \%$ for conservatism and allowing for less than complete compensation for changes in width or other effects by $k_{i, e}$. Thus, taking the magnitude of the total deviation in mill exit thickness to be the sum of the magnitude of the maximum deviation in mill exit thickness considering disturbances and uncertainties (i.e. .08\%), and the magnitude of the maximum cold mill eccentricity (i.e. .12\%), the magnitude of the maximum total deviation in 
mill exit thickness is about $.2 \%$. This estimate is conservative, since as noted earlier, the disturbances and uncertainties in modeling and in measurements were assumed to be combined to give approximately the maximum percent deviations from the operating point values, which is considered to be very unlikely in an actual operation. Comparison of this result with the data presented [20, 49, 60] for deviations in exit thicknesses for other mills can be done only in general since there are differences in mill properties, in operating points, and in material properties between the systems being compared, and also the disturbances and uncertainties of the two industrial systems are not given. On this basis Table 62 presents the mill exit thickness data for the pointwise linear quadratic controller and the two industrial controllers, with the improvement achieved using the pointwise linear quadratic technique being evident.

Table 62 Comparison of Magnitudes of Maximum Percent Deviation of Mill Exit Thickness with Industrial Controller A [49] and Industrial Controller B [60]

\begin{tabular}{|c|c|}
\hline Controller & $\begin{array}{c}\text { Magnitude of Maximum Percent } \\
\text { Deviation of Mill Exit Thickness }\end{array}$ \\
\hline $\begin{array}{c}\text { Pointwise Linear } \\
\text { Quadratic }\end{array}$ & $.2 \%$ \\
\hline Industrial A & .5 \\
\hline Industrial B & .8 \\
\hline
\end{tabular}

Some desirable features of the pointwise linear quadratic controller are its simplicity and its capability for the use of physical intuition during design, commissioning, and operation. Comparison of the pointwise linear quadratic technique with the industrial controllers for robustness to specific uncertainties and disturbances is precluded due to a lack of data, and also because a requirement for robustness usually is not included in the design of the industrial controllers. Thus, in general, the pointwise linear quadratic controller has the desirable features of the industrial controllers, and in addition provides an improvement in performance as noted in Table 62 . 


\subsection{COMMENTS}

1. The dynamic responses to the mill entry disturbances without uncertainties are presented in Figure 38 through Figure 45, Figure 37 through Figure 54, and Figure 55 through Figure 62. The dynamic responses to mill entry disturbances with uncertainties depend on the application and how the disturbances and uncertainties interact at the time of the actual measurements. The approximate magnitudes of the deviations of variables from their operating point values in the presence of mill entry disturbances and uncertainties as given in Table 50, in Table 54, and in Table 59, are considered to be close to maximum values. The deviations expected during actual operation are expected to be less than these values.

2. For the cases evaluated, the closed loop simulations have shown that the pointwise linear quadratic controller provides an improvement in performance over the two industrial control techniques considered, with strong robustness to typical disturbances and to uncertainties during operation at steady speed, during deceleration from run speed to thread speed, and during acceleration from thread speed to run speed. 


\subsection{DISCUSSION AND CONCLUSION}

A simple model of the tandem cold rolling process was developed and verified by comparison with well accepted results of previous simulations. A pointwise linear quadratic controller was coupled to the model and simulations were done to verify the performance and robustness to disturbances and uncertainties. The results, which were compared to two typical industrial controllers, show the improvements available with the pointwise linear quadratic method. However, because of the present lack of a useful theoretical basis, the application of the pointwise linear quadratic controller requires simulations to be performed to verify global asymptotic stability, performance, and robustness. This is not considered a significant drawback since similar simulations confirming the design must be performed prior to application for other control strategies which have a well-developed analytical basis.

The results provided herein are based on a simple process model which is developed mostly using the results of previous work by Bryant [1] and on empirical relationships derived by Roberts [6]. While it is considered that this model is adequate for the investigation of the workability of the pointwise linear quadratic control for a tandem cold mill, preparation for an actual implementation requires additional simulations for final verification using more detailed process models of the specific application being evaluated.

During this investigation, the pertinent measured signals were assumed to be free of the effects of random noise. It is expected that the more detailed simulations of specific applications 
would include the means to mitigate any effects of random noise as determined by need on a case-by-case basis.

In conclusion, the results of the effort described herein have shown that the pointwise linear quadratic optimal control technique is well-suited for the control of a tandem cold rolling process and provides a significant improvement in performance over typical industrial control strategies, with a strong robustness to typical disturbances, to modeling uncertainties, and to uncertainties in the measurements of variables used in the control strategy. Thus the objective of this investigation has been met. Some future efforts to expand this work include:

- The development of a method of active eccentricity compensation, compatible with the pointwise linear quadratic controller, which mitigates the effects of eccentricity of both backup rolls and both work rolls, over the entire range of mill operation.

- Investigation of controlling the mill using the pointwise linear quadratic technique from initial threading to fully threaded operation at thread speed, and similarly for dethreading.

- Adaptation of the pointwise linear quadratic technique for continuous operation of the mill when coupled to a pickling process. This involves control of the rolling process wherein the product characteristics change on the fly.

- Investigation of the interactions of the pointwise linear quadratic technique with strategies for controlling the shape of the strip. 


\section{APPENDIX A}

\section{DEFINITIONS AND THEOREMS}

Definition A.1 [61]: A system is considered an autonomous system if the function $f$ does not depend explicitly on $t$, i.e.

$$
\dot{x}=f(x) \text {. }
$$

Definitions A.2 through A.8 are based on an autonomous system, where $f: D \rightarrow R^{n}$ is a locally Lipshitz map from a domain $D$ into $R^{n}$.

Definition A.2 [61]: The point $\tilde{x}$ is an equilibrium point of (A-1) if

$$
f(\tilde{x})=0 .
$$

Definition A.3 [61]: Taking $\tilde{x}=0$ for convenience and without loss of generality, the equilibrium point of (A-2) is stable if for each $\varepsilon>0$ there is a $\delta$ such that

$$
\|x(0)\|<\delta \Rightarrow\|x(t)\|<\varepsilon, \quad \forall t \geq 0 .
$$

Definition A.4 [61]: The equilibrium point of (A-2) is unstable if it is not stable.

Definition A.5 [61]: The equilibrium point $\tilde{x}=0$ is asymptotically stable if it is stable and a $\delta$ can be chosen such that

$$
\|x(0)\|<\delta \Rightarrow \lim _{t \rightarrow \infty} x(t)=0 .
$$


Definition A.6 [61]: Let $\phi(x ; t)$ be the solution of (A-1) that starts at time $t=0$ and at an initial state $x_{0}$, with $\tilde{x}=0$. Then the region of attraction is the set of all points $x$ such that

$$
\lim _{t \rightarrow \infty} \phi(t ; x)=0
$$

Definition A.7 [61]: The equilibrium point $\tilde{x}=0$ is locally asymptotically stable if it is asymptotically stable and its region of attraction is some neighborhood of the origin.

Definition A.8 [61] : The equilibrium point $\tilde{x}=0$ is globally asymptotically stable if

$$
\lim _{t \rightarrow \infty} \phi(t ; x)=0
$$

no matter how large $\|x\|$ is.

Definition A.9 [22]: $\{C(x), A(x)\}$ is a pointwise observable parameterization of the nonlinear system in a region $\Omega$ if the pair $\{C(x), A(x)\}$ is pointwise observable (in the linear sense) for all $x \in \Omega$.

Definition A.10 [22]: $\{C(x), A(x)\}$ is a pointwise detectable parameterization of the nonlinear system in a region $\Omega$ if the pair $\{C(x), A(x)\}$ is pointwise detectable ${ }^{8}$ (in the linear sense) for all $x \in \Omega$

Definition A.11 [22]: $\{A(x), B(x)\}$ is a pointwise controllable parameterization of the nonlinear system in a region $\Omega$ if the pair $\{A(x), B(x)\}$ is pointwise controllable (in the linear sense) for all $x \in \Omega$

Definition A.12 [22]: $\{A(x), B(x)\}$ is a pointwise stabilizable parameterization of the nonlinear system in a region $\Omega$ if the pair $\{A(x), B(x)\}$ is pointwise stabilizable ${ }^{9}$ (in the linear sense) for all $x \in \Omega$.

\footnotetext{
${ }^{8}$ In a linear sense, the pair $\{C, A\}$ is detectable if and only if every unstable mode is observable [15].

${ }^{9}$ In a linear sense, the pair $\{A, B\}$ is stabilizable if and only if every unstable mode is controllable [15].
} 
Theorem A.13 [22] : In addition to $a(x), b(x), R(x), Q(x) \in C^{k}, k \geq 1$, assume that $A(x)$ is smooth (i.e. $A(x) \in C^{k}$ ) and that $A(x)$ is both a stabilizable and detectable coefficient parameterization of the nonlinear system. Then the state-dependent Riccati equation method produces a closed loop solution which is locally asymptotically stable.

Proof: The proof is provided in [22].

Theorem A.14 [22]: Assume that the functions $A(x), b(x), K(x), Q(x)$, and $R(x)$, and their gradients $^{10} \nabla_{x} A(x), \nabla_{x} b(x), \nabla_{x} K(x)$, and $\nabla_{x} R(x)$ are bounded along trajectories. Then, under stability, as the state $x$ is driven to zero, the necessary condition for optimality is asymptotically satisfied at a quadratic rate.

Proof: The proof is provided in [22].

${ }^{10}$ The notation for gradient is as given in Appendix B. 


\section{APPENDIX B}

\section{COMPUTATION OF GRADIENTS}

With $x \in R^{n}, Q^{\prime}(x)=Q(x) \in R^{n x n}$, and $Q(x) \in C^{l}$, and using matrix differentiation formulae as given in [62],

$$
\nabla_{x}\left(x^{\prime} Q(x) x\right)=2 Q(x) x+x^{\prime} \nabla_{x} Q(x) x
$$

where

$$
x^{\prime} \nabla_{x} Q(x) x=\left[\begin{array}{c}
x^{\prime} \nabla_{x_{1}} Q(x) x \\
x^{\prime} \nabla_{x_{2}} Q(x) x \\
\cdot \\
\cdot \\
\cdot \\
x^{\prime} \nabla_{x_{n}} Q(x) x
\end{array}\right] \text {, }
$$


and

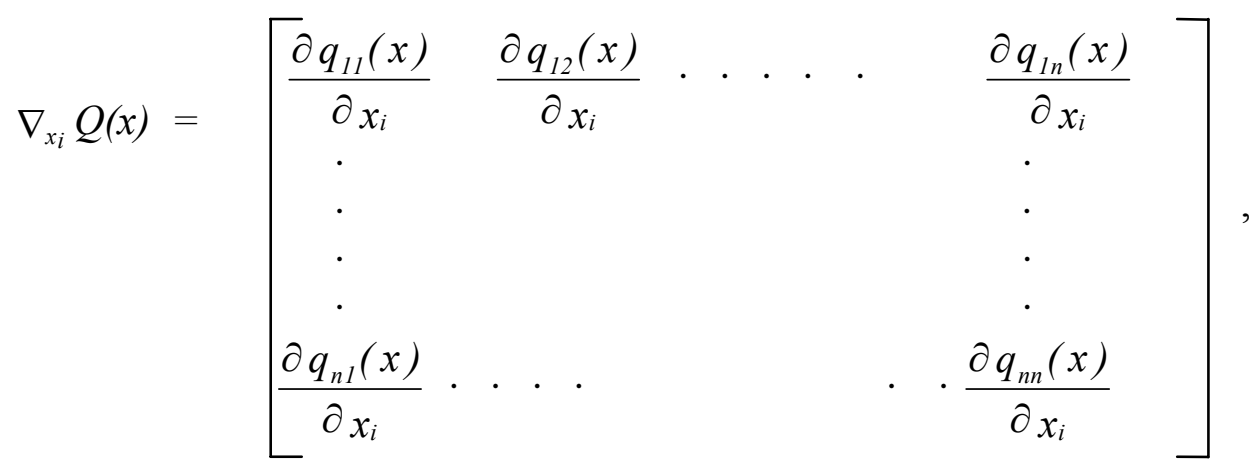

$$
i=1,2, \ldots n .
$$

Equation (B-1) can be verified by first computing $x^{\prime} Q(x) x$ on an element-by-element basis, and then computing $\nabla_{x}\left(x^{\prime} Q(x) x\right)$.

Example 1:

Computation of $\nabla_{x}\left(x^{\prime} Q(x) x\right)$, for $n=2, x \in R^{2}, Q^{\prime}(x)=Q(x) \in R^{2 x 2}, Q(x) \in C^{l}$ : Using (B-1) and (B-2), and not showing function arguments,

$$
\nabla_{x}\left(x^{\prime} Q x\right)=2\left[\begin{array}{ll}
q_{11} & q_{12} \\
q_{21} & q_{22}
\end{array}\right]\left[\begin{array}{l}
x_{1} \\
x_{2}
\end{array}\right]+\left[\begin{array}{c}
x^{\prime} \nabla_{x_{1}} Q x \\
x^{\prime} \nabla_{x_{2}} Q x
\end{array}\right],
$$

and then using (B-3),

$$
x^{\prime} \nabla_{x l} Q x=\left[\begin{array}{ll}
x_{1} & x_{2}
\end{array}\right]\left[\begin{array}{ll}
\frac{\partial q_{11}(x)}{\partial x_{1}} & \frac{\partial q_{12}(x)}{\partial x_{1}} \\
\frac{\partial q_{21}(x)}{\partial x_{1}} & \frac{\partial q_{22}(x)}{\partial x_{1}}
\end{array}\right]\left[\begin{array}{l}
x_{1} \\
x_{2}
\end{array}\right]
$$




$$
x^{\prime} \nabla_{x 2} Q x=\left[\begin{array}{ll}
x_{1} & x_{2}
\end{array}\right]\left[\begin{array}{ll}
\frac{\partial q_{11}(x)}{\partial x_{2}} & \frac{\partial q_{12}(x)}{\partial x_{2}} \\
\frac{\partial q_{21}(x)}{\partial x_{2}} & \frac{\partial q_{22}(x)}{\partial x_{2}}
\end{array}\right]\left[\begin{array}{c}
x_{1} \\
x_{2} \\
\end{array}\right]
$$

Performing the multiplications and substituting into (B-4), and noting that $\mathrm{q}_{12}=\mathrm{q}_{21}$,

$$
\nabla_{x}\left(x^{\prime} Q x\right)=\left[\begin{array}{c}
2 x_{1} q_{11}+2 x_{2} q_{12}+x_{1}^{2} \frac{\partial q_{11}}{\partial x_{1}}+2 x_{1} x_{2} \frac{\partial q_{12}}{\partial x_{1}}+x_{2}^{2} \frac{\partial q_{22}}{\partial x_{1}} \\
2 x_{1} q_{12}+2 x_{2} q_{22}+x_{1}^{2} \frac{\partial q_{11}}{\partial x_{2}}+2 x_{1} x_{2} \frac{\partial q_{12}}{\partial x_{2}}+x_{2}^{2} \frac{\partial q_{22}}{\partial x_{2}}
\end{array}\right]
$$

Computing $x^{\prime} Q x$ on an element-by-element basis and then computing $\nabla_{x}\left(x^{\prime} Q x\right)$ verifies the result obtained in (B-7).

Example 2:

Computation of $\nabla_{x}\left[\lambda^{\prime} A(x) x\right]$, where $x \in R^{2}, A(x) \in R^{2 x 2}, \lambda \in R^{2}, A(x) \in C^{l}$, for all $x$. Using matrix differentiation formulae, and not showing function arguments,

$$
\nabla_{x}\left(\lambda^{\prime} A x\right)=\left(x^{\prime} \nabla_{x} A^{\prime}+A^{\prime}\right) \lambda
$$

where

$$
x^{\prime} \nabla_{x} A^{\prime}=\left[\begin{array}{ll}
x^{\prime} \nabla_{x_{1}} A^{\prime} \\
x^{\prime} \nabla_{x_{2}} A^{\prime}
\end{array}\right],
$$

and 


$$
\begin{aligned}
& x^{\prime} \nabla_{x 1} A^{\prime}=\left[\begin{array}{cc}
x_{1} & x_{2}
\end{array}\right]\left[\begin{array}{ll}
\frac{\partial a_{11}}{\partial x_{1}} & \frac{\partial a_{21}}{\partial x_{1}} \\
\frac{\partial a_{12}}{\partial x_{1}} & \frac{\partial a_{22}}{\partial x_{1}}
\end{array}\right] \\
& x^{\prime} \nabla_{x 2} A^{\prime}=\left[\begin{array}{ll}
x_{1} & x_{2}
\end{array}\right]\left[\begin{array}{ll}
\frac{\partial a_{11}}{\partial x_{2}} & \frac{\partial a_{21}}{\partial x_{2}} \\
\frac{\partial a_{12}}{\partial x_{2}} & \frac{\partial a_{22}}{\partial x_{2}}
\end{array}\right]
\end{aligned}
$$

It is straightforward to use (B-10) and (B-11) and substitute into (B-9) and (B-8) to obtain the result. 


\section{APPENDIX C}

\section{DERIVATION OF VARIOUS RELATIONSHIPS AS FUNCTIONS OF THE STATE VARIABLES}

\section{C.1 RELATIONSHIPS FOR OUTPUT THICKNESS AND SPECIFIC ROLL FORCE}

During each scan of the controller, $\xi$ and $\alpha$ are computed at a number of equally spaced points in a predetermined neighborhood of $h_{\text {out } 0}$ as

$$
\xi=\frac{\mu \sqrt{R^{\prime}\left(h_{\text {in }}-h_{\text {out }}\right)}}{\bar{h}},
$$

and

$$
\alpha=\sqrt{\frac{h_{\text {out }}}{h_{\text {in }}}} \exp (\xi)-1,
$$

where $h_{\text {in }}$ for stand 1 is the input thickness to the mill, and $h_{\text {in }}$ for stands $2,3,4,5$ is the output thickness of the previous stand delayed by the appropriate interstand time delay,

$$
h_{\text {in,i+l }}(t)=h_{\text {out }, i}\left(t-t_{d, i, i+1}\right), \quad i=1,2,3,4,
$$

with $\mu$ and $R^{\prime}$ as given previously. 
During the same controller scan, using (2-12) and noting that $F=P W$, the total roll force is computed (at each point) as

$$
F=(\bar{k}-\bar{\sigma}) \sqrt{R^{\prime} \delta}(1+.4 \alpha) W
$$

where $W$ is the strip width, and other variables are as previously noted. In the neighborhood of $h_{\text {out }}, F$ then is approximated by a linear fit, which is reasonable because the neighborhood is not large,

$$
F=c_{1} h_{\text {out }}+c_{2}
$$

where $c_{1}$ and $c_{2}$ are constants. Using (2-26) and (C-5), $h_{\text {out }}$ is then

$$
h_{\text {out }}=\frac{M\left(S+S_{0}\right)+c_{2}}{\left(M-c_{1}\right)} \text {, }
$$

and the specific roll force is

$$
P=\frac{M\left(h_{\text {out }}-\left(S+S_{0}\right)\right)}{W},
$$

and thus for stands $2,3,4,5, h_{\text {out }}$ and $P$ for the present stand depend on the state variables, and on the delayed state variables used in the computation of $h_{\text {out }}$ of the previous stand. 


\section{C.2 RELATIONSHIPS FOR ENTRY AND EXIT STRIP SPEEDS}

Using (2-19) the strip speed at the exit of the roll bite can be written as

$$
V_{\text {out }}=V(f+1)
$$

where the forward slip $f$ as given in (2-23) ultimately depends on both the state variables and the delayed stated variables. By conservation of volume through the roll bite,

$$
V_{\text {in }, i+1}=\frac{V_{\text {out }, i+1} h_{\text {out }, i+1}}{h_{\text {in }, i+1}}=\frac{V_{i+1}\left(f_{i+1}+1\right) h_{\text {out }, i+1}}{h_{\text {out }, i}\left(t-t_{d, i, i+1}\right)}
$$

and thus $\left(V_{\text {in }, i+1}-V_{\text {out }, i}\right)$ also depends on the state variables and on the delayed state variables. 


\section{APPENDIX D}

\section{DERIVATION OF THE NECESSARY CONDITION FOR OPTIMALITY}

From the cost function (3-5) and the nonlinear constraint (3-3), the Hamiltonian function is formed as:

$$
H(x, u, \lambda)=\frac{1}{2}\left(x^{\prime} Q(x) x+u^{\prime} R(x) u\right)+\lambda^{\prime}(A(x) x+B u),
$$

where $\lambda \in R^{n}$ is a Lagrange multiplier. The necessary conditions for optimality of a nonlinear controller are:

$$
\begin{aligned}
& \nabla_{\lambda} H=\dot{x}, \\
& \nabla_{x} H=-\dot{\lambda}, \\
& \nabla_{u} H=0 .
\end{aligned}
$$

Using (D-1) and the control law

$$
u=-R^{-1}(x) B^{\prime} K(x) x
$$

gives

$$
\begin{aligned}
\nabla_{u} H & =R(x) u+B^{\prime} \lambda, \\
& =R(x)\left(-R^{-1}(x) B^{\prime} K(x) x\right)+B^{\prime} \lambda, \\
& =B^{\prime}(\lambda-K(x) x) .
\end{aligned}
$$


$\nabla_{u} H$ will be zero if $\lambda$ is chosen so that

$$
\lambda=K(x) x
$$

Differentiating (D-9) with respect to time results in

$$
\dot{\lambda}=\dot{K}(x) x+K(x) \dot{x} .
$$

Using (D-1) and (D-3) ${ }^{11}$,

$$
\dot{\lambda}=-Q(x) x-\frac{1}{2}\left(x^{\prime} \nabla_{x} Q(x) x+u^{\prime} \nabla_{x} R(x) u\right)-\left(x^{\prime} \nabla_{x} A^{\prime}(x)+A^{\prime}(x)\right) \lambda .
$$

Equating (D-10) and (D-11), and using (3-3), (D-2), (D-5) and (D-9),

$$
\begin{aligned}
& \dot{K}(x) x+K(x)\left(A(x) x-B R^{-1}(x) B^{\prime} K(x) x\right)= \\
& \quad-Q(x) x-\frac{1}{2}\left(x^{\prime} \nabla_{x} Q(x) x+u^{\prime} \nabla_{x} R(x) u\right)-\left(x^{\prime} \nabla_{x} A^{\prime}(x)+A^{\prime}(x)\right) K(x) x .
\end{aligned}
$$

Rearranging and grouping terms,

$$
\begin{aligned}
\dot{K}(x) x+\frac{1}{2}\left(x^{\prime} \nabla_{x} Q(x) x+u^{\prime} \nabla_{x} R(x) u\right)+x^{\prime} \nabla_{x} A^{\prime}(x) K(x) x & \\
& +\left(A^{\prime}(x) K(x)+K(x) A(x)-K(x) B R^{-1}(x) B^{\prime} K(x)+Q(x)\right) x=0 .
\end{aligned}
$$

From the state-dependent algebraic Riccati equation (3-6), the expression $\left(A^{\prime}(x) K(x)+K(x)\right.$ $\left.A(x)-K(x) B R^{-1}(x) B^{\prime} K(x)+Q(x)\right)$ is equal to zero, and substituting for $u(\mathrm{D}-5)$ gives the necessary condition for the closed loop solution to be near-optimal:

$$
\dot{K}(x) x+\frac{1}{2}\left(x^{\prime} \nabla_{x} Q(x) x+x^{\prime} K(x) B R^{-1}(x) \nabla_{x} R(x) R^{-1}(x) B^{\prime} K(x) x\right)+x^{\prime} \nabla_{x} A(x) K(x) x=0 .
$$

\footnotetext{
${ }^{11}$ See Appendix B for computation of $x^{\prime} \nabla_{x} Q(x)$ and other gradient functions, and associated notation.
} 


\section{BIBLIOGRAPHY}

[1] Bryant, G. F., The Automation of Tandem Mills, The Iron and Steel Institute, London, 1973

[2] Carlton, A., J., et. al., "Automation of the LTV Steel Hennepin Tandem Cold Mill," Iron and Steel Engineer, June 1992

[3] Duval, P., Parks, J. C., and Fellus, G., "Latest AGC Technology Installed at LTV's Cleveland 5-Stand Cold Mill," Iron and Steel Engineer, November, 1991

[4] Geddes, E. J. M., and Postlewaite, I., "Improvements in Product Quality in Tandem Cold Rolling Using Robust Multivariable Control," IEEE Transactions on Control Systems

Technology, Vol. 6, No. 2, March 1998

[5] Hoshino, I., et. al., "Observer-based Multivariable Control of the Aluminum Cold Tandem Mill," Automatica, Vol. 24, No. 6, pp. 741-754, 1988

[6] Roberts, W. L., Cold Rolling of Steel, Marcel Dekker, New York, 1978

[7] Samaras, N. S., and Simaan, M. A., "Metals Industry," Wiley Encyclopedia of Electrical and Electronic Engineering Vol. 12, Wiley, New York, 1999

[8] Samaras, N. S., and Simaan, M. A., "Optimized Trajectory Tracking Control with Disturbance Attenuation of Dynamic Multistage Metal-Cooling Processes," IEEE Transactions on Industry Applications, Vol. 40, No. 4, July/Aug. 2004

[9] Samaras, N. S., and Simaan, M. A., "Optimized Trajectory Tracking Control of Multistage Dynamic Metal-Cooling Processes," IEEE Transactions on Industry Applications, Vol. 37, No. 3, May/June 2001

[10] Samaras, N. S., and Simaan, M. A., "Water-Cooled End-Point Boundary Temperature Control of Hot Strip via Dynamic Programming," IEEE Transactions on Industry Applications, Vol. 34, No. 6, Nov./Dec. 1998

[11] Samaras, N. S., and Simaan, M. A., "Optimized Trajectory Tracking Control of Dynamic Multistage Metal-Cooling Processes with Nonlinear Disturbances," in Industry Applications Conference Record, 37 ${ }^{\text {th }}$ Annual Meeting, Vol. 1, Oct. 2002 
[12] U.S. Steel Corporation, The Making, Shaping, And Treating of Steel 10th Edition, Pittsburgh, 1985

[13] Kugi, A., et. al., "Nonlinear Control In Rolling Mills: A New Perspective," IEEE Transactions on Industry Applications, Vol. 37, No. 5, Sept./Oct. 2001

[14] Green, M., and Limebeer, D. J. N., Linear Robust Control, Prentice-Hall, New Jersey, 1995

[15] Zhou, K, and Doyle, J. C., Essentials of Robust Control, Prentice-Hall, New Jersey, 1998

[16] Francis, B. A., and Wonham, W. M., "The Internal Model Principle of Control Theory," Automatica, Vol. 12, pp. 457-465, 1976

[17] Orowan, E., "The Calculation of Roll Pressure in Hot and Cold Flat Rolling," Proceedings of the Institution of Mechanical Engineers, Vol. 150, No. 4, pp. 140-167, 1943

[18] Bland, D. R., and Ford, H., "The Calculation of Roll Force and Torque in Cold Strip Rolling with Tension," Proceedings of the Institution of Mechanical Engineers, Vol. 159, pp. 144-153, 1948

[19] Neville, P. (Kvaerner Metals) "Introduction to Automatic Gauge Control," Cold Rolling Fundamentals, AISE Conference, 1999.

[20] Geddes, E. J. M., Tandem Cold Rolling and Robust Multivariable Control, PhD Thesis, University of Leicester, UK, 1998

[21] Guo, R. M., "Analysis of Dynamic Behaviors of Tandem Cold Mills Using Generalized Dynamic and Control Equations," ARMCO Technology Center Report, (undated)

[22] Clautier, J. R., D'Souza. N., and Mracek, C. P., "Nonlinear Regulation and Nonlinear $\mathrm{H}^{\infty}$ Control Via the State-Dependent Riccati Equation Techniques: Part1, Theory," Proceedings of the International Conference on Nonlinear Problems in Aviation and Aerospace, Embry Riddle University, 1996

[23] Friedland, Advanced Control System Design, Prentice Hall, New Jersey, 1996

[24] Lewis, F. A., Optimal Control, Wiley, New York, 1986

[25] Athans, M., and Falb, P. L., Optimal Control An Introduction to the Theory and Its Applications, McGraw-Hill, New York 1966

[26] Cloutier, J. R., and Stansbery, D. T., "The Capabilities and Art of State-Dependent Riccati Equation-Based Design," Proceedings of the American Control Conference, Anchorage, Alaska, May 2002 
[27] Hammet, K. D., Control of Nonlinear Systems via State Feedback State-Dependent Riccati Equation Techniques, PhD Thesis, Air Force Institute of Technology, 1997

[28] Erdem, E. B., Analysis and Real-Time Implementation of State-Dependent Riccati Equation Controlled Systems, PhD Thesis, University of Illinois, Urbana-Champaign, 2001

[29] Rugh, W. J., and Shamma, J. S., "Research on Gain Scheduling," in Automatica, 36, 2000, pages 1401-1425

[30] Roberts, P. D., "A Brief Overview of Model Predictive Control," IEE Seminar on Model on Model Predictive Control, London, UK, Feb. 2000

[31] Mayne, D. Q., "Nonlinear Model Predictive Control: An Assessment," in Fifth International Conference on Chemical Process Control," pages 217-231, CACHE, AIChE, 1997

[32] Mayne, D. Q., "Nonlinear Model Predictive Control: Challenges and Opportunities," in Progress in Systems and Control Theory, Vol. 26, Birkhauser Verlag, Switzerland, 2000

[33] Langson, W., and Alleyne, A., "A Stability Result with Application to Nonlinear Regulation: Theory and Experiments," in Proceedings of the American Control Conference, San Diego, California, June 1999

[34] Tsiotras, P., et. al., "Counterexample to a Recent Result on the Stability of Nonlinear Systems," in IMA Journal of Mathematical Control and Information, Vol.13, No. 2, pp. 129-130, 1996

[35] Gong, C., and Thompson, S., "A Comment on 'Stabilization and Optimal Control for Nonlinear Systems," in IMA Journal of Mathematical Control and Information, Vol. 12, 1995, pages 395-398

[36] Banks, S. P., and Mhana, K., J., "Optimal Control and Stabilization for Nonlinear Systems," IMA Journal of Mathematical Control and Information, Vol. 9, pp. 179-196, 1992

[37] Huang, Y., and Lu, W. M., "Nonlinear Optimal Control: Alternatives to Hamilton-Jacobi Equation," in IEEE Proceedings of the $35^{\text {th }}$ Conference on Decision and Control, Kobe, Japan, Dec. 1996

[38] Teoh, E. K., et. al., "An Improved Thickness Controller for A Rolling Mill," in Proceedings of IFAC $9^{\text {th }}$ Triennial World Congress, Budapest, Hungary, 1984

[39] Edwards, W. J., "The Influence of Strip Width on Rolling Mill Stand Deformation," Conference on Stress and Strain in Engineering, Institution of Engineers, Australia, Pub. 7375,1973

[40] Roberts, W. L., Flat Processing of Steel, Marcel Dekker, New York, 1987 
[41] Goodwin, G. C., el. al., Control System Design, Prentice Hall, New Jersey, 2001

[42] Pittner, J., and Simaan, M. A., "A Simple Rolling Mill Model with Linear Quadratic Optimal Controller," in Industry Applications Conference Record, $37^{\text {th }}$ Annual Meeting, Vol. 1, Oct. 2002

[43] Kawasaki Steel $21^{\text {st }}$ Century Foundation, Kawasaki Steel Tutorial, Chapter 3, Part B (2), "Deformation of Rolling Mill," 2002

[44] Ginzburg, V. B., High Quality Steel Rolling, Theory and Practice, Marcel-Dekker, New York, 1993

[45] George Kelk Corp., "Accuspeed Laser Velocimeter Model ASD1000A Description and Specifications DS.ASPD.808.2," per Kelk quotation US-7196Q, Oct 21, 2004

[46] Pittner, J., and Simaan, M. A., "Pointwise Linear Quadratic Optimal Control of a Tandem Cold Rolling Mill," in Industry Applications Conference Record, $39^{\text {th }}$ Annual Meeting, Vol. 2, Oct. 2004

[47] Pittner, J., and Simaan, M. A., "State-Dependent Riccati Equation Approach for Optimal Control of a Tandem Cold Metal Rolling Process," IEEE Transactions on Industry Applications, Vol. 42, 2006 (to appear)

[48] Pittner, J., and Simaan, M. A., "Optimal Control of Tandem Cold Rolling Using a Pointwise Linear Quadratic Technique with Trims," IEEE Transactions on Control Systems Technology, (under review)

[49] Tezuka, T., et. al., "Application of a New Automatic Gauge Control System for the Tandem Cold Mill," in IEEE IAS 2001 Conference Record of the $36^{\text {th }}$ IAS Annual Meeting, Vol. 2, Sept/Oct, 2001

[50] Ginzburg, Roll Eccentricity, Rolling Mill Technology Series, Volume 1, Pittsburgh, Pa. International Rolling Mill Consultants, 1998

[51] Choi, S. G., Johnson, and M. A., Grimble, M. J., "Polynomial LQG Control of Back-UpRoll Eccentricity Gauge Variations in Cold Rolling Mill," Automatica, Vol. 30, No.6, pages 975-992, 1994

[52] Kugi, A. et. al., "Active Compensation of Roll Eccentricty in Rolling Mills," IEEE Transactions on Industry Applications, Vol. 36, No. 2, March/April 2000

[53] Garamella, S. S., and Srinivasan, K, "Application of Repetitive Control to Eccentricity Compensation in Rolling," Transactions of the ASME, Journal of Dynamic Systems, Measurement, and Control, Vol. 118, Dec. 1996

[54] Kugi, A., et. al., Method for Compensating Eccentricity of Supporting and/or Working Roller in Dual or Quadruple Roll Housing, German Patent, World International Property Organization WO 98/24567, 1998 
[55] Garamella, S. S., Application of Repetitive Control and Iteratitive Learning to Cold Rolling Processes, PhD dissertation, Ohio State University, 1994

[56] Hayes, M. H., Statistical Digital Signal Processing and Modeling, Wiley and Sons, New York, 1996

[57] Widrow, B., and Stearns, S., Adaptive Signal Processing, Prentice Hall, New Jersey, 1986

[58] Neumerkel, D., et. al. "Robust Learning Algorithms for Nonlinear Filtering," in Proceedings of 1996 IEEE International Conference on Acoustics, Speech, and Signal Processing, Vol. 6, May 1996

[59] ABB , Millmate Roll Force Systems Description, ABB Automation Products AB, Sweden, 1998

[60] Sekiguchi, K., et. al., "The Advanced Set-Up and Control System for Dofasco's Tandem Cold Mill," in IEEE Transactions on Industry Applications, Vol. 32, No. 3 May/June 1996

[61] Khalil, H. K., Nonlinear Systems, Macmillan, New York, 1992

[62] Vetter, W. J., "Derivative Operations on Matrices," in IEEE Transactions on Automatic Control, April, 1970 